\title{
$D R-0357.3$
}

THERMIONIC CONVERSION REACTOR TECHNOLOGY ASSESSMENT

Final Report

February 1984

Work Performed Under Contract No. AC03-83SF11725

Space Power, Inc.

Sunnyvale, California

Technical Information Center

Office of Scientific and Technical Information United States Department of Energy 


\section{DISCLAIMER}

This report was prepared as an account of work sponsored by an agency of the United States Government. Neither the United States Government nor any agency Thereof, nor any of their employees, makes any warranty, express or implied, or assumes any legal liability or responsibility for the accuracy, completeness, or usefulness of any information, apparatus, product, or process disclosed, or represents that its use would not infringe privately owned rights. Reference herein to any specific commercial product, process, or service by trade name, trademark, manufacturer, or otherwise does not necessarily constitute or imply its endorsement, recommendation, or favoring by the United States Government or any agency thereof. The views and opinions of authors expressed herein do not necessarily state or reflect those of the United States Government or any agency thereof. 


\section{DISCLAIMER}

Portions of this document may be illegible in electronic image products. Images are produced from the best available original document. 


\title{
DISCLAIMER
}

\begin{abstract}
This report was prepared as an account of work sponsored by an agency of the United States Government. Neither the United States Government nor any agency thereof, nor any of their employees, makes any warranty, express or implied, or assumes any legal liability or responsibility for the accuracy, completeness, or usefulness of any information, apparatus, product, or process disclosed, or represents that its use would not infringe privately owned rights. Reference herein to any specific commercial product, process, or service by trade name, trademark, manufacturer, or otherwise does not necessarily constitute or imply its endorsement, recommendation, or favoring by the United States Government or any agency thereof. The views and opinions of authors expressed herein do not necessarily state or reflect those of the United States Government or any agency thereof.
\end{abstract}

This report has been reproduced directly from the best available copy.

Available from the National Technical Information Service, U. S. Department of Commerce, Springfield, Virginia 22161.

Price: Printed Copy A10

Microfiche A01

Codes are used for pricing all publications. The code is determined by the number of pages in the publication. Information pertaining to the pricing codes can be found in the current issues of the following publications, which are generally available in most libraries: Energy Research Abstracts (ERA); Government Reports Announcements and Index (GRA and I); Scientific and Technical Abstract Reports (STAR); and publication NTIS-PR-360 available from NTIS at the above address. 
$\mathrm{DOE} / \mathrm{SF} / 11725-\mathrm{T} 1$

(DE84007611)

Distribution Category UC-33

\title{
THERMIONIC CONVERSION REACTOR TECHNOLOGY ASSESSMENT
}

\author{
FINAL REPORT \\ February, 1984 \\ Prepared in Support of the \\ U.S. DEPARTMENT OF ENERGY \\ and the \\ TRI-AGENCY SP-100 PROGRAM OFFICE
}

\author{
Prepared by \\ SPACE POIVER, INC. \\ 253 Humboldt Court \\ Sumnvale, California 94089
}




\subsection{PURPOSE OF IN-CORE THERMIONIC FUEL ELEMENT CONVERTER PERFORMANCE AND ENDURANCE ASSESSMENT}

The in-core thermionic space nuclear power supply may be the oniy identified reactor-power concept that can meet the $S P-100$ size functional requirements with demonstrated state-of-the-art reactor system and space-qualified power system component temperatures. The SP-100 configuration limits provide a net $40 \mathrm{~m}^{2}$ of primary non-deployed radiator area. If a reasonable 7 -year degradation a 11 owance of $15 \%$ to $20 \%$ is provided then the beginning of 1 ife ( $\mathrm{BOL}$ ) net power output requirement is abcut $120 \mathrm{kWe}$. Consequently, the SP-100 power system must produce a P/A of 2.7 $\mathrm{kWe} / \mathrm{m}^{2}$. This non-deployed radiator area power density performance can only be reasonably achieved by the thermionic in-core converter system, the potassium Rankine turbine system and the Stirling engine system (see Fig. 1-1). The Brayton regenerative system could require $1600 \mathrm{~K}$ turbine inlet temperature.

The Rankine vapor turbine system concept shows promise of meeting SP-100 envelope requirements $\left(2.7 \mathrm{kWe} / \mathrm{m}^{2}\right)$ and 1 megawatt per shuttle capabilities, i.e., $\left(\sim 6 \mathrm{kWe} / \mathrm{m}^{2}\right)$. This system also requires a liquid-metal-cooled reactor vessel and piping in the $1500 \mathrm{~K}$ temperature regime. The long dormancy and restart requirement may be extremely difficult to achieve. The potassium vapor turbine alternator system will require a long and expensive development effort.

The Stiriing free piston linear aiternator system has the potential of meeting SP-100 functional requirements with $1200 \mathrm{~K}$ cylinder head temperatures and about $1200-1300 \mathrm{~K}$ reactor outlet temperatures. A refractory metal alloy reactor is required.

The thermionic in-core converter reactor shows good promise of meeting SP-100 requirements with state-of-the-art $900 \mathrm{~K}$ to $1000 \mathrm{~K}$ reactor and liquid-metal primary loop systems (see Fig. 1-2). Thus, it is the only system that can potentially be built and operated using stainless stee? and/or superailoy materials. The reflector and controls for SP-100 can be made of state-of-the-art beryllium metal instead of beo, and the neutron 
$T_{1}$ 14001500160017001800190020002100

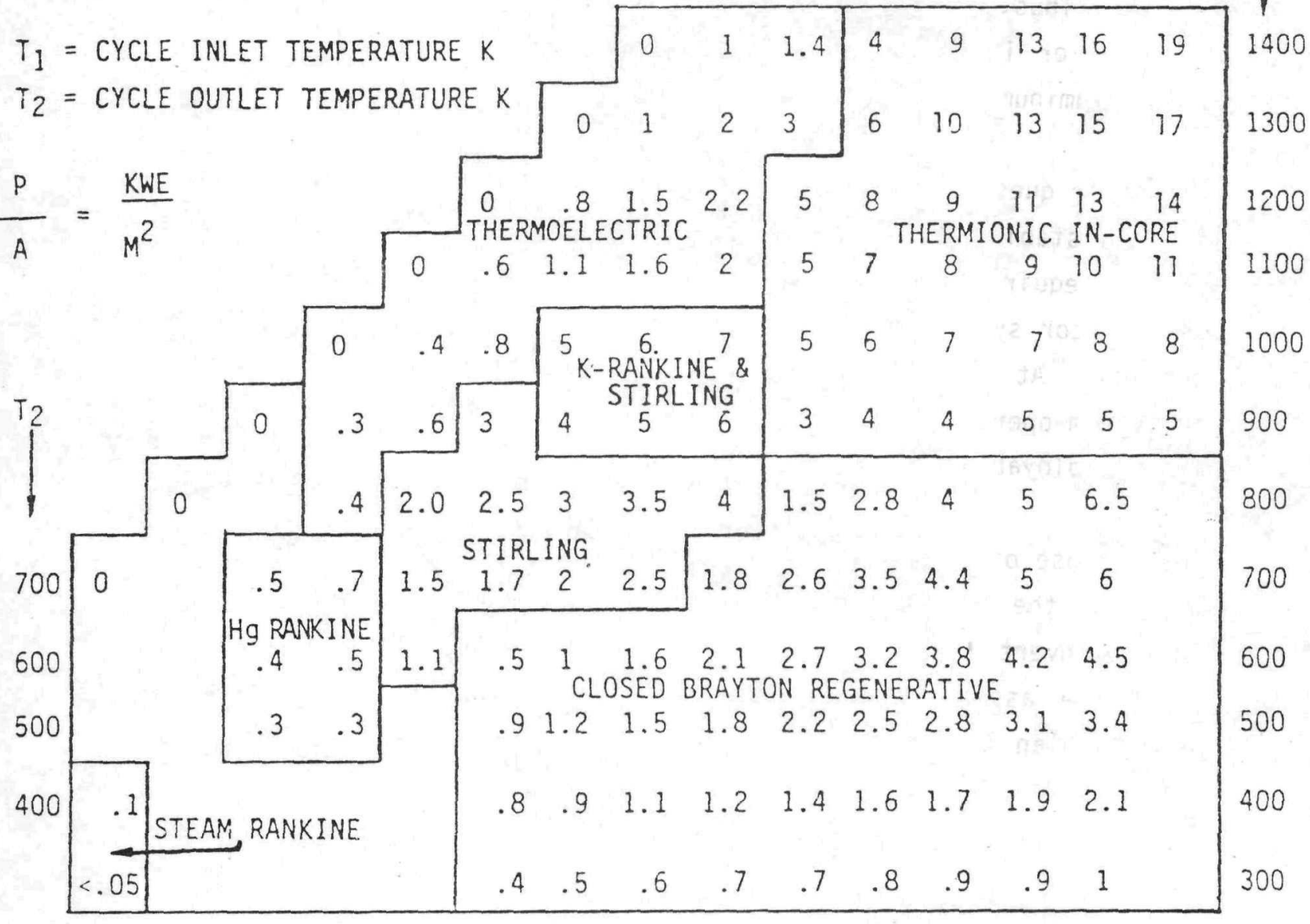

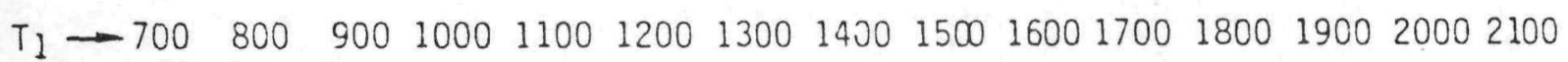

$T_{\text {RADIATOR }}=T_{2}-100 \mathrm{k}$ ALL CYCLES EXCEPT BRAYTON WHERE $T_{R}=T_{2}$

$T_{\text {REACTOR }} \cong T_{1}+(50 \mathrm{~K}$ to $100 \mathrm{~K})$ ALL CYCLES, EXCEPT THERMIONIC IN-CORE HHERE

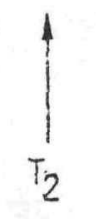

$T_{\text {REACTOR }} \cong T_{2}-40 \mathrm{~K} ;$ AND $T_{1}=$ FUEL SURFACE

$P_{\mathrm{e}} / \mathrm{A}_{\mathrm{R}}=3 \mathrm{KWE} / \mathrm{M}^{2} \approx 500 \mathrm{KWE}$ IN SHUTTLE

$P_{\mathrm{e}} / \mathrm{A}_{\mathrm{R}}=6 \mathrm{KWE} / \mathrm{M}^{2} \approx 1 \mathrm{MHE}$ IN SHUTTLE

Fig. 1-1 POTENTIAL ELECTRIC POWER OUTPUT PER UNIT RADIATOR AREA 
shield can be made of developed honeycomb-cast LiH, operating at temperatures below $700 \mathrm{~K}$. Thus, the system could be ground tested in a typical inert gas (argon) vault or in vacuum in an economically achievable low activation, disposable aluminum vessel.

The major question regarding the suitability of this system concept is the life and stability of the nuclear-fueled emitter. In order to achieve the SP-100 requirements with a $<1000 \times$ oxygen-air resistent metal reactor-radiator system, emitter-fuel surface temperatures of $175 \mathrm{C}$ to $1850 \mathrm{~K}$ are required. At a $1700 \mathrm{~K}$ emitter temperature limit, a refractory meta? reactor system operating at $1100 \mathrm{~K}$ has been indicated for SP-100 requirements with a non-deployable radiator.

The purpose of this study is to examine past and current tests and data, and to assess the potential for successful development of suitable fueledthermionic converters that will meet SP-100 and growth requirements. The basis for the assessment will be provided and the recommended key developments plan set forth. 


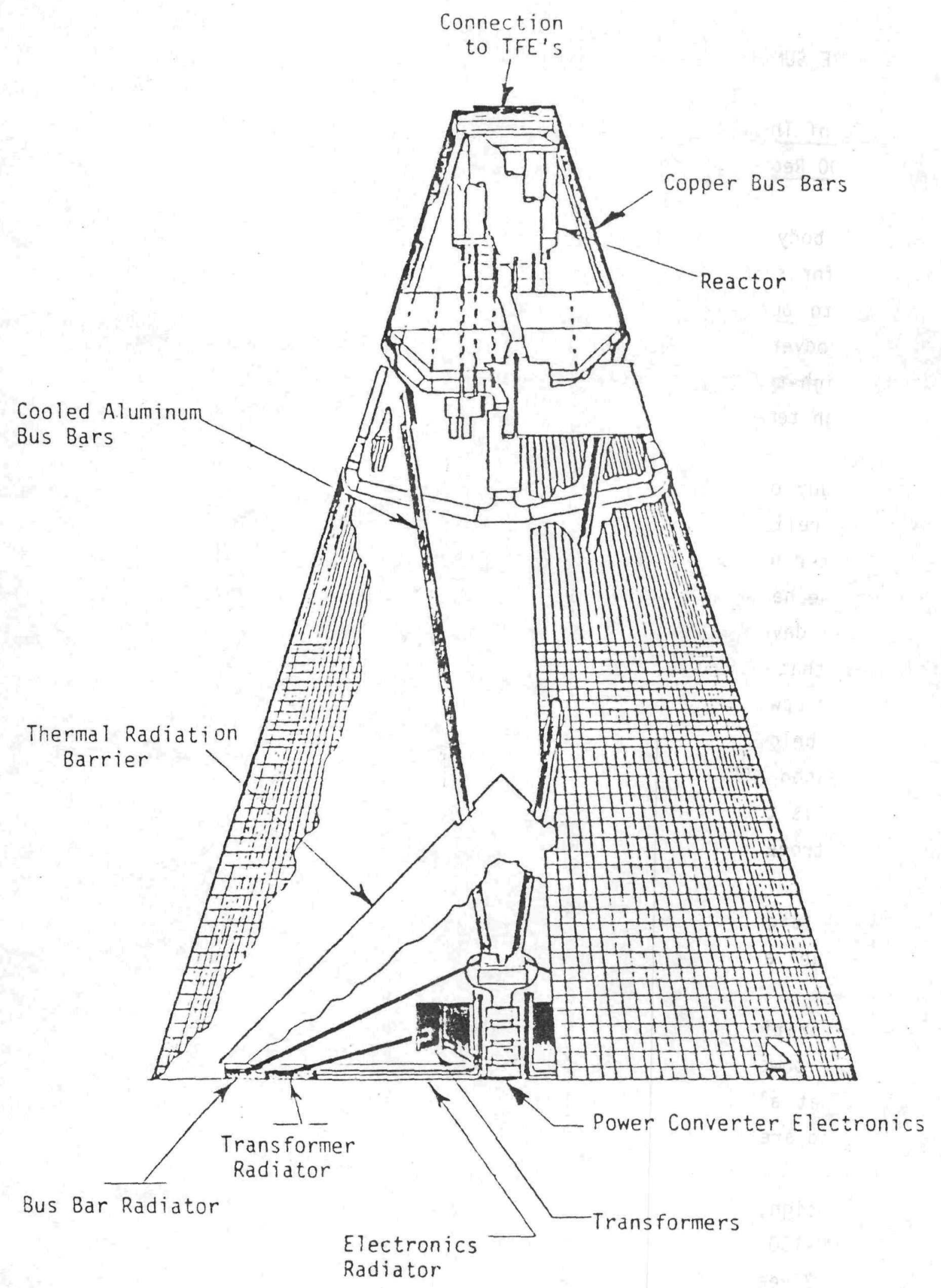

Fig. 1-2 PRIMARY ELECTRICAL SYSTEM 


\subsection{EXECUTIVE SUMMARY}

\subsection{Summary of Thermionic Performance Tests and Developments Pertaining to SP-100 Requirements}

A great body of thermionic engineering development conducted over the past decade for solar and other non-reactor heat sources would find direct application to out-of-core thermionic conversion. Although, out-of-core thermionic conversion is a static, potentially reitiable, reasonabiy efficient, high-temperature radiator power conversion system, it would still require a high temperature refractory metal reactor heat source system.

This study only examines the data that directly applies to improving performance, reliability, or endurance of the in-core thermionic fuel element (TFE) converter useful in state-of-the-art temperature reactors, which can operate at the heat sink temperatures. Fig. 2-1 depicts reactor system goals versus actual development success in the U.S. over the past 30 years. It is significant that reactor systems operating above about $1000 \mathrm{~K}$ have only performed for upwards to a few hundred hours. One year system lifetimes have been reached below $1000 \mathrm{~K}$ and 5 to 10 year systems are generally below $900 \mathrm{~K}$. The basic reason that reactor systems have not had longer endurance at higher temperatures is the loss of strength and creep in metals that can operate in an oxygen-nitrogen contaminated environment.

The key significant elements of progress in the past 20 years of thermionic fuel element converter development are:

1. Operation in the ignited mode (Cs vapor in the interelectrode gap) at power densities, efficiencies, temperatures and gap spacings that allow in-core thermionic conversion engineering feasibility and are of direct application to SP-100.

2. Design, fabrication and test of thermionic converters very near SP-100 design requirements that have operated out-of-pile for up to 5.3 years without failure [1]. 


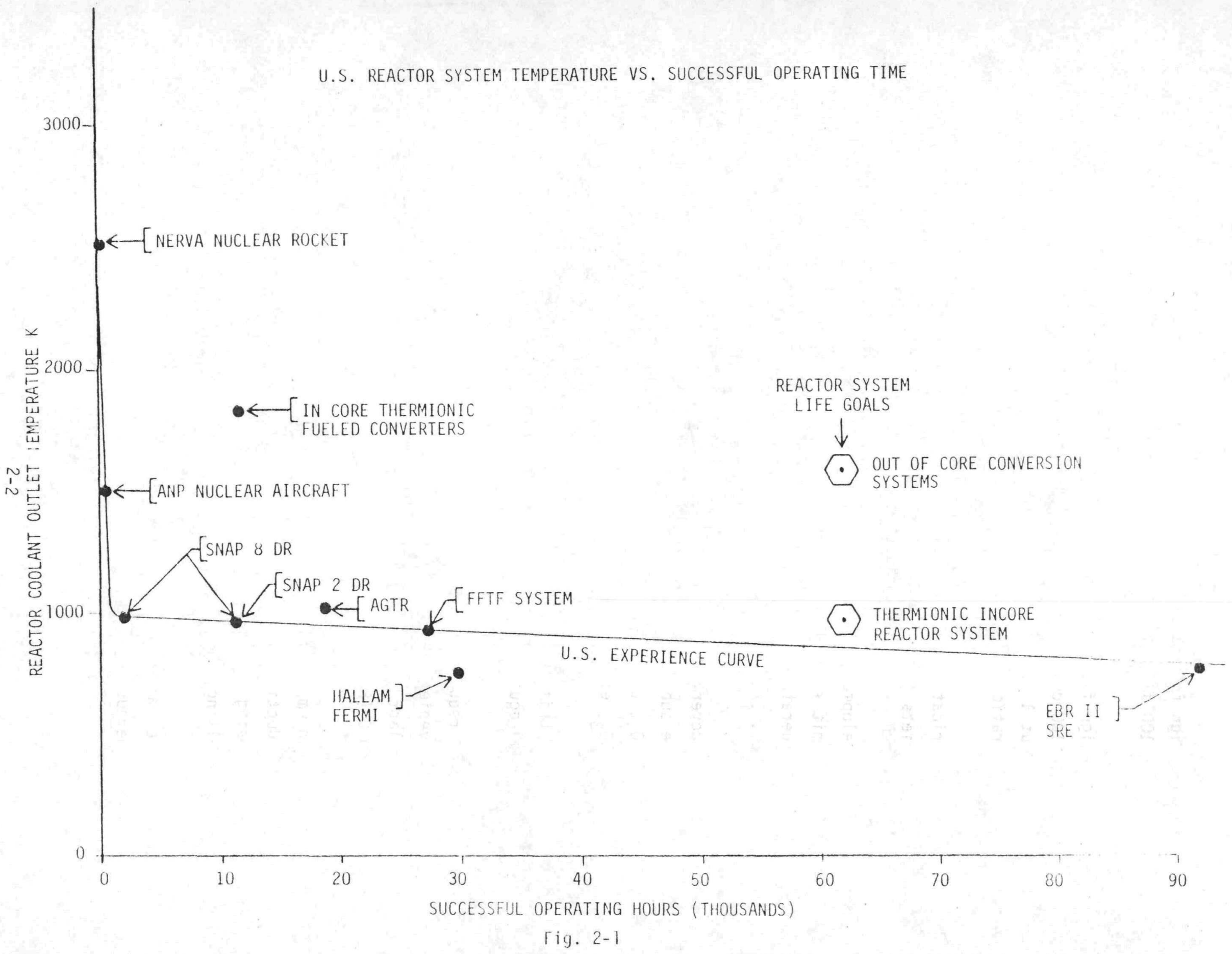


3. Design fabrication and test of thermionic converters similar to the SP-100 design that have operated in-pile for 2.6 vears [2].

4. Design fabrication and test of TFE's nearly identical to required SP-100 designs that have operated in-pile (as fuel elements) for about 1 year without failure under conditions nearly equivalent to operation in the SP-100 design [1].

5. Fabrication and ground test of 4 in-core thermionic reactors by the Soviets for potential application to space power [3].

6. Development of emitter surfaces and oxygen additive techniaue that permit excellent performance in the $1700 \mathrm{~K}$ to $1800 \mathrm{~K}$ emitter temperature regime at enlarged gap spacings of $20 \mathrm{mils}$ and greater, i.e., $1 / 2 \mathrm{~mm}$ to $3 / 4 \mathrm{~mm}$.

7. Discovery that $\mathrm{Y}_{2} \mathrm{O}_{3}, \mathrm{Y}_{3} \mathrm{Al}_{5} \mathrm{O}_{12}, \mathrm{Si}_{3} \mathrm{~N}_{4}$, and $\mathrm{Si}_{2} \mathrm{ON}_{2}$ sheath insulators have substantially higher fast neutron irradiation resistance than $\mathrm{Al}_{2} \mathrm{O}_{3}$, and that $\mathrm{Al}_{2} \mathrm{O}_{3}$ may be improved with pinning additions of $\mathrm{La}_{2} \mathrm{O}_{3}$, etc. Development is required before application.

8. The United States and Soviet in-pile experience has demonstrated the requirement that fission products be vented from the fuel.

9. The required 1 to 2 torr Cs pressure in the electrode gap can be conveniently provided with pyrolytic graphite in the reactor inlet coolant end of the TFE at reactor inlet temperatures of $600^{\circ} \mathrm{C}$ to $650^{\circ} \mathrm{C}$ ( 873 to $923 \mathrm{~K}$ ) (see Fig. 5-29).

10. Uranium carbide fuel has a higher $U$ density and a higher thermal conductivity than $\mathrm{UO}_{2}$. However, the porous UC typically sintered, closing gas venting passages and exhibited excessive breakaway swelling [1] at burnups near $3 \times 10^{19} \mathrm{f} / \mathrm{cc}$.

Some late tests with a porous UC-10ZrC fuei body drilled with numerous small venting holes showed promise of dimensional 
stability to burnup of $3 \times 10^{20}$ at $1873 \mathrm{~K}$ [4]. However, chemical reaction with the tungsten emitter and uranium diffusion through the emitter typically led to degraded thermionic performance and tungsten embrittlement. Uranium carbide particles coated with zirconium carbide have shown promise of nigh uranium burnup without gas release [5]. However uranium density and burnup per unit volume of fuel element remain relatively low and lead to relatively large reactor cores for a given energy output.

11. Uranium nitride fuel has not been seriously considered for thermionic reactors due to the necessity to maintain a substantiai nitrogen vapor pressure over the fuel. This requirement conflicts with the fission gas venting requirement.

12. Pressed powder uranium oxide fuel pellets have been most successful in in-core thermionic fuel element converters (see Fig. 2-2). Uranium dioxide has exhibited chemical stability with tungsten emitter clads to temperatures of over $2100 \mathrm{~K}[6,7]$. As uranium fissions, the freed oxygen reacts with fission products to reduce their corrosiveness and mobility. A trace amount of freed oxygen migrates into the interelectrode space and improves the emitter work function. Uranium oxide is the most developed and understood nuclear fuel in the U.S. It can be provided at high quality in production quantities by at least 5 qualified U.S. suppliers.

Table 2-1 presents the results of the 2 latest of $14 \mathrm{UO}_{2}$-fueled, thermionic fuel-element converter in-pile tests [1]. Neither test was taken to failure. The results are compared to nominal SP-100 TFE requirements partially based upon 2 conceptual designs. The tests were fairly prototypical except in diode spacing (.010 to .014 inches instead of .020 inches), in burnup (17\% to $50 \%$ ) and in fast fluence $7 \%$ to $12 \%$ of the 7 -year, SP-100 requirement. 

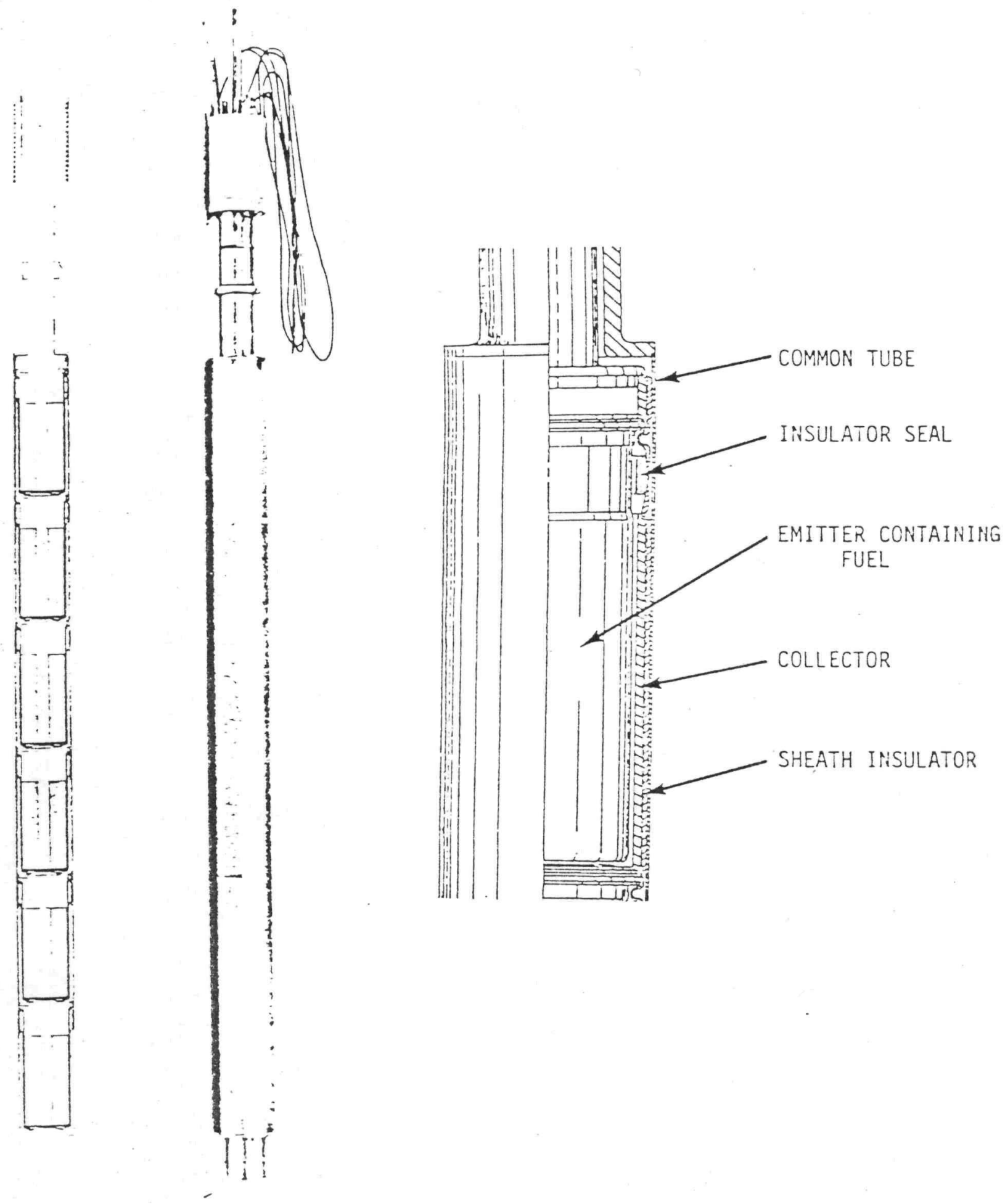

Fig. 2-2 Thermionic Fuel Element For Flashight Reactor 


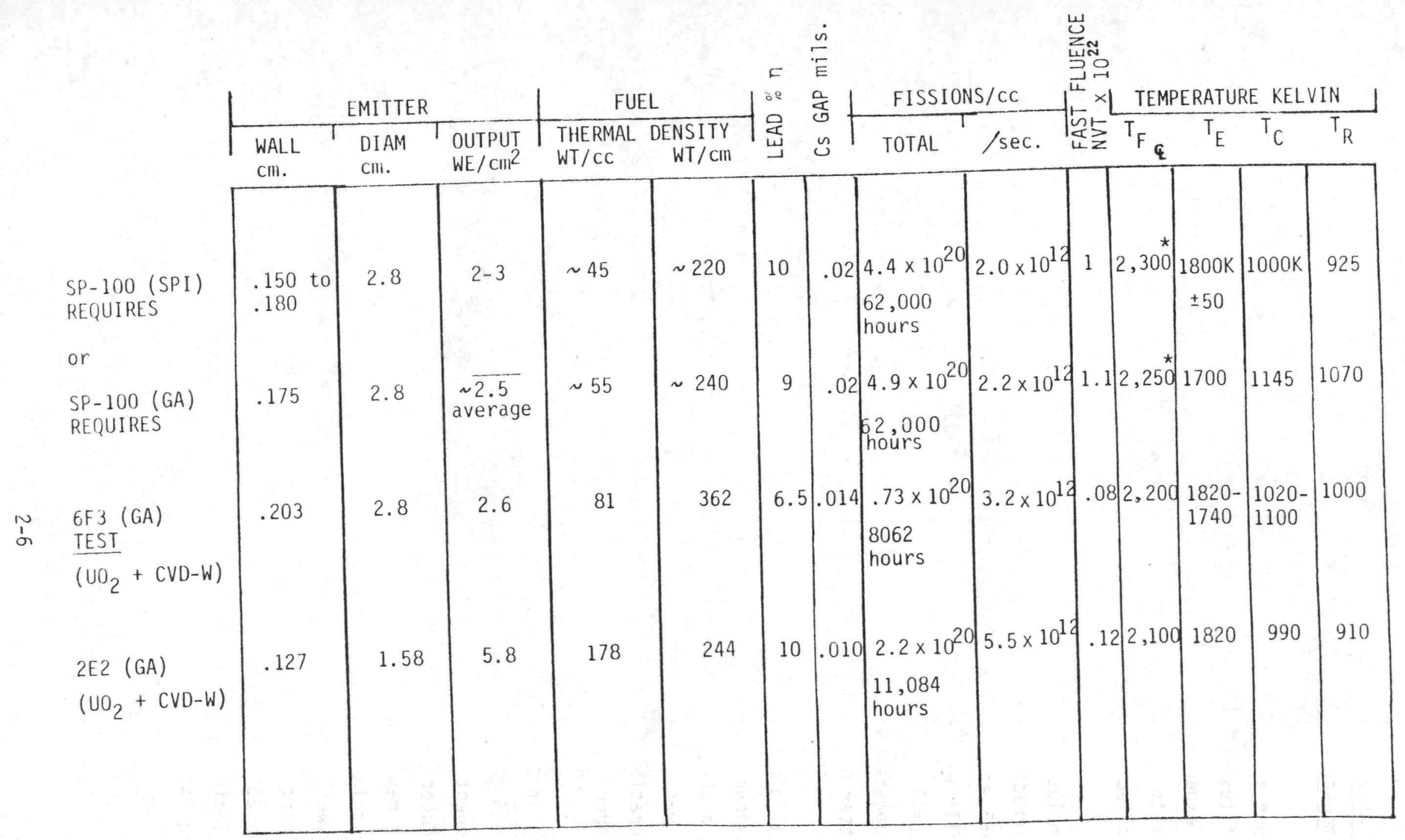

*Higher due to fast fission flux.

TABLE 2-1 
2.2 Summary Assessment of the Potential Endurance of an SP-100 Reactor Based upon Demonstrated TFE-Converters

Based upon a review of the past U.S. thermionic fuel element tests and a comparison of test conditions to current SP-100 design-operating conditions, an endurance expectation of (to 2 years appears to be well assured and 2 to 4 years appears to be justified at an emitter operating condition of 1750 to $1820 \mathrm{~K}$ and collector operating temperature of $21000 \mathrm{~K}$ (Fig. 2-3).

This conclusion is based primarily upon a review of the Gulf General Atomic TFE irradiations completed in 1971 and 1972. The most evolved, $\mathrm{UO}_{2}$-fueled $6 \mathrm{~F} 3$ and $2 \mathrm{E} 2$ irradiations were particularly significant. Both series of cells were operated for over 8000 hours and neither series had experienced cell failures at program termination. Both series utilized strong CVD tungsten emitter clads with wall thickness of which were $15 \%$ of the fuel-emitter outer radius.

The total diametral deformation in $6 F 3$ was .008 inch to .010 inch vs. .028 inch maximum allowable before shorting. A modern .020 inch gap design may tolerate a .040 inch maximum diametral deformation before shorting. The total burnup was $0.32 \mathrm{U}$ atom $\%$ versus the $2.1 \mathrm{U}$ atom $\%$ required for 7 years of SP-100 operation. Direct extrapolation would indicate a potential life of to 4 years under SP-100 design and operating conditions.

However, in an SP-100 fast reactor, the potential fast neutron flux would be 3 to 5 times higher than was available in the TRIGA test reactor in 1972. Consequently at the equivalent 1 year (6F3) to $3 \frac{1}{2}$ years (2E2) burnup, radiation-induced creep to the emitter may not have been noticed if it occurs. This may or may not be a critical problem. Experience with other metals (particularly stainless steels) indicates that maximum fast neutron irradiation swelling and radiation-enhanced creep occurs at 35 to $47 \%$ of the absolute melting point of the metal [8]. For tungsten, this rule would correspond to 1300 to $1720 \mathrm{~K}$. Data by Matolich, Nahm, Moteff [9] and by Wiffen [10] indicate tungsten maximum swelling at about $900 \mathrm{~K}$ to $1200 \mathrm{~K}$ (see Fig. 7-31 and 7-32). Minimum ductility appears to be at $1700 \mathrm{~K}$ to $2000 \mathrm{~K}$ (Fig. 2-4). At higher temperatures the radiation induced swelling and 
EXTRAPOLATED LIFE: 2E2, 6F3 DATA BASE

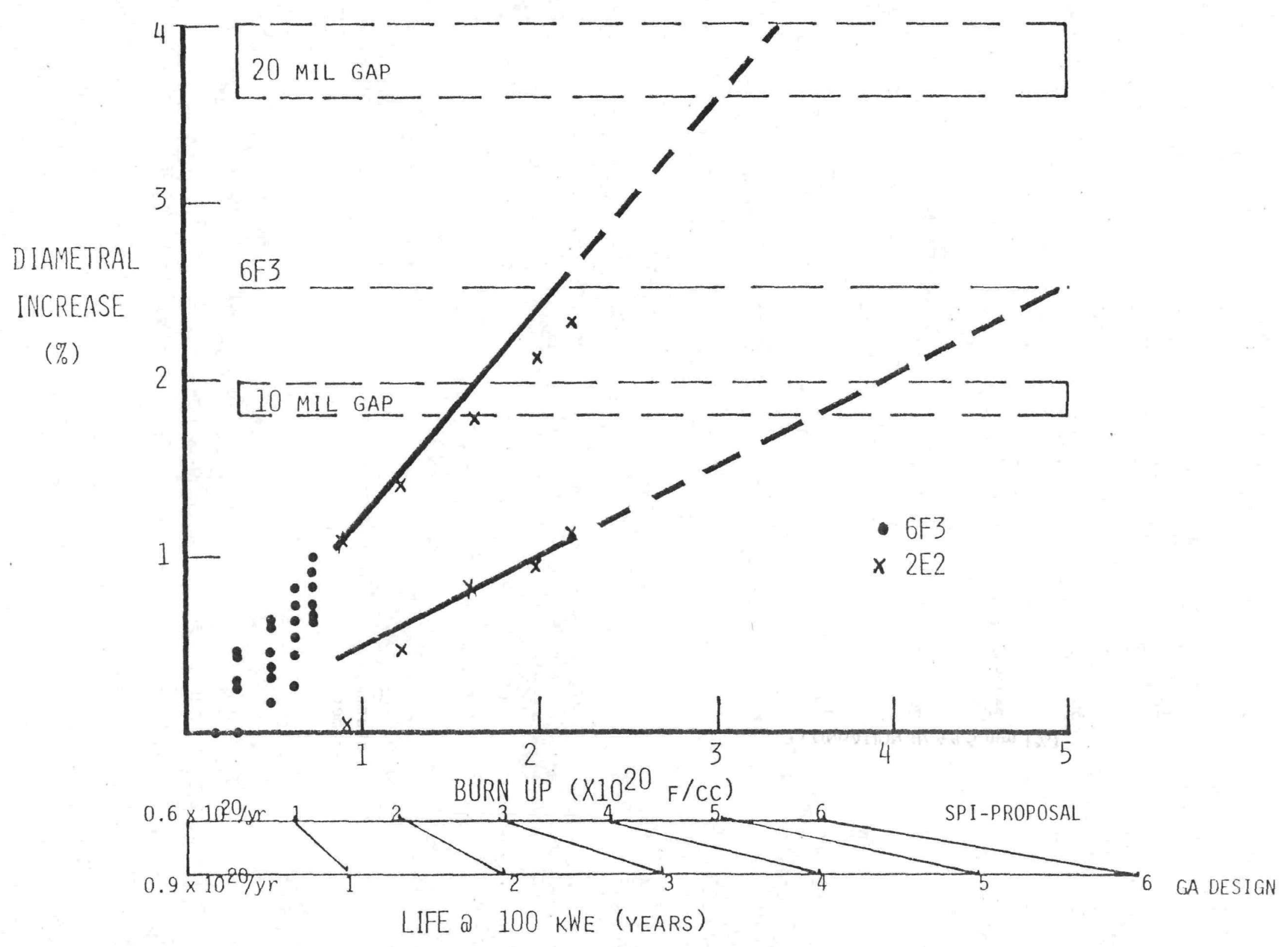

Fig. 2-3 


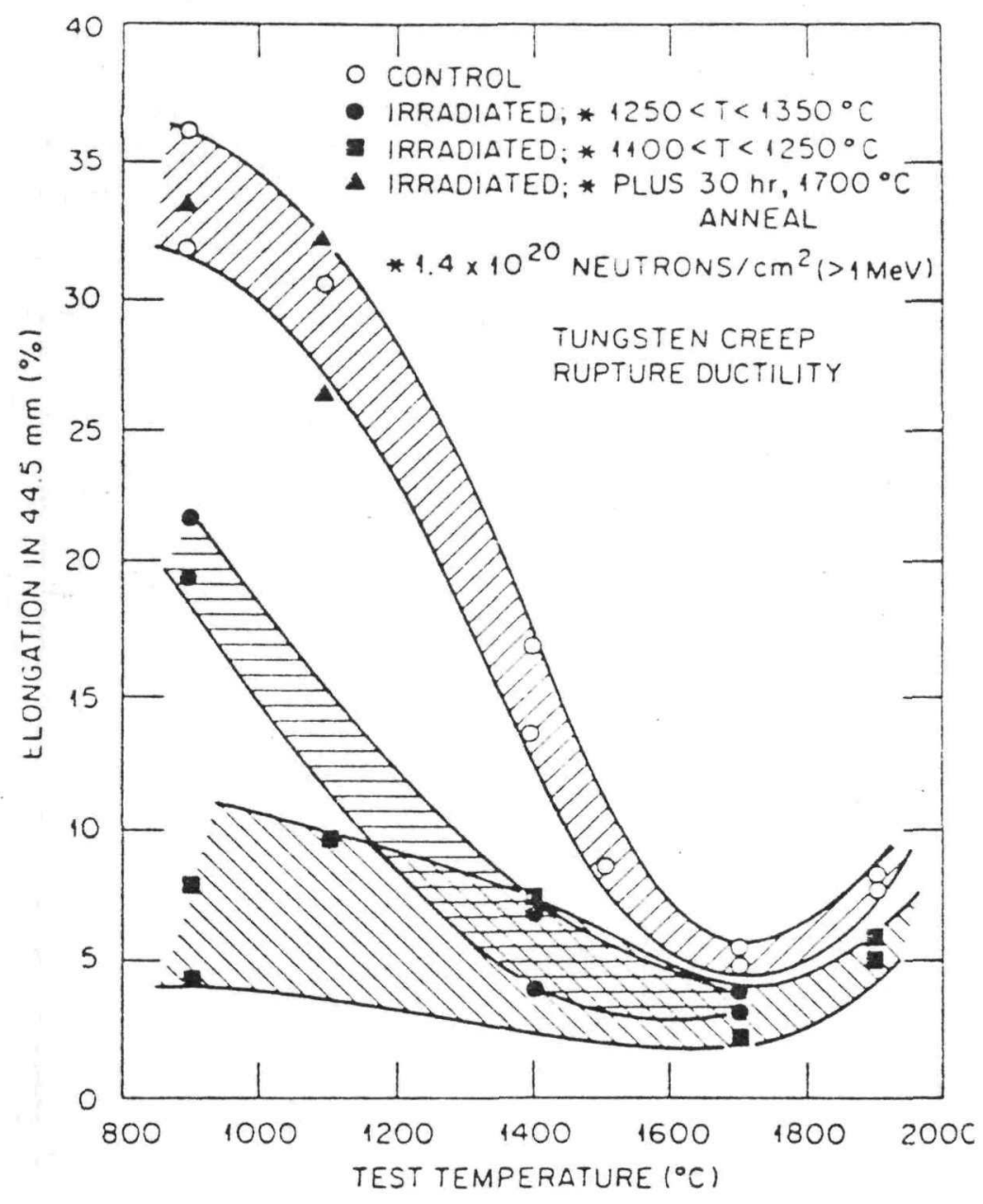

Fig. 2-4

Creep-rupture ductility of tungster as a function of test temperature for specimens irradiated at elevated temperature and control specimens. 
ductility loss is largely annealed such that the hotter metals under irradiation tend to behave more like unirradiated metal. Consequently, $1800 \mathrm{~K}$ to $1850 \mathrm{~K}$ could be as satisfactory an operating temperature as $1700 \mathrm{~K}$, from the point of view of ductility. Fast reactor, CVD-tungsten, irradiation creep and swelling data over the temperature range of interest to $2 \times 10^{22}$ nvt is needed to validate ultimate fuel emitter life. Thoriated and $\mathrm{HFC}$-doped $W$-Re alloy is predicted to have an order of magnitude lower creep rate than CVD-W. It too, should be irradiated and tested (Fig. 7-41).

The suggestion that extended ( 7 year) endurance might be achieved from $6 F 3$-type TFE's (with 20 mils gap spacing) by reducing emitter temperature to $1700 \mathrm{~K}$ might be true. The reduced temperature may reduce thermal ratcheting of the fueled emitter, but it also reduces efficiency and performance.

Consequently, the radiator temperature is increased to nearly $1100 \mathrm{~K}$ in order to meet SP-100 envelope (size) requirements without a deployable radiator. This increased reactor temperature would require superalloy or even $\mathrm{Nb}-1 \mathrm{Zr}$ reactor vessel and primary loop construction. Thus, a maior unique and early development advantage of the tesied thermionic fuel elements, namely their ability to meet SP-100 requirements with proven reactor, primary 100p, radiator, and reflector and control materials may be sacrified. The Nb-1Zr primary loop is highly desirable in higher powered growth versions of space reactor power systems, but should not be required for America's first reactor to return to space in 25 years. The Nb-1Zr alloy primary system will be much more difficult and expensive to ground test for endurance. This alloy could require a very high vacuum $\left(\sim 10^{-8}\right.$ torr) to survive 2 years of testing and may be subject to mass-transfer embrittlement in liquid metals, especially Li.

Thermal-convection, mass-transfer and corrosion thermal-harp tests are needed over the potential primary loop temperature ranges to test a $\mathrm{Nb}-1 \mathrm{Zr}$-converter sheath-tube cladding in a Nb-1Zr loop, a Hastelloy $X$ loop, a 316-317 SS $100 \mathrm{p}$ and a MA-957 loop.

Potential coolants should include $\mathrm{Na}$, NaK and $\mathrm{Li}$. Selection of $\mathrm{NaK}-\mathrm{i} 8$ at $1100 \mathrm{~K}\left(2800^{\circ} \mathrm{C}\right)$ as the primary coolant and temperature, and use of $\mathrm{Nb}-12 \mathrm{r}$ for the primary loop places the primary coolant containment at the maximum Nb-1Zr irradiation swelling temperature (see Fig. 2-5), and will require 2 to $3 \mathrm{~atm}$ operating pressure to suppress hot spot vaporization of potassium. Nak 


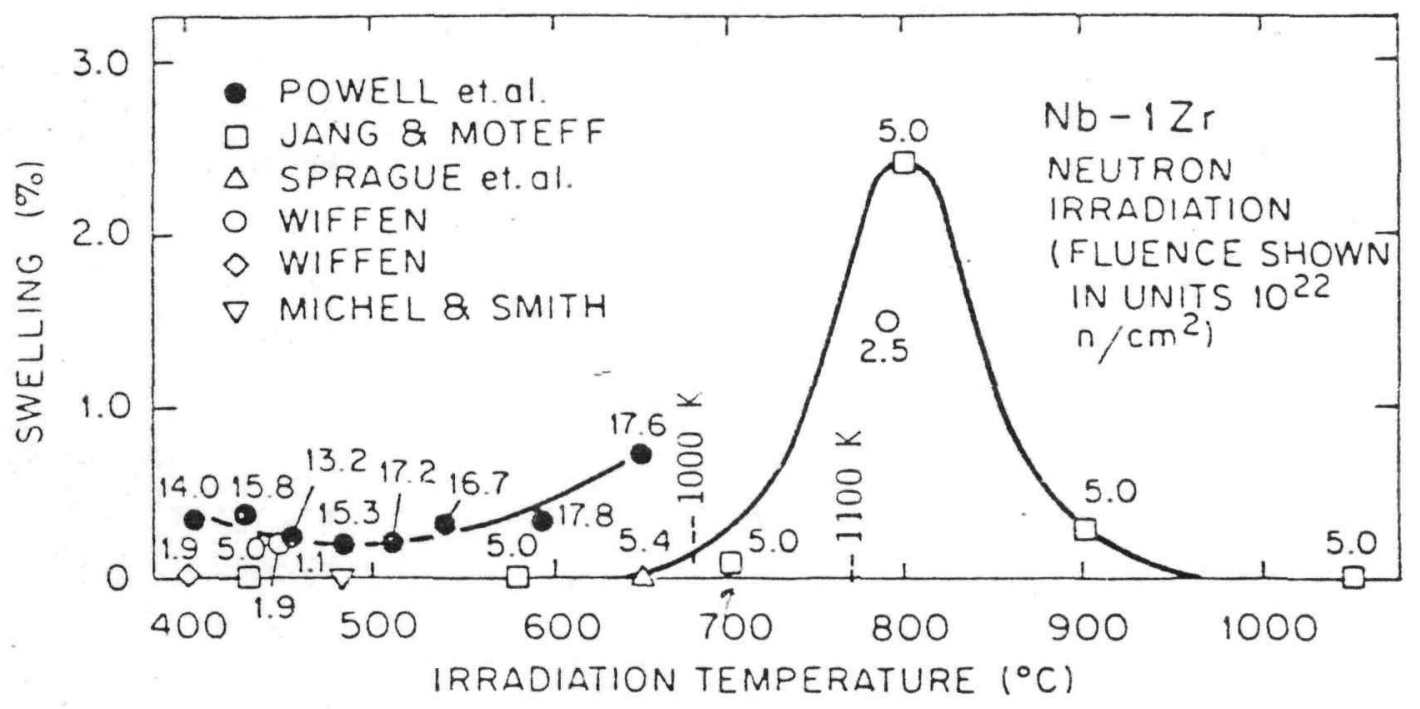

FIG. 2-5 Comparison of the available neutron irradiation swelling data on $\mathrm{Nb}-1 \mathrm{Zr}$. The numbers alongside the data points indicate the neutron fluence in units of $10^{22} \mathrm{n} / \mathrm{cm}^{2}(E>0.1 \mathrm{MeV})$. 
primary loop coolant at $1100 \mathrm{~K}$ could require 2 to 3 times the reactor vessel wall thickness over $\mathrm{Na}$ or Li at the same creep limits at $1100 \mathrm{~K}$.

\subsection{Summary Assessment of the Potential SP-100 In-Core Thermionic Converter Fuel Endurance Assessment}

The fuel burnup required for 7 years of full power SP-100 thermionic reactor operation is about $2 \mathrm{U}$ atom $\%$ in $\mathrm{UO}_{2}$. The study conducted herein indicates that $\mathrm{UO}_{2}$-fueled emitters might be capable of sustaining over $6 \mathrm{U}$ atom \% B.U. (equivalent to 20 years of SP-100 operation) at the SP-100 1inear power densities of 5 to $7 \mathrm{~kW} / \mathrm{ft}$ in 1 inch diameter fue $1\left(40 \mathrm{~W} / \mathrm{cm}^{3}\right)$ and at $1800 \mathrm{~K}$ emitter temperatures. Higher emitter temperatures may be achievable in smaller fuel pins at higher volumetric power densities in higher powered in-core thermionic reactors. Lower emitter temperatures should reduce thermal-ratchet fuel-emitter distortion mechanisms, but could possibly increase bladder-effect and fuel material volumetric swelling. Preliminary 2-dimensional viscoelastic fuel-emitter distortion calculations conducted herein provide SPI with the necessary tools to more completely predict performance behavior. Section 7.0 of this report provides considerable evidence that proper design, test and operating conditions should allow very high burnup thermionic-fueled emitter performance.

In order to achieve high burnups and 7-year life in highly enriched $\mathrm{UO}_{2}$, it appears that the reactor and in-pile tests must be run at a nearly constant power output. Due to thermal ratcheting it appears that the reactor should not be reduced from full power to part-load (100 K emitter temperatuare drop) for more than tens of cycles (TBD by experiment and further analysis, and dependent upon cycle time and emitter temperature). This restriction is greatly relaxed at lower temperatures and shorter time power level reductions. Rapid startups and shutdowns do not yet appear to be harmful to the fuel although they may lead to fission gas-Cs gap leaks. Further 2-dimensional thermal, viscoelastic-transient analysis and out-of-pile experiments are required to confirm thermal cycle tolerance of the emitter-insulator-collector structure. 
Long-term operation at constant power might lead to central fuel cavity fission-gas pressure buildup. Such a buildup could be about 1 to 2 psi per day and could lead to excessive CVD tungsten emitter creep in 6 to 12 months of operation. Without venting, the gas release in SP-100 fuels could lead to several hundred atmospheres of internal pressure. Past experiments have largely avoided this problem through diffusion partial venting and frequent 2 to 6 week test reactor shutdowns that result in fuel cracking and gas release through the gas vent system. The problem might also be avoided by fission gas diffusion venting through the fuel cavity skull during operation at temperature. The preliminary 2-dimensional viscoelastic analysis, reported herein indicates that in a TRIGA test with a high enrichment fuel internal pressure of 50 psi could potentially buildup in some 5 weeks, and could potentially creep the emitter to an interelectrode short. The skull integrity and shape could be maintained, and still over about $99 \%$ of the fission gas could leak out over 7 years of irradiation. The required diffusion venting should be enhanced in prototype, fast-reactor (hotter and thinner sku11) environments. However, the adequacy of diffusion venting of the central fuel cavity has not yet been confirmed by analysis or experiment. Until SPI can develop such firm data, high-temperature, space-reactor fuel element designs should be provided with positive hot "snorkel" vents similar to Soviet design. An out-of-pile test can be designed to determine whether skull diffusion venting is adequate at the low SP-100 fission rates and confirm whether central cavity pressure buildup can cause iong-term emitter distortion.

The literature consistentiy supports an estimate of 0.4 to 0.7 percent $\Delta V / V(\Delta V / V$ refers to local fuel density decrease due to fission product accumulation) in near-theoretical density $U_{2}$ for each percent uranium burnup due to solid fission product formation and retention. This growth seems quite independent of temperature and other operating parameters.

An examination has been made of theoretical and experimental literature on $\mathrm{UO}_{2}$ fuel fission gas release, bubble formation and gas bubble swelling of fuel material. Approximately one out of every 4 fissions creates an inert gas atom. At $\mathrm{UO}_{2}$ fuei temperatures below $1273 \mathrm{~K}$ fission gas atoms are quite 
immobile and remain dissolved in the $\mathrm{UO}_{2}$ lattice. At these temperatures they contribute little to fuel swelling (equivalent to solid atoms).

At temperatures above $1273^{\circ} \mathrm{C}\left(1000^{\circ} \mathrm{C} \mathrm{K}\right)$, fission gas atoms become mobile and can coalesce into microbubbles at lattice dislocations. At temperatures of $1473 \mathrm{~K}$ to $1673 \mathrm{~K}\left(1200^{\circ} \mathrm{C}\right.$ to $\left.1400^{\circ} \mathrm{C}\right)$, bubbles grow, migrate to grain boundaries and swell the fuel by decreasing its density. At high thermal gradients, the bubbles tend to migrate toward the high temperature center of the fuel pellet and vent from the fuel, thus decreasing the fuel density loss and swelling rate. As burnup increases and the lattice saturates with gas, the fuel density decrease rate as a function of burnup begins to level off at about $2 \mathrm{U}$ atom \% burnup. Thus, maximum density loss rates per unit of burnup (or energy release) due to fission gas coalescence and growth lie approximately between $\mathrm{O}$ and $2 \% \mathrm{U}$ burnup in $\mathrm{UO}_{2}$ and in the temperature range $1473 \mathrm{~K}$ $\left(1200^{\circ} \mathrm{C}\right)$ to $1873 \mathrm{~K}\left(1600^{\circ} \mathrm{C}\right)$. Above about $1873 \mathrm{~K}\left(1600^{\circ} \mathrm{C}\right) \mathrm{UO}_{2}$ fuel restructures by vaporizing and condensing on the colder surfaces inside the fuel cladding. This restructuring increases the local fuel density (from typically $94 \%$ density to over $98 \%$ theoretical density) and transfers the distributed void of pressed powder fuel to a large central void cavity in the pellet. This restructuring creates elongated, radial columnar grains of $\mathrm{UO}_{2}$. The gas atoms, dislocations and microbubbles rapidly diffuse to the columnar grain boundaries at temperatures above $1873 \mathrm{~K}\left(1600^{\circ} \mathrm{C}\right)$. When the microbubbles and gas atoms reach the columnar grain boundaries, the bubbles quickly grow and migrate toward the central void cavity. Under SP-100 thermionic fuel conditions, the central void cavity will be at temperatures of $2200 \mathrm{~K}$ to $2400 \mathrm{~K}$. At these central void temperatures, the fuel has a very high vapor pressure. Any cracks formed along a temperature gradient are quickly sealed in minutes and seconds (see Fig. 7-2). The conclusion of this preliminary study is that the GRASS-SST computer code developed at Argonne National Laboratory should best describe fission gas behavior in space reactor fuel elements. It is anticipated that the FAST-GRASS version will also be applicable at much less cost in running time.

Consequently, theory and experimental examination of high temperature $\mathrm{UO}_{2}$ microstructure tends to support the position that: 1) Fuel density $(\Delta V / V)$ loss and gas release swelling may be less at temperatures above $1873 \mathrm{~K}$ 
$\left(1600^{\circ} \mathrm{C}\right)$ than at temperatures between $1400 \mathrm{~K}$ and $1700 \mathrm{~K}$. 2) Therma ratcheting (vapor transport across a differential expansion gap and condensation on colder surface) is a major concern that can be eliminated or controlled by controlled thermal cycles, lower temperature operation or by constant power output operation. Analytical and experimental data should be developed to ascertain design operating and in-pile test operating limitations. 3) The absence of a bladder effect must be confirmed by means of out-of-pile experiments, or an adequate hot snorkel should be provided to in-pile tests and TFE designs. 4) High strength, low creep emitters should be developed. The $\mathrm{HfC}$ or $\mathrm{Th}_{2} \mathrm{O}_{3}$ [11] stabilized $\mathrm{W}$-Re alloy shows promise of nearly an order of magnitude lower creep than CVD tungsten at operating temperatures. 


\subsection{Summary of the Immediate Work Required to Validate the Assessments}

\section{Near-Term Tasks}

1. Prepare prototypic tungsten emitter blanks:

1) CVD-WF base $+\mathrm{CVD}^{-W C T_{6}}$ surface layer (duplex CVD-W structure.

2) $\left[\mathrm{W}-\mathrm{Re}-\mathrm{ThO}_{2}\right]$ alloy base $\left.+\mathrm{CVD}-\mathrm{WC}\right]_{6}$ surface layer

3) $[\mathrm{W}-\mathrm{Re}-\mathrm{HfC}]$ alloy base $+[\mathrm{CVD}-\mathrm{WC}]_{6}$ surface layer.

Conduct inpile creep test (pressurized) at $1700 \mathrm{~K}$ and $1800 \mathrm{~K}$ to $2 \times 10^{22}$ nvt and $6 \times 10^{22}$ nvt. Suggest accelerated test to $10^{22}$ nvt in 6 month to 1 year at EBR-II.

2. Fabricate: $\mathrm{Y}_{2} \mathrm{O}_{3}$ and pinned $\mathrm{Al}_{2} \mathrm{O}_{3}$ sheath insulators for thermal cycie and fast neutron irradiation testing at $1000 \mathrm{~K}$ and $1100 \mathrm{~K}$. Test to at least $2 \times 10^{22}$ fast nivt. Examine feasibility of fabricating $\mathrm{Y}_{3} \mathrm{Al}_{5} \mathrm{O}_{12}, \mathrm{Si}_{3} \mathrm{~N}_{4}$, and $\mathrm{Si}_{2} \mathrm{ON}_{2}$ insulators and seals.

3. Complete time (rate) dependent 2-dimensional $\mathrm{UO}_{2}$ thermal ratcheting analysis and confirm with out-of-pile experiment if necessary.

4. Conduct 2-dimensional analysis of fuel central void pressure creep of fuel and emitter for CVD Tungsten and Thoria stabilized W-25Re alloy using uniform heat generation representative of fast reactor operation. Determine limits of applicability and maximum cavity pressures that will not destroy the skull.

5. If results of (4) indicate that a control void cavity skull can exist, with uniform heat generation, at pressures that can cause emitter creep, conduct a skull diffusion venting experiment to determine if a hot snorkel is required to prevent "bladder swelling" deformation of emitter at SP-100 conditions. 
6. Reestablish total thermionic fuel element converter fabrication and quality central capability.

7. Test $\mathrm{UO}_{2}$-fueled pellets in-pile under recommended prototypic conditions utilizing prototypic emitter-claddings and surface temperatures of $1700 \mathrm{~K}, 1750 \mathrm{~K}, 1800 \mathrm{~K}$ and $1850 \mathrm{~K}$.

8. Test thermionic fuel element converters in fast reactor under prototypic conditions of power density, fast flux and temperatures with a $20 \mathrm{mil}$ Cs gap. Utilize highest strength emitter wall materials best insulators and seals, and snorkel if necessary. Test under conditions of constant power output, power cycle limitation, and central cavity venting, if determined necessary by means of 2 dimensional visco-elastic analysis and out-of-pile cavity diffusion vent testing.

9. Conduct thermal convection harp non-isothermal corrosion and mass transport tests for primary loop components and TFE outer sheath material.

Tests to include:

$$
\begin{aligned}
& (\mathrm{Na}+\mathrm{NaK}) \quad 317 \mathrm{SS} \mathrm{loop} \quad 900 \mathrm{~K} \text { in }-1000 \mathrm{~K} \text { out } \\
& +\mathrm{Nb}-1 \mathrm{Zr} \text { (coupon } 1000 \mathrm{~K} \text { ) } \\
& (\mathrm{Na}+\mathrm{NaK}) \quad 317 \mathrm{SS} \mathrm{loop} \quad 1000 \mathrm{~K} \text { in }-1100 \mathrm{~K} \text { out } \\
& \text { + Nb-1Zr (coupon } 1100 \mathrm{~K} \text { ) } \\
& \text { ( } \mathrm{Na}+\mathrm{NaK} \quad \mathrm{MA}-957 \text { loop } 1000 \mathrm{~K} \text { in }-1100 \mathrm{~K} \text { out } \\
& +\mathrm{Li}) \quad+\mathrm{Nb}-1 \mathrm{Zr} \text { (coupon } 1100 \mathrm{~K} \text { ) } \\
& (\mathrm{Na}+\mathrm{NaK} \quad \mathrm{Nb}-12 \mathrm{r} \text { loop } \quad 1000 \mathrm{~K} \text { in }-1100 \mathrm{~K} \text { out } \\
& +\mathrm{Li}) \quad+\mathrm{Nb}-1 \mathrm{Zr} \text { (coupon } 1100 \mathrm{~K} \text { ) }
\end{aligned}
$$

10. Conduct non-isothermal vacuum and enert gas corrosion tests on $\mathrm{Nb}-1 \mathrm{Zr}$ sheets or tubes at $1100 \mathrm{~K}$ and $10^{-4}$ to $10^{-8}$ torr, and in high purity $\mathrm{O}_{2}, \mathrm{~N}_{2}$, and $\mathrm{H}_{2}$-gettered argon gas environment.

11. Conduct frozen primary loop startup feasibility demonstration tests utilizing SPI proprietary startup design or equivalent. 
12. Build and demonstrate low voltage to high voltage compact power conditicner module as proposed by SPI to SP-100 systems management.

13. Examine diode performance with $\mathrm{Xe}$ and $\mathrm{Kr}$ contamination. Estabiish the system design and performance wherein cesium gap to fission gas seals are not required. 


\section{REFERENCES}

1. "Development of a Thermionic Reactor Space Power System - Final Summary Report" GULF-GA-A12608, June 30, 1973.

2. H. Gross, private communication, Feburary 1978.

3. N.S. Rasor, "A Summary of USSR Thermionic Energy Conversion Activity" 13th Intersociety Energy Conversion Engineering Conference, San Diego, August 1978 .

4. L. Yang, R.G. Hudson, H. Johnson, H. Horner, D.T. Allen, "Material Development for Thermionic Fuel Cladding Systems", 3rd Internationa? Conference on Thermionic.

5. L. Yang, "Nuclear Fuel Systems for Space Power Applications", AFOSR Special Conference on Prime-Power for High Energy Space Systems.

6. M.J. Sanderson, L.N. Grossman, H.W. Hill and A.I. Kaznoff "Compatibility of Nuclear and Thermionic Emitter Materials", Thermionic Conversion Conference, Gatlinburg, October 1963.

7. J.M. Scott, J.C. Danko, J.M. Case, "Post Test Examination and Analysis of a Cylindrical Thermionic Converter "Thermionic Conversion Specialist Conference, Palo Alto, October 1967.

8. F.W. Wiffen, "Radiation Damage to Refractor Metals as Related to Thermionic Converters", Proc IEEE Thermionic Converter Specia] Conference (1970).

9. J. Matolich, N. Nahm, and J. Moteff, "Swelling in Neutron Irradiated Tungsten and Tungsten-25 Percent Rhenium," Scripta Met. 8, 837-842, (1974).

10. F.W. Wiffen, "Effects of Irradiation in Properties of Refractory Alloys, with Emphasis on Space Power Reactor Applications," Symposium on Refractory Alloy Technology for Space Nuclear Power Applications, (August 1983).

11. James F. Morris, "Pre-1973 Refractory Alloy Technology to Improve and Simplify In-Core Thermionic Energy Conversion", Arizona State University, AFWAL-TM- , December 1983. 


\subsection{BACKGROUND OF THERMIONIC REACTOR. DEVELOPMENT}

\subsection{Thermionic Energy Conversion Process}

The thermionic energy converter is a non-mechanical gaseous-electronic device for converting heat directly into electric power by thermionic electron emission. Its simplest form, the diode shown schematically in Fig. 3-1, has two electrodes separated by a narrow gap, typically 0.2 to $1 \mathrm{~mm}$ wide. Electrons are emitted from a hot electrode, which is the emitter, and are collected at a different potential by a colder electrode, which is the collector. The basic engineering aspects of the thermionic converter are summarized in Ref. [1], and the basic physics is summarized in Ref. [2].

As described in Ref. [1], the basic thermionic cycle is similar to a modified Rankine (steam engine) cycle which uses electrons directly as the sole working fluid. The emitter is the "electron boiler" and the collector is the "electron condenser," which together develop an electric pressure (potential) difference to produce electrical work rather than a vapor pressure difference to produce mechanical work. The amount of electrical work produced per electron is equal to the difference between the heat of vaporization of the electrons from the emitter and the heat of condensation of the electrons into the collector. Actual converter performance depends strongly on the design operating conditions. Presently available thermionic converters work best with emitter temperatures above $1600 \mathrm{~K}$ and collector temperature between $900 \mathrm{~K}$ and $1100 \mathrm{~K}$. Electrical output power densities are typically several watts per square centimeter of emitter surface. Efficiencies of present, practical devices are typically between 10 and $15 \%$

\subsection{Types of Thermionic Reactor Systems}

\subsubsection{In-Core Thermionic Reactors}

3.1.1.1 Flashlight Type - The "flashlight"-type, thermionic-reactor system invented in 1959 by Dr. Ned Rasor and Dr. Robert Hirsch, is by far the most highly developed at present. Cylindrical thermionic cells with internally-fueled emitters are connected in a series string like flashlight 


\section{BASIC PROCESS}

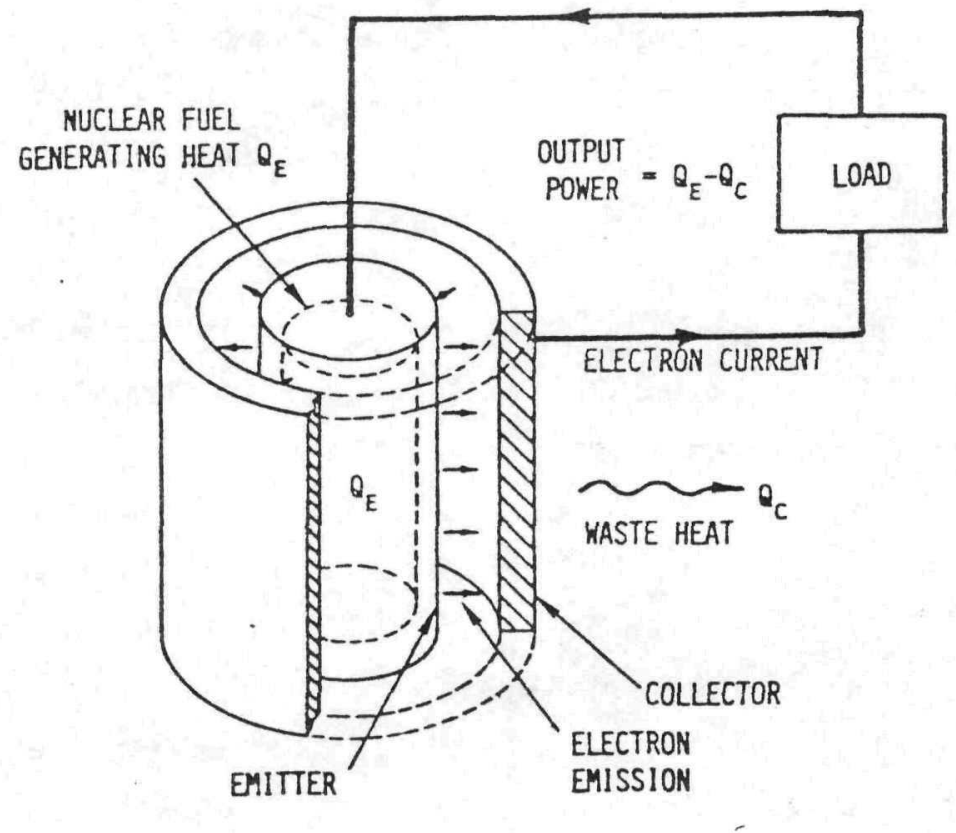

Fig. 3-1 Schematic Diagram of Basic Nuclear Thermionic Energv Converter 
batteries to form a thermionic fuel element (TFE). The cells are electrically insulated from the TFE envelope by a thermally-bonded insulating layer. As shown in Fig. 3-2, the TFE's can be assembled to form the reactor core in several ways:

a) Full Thermionic Fast Reactor (U.S. Approach) - A sufficient number of TFE's to achieve nuclear criticality are assembled in a core vessei surrounded by a neutron a reflector, and a liquid metal coolant (typically $\mathrm{Na}$ or $\mathrm{NaK}$ ) is passed axially through the vessel to remove reject heat from the TFE's. A fast reactor typically has the minimum weight for powers above about $100 \mathrm{kWe}$, but exposes the insulators to a high flux of high energy neutrons. Fuel inventory typically is $150-250 \mathrm{~kg}$ of $\mathrm{U}^{235}$.

b) Thermal Driver Reactor (German and later U.S. Approach) - If the number of TFE's required at lower power levels is too small to achieve criticality, enough conventional fuel elements and moderator (e.g., SNAP-type $\mathrm{UZrH}_{1.8}$ or $\mathrm{UO}_{2}$ pins-ZrH rods) are added to the core at heat rejection temperature to achieve criticality. The heat from these driver elements is all wasted, lowering overall efficiency, but the radiator for a lower power thermionic system is a small fraction of total weight. Neutron damage to insulators is low, and total fuel inventory is typically only $10-20 \mathrm{~kg}$. Choice of materials for TFE's sheaths and collectors is severely limited, however due to the potential presence of $\mathrm{H}_{2}$ in the core liquid-metal system and due to the thermal neutron spectrum.

c) Full Thermionic Thermal Reactor (USSR TOPAZ and French Approaches) Sufficient moderator is added to the full thermionic core to obtain an epithermal spectrum. In the French Diogene and Triton terrestrial thermionic reactor designs, the moderator was the water coolant. In TOPAZ, space reactor test designs the moderator consists of a stack of thick zirconium hydride discs which almost fill the core vessels between tube sheets. The TFE's are inserted into holes through these discs and are welded into the tube sheets. Liquid metal coolant ( $\mathrm{NaK}$ ) is passed through the annulus between each moderator hole and its TFE. Neutron damage is moderate and choice of materials is limited due to potential free $\mathrm{H}_{2}$ and the thermal neutron spectra. Fuel inventory was about $10-20 \mathrm{~kg}$ of $\mathrm{U}^{235}$. 


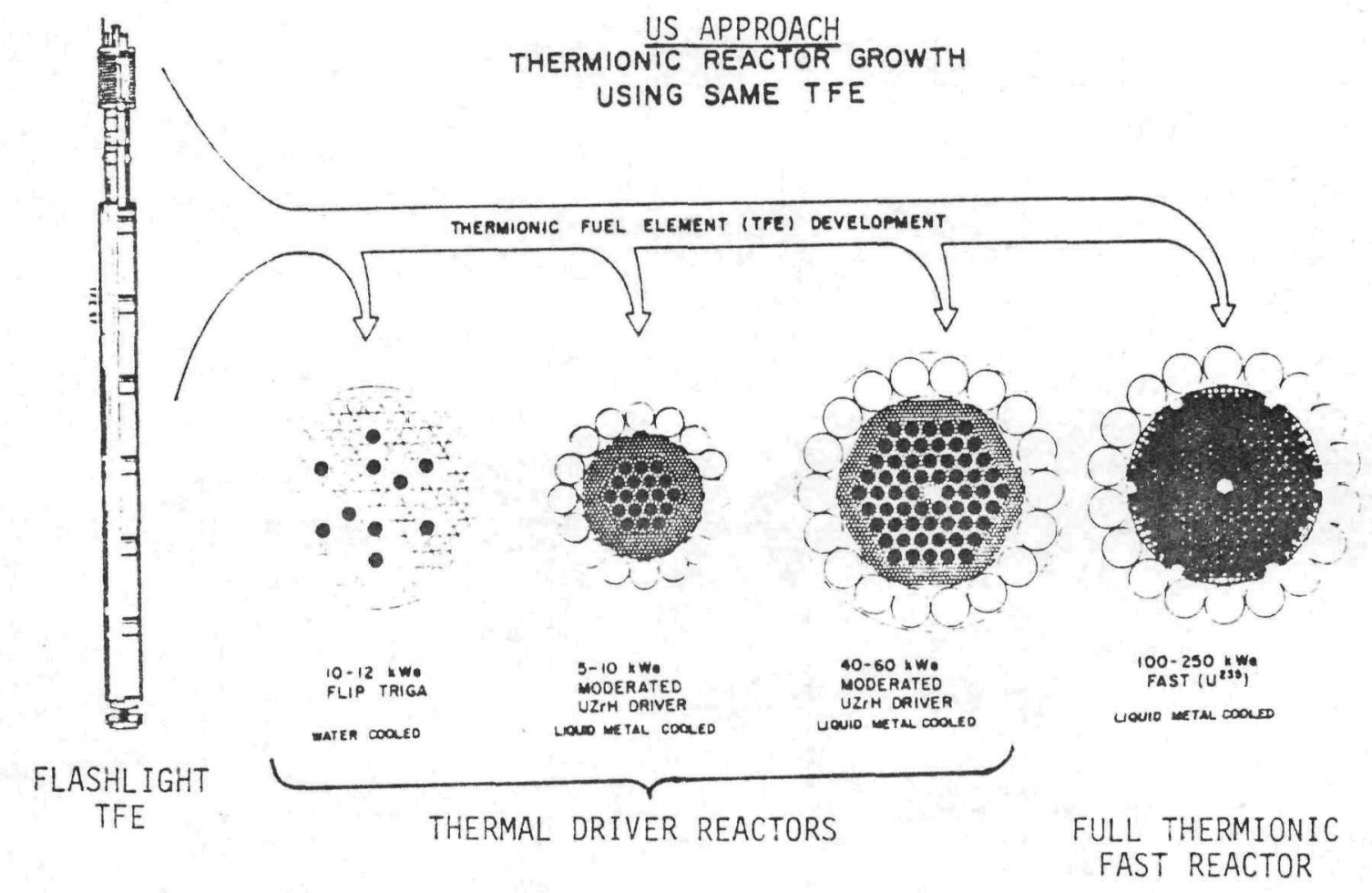

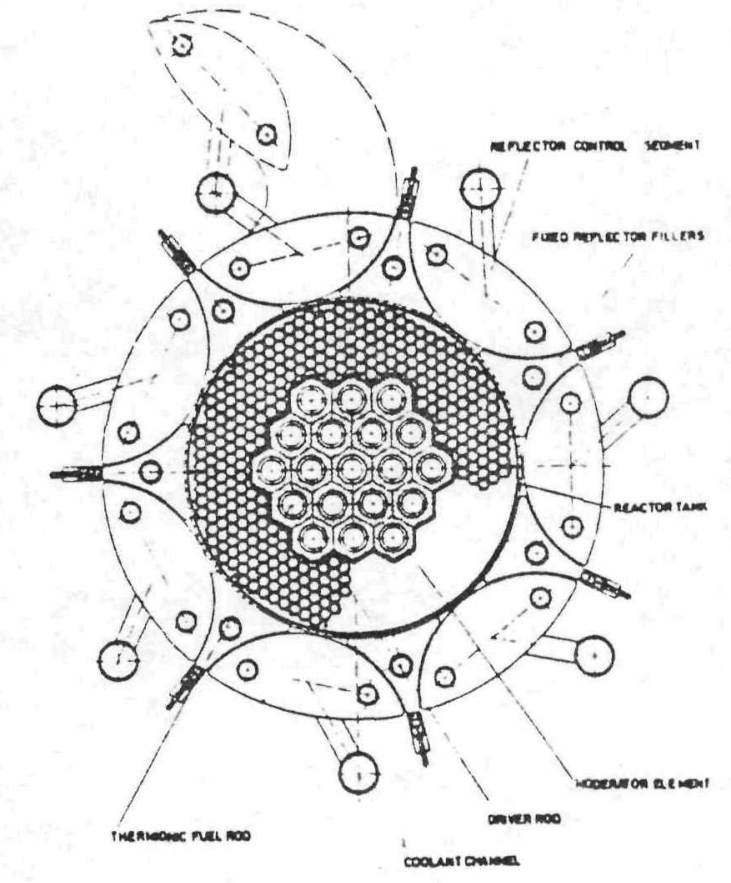

GERMAN ITR THERMAL DRIVER REACTOR APPROACH

Fig. 3-2

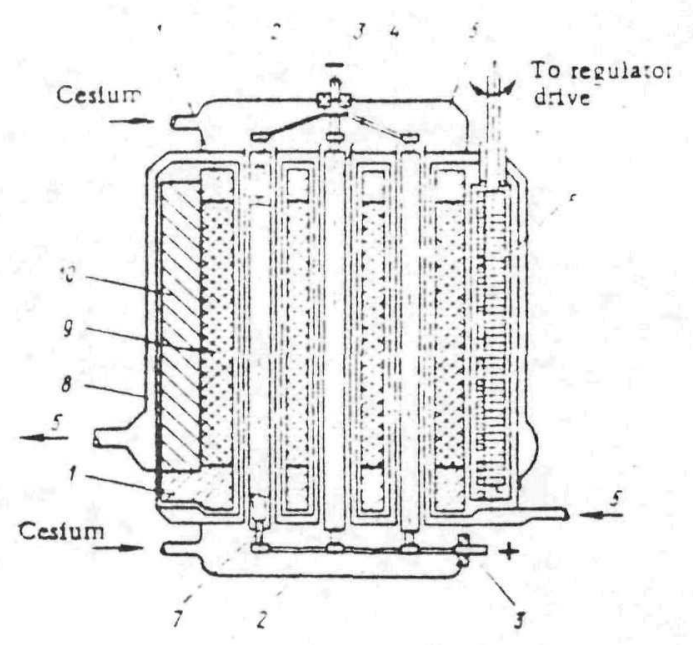

USSR FULL THERMIONIC THERMAL REACTOR TOPAZ

Construction of the converter reactor: 1) end reflector; 2) switching cinamber; 3) current leads of reactor; 4) power channel; 5) coolant; 6) regulating cyllader; 7) current takeoff of power channel; 8) reactor vessel; 9) moderator; 10) side reflector.

Fig. 3-2 A VARIETY OF REACTOR DESIGNS USING THERMIONIC FUEL ELEMENTS

$$
3-4
$$


3.1.1.2 External Fuel Type - The collector in each element is a coolant tube or heat pipe surrounded by a core-length fueled emitter. These elements are assembled without electrical contact inside a thermally insulated core vessel and reflector somewhat similar in layout to the heat-pipe-cooled SPAR or SABRE reactor. This concept, investigated by Schock and co-workers at Republic Aviation and JPL [3-5], has many inherent advantages over the flashlight type relative to pre-testing, fuel swelling and venting, heat transfer, insulator stability, redundancy and fuel volume fraction. These are offset somewhat by inherent disadvantages such as maintenance of long internal and external gaps, large element currents, inability to incorporate drivers or moderator, need to support and insulate the entire high temperature core, and a tendency to give heavier systems above about 100 kwe due to a limited core length. See Fig. 3-3.

3.1.1.3 Pancake Type - Single internally-fueled cylindrical cells are assembled and interconnected on trays across which coolant flows to cool the electrically insulated cell collectors. These trays are stacked to form the core and are surrounded by a reflector. This was the reference design concept for General Atomic prior to $1968[6,7]$. Principal advantages are the increased cell redundancy and associated network reliability, and the simplicity and pretestability of the single-cell module. These are more than offset by penalties imposed on the total system by the complex transverse coolant flow and the low fuel volume fraction. The principal historic significance of the concept is that it caused GA to concentrate on developing a highly compact and reliable cell prior to joining them into a flashiight TFE. See Fig. 3-3.

3.1.1.4 Sandwich Type - It this relatively unexplored type of in-core reactor, a planar array of fueled emitter tiles is attached to a flat core-length heat pipe with an intervening electrically-conducting and compliant radiation shield "mattress." These planar elements are then stacked to form the reactor core. This concept was originally patented by Grover at Los Alamos in 1964 [8]. It was revived recently by Rasor Associates to explore in-core reactor utilization of the very high power densities and high efficiencies presently obtainable by the unignited thermionic converter for very high but credible fuel temperatures [26]. With 

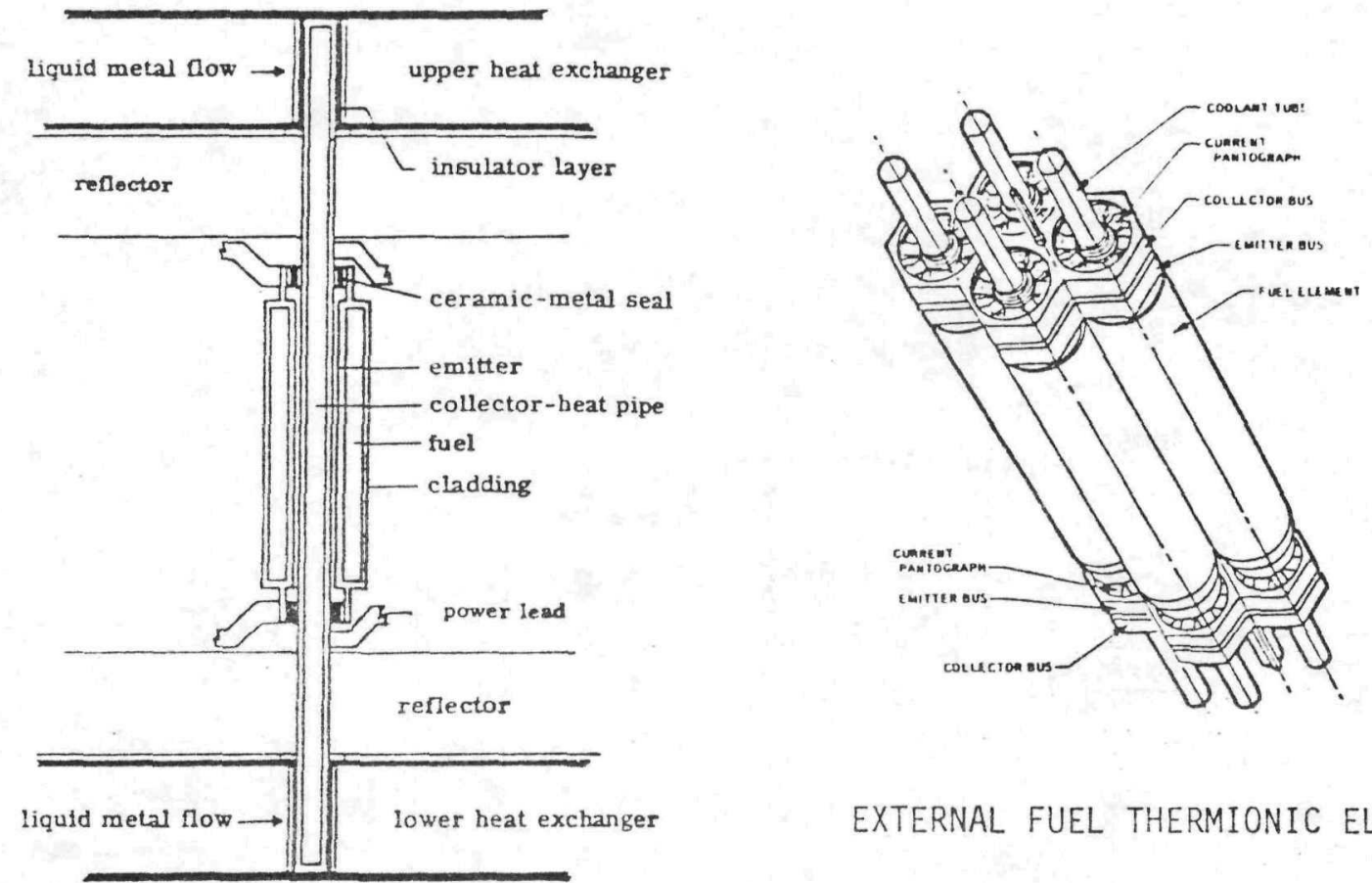

EXTERNAL FUEL THERMIONIC ELEMENT

EXTERNAL FUEL REACTOR CONFIGURATION

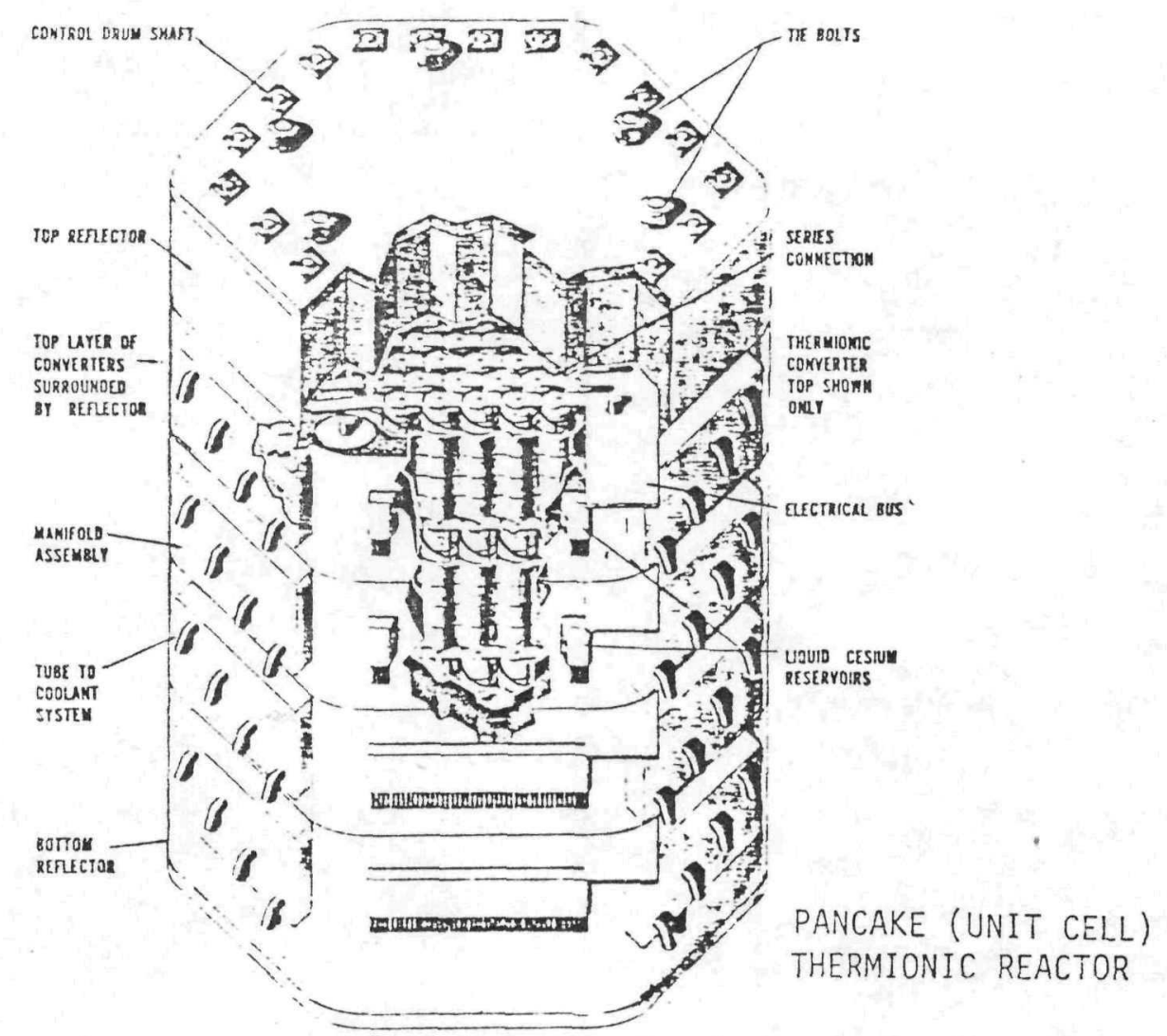

Fig. 3-3 THE EXTERNAL FUEL AND PANCAKE REACTOR CONCEPTS 
such performance, preliminary evaluation indicates that a shuttle-launchable system might generate 10-20 MWe continuously for several weeks, and a tenth of that power for several years. The unidirectional flow of current and coolant through the core, and the ability to absorb fuel distortion in the mattress, are the principal features of the concept which permit use of the high power densities and temperatures. Major problems are the unusual configuration of the insulator seals and development of a means for preventing non-catastrophic failure upon loss of cesium vapor. See Fig. 3-4.

\subsubsection{Core Surface Thermionic Reactors}

3.1.2.1 STAR-R - Heat is conducted from the interior of a solid reactor core to planar thermionic converter emitters bonded to its surface. Heat is conducted from the collectors through attached neutron-reflector segments and radiated directly from the surface of the reactor. Electrical isolation of the converters is achieved either by interposing a thermally-conducting layer of electrical insulator between the emitters and a monolithic core, or by attaching each emitter directly to its own isolated and externaliy-suspended segment of the core. This concept was patented in $1965[9,10]$ by Hobson* at GE and evaluated analytically for the U.S. Air Force [11]. Its major generic advantages are the complete absence of coolants, compactness, potential high redundant reliability and ease of startup. Its major generic disadvantage is the inherent growth limit $(<40 \mathrm{kWe})$ imposed by its dependence on conduction of heat from its core and radiation of heat from its surface.

3.1.2.2 Thermionic ROMASHKA - Rasor and co-workers at McDonnel1-Douglas in 1967 proposed a system which combined the highly-developed Solar Energy Thermionic (SET) converters, developed by Thermo Electron for JPL, with the Romashka reactor tested by the USSR [12]. The extremely simple Romashika reactor consisted of a stack of graphite-clad $U C_{2}$ discs surrounded by a beryllium radial reflector and Be 0 axial reflectors. Overall, Romashka was a 19-inch diameter $X 24$-inch high reactor with $50 \mathrm{~kg}$ of $u^{235}$. It was operated for a total of 2 years at a maximum core temperature of about $2200 \mathrm{~K}$. Heat conducted from the core to finned $\mathrm{Si}-\mathrm{Ge}$ thermocouples mounted on the outer surface of the radial reflector generated a total of $.5-1 \mathrm{kWe}$. In the proposed thermionic version, heat would be radiated from the core to the 


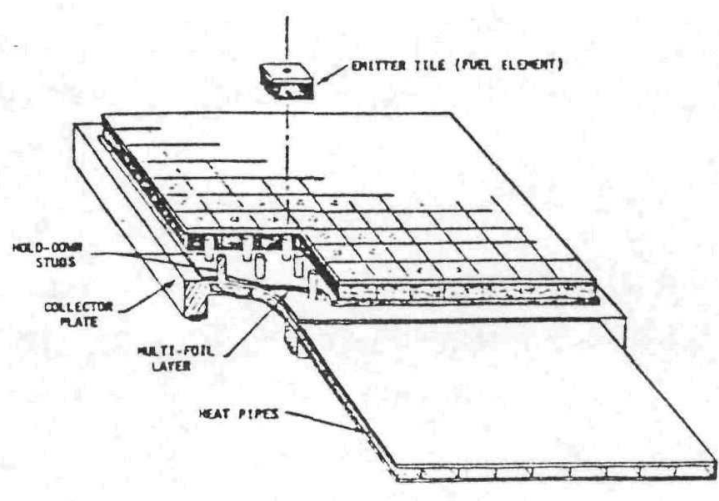

Module

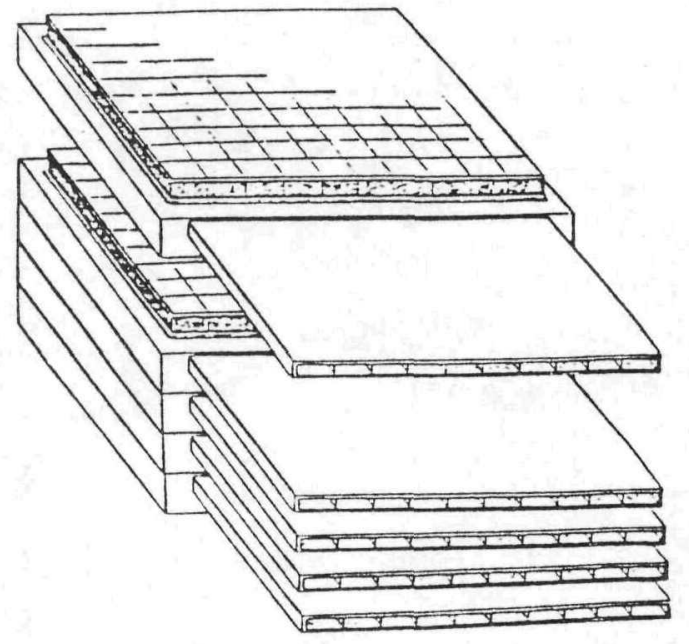

Reactor Core Assembly

SANDWICH THERMIONIC REACTOR

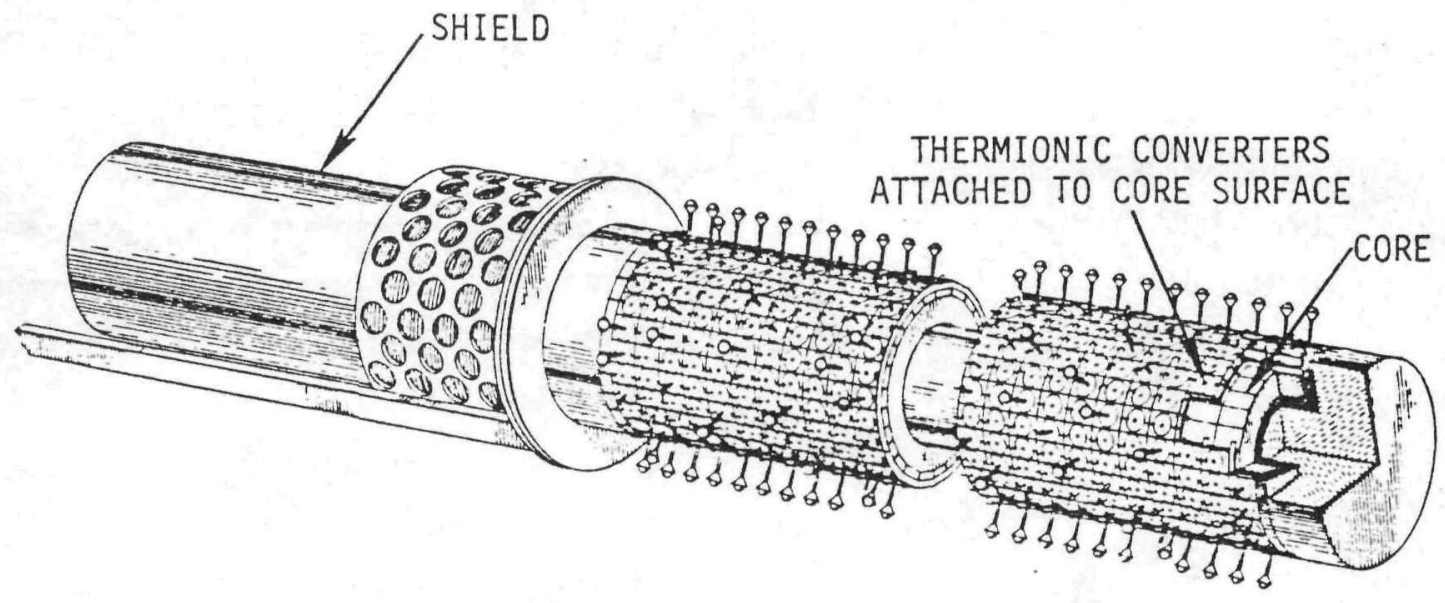

STAR-R CORE SURFACE THERMIONIC REACTOR

Fig. 3-4 THE SANDWICH AND STAR-R REACTOR CONCEPTS 
isolated emitters of SET thermionic converters attached by their collectors to the inner surface of the reflector. Reject heat would be conducted through the reflector and radiated directly from its outer surface. Ana?ysis indicated that a thermionic version of the original Romashka could generate $5 \mathrm{kWe}$ at a total shielded weight of less than $1000 \mathrm{lb}$, and a $30 \mathrm{kWe}$ version would weigh less than $2000 \mathrm{lb}$, nearly half the weight and size of other space reactor systems in this power range. The thermionic Romashka has the same generic advantages and disadvantages as STAR-R. In addition, Romashka radiant heating eliminates the need for an emitter insulator or a suspended-segment core. See Fig. 3-5.

\subsubsection{Out-of-Core Thermionic Reactors}

A number of systems have been studied in which heat is removed from the reactor core by a coolant loop or heat pipes and delivered to the emitters of external thermionic converters either bonded through insulators to the pipes, or isolated and radiantly heated by them [13]. Heat is radiated directiy from the collectors if the converters are mounted in the radiator, or is transferred to the radiator by a second low temperature set of heat pipes. The most recent such system is the thermionic version of the SPAR or SP-100 reactor systems studied by LANL and JPL for NASA and DOE. The principal advantages of this type of system are the ability to separately develop and test the reactor and the energy conversion subsystems, and the somewhat smaller size and fuel inventory of the reactor itself. The principal disadvantages are the need for a complex refractory metal core and external heat transfer system (possibly including electrical insulators), all operating at the high emitter temperatures. See Fig. 3-5.

\subsection{Development History in the U.S.}

\subsubsection{Discovery and Initial Exploration (1957-1961)}

The basic principles of thermionic electron emission and of its potential use for producing electric power were known by 1923 . No significant work was performed on it, however, until 1957-1958 when several U.S. investigators independently demonstrated production of electric power by thermionic conversion at practical efficiencies and output power densities. 


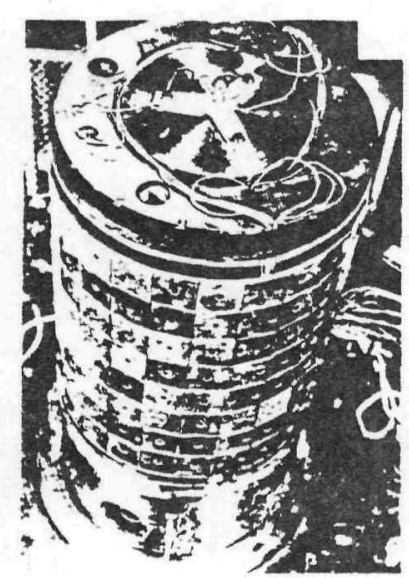

Photograph of Romashka Reactor

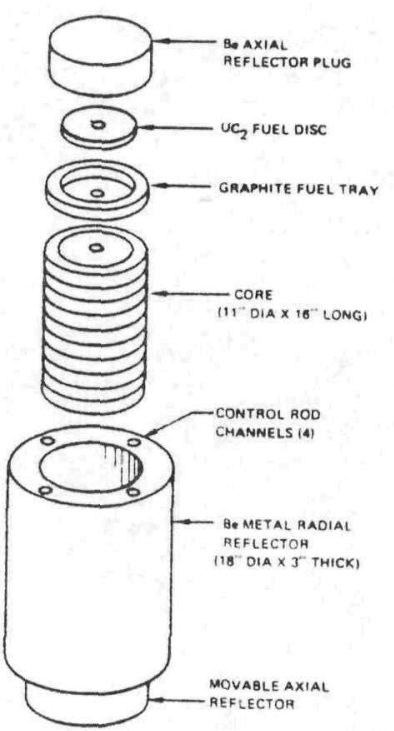

Romashka Reactor Configuration
THERMIONIC CONVERTERS

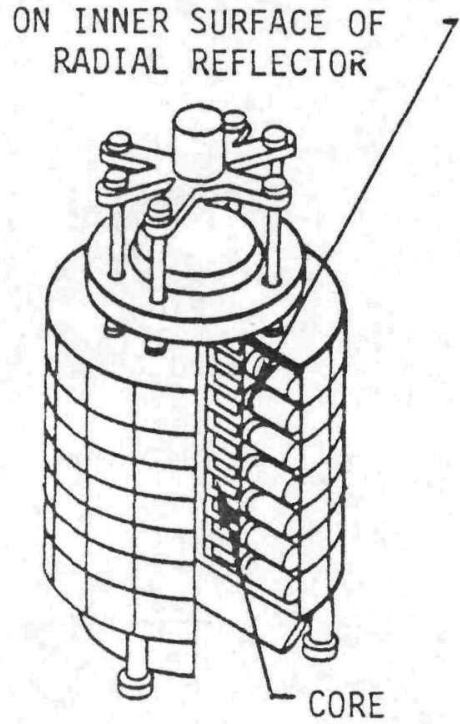

Thermionic Version

THERMIONIC ROMASHKA CORE SURFACE REACTOR

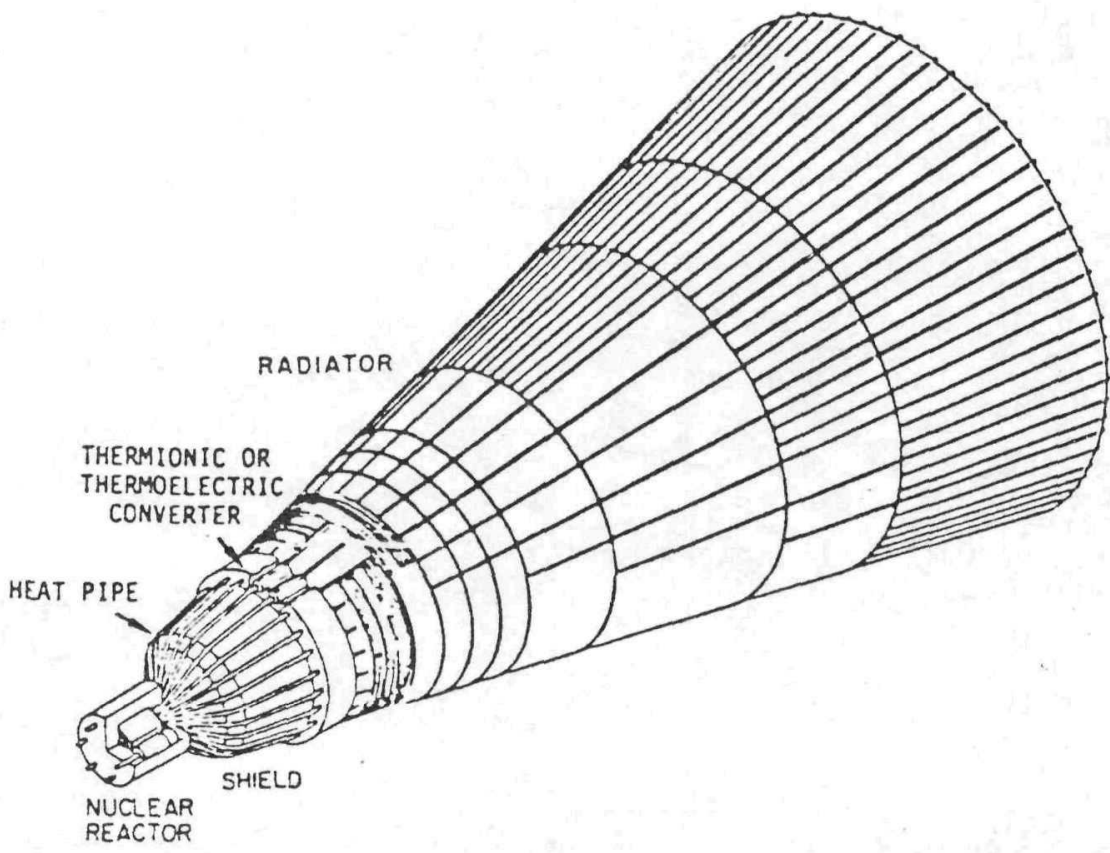

OUT-OF-CORE THERMIONIC REACTOR SYSTEM

Fig. 3-5 THE ROMASHKA AND OUT-OF-CORE REACTOR CONCEPTS 
In the period 1958-1961, basic and exploratory development of thermionic converters was performed in the U.S. primarily by Grover, et al. at LoS Alamos, Wilson, et al., at General Electric, Rappoport and Eastman at RCA, Rasor, et al., at Atomics International, Hatsopoulos, et al., at Thermo Electron and Pidd, et al., at General Atomic, with funding by the AEC, Air Force, Navy and NASA, in approximate descending order of funding support at the \$1-4 million/year total level.

\subsubsection{Early In-Core Thermionic Reactor Technology Exploration (1962-1968)}

An in-core nuclear thermionic cell was first operated by Grover and coworkers at LoS Alamos in 1958 (unignited mode) [14]. The first in-core thermionic reactor patent the "flashlight" concept was filed in 1960 by Rasor and Hirsch at Atomics International [15], and a major program for development of the in-core thermionic reactor was initiated by the AEC and NASA at General Atomic and General Electric in 1962. In the period 1962-1968, research and development in thermionic conversion was performed for a variety of nuclear and non-nuclear applications at a total level of \$7-10 million/year (about $\$ 30,000 /$ man-year), of which one-half to two-thirds was for in-core thermionic reactor development. A preliminary listing of efforts targeted at reactor power systems is shown in Table 3-1 [16].

At the time the U.S. thermionic reactor program was initiated, the development of SNAP hydride reactor systems for the 30-60 kWe power region was well underway, and was expected to evolve to somewhat higher power levels. The thermionic reactor was felt to be a long range advanced system and, therefore, was given the power range above $200 \mathrm{kWe}$ as its program objective. Since fuel burnup becomes a major constraint in compact reactor design above about $100 \mathrm{kWe}$, this resulted in exclusive attention to fast-spectrum thermionic reactor technology in the early U.S. program. By 1968, however, it became apparent that the level of development of the thermionic reactor fuel element was approaching that of the hydride reactor systems, so that the design objectives of the U.S. thermionic reactor program subsequently were broadened to include the 20-200 kWe power range. The U.S. program thereupon adopted many aspects of the thermal driver conceptuai technology for the lower power regime, which was being developed in Germany. 
THERMIONIC FUNDING SUMARY

ATOMIC ENERGY COMMISSION

$\begin{array}{llllllllllllllll}\text { Fiscal Year } & \\ \text { Program } & \text { Contractor } & 58 & 59 & 50 & 61 & 62 & 63 & 64 & 65 & 66 & 67 & 68 & \text { Thry } & \text { FY } & 68\end{array}$

REACTOR IN-CORE

Low temp. water-cooled
TI reactor

Plasma thenocouple prog.

TI reactor technology

II reactor development

TI reactor development

Cermet fuels with

rhenium entiters

TI reactor dynamics

300 kwe design study

300 kHe design study

300 kwe design study

Sheath insulator testing

Contractor

Martin

LASL

LASL

GGA

GE

TECO

$U$ of $A Z$

GGA

GE Artat.

ORNL

$\begin{array}{llllrrr}750 & 750 & 1410 & 1648 & 1429 & 1700 & 1400\end{array}$

$\begin{array}{lllllll}55 & 450 & 495 & 835 & 800 & 800 & 550\end{array}$

$\begin{array}{lllllll}16 & 480 & 532 & 982 & 1700 & 1566 & 1660\end{array}$

$\begin{array}{rrrr}6 \quad 95 \quad 92 & 110 & 90 \\ & 40 & 40 \\ & & 100\end{array}$

90

100

REACTOR OUT-OF-CORE

Liquid-metal-cooled reactor program

Advanced heat pipe

thermionics

KASA

Program

Contractor

$58 \quad 59$

61

Fiscal Year

65

66

$67 \quad 68$

TOTALS Thru Fy 68

REACTOR IN-CORE

Parametric study of

nuclear electric engine

Redeposition properties

to reduce vaporization

Carbide cathodes

TI materials for space

Dower applications

TI materials and diode

research

In-plle space power

plant study

in-pile TI systems study

Metal oxides in radiation

fielos

Externally fueled TI

converter

Fuel/clad diode testing

Fuel and dode irradiations

Fuel and diode trradiations

Nuciear-plasma diode

interactions

Lewis

GGA

GGA

GGA

GE

$P$ \& $W$

Martin

$U$ of $A Z$

Repb. Aviat.

GE

BMI

Lewis

Lewis

GE

II fuel investigation

Converter performance

mapping \& life test

$\mathrm{NO}_{2}$ loss rate

GE

REACTOR OUT - OF-CORE

Qut-of-pile Ti study Heat Pipe and converter integration

GE (MSO)

RCA

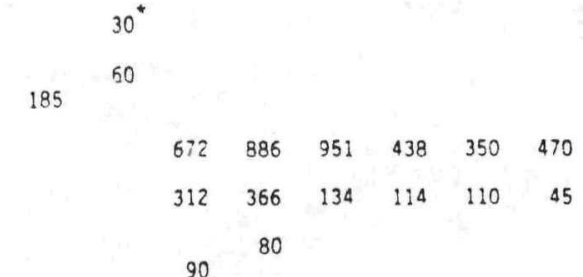

90

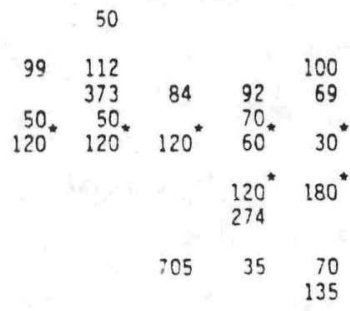

72

205

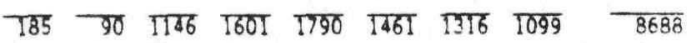

Table 3-1 
AIR FORCE

Program

Contractor

$\begin{array}{llll}58 & 59 & 60 & 61\end{array}$

Fiscal Year

$\begin{array}{lllllll}62 & 63 & 64 & 65 & 56 & 67 & 68\end{array}$

TDTALS

REACTOR IN-CORE

High temp. vapor filled GGA

converter

cylindrical il convrtr.

Nuclear fuel clad convirs.

Nuclear fuel clad convers.

RCA

Martín

REACTOR OUT-OF-CORE

Radiator TI generator

Radiator generator

STAR-R power system

High temp. collectors

insulated TI heat pipe

module

100

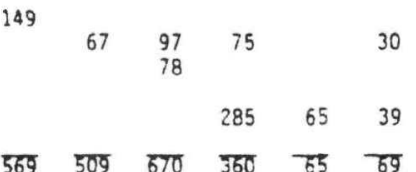

MaVY

Program

Contractor

$58 \quad 59$

$60 \quad 61$

$62^{\text {Fiscal Year }} 63^{64}$

$\begin{array}{llll}65 & 65 & 67 & 68\end{array}$

TOTALS
ThrU FY 68

REACTOR IN-CORE

O1rec: conversion reactors

GGA

Low temp. II for nuclear applications

Urantum bearing emitters TFE connectors development Materials investigations

Il diode converters

Metwork reliabllity

Simulated F.P. effects

TI converter program

TI converter materials

Nuclear thermionic plasma

dlode
69

$\begin{array}{rr}574 & 159 \\ 40 & 40\end{array}$

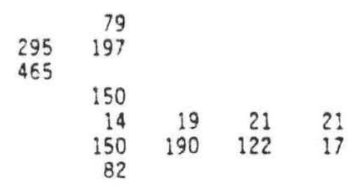

274

ARMY

Program

Contractor

$\begin{array}{llll}58 & 59 & 60 & 61\end{array}$

Fiscal Year

$65 \quad 66$

$67 \quad 68$

REACTOR IM-CORE

Terrestrial reactor

design study

GE

92

REACTOR OUT-OF-CORE

MATTRAC reactor study

Hittman

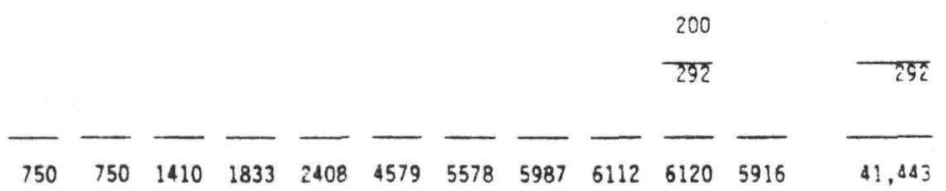

Table 3-1 (continued) 
The history of the early in-core thermionic reactor technology is shown in Fig. 3-6.

\subsubsection{Prototype TFE Development and System Design (1969-1972)}

In 1968, the AEC-NASA program was focused on competitive development of the "flashlight" type of in-core thermionic reactor system by General Electric and General Atomic, with primarily Rasor at Thermo Electron, NASA JPL and NASA Lewis Laboratories providing supporting research and advanced development. In 1970, the General Electric work was terminated, and General Atomic and Thermo Electron were supported for more intensive development of a prototype TFE for the selected reactor and system designs, including preparation for a full thermionic reactor test system (17). Total thermionic funding in the 1968-1972 period was \$5-7 million/year (including $\$ 2$ million by NASA) nearly all of which was for development of the in-core reactor system. Prototype TFE development history is depicted in Fig. 3-7. At the time of cancellation of all U.S. space reactor programs in 1973, the prototype TFE performance and lifetime objectives for the reference system were being met in multiple in-core tests $[18,19]$, as described in section 8.0 .

\subsubsection{Terrestrial Thermionic Application Technology Exploration $(1973-1983)$}

During the period 1973-1983 nearly all thermionic work in the U.S. was performed by Thermo Electron and Rasor Associates, along with some basic research at Lewis, JPL and a few universities. The greater part of this was funded by AEC-ERDA-DOE at \$1-3 million/year for development of flame-heated converters capable of efficient operation for terrestrial applications. This work emphasized development of technology for low temperature converter operation and atmospheric and flame protective coatings that are not directly related to the in-core space reactor application. NASA and DOE provided a few hundred thousand dollars per year in this period, however, for thermionic technology and the investigation of the application of thermionic converters in the low temperature out-of-core heat-pipe-coolant reactor systems [20-24]. 


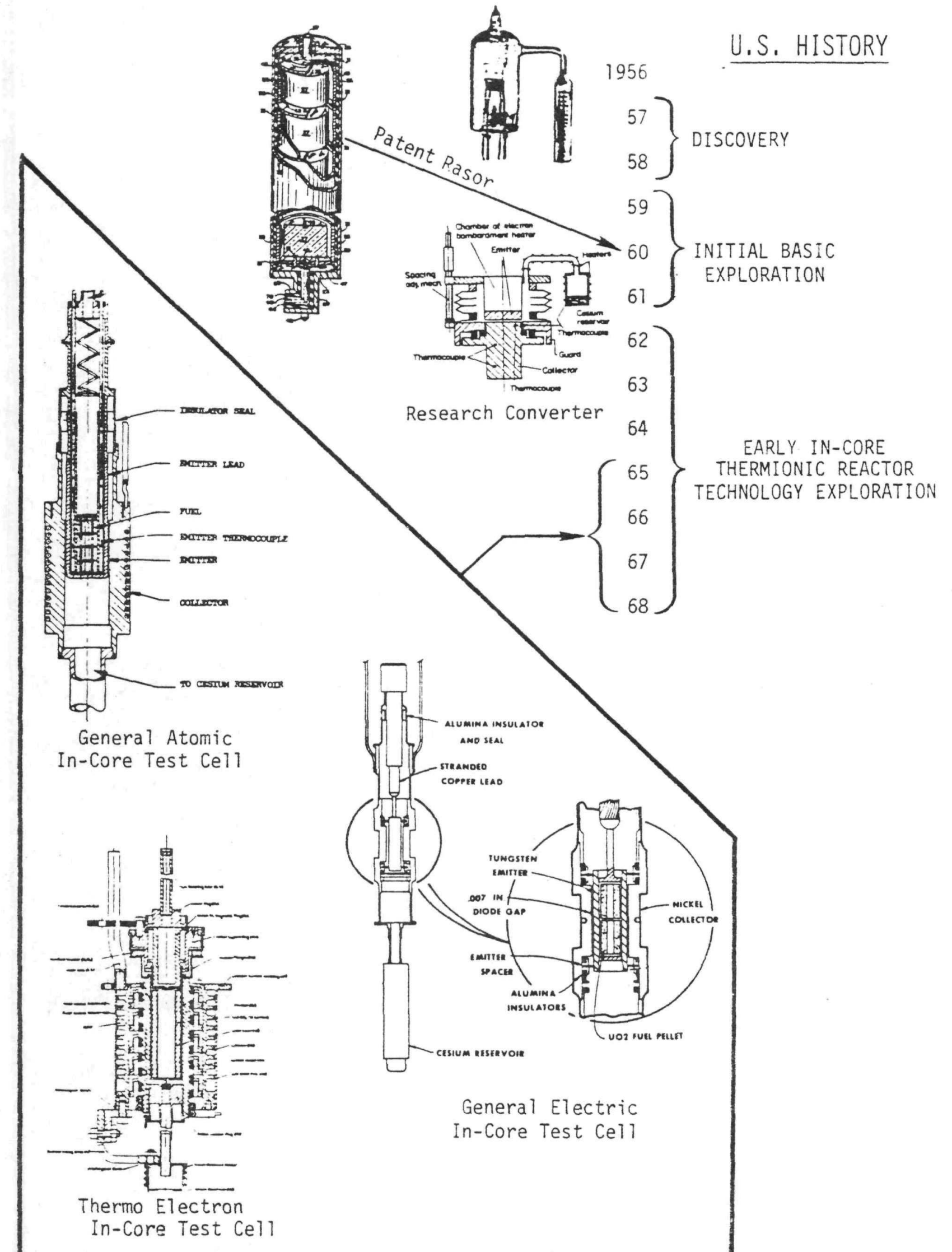

Fig. 3-6 THE EARLY U.S. THERMIONIC PROGRAM 

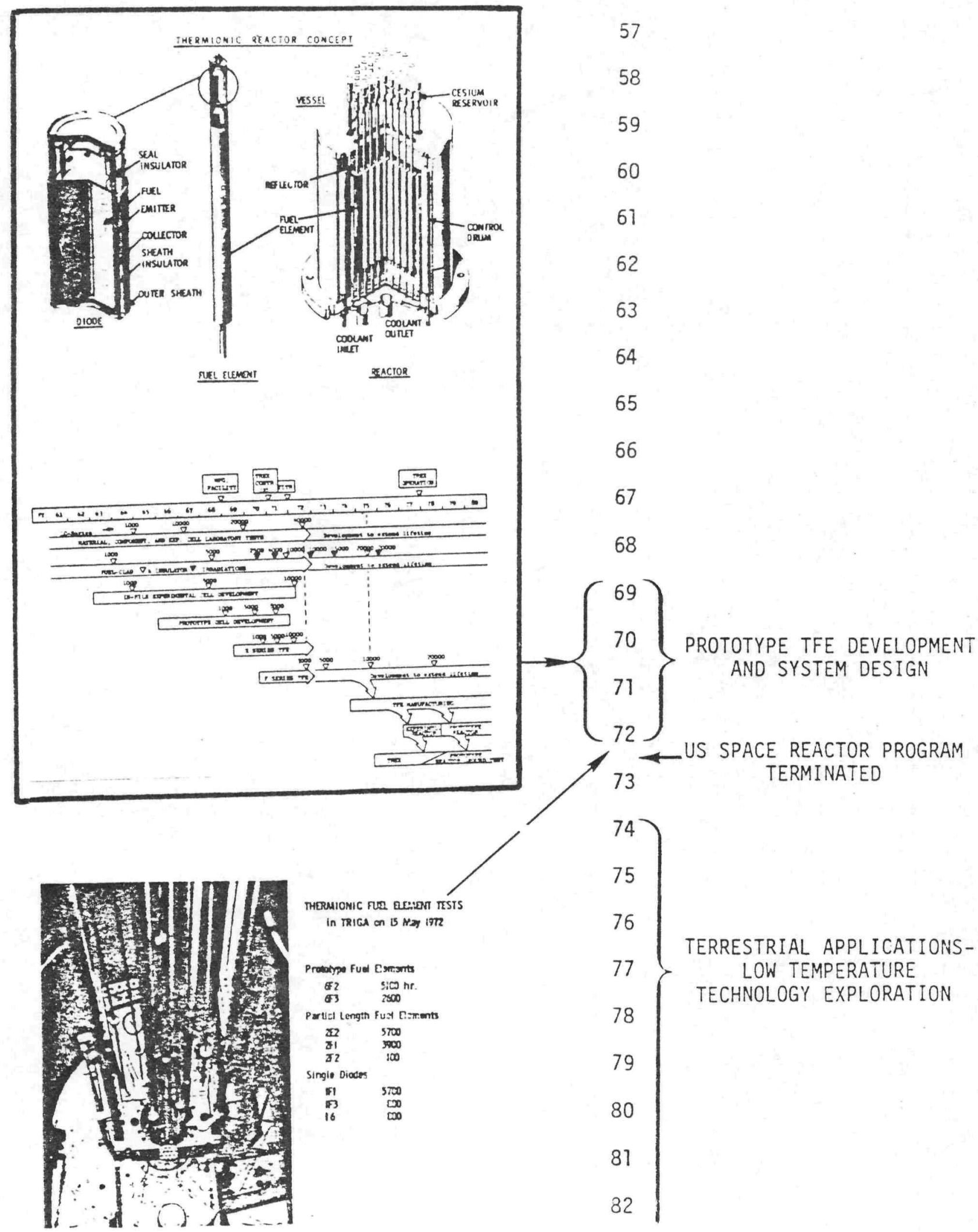

Probiype fuel Exrsm

E2
ब3
क3
5000

Particl lengen Fuy Esmants

$\begin{array}{ll}81 & 5700 \\ 81 & 3000\end{array}$

$\begin{array}{ll}81 & 7000 \\ 21 & 100\end{array}$

Singilo Diccess

15 5000

LOW TEMPERATURE

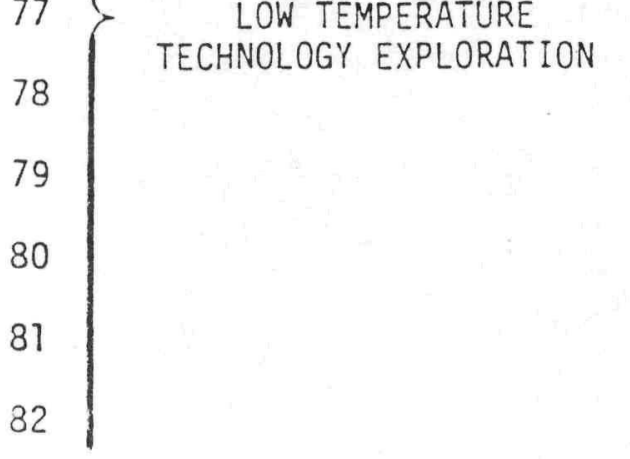

Fig. 3-7 THE U.S. PROTYTYPE TFE PROGRAM 
The Air Force supported a small overview study of thermionic reactor systems $[25,26]$ and a modest research program.

\subsection{Development History in Western Europe}

\subsubsection{Initial Exploration (1960-1966)}

West European involvement in thermionic conversion research lagged that in the U.S., but in the period 1962-1966, several groups in Germany, France, England and the Euratom Laboratory in Italy began to follow the basic U.S. work closely and to reproduce its results, including a few in-core tests of nuclear-heated cells.

\subsubsection{Prototype TFE Development and System Design (1967-1972)}

Beginning in about 1967, both the German and French governments initiated independent national programs to develop in-core thermicnic reactors. The German In-core Thermionic Reactor (ITR) project consisted of a consortium of component-developing companies, Brown-Boveri and Siemens, and a system design and test integrator, Interatom, funded through the Nuclear Research Center at Juelich which also performed supporting research. A $20 \mathrm{kWe}$ thermal-driver reactor was chosen to power a projected European direct-broadcast television satellite. The ITR project, which was supported at about the same level as the U.S. thermionic reactor program, achieved in-core tests of high performance long-life prototype TFE's by 1972, and was preparing to construct a complete reactor test facility [27]. In 1972, however, cutbacks in the U.S. space program caused the U.S. to withdraw its commitment to launch the projected television satellite, which resulted in cancellation of the ITR project.

The object of the comparably-sized French program was to develop a 20 kWe water-moderated in-core reactor for use in sea bottom applications such as deep submerged oil well drilling and pumping platforms. The project was led by the Center for Nuclear Studies at Saclay, with participation of the CSF and Thomson-Huston Companies. Cost reduction was emphasized, and a high degree of automation was achieved during production of the TFE's for a 
planned test reactor [28]. Before the reactor was assembled, however, the project was cancelled in 1974 when French coast oil spills caused French environmental groups to successfully oppose drilling for oil in French coastal waters. The West European history is depicted in Fig. 3-8.

\subsection{Developmental History in the USSR}

\subsubsection{Discovery and Initial Exploration (1956-1964)}

Successful demonstration of thermionic conversion using the cesium vapor diode was first published in the USSR in 1956, one year before announcement of equivalent work in the U.S. and two years before similar U.S. publications [29]. U.S. workers were then unaware of this work, however, due to the delay in publication of the English translations. A reciprocal delay apparently occurred, however, because USSR investigators persisted in their near-exclusive investigation of the unignited mode of converter operation long after it had been discarded in favor of the more practical ignited mode by U.S. investigators. Successful tests of ignited in-core converters were not published by the USSR until 1965, and were primitive compared to the then-classified U.S. technology. The size of the USSR thermionic conversion program during this period apparently was comparable to that of the U.S. program.

\subsubsection{Prototype In-core Reactor Development (1964-1969)}

While the U.S. chose to evaluate and develop TFE technology via iterative in-core testing of single cells and TFE's, the USSR elected in about 1965 to concentrate its resources on building a facility said to be capable of producing complete in-core thermionic reactors and of testing such reactors at the rate of about two per year. Their space-environment thermionic reactor test cells, are similar to the SNAP reactor test facilities in the U.S. The funding level of the USSR program during this period was substantially greater than that in the U.S. due to construction of complete thermionic reactor systems and their test facilities, while maintaining a basic converter research effort that was several time larger than that in the U.S. (based on number and quality of publications). 


\section{6}

57

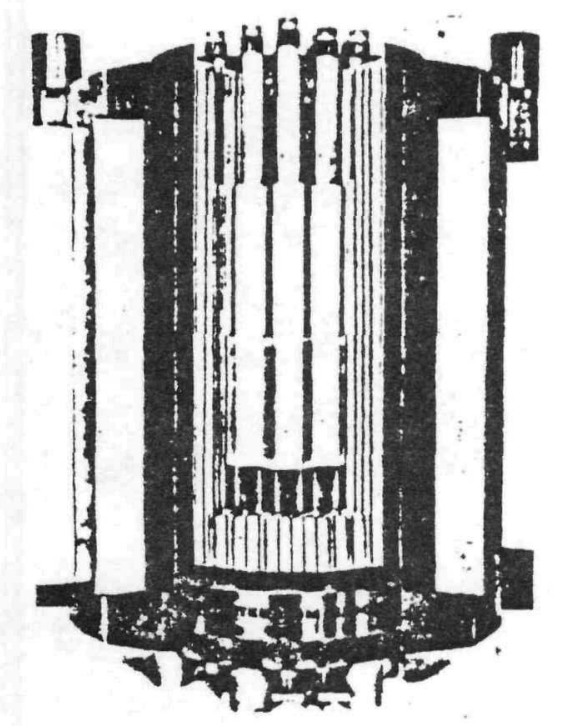

German ITR Reactor

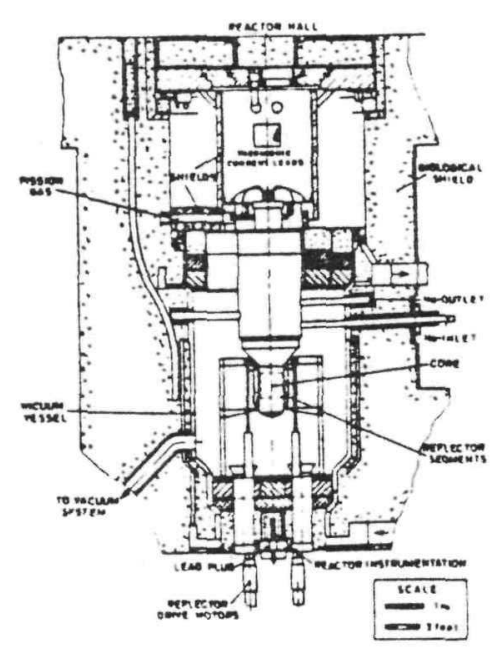

ITR Reactor Test Facility
58

59

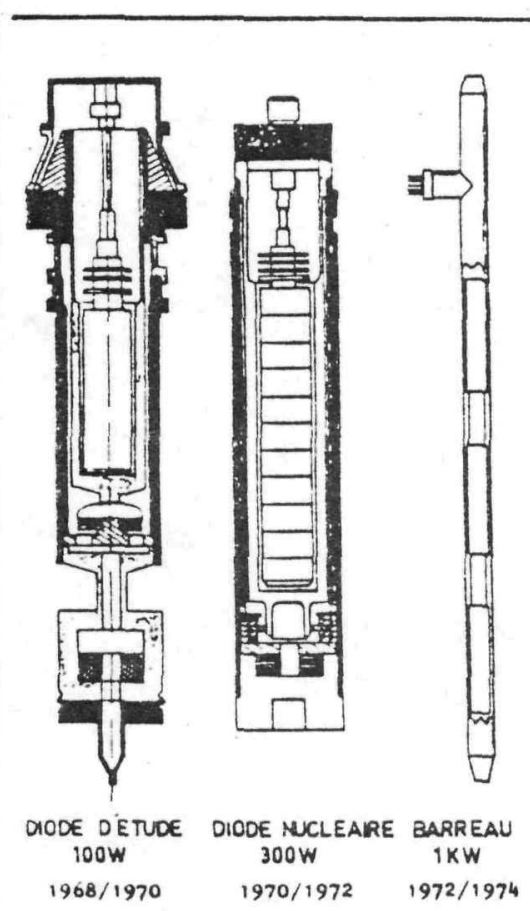

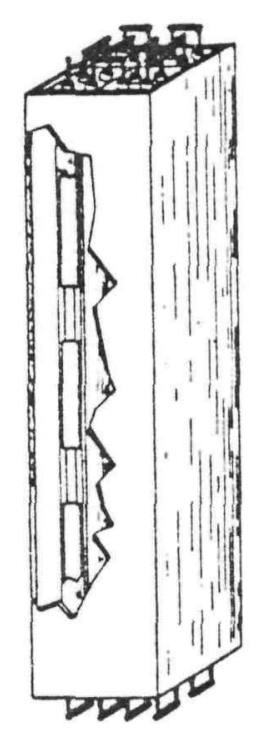

DIOGENE

10KW

$1974 / 1976$

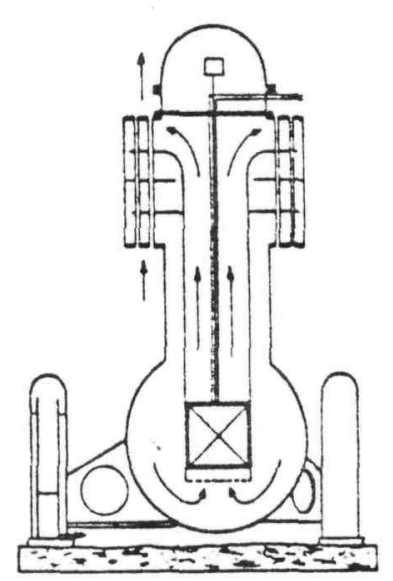

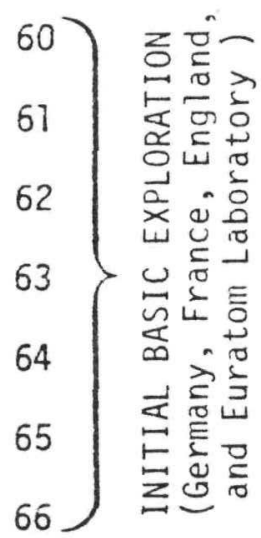

$67)$ 岕

68 过怘㐫

69 岁㟔怘总

$70\}$ 嵌岕止市

71 는듀

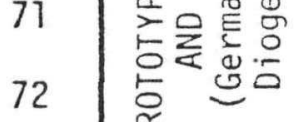

$73 \stackrel{2}{\longleftarrow}$ BOTH PROJECTS

74 TERMINATED

75

76

77

78

REACTEUR PROTOTYPE

$20-100 \mathrm{KW}$

$1976 / 1980$

French Undersea In-Core Thermionic Reactor Project 80

Fig. 3-8 THE WEST EUROPEAN THERMIONIC REACTOR PROGRAM 


\subsubsection{Prototype In-core Reactor Testing (1970-1977)}

The USSR published a description of the operation of the TOPAZ-1 in-core thermionic reactor in 1971 [30], TOPAZ-2 in 1972 [31] and TOPAZ-3 in 1974 $[32,33]$. The TOPAZ series were thermal reactors generating an output power of 5-10 kWe, but were said to be able to be scaled up to the $100 \mathrm{kWe} l e v e 1$. The TOPAZ TFE's were primitive by U.S. standards, with a performance inferior to that obtained by the U.S. in the mid-1960's. Individual TFE tests were performed and reported by the USSR in the mid-1970's, however, which showed significant improvement. Fig. 3-9 displays USSR thermionic development history. In 1977, a U.S. delegation visited the TOPAZ test facility and were briefed on the results of the tests of a "research reactor" in the TOPAZ test facility which was used as a test bed to evaluate several new types of TFE's in the same core [34]. These as-yet unpublished results suggested that the gap between the 1972 U.S. TFE performance and that being obtained by the USSR had been substantially closed by their ongoing TFE development.

\subsubsection{Unknown Recent Progress (1977-1983)}

It is clear that USSR in-core thermionic reactor development continued at a high level after termination of the U.S. program in 1972. Less is known of the period between 1977 and the present since the exchange of personal contacts and publications virtually ceased after imposition of the communication ban by the U.S. following the Afghan invasion. After the nuclear-powered USSR satellite Cosmos 954 reentered in Canada, however, a USSR publication [35] reviewed the USSR space nuclear development program and stated that at power levels of 5-10 kWe and greater, the in-core thermionic reactor is the most promising. Soviet technical journals continue to report significant progress and activity in thermionic fuel element performance improvement and crucial understanding of basic fuel and thermionic surface and plasma phenomena. 


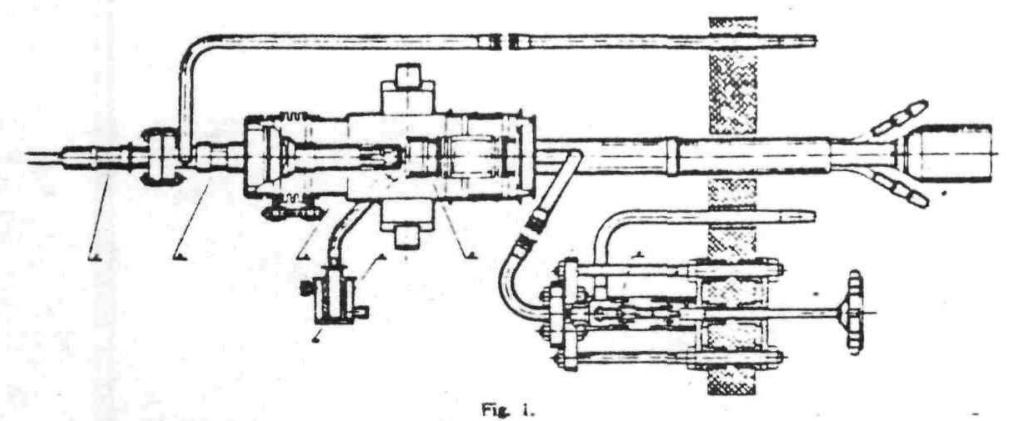

Fie 1.

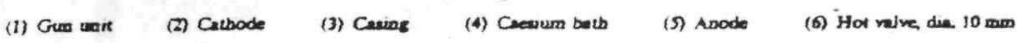

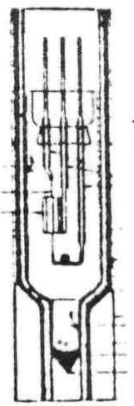

USSR HISTORY

1956

$57 \int$

DISCOVERY

$\left.\begin{array}{l}58 \\ 59 \\ 60 \\ 61 \\ 62\end{array}\right\} \begin{gathered}\text { INITIAL BASIC } \\ \text { EXPLORATION }\end{gathered}$

63

64)

USSR Thermionic Reactor Test Facility

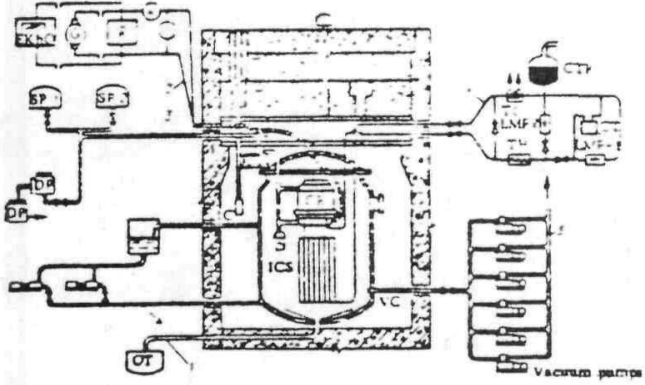

Fis. 6. Tecboological Lest oysuem: CR) cooverter reactor; VC, necuum chamber: TC) loa ization chamber: 1) sy stem of Lquid-metai coolan $R$ (P) liqud

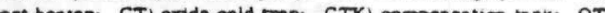

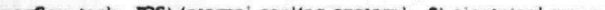

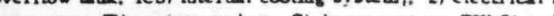
ing system (R) resialance bax: G) de generator: EKhOl code anme lor a device recording the rolt-ampere characteristlcs by a pulse metbod): 3) vacurum-cesium system (C) cestum the rmostat; CT) cold trap for cestum vapor: SP) sorption pumps: DP) diftasioe pumpe I;

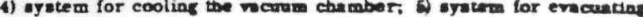
the recurum chamber.

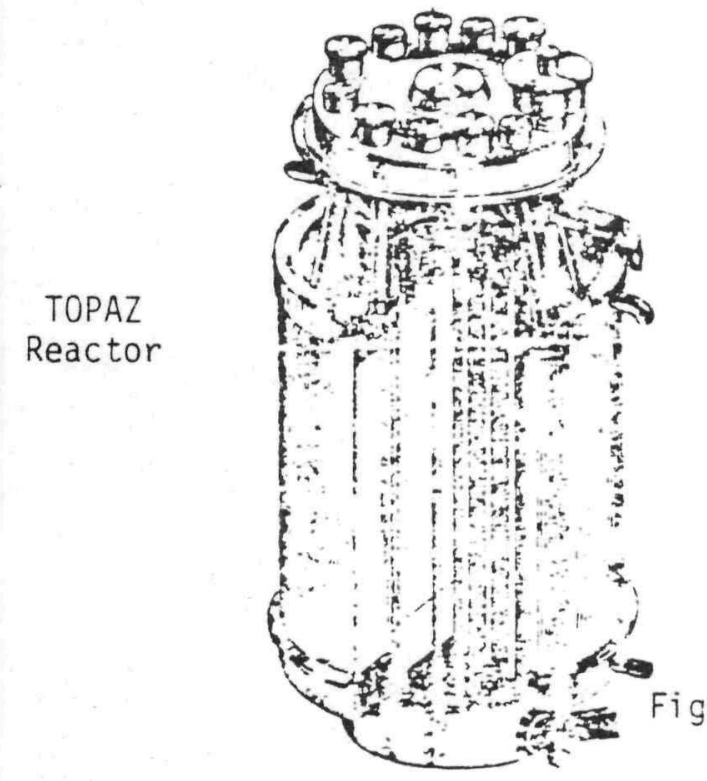

TOPAZ TFE

65

66

67

68

69

$70)$

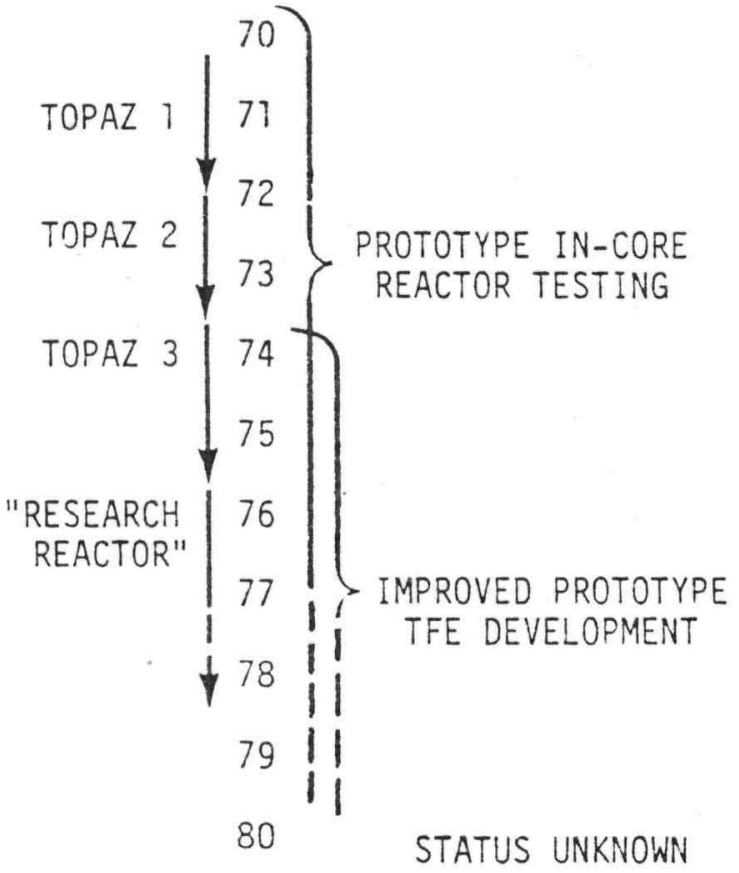

87

82
PROTOTYPE IN-CORE

REACTOR DEVELOPMENT (TOPAZ) 


\section{REFERENCES}

1. N. S. Rasor, "Thermionic Energy Conversion" Chapter 7 in Fundamentals Handbook of Electrical and Computer Engineering, Vol. II, S. L. Chang, Editor (John Wiley \& Sons, 1983).

2. N. S. Rasor, "Thermionic Energy Conversion" Chapter 5 in Applied Atomic Collision Physics, Vol. 5, H. S. W. Massey, B. Bederson and E. W. McDaniel, Editors (Academic Press, New York, 1982).

3. J. F. Mondt and M. L. Peelgren, "External Fuel Thermionic Reactor System," Thermionic Conversion Specialist Conf. (October, 1971).

4. A. Schock and B. Raab, "Development of a Full-Length External-Fuel THermionic Converter for In-Pile Testing," Thermionic Conv. Spec. Conf. (October, 1971).

5. M. J. Abbate, C. L. Eisen, B. Raab, B. and A. Schock," External-Fuel Thermionic Reactors," 2nd International Conf. on THermionic Power Generation, Stresa, Italy (May, 1968).

6. W. G. Homeyer, "Low Power Reactor Comparison," Gulf General Atomic, GA-8981 (Confidential/Restricted Data) (February, 1969).

7. "A Design Study of the Unit-Cell Thermionic Reactor for Space Applications," Gulf General Atomic, GA-8917, (Confidential/Restricted Data) (January, 1969).

8. G. Grover, U.S. Patent No. 3,243,613.

9. R. Hobson, U.S. Patent No. 3,623,946.

10. R. Hobson, U.S. Patent No. 3,623,947.

11. "Design Analysis of STAR-R Nuclear Thermionic Power Systems," General Electric Company, AFWL-TR-6615, (Confidential/Restricted Data) (July, 1966).

12. N. Rasor, J. Greenborg, and M. Moyer, "A Thermionic Reactor Based on Radiant Heat Transfer and Demonstrated Components," Thermionic Conv. Spec. Conf. (October, 1967).

13. R. Breitweiser and E. Lauty, "A Design Study of a 350 kWe Out-of-Core Nuclear Thermionic Converter Systems," Fifth Intersociety Energy Conv. Engineering Conf. (1970).

14. G.M. Grover, D.J. Roehling, E.W. Salmi and R.W. Pidd, J. Appl. Rays 291611 (Nov. 1978).

15. N. S. Rasor, U.S. Patent No. 3,113,091 
16. L. Price memo.

17. D. S. Beard and J. J. Lynch, "Thermionic Reactor Program, An Overview," Proc. 7th Intersoc. Energy Conv. Eng. Conf., San Diego, p. 1036 (1972).

18. J. W. Holland, "Thermionic Fuel Element Development Status Summary," Proc. 7th Intersoc. Energy Conv. Eng. Conf., San Diego, p. 1060 (1972).

19. M. K. Yates, G. O. Fitzpatrick and D. E. Schwarzer, "Thermionic Fuel Element Testing at Gulf General Atomic," 3rd International Conf. on Thermionic Electrical Power Generation, Juelich (June, 1972).

20. J. P. Mullin, W.R. Hudson and L.P. Randolph, et al., "The NASA Space Power Technology Program," 14th Intersoc. Energy Conv. Eng. Conf., Boston (August, 1979).

21. J. F. Morris and J. G. Lundholm, "NASA Thermionic-Conversion Program," 11th Intersoc. Energy Conv. Eng. Conf., Stateline, Nevada (September, 1979).

22. W. M. Phillips and E. V. Pawlik, "Design Considerations for a NEP System," AIAA/DGLR 13th International Electric Propulsion Conf., San Diego (1978).

23. D. Buden, et al., "Selection of Power Plant Elements for Future Reactor Space Electric Power System," Report LA-7858, LoS Alamos National Laboratory, New Mexico (September, 1979).

24. J. F. Mondt, "Electrical Power and Propulsion, Thermal-to-Electric Conversion, Thermionic and Brayton Power Subsystem Comparison for NEP," NASA, JPL 715-40 (March 15, 1980).

25. T. Mahefkey, "Thermionic Application for Future Air Force Space Power Systems," 16th Intersoc. Energy Conv. Eng. Conf., Atlanta (August, 1981).

26. E. J. Britt and G. 0. Fitzpatrick, "Direct Conversion Nuclear Reactor Space Power Systems," AFWAL-TR-82-2073 (December, 1982).

27. R. Pruscheck, "Status Report on Reactor Development Activities in the FRG," 3rd International Conf. on Thermionic Electrical Power Generation, Juelich (June, 1972).

28. B. Devin, "Status Report on Realtor Development Activities in France," 3rd International Conf. on Thermionic Electrical Power Generation, Juelich (June, 1972) (in French).

29. P.M. Marchuk, Zapishki Fizicheskovo Instituta

30. G.M. Gryaznov, et al., 4th International Conference on the Peaceful Uses of Atomic Energy, Geneva, Switzerland, Paper No. 852 (1971).

31. V. A. Kuznetsov, "Thermionic Reactors," 3rd International Conf. on Thermionic Electrical Power Generation, Juelich (June, 1972). 
32. V. A. Kuznetsov, et al., "Development and Construction of the Nuclear Power Installation TOPAZ," Sov. At. Energy (USA) 36, 578 (1974).

33. "The USSR Thermionic Energy Converters Status and Prospects," distributed at the 1975 Thermionic Conv. Spec. Meeting, Eindhoven (September, 1975).

34. N. S. Rasor, "A Summary of USSR Thermionic Energy Conversion Activity," 13th Intersoc. Energy Conv. Eng. Conf., San Diego (August, 1978).

35. E. Knorre, "The Atom in Space." "New Times" $I$ (Feburary 10, 1978). 


\subsection{DATA BASE}

\subsection{General Contents of Data Base}

A data base of over 1200 articles has been compiled of articles published prior to December 31, 1982, pertinent to the analysis, research and development, and cost of thermionic converters for space reactor applications. This data base is divided into seven subtopics: 1)electric propulsion, which deals primarily with orbital transfer vehicles; 2) nuclear fuels, with an emphasis on oxide fuels, covering both testing and theoretical modeling; 3) reactors, primarily thermionic reactors; 4) refractory metals, dealing primarily with test results of material properties; 5) thermionic research and physics, which deals primarily with basic research on mechanisms; 6) thermionic development and devices, covering both experimental studies as well as theoretical modeling; and 7) thermionic fuel elements, with a primary emphasis on test results and interpretation. The entries have been compiled from a variety of sources such as journals, conference proceedings, government and technical reports, etc. The current breakdown of articles in the data base is shown in table 4.1 .

A data base program has been written in BASIC for use on the Hewlett-Packard Series 200 personal computer. The program provides easy user input, identification and retrieval of the entries in the data base. The articles (or bibliographies) can then be located in the SPI offices where they are filed by entry number.

The data base will continue to evolve as SPI receives new acquisitions. A current listing of the entries in the data base, as well as a detailed description of the data base structure and program is given in Appendix. A (bound separately). 


\begin{tabular}{|c|c|c|c|c|c|}
\hline & $\begin{array}{l}\text { ARTICLES } \\
\text { (IN HOUSE) } \\
\end{array}$ & $\begin{array}{r}\text { ABSTRACTS } \\
\text { (IN HOUSE) } \\
\end{array}$ & $\begin{array}{l}\text { BIBLIO- } \\
\text { GRAPHIC } \\
\text { REFERENCE }\end{array}$ & ON ORDER & TOTAL \\
\hline ELECTRIC PROPULSION & 5 & 6 & 0 & 0 & 11 \\
\hline NUCLEAR FUELS & 237 & 17 & 22 & 48 & 324 \\
\hline REACTORS - THERMIONIC & 112 & 62 & 38 & 0 & 212 \\
\hline REFRACTORY METALS & 81 & 8 & 3 & 0 & 92 \\
\hline RESEARCH - THERMIONIC & 188 & 1 & 0 & 0 & 189 \\
\hline THERMIONIC DEVICES & 110 & 66 & 7 & 0 & 183 \\
\hline THERMIONIC FUEL & 119 & 84 & 31 & 0 & 234 \\
\hline & 852 & 244 & 101 & 48 & 1245 \\
\hline
\end{tabular}

TABLE 4.1

$4-2$ 


\subsection{PREVIOUS TFE AND FUEL CAPSULE EXPERIENCE}

\subsection{Past TFE Development Efforts}

\subsubsection{Overview}

The "flashight" thermionic fuel element developed in the previous space reactor program has the potential for achieving the power level, size, mass, reliability, and life objectives of the SP-100 program. It uniquely, has an integrated reactor-fuel-conversion system data base sufficiently extensive to have defined failure modes, potential life-limiting processes, and fabrication problem areas. Consequently, its development status was selected for review in this project.

Extensive development of the flashlight type of TFE design occurred in Europe and the Soviet Union, but those initial efforts concentrated on thermal reactor concepts rather than the fast reactor designs required for the high power systems presentiy of interest. Thermal reactor designs are significantly penalized by the use of tungsten in the core, and consequently most of the European and initial Soviet effort concentrated on the development of molybdenum emitter structures. Fast reactors are little affected by the use of tungsten, and as a consequence, the U.S. program used higher strength tungsten emitter structures in its development program. A second difference lies in the fuel loadings required; thermal reactors require approximately one tenth the uranium inventory of fast reactors. Finaliy, the amount of fast neutron damage to key, components, used as insulators, is lower in the thermal neutron reactor concept.

Because of these differences and the present emphasis on power leveis at or above $100 \mathrm{kWe}$, this review is concentrated on the U.S. TFE development experience. The Soviet, FRG, and French work will be reviewed briefly to provide a context for the U.S. experience. It should be realized, however, that the USSR is known to be working on TFE'S with tungsten emitters for the past decade in an attempt to duplicate or exceed the U.S. TFE technology. In addition, they have reported extensively on analytical treatments of very high-temperature, high-power-density, $\mathrm{UO}_{2}$-fueled emitter characteristics. 


\subsubsection{West German Program}

The West German space nuclear reactor program, ITR, was targeted at a 20 kWe thermionic in-core design for use in direct broadcast television satellites. The project was funded by the Federal Ministry of Education and Science and the Federal State of Nordheim Westfalen. It was a joint venture of the Nuclear Research Center (Kernforschunganlage GmbH) at Julich and an industrial consortium of Brown Boveri Corporation/Interatom/Siemens. The Research Institutes at Braunschweig and Stuttgart also participated with supporting research and technology.

The design of the ITR TFE is shown in Fig. 5-1 [1]. It is a "revolver"type design with $\mathrm{UO}_{2}$ fuel inserted in holes in a molybdenum emitter. The collector is made from niobium. A plasma-sprayed-alumina sheath insulator, which was $0.2 \mathrm{~mm}(8 \mathrm{mils})$ thick, was used. A NiCrCu bond was used between the ceramic and metal surface. A Nb-12r sheath tube was used, and the tri-layer structure was formed by stretch-forming this sheath tube over the ceramic.

By 1972, the ITR project had designed a moderated, liquid-metal-cooled reactor incorporating $16 \mathrm{~kg}$ of $\mathrm{U}^{235}$, designed the reactor test facility, operated a critical experiment, calculated control and dynamic behavior of the reactor, initiated development of the $\mathrm{U}-\mathrm{ZrH}$ driver rods, and begun development of the TFE.

As of May, 1972, six single-cel1, in-core tests had been operated with typical lifetimes of 3000 hours. One three-cell TFE was on test, one having failed at 1580 hours. Many out-of-pile diodes had been tested with the longest lived still operating after 30,000 hours. Following termination of the program, a single-cel1, in-pile TFE test with an emitter temperature of $1830 \mathrm{~K}$ was continued. Testing was terminated in May, 1977 after 23,240 hours of full in-pile power operating time followed by 8655 hours of further non-operating irradiation [1]. The converter generated $1.98 \mathrm{MWh}$ of energy during the test and experienced a uranium burnup of 5 atom $\%[2,3,4]$. 


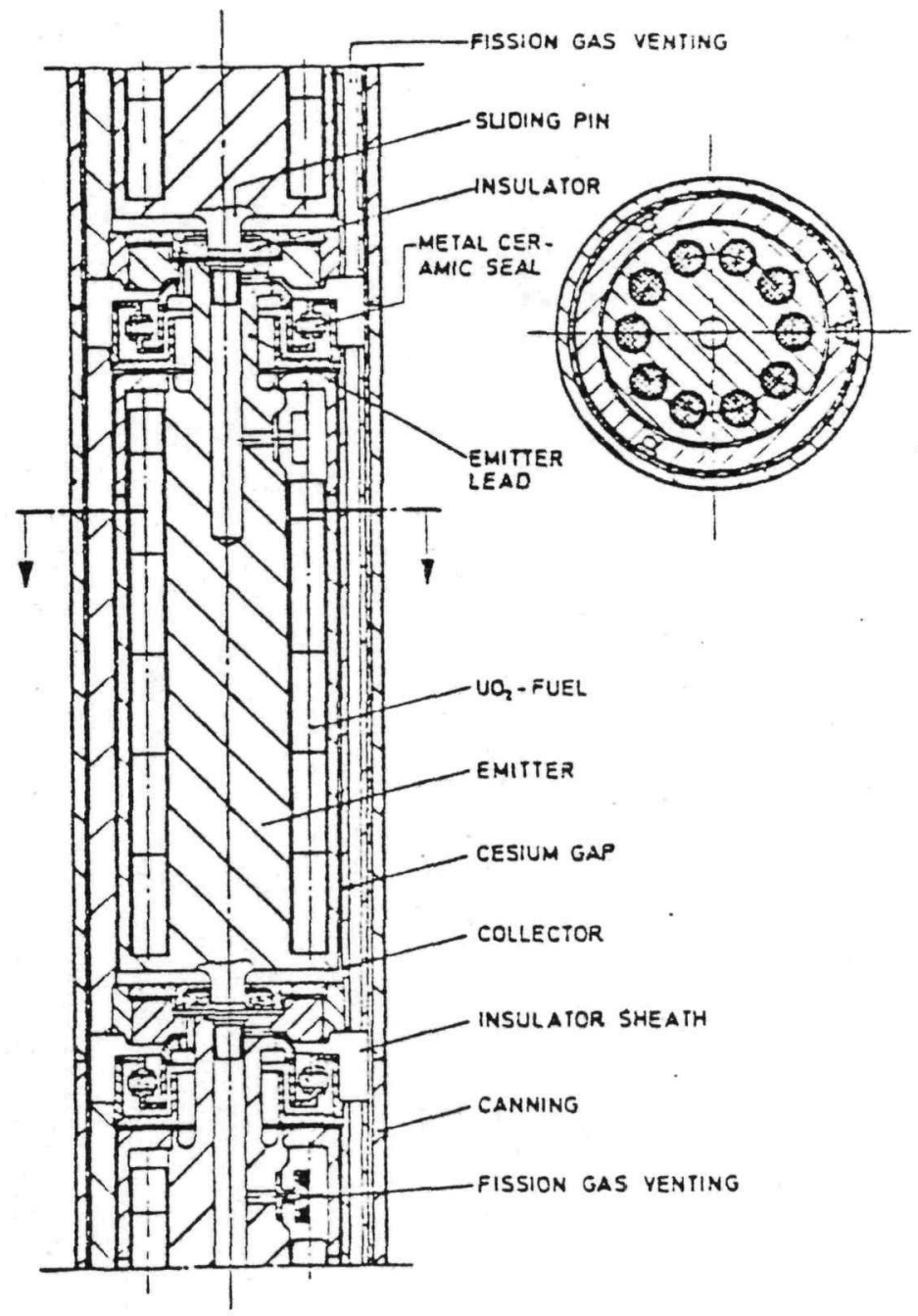

Fig. 5-1 W. GERMAN TFE CELL DESIGN 


\subsubsection{French Program}

The French program, unlike the other thermionic reactor programs, was targeted for use as an off-shore, underwater (to $2000 \mathrm{~m}$ ), power plant for $0 i 1$ production. As a result the design objectives differed from those of the space reactor efforts. Cost was a major factor in the design, size was relatively unimportant. As in the space systems, an unattended operation without maintenance was required.

The objective of the French program led to the design of a watermoderated thermal reactor requiring $10 \mathrm{~kg}$ of $\mathrm{U}^{235}$ for a $20 \mathrm{kWe}$ plant and $15 \mathrm{~kg}$ for a $100 \mathrm{kWe}$ plant [5]. The TFE design shown in Fig. 5-2 had a relatively high non-fuel volume fraction. Only three converter cells were used in each TFE. Emphasis in the French program was given to the development of Cs-Gr integral reservoirs with the intent of having separate cesium reservoirs for each converter. Since the TFE's were water-cooled, helium gaps served in place of sheath insulators to provide electrical isolation for the collectors. The helium gaps also served as a conduit for fission product transport to charcoal traps.

The French program was an aggressive one, including extensive out-ofpile converter life tests (to beyond 28,000 hours), in-pile tests (to 500 hours) and an extensive effort to automate converter production. Actual competitive production runs of TFE manufacture by private companies were conducted to determine and minimize production costs. Components for a 10 KWe TFE array (Diogene) were produced for a test planned for the 1974-1976 period. Unfortunately, while much excellent materials, design and production data are available from the French program, the TFE design details differ sufficiently from those of a space reactor to make direct application of in-pile test data difficult. The program was terminated when environmental groups in France pressured the government to cease support of deep water oil drilling after a series of oil-spill incidents $[6,7]$. 


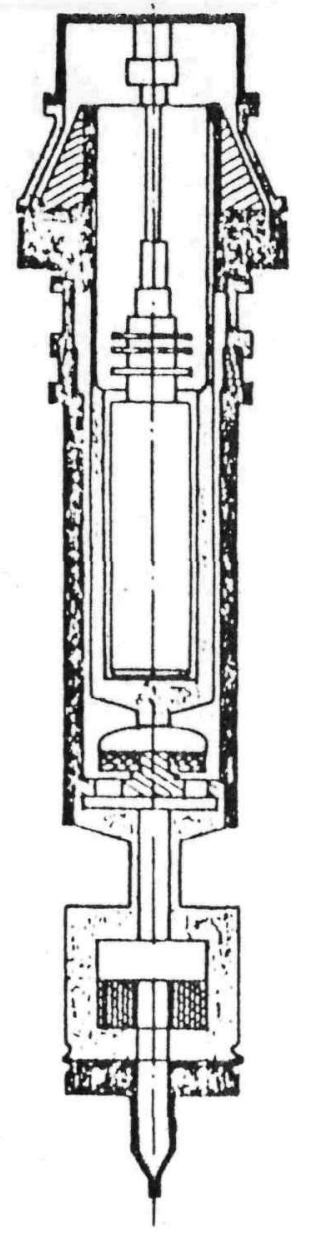

DIODE DETUDE $100 \mathrm{~W}$

$1968 / 1970$

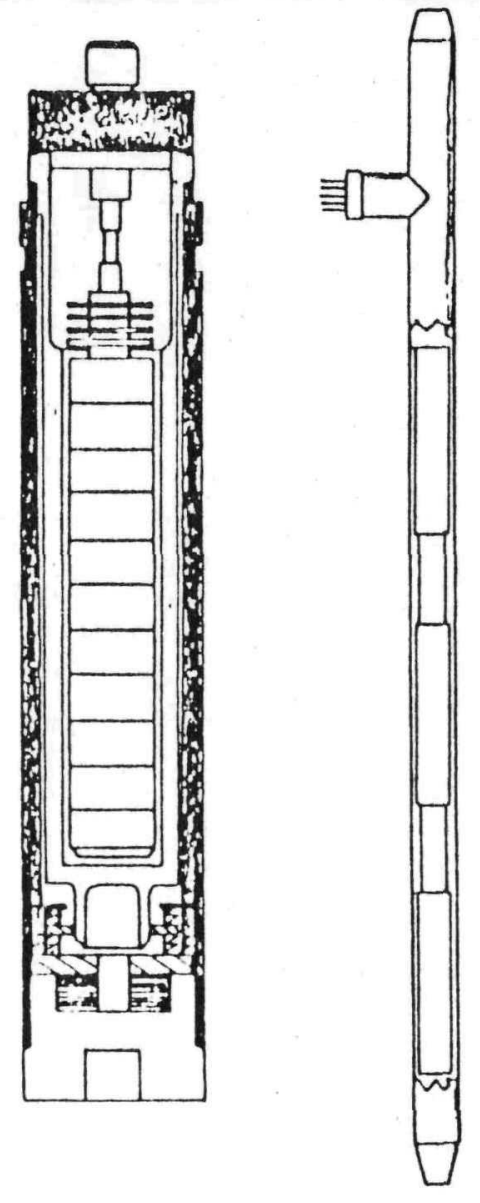

DIODE NUCLEAIRE BARREAU $300 \mathrm{~W}$

$1970 / 1972$

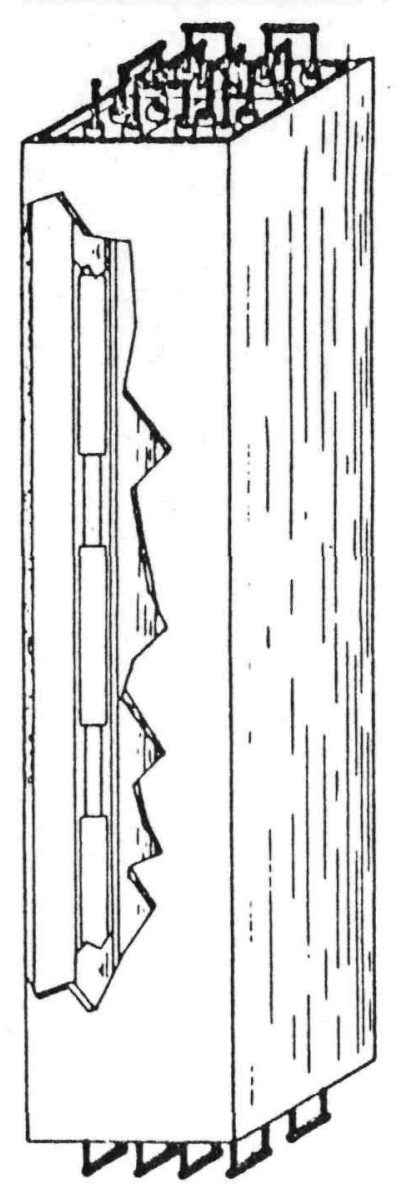

DIOGENE $10 \mathrm{KW}$

$1974 / 1976$

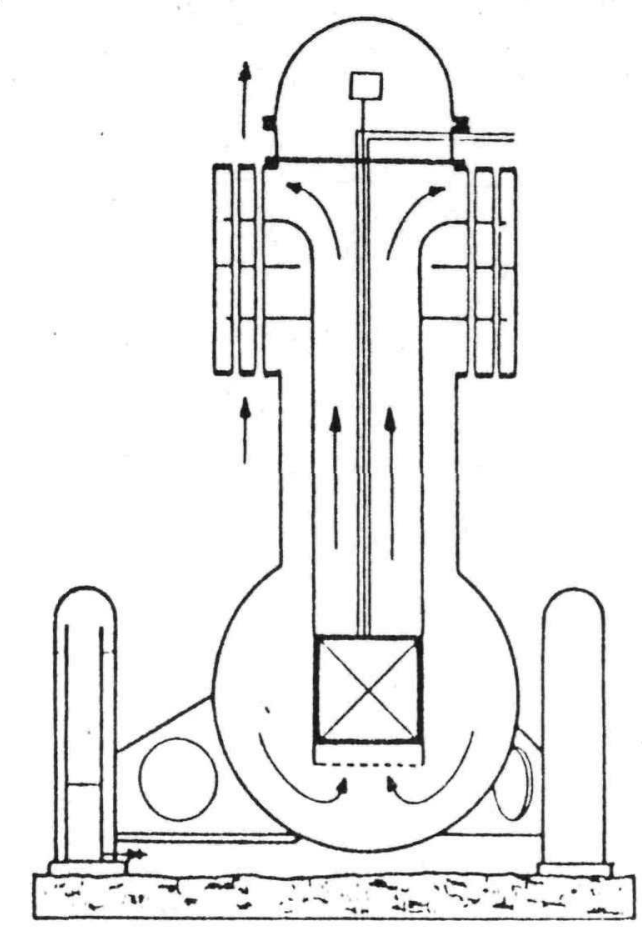

REACTEUR PROTOTYPE

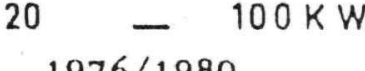

ETAPES DU DEVELOPPEMENT TECHNIQUE 


\subsubsection{Soviet Program}

The Soviet thermionic reactor program was and probably still is the largest thermionic reactor activity in the world [8]. The focus of the work has been the Institute of Physics and Power Engineering, State Committee on Atomic Energy in Obninsk. In 1977 this institute employed 4500 people including 1500 scientists. Their main activity has been development of a fast breeder reactor, but as many as 200 have been said to be involved in their thermionic reactor development work. Major work has been conducted at the Kurchatov Institute of Atomic Energy in Moscow, the Ioffe Physical Technical Institute in Leningrad, the Institute of Physics in Kiev, and the Physical-Technical Institute in Sukhumi, as well as supporting work at several other sites.

The emphasis in the Soviet program has been on development of a complete reactor system, supported by extensive R\&D on the physics and technology of the converter. A total of four thermionic reactors are known to have been built and tested by 1977. Development of the TFE, as such, was not emphasized prior to the mid-1970's, but indications are that it has been given a high priority since then.

As in the West German program, the early Soviet "TOPAZ" thermionic reactors were zirconium-hydride-moderated, thermal reactors, $\mathrm{UO}_{2}$-fueled and NaK-cooled, and were targeted toward low powers, 5-50 kWe. Fig. 5-3 shows a structural schematic of the reactor, and the layout of the TFE is shown below it. The TOPAZ-TFE has a number of features which differ from the U.S. designs $[9-13]$ :

- Five cells with two different lengtins, 5 and $10 \mathrm{~cm}$ were used in each TFE. The larger cells, which had a greater emitter area, were used at the ends of the TFE where the reactor thermai input power profile was depressed. Since each series-connected cell in the TFE carries the same total current, these larger cells operated at a lower current density. As a consequence, they operate at the same emitter temperature as the central cells despite their lower input power. 


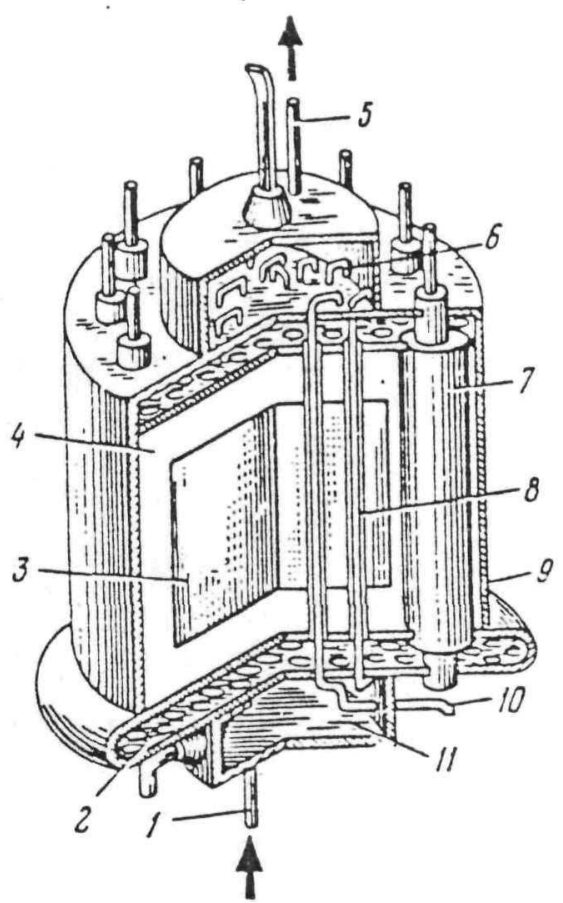

Fig. I - Structural schematic of the thermionic reactor TOPAZ-I: 1, cesium input; 2, coolant; 3 , zirconium hydride moderator; 4, beryllium reflector; 5, cesium output; 6, TFE connection chamber; 7 , rotating cylinder; 8 , thermionic fuel element (TFE); 9, reactor vessel; 10, current lead; 11 , TFE connection chamber

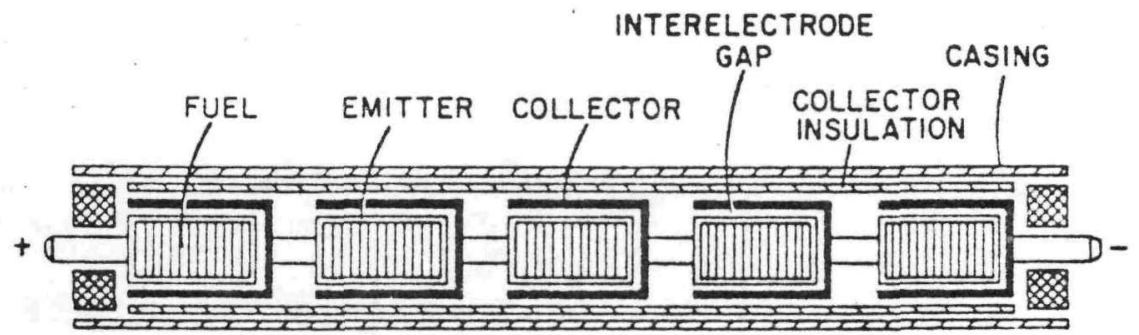

Schematic crossection of a Topaz TFE

Fig. 5-3 SOVIET TOPAZ REACTOR AND TFE 
- The emitters, $1 \mathrm{~cm}$ in diameter, where normaliy made from a single crystal of molybdenum, since the high thermal neutron absorption cross-section of tungsten makes it unsuitable for the TOPAZ design. In the fourth "research test bed," TOPAZ reactor test, however, 15 of the TFE's, all in the central zone of the reactor, were coated with tungsten.

- The emitter collector gap, $0.4 \mathrm{~mm}$, is maintained by BeO spacers. While niobium is used as the collector, a BeO sheath insulator is used, not alumina or ytrria, and the sheath tube is "stainless steel" (possibly a low expansion alloy). The sheath insulator is exposed to cesium during operation.

- The fission gases are vented from each emitter directly into the interelectrode space. Thus the "insulator seal" of the western designs is not needed, but the electrodes are exposed to fission products (noble gases).

- Finally, the interelectrode spaces of all TFE's are open at both top and bottom to common cesium plenums. This permits outgassing of all TFE's at high temperature following installation in the reactor, and it also permits use of "flowing" cesium through the interelectrode space to remove contaminents and fission products. This imposes a performance penalty by requiring the use of only one cesium pressure for all TFE's.

The first reactor, TOPAZ-1, was only operated for a short time (1500 hours). Subsequentiy, the TFE's were removed for examination and a 1179 were in working condition at that time. TOPAZ-2 operated for a total of 6000 hours, 5000 hours at full thermal power in a stable $(5-10 \mathrm{kWe})$ regime, of which 1600 hours were at full power (near $10 \mathrm{kWe}$ ). The maximum output voltage was 20 volts and the average emitter power density was $1.2 \mathrm{~W} / \mathrm{cm}^{2}$ at $10 \mathrm{kWe}$ reactor output. Following an apparent cesium leak, the reactor was operated for 1000 hours in a short circuit mode to obtain radiation exposure data. The penetration of NaK into the interelectrode space with consequent shorting of the TFE's may have been a reason for shutting down the TOPAZ-2 
reactor. Apparently, both reactors experienced a siow degradation in performance after 1000-1200 hours, attributed to the deposition of the emitter material on the BeO spacers. The results of operation of TOPAZ-1, 2, and 3 reactors were described in detail in international meetings and publication.

The fourth ("research") reactor operated with at least 37 TFE's. The use of the remaining 42 core locations is unclear, aithough driver elements may have been used, since a tungsten emitter coating was used in 15 of the TFE's. The results of the tests of the "research" reactor were never published, but were outlined verbally to an 8-man US delegation (including this author) which visited the TOPAZ and other USSR facilities in 1978. It is possible that the TFE's were simply larger in diameter and fewer were required to make the core. The reactor operated for 5000 hours. The 15 tungsten zone TFE's produced $2+k W e$ and the 22 molybdenum zone TFE's produced $7 \mathrm{kWe}$, for a total $9 \mathrm{kWe}$. The overall efficiency of the reactor was said to be $7+\%$. The low output from the tungsten zone TFE's was explained as resulting from their higher thermal emissivity, which led to a lower emitter temperature and power density, $1 \frac{1}{2} \mathrm{~W} / \mathrm{cm}^{2}$ average. In the molybdenum zone the average power density was about $3 \mathrm{~W} / \mathrm{cm}^{2}$, twice that obtained in the earlier TOPAZ tests. An important result, conveyed verbally, was that the TFE sheath insulators were capable of withstanding up to 35 volts without breakdown in the presence of cesium.

The results of the TOPAZ test series through 1977 are difficuit to interpret because of a lack of knowledge, but it is clear that progress in TFE performance was being made. The performance of the Soviet TFE's stil1, however, appeared to be less than those of the U.S. As described, the Soviet TFE design incorporates a number of features which can potentially result in improved performance from the integrated reactor system.

\section{1 .5 U.S. Program}

As described in section 3.0, there were two primary approaches to "flashlight"-reactor, fuel-element concepts which received substantial early development: the GE "wet-ce11" concept and the GGA "dry-cell" concept. In the GE concept, shown schematically in Fig. 5-4, subassemblies consisting of 

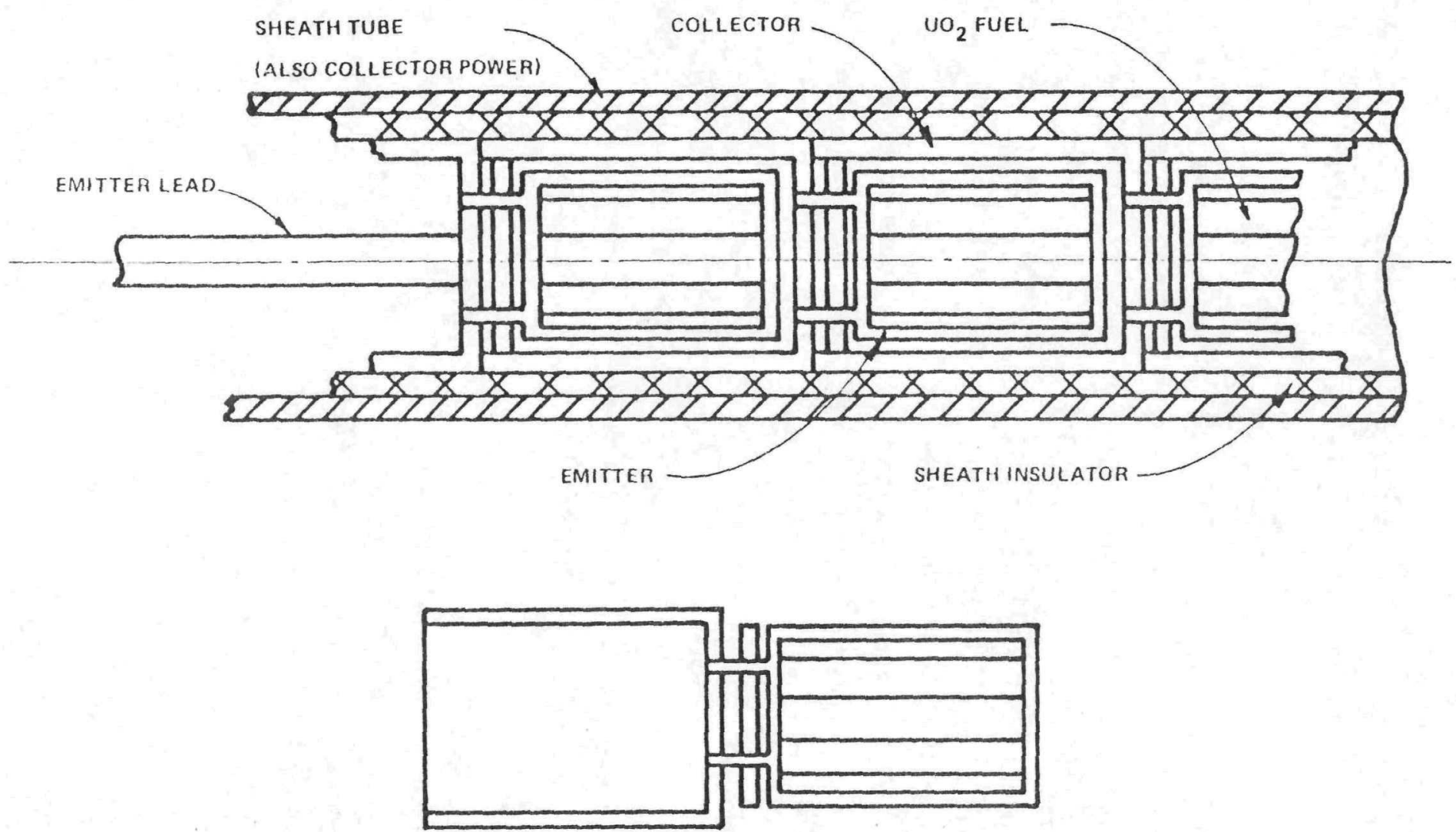

COLLECTOR-EMITTER SUB.ASSEMBLY

Fig. 5-4 GENERAL ELECTRIC "WET-CELL" THEPMIONIC FUEL ELEMENT CONCEPT 
the emitter of one converter and the collector of the next are slipped inside a long "bilayer" tube of insulator and metal [14]. Between 10 and 12 converters formed by a nested emitter-collector electrode pair comprise the fuel element. The concept is called a "wet-cell" because the cesium required for the electrodes is exposed directly to the sheath insulator. No insulator-seal separates the interelectrode and sheath insulator spaces.

Initially, the GE design included no provision for fission gas venting from the fuel cavity. Fission gas pressure buildup combined with power gradients in the fuel and possible impurity effects led to emitter cracking and interelectrode short-circuits in in-pile prototype cell tests. The addition of emitter vents in 1968 enabled successful operation to 1000 hours. Fission product buildup in the interelectrode space resulted in poor performance, however, and "porting" tubes were incorporated in 1969. Fission gas was bled out of the interelectrode space through these tubes, reducing the pressure of fission gases to an acceptable level at the cost of a slow cesium loss and a consequent need for larger cesium reservoirs. By the end of 1969, lifetimes of three-cel1 prototypes had reached the 2500 hour range. Emitter swelling followed by interelectrode shorting remained the life-limiting problem [15].

The GE TFE development effort was dropped in 1970 when, in August of that year, GGA was selected for the prime role of developing TFE and constructing a thermionic reactor test [16]. The in-pile test data acquired with the GA "dry-cel1" concept greatly exceeds that obtained with the GE "wet-cell". A review of the dry-cell data base has been the primary focus of this review.

The design of the "dry-cell flashlight", thermionic fuel element is shown in Fig.5-5[17]. It consists of six converters connected electrically in series contained in a common outer tube. Each is electrically isolated from the outer tube by a sheath insulator. A cesium reservoir at the top of the TFE, outside the reactor core, supplies cesium vapor to all six converters. The reactor core consists of an assembly of such TFE's. Reject heat is removed from the core with a flowing, liquid-metal loop. This loop 

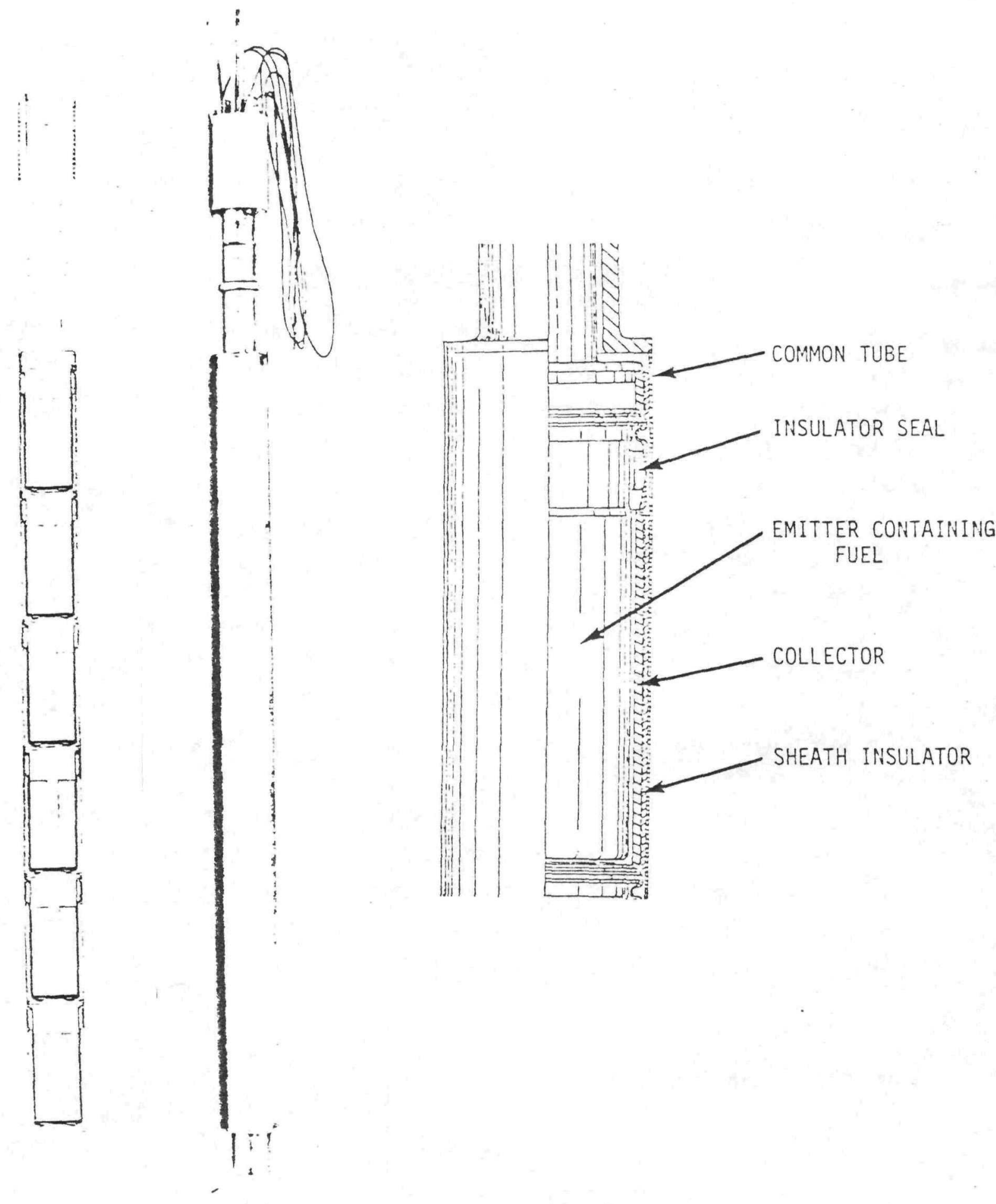

FIg. 5-5 THERMIONIC FUEL ELEMENT FOR FLASHLIGHT REACTOR 
delivers the waste heat to a heat exchanger and radiator for rejection to space.

Two dry-cell, flashlight TFE designs were developed in the U.S. The first and most extensively tested was the "unit-celi" design of GGA, developed in both a smaller diameter "E-series" and a larger diameter "F-series" configuration. The second was a more compact, higher performance "G-series" design that was developed by Thermo Electron Corporation, and was intended to follow the F-series. (GGA's design is shown in Fig. 5-6.) The Thermo Electron G-series design, shown in Fig. 5-7, eliminated the use of a separate insulator seal by incorporating its function into a "pentalayer" sheath insulator [18]. This allows smaller inter-cell spacing between converters and a consequently higher fuel loading in the reactor. A shorter emitter is also used, eliminating the need for a centering washer at the unsupported end of the cantilevered emitter structure. This permits the end of the emitter to be used for power production.

The development of the TFE was a phased effort. First, new design concepts and fabrication processes were tested in electrically-heated converters of prototype (cylindrical) geometry in the laboratory. These well-instrumented tests served to establish the basic thermal, electrical, mechanical and materials characteristics of the converter outside of a radiation environment. The results of these tests were then incorporated in the design of single cell experimental converters which were tested in-core. Next single cells of prototypic configurations were developed and tested in-core, followed by partial-length TFE's. The latter included all of the major components of the TFE, but typically contained only one or two cells. Finally, full-length complete TFE's were developed and tested. Two different TFE models were extensively developed during the program.

Both the "E-series" (emitter diameter of $16 \mathrm{~mm}(0.63 \mathrm{in.})$ ) and the later "F-series" (emitter diameters of $27.9 \mathrm{~mm}(1.1 \mathrm{in.})$ ) were tested in-core. The E-series devices were optimized to meet the needs of systems requiring 300 kWe and more. They were operated at high power densities. The F-series devices were targeted at the $120 \mathrm{kWe}$ power level and were operated at lower power densities. The G-series converters were well-developed, out-of-core, 


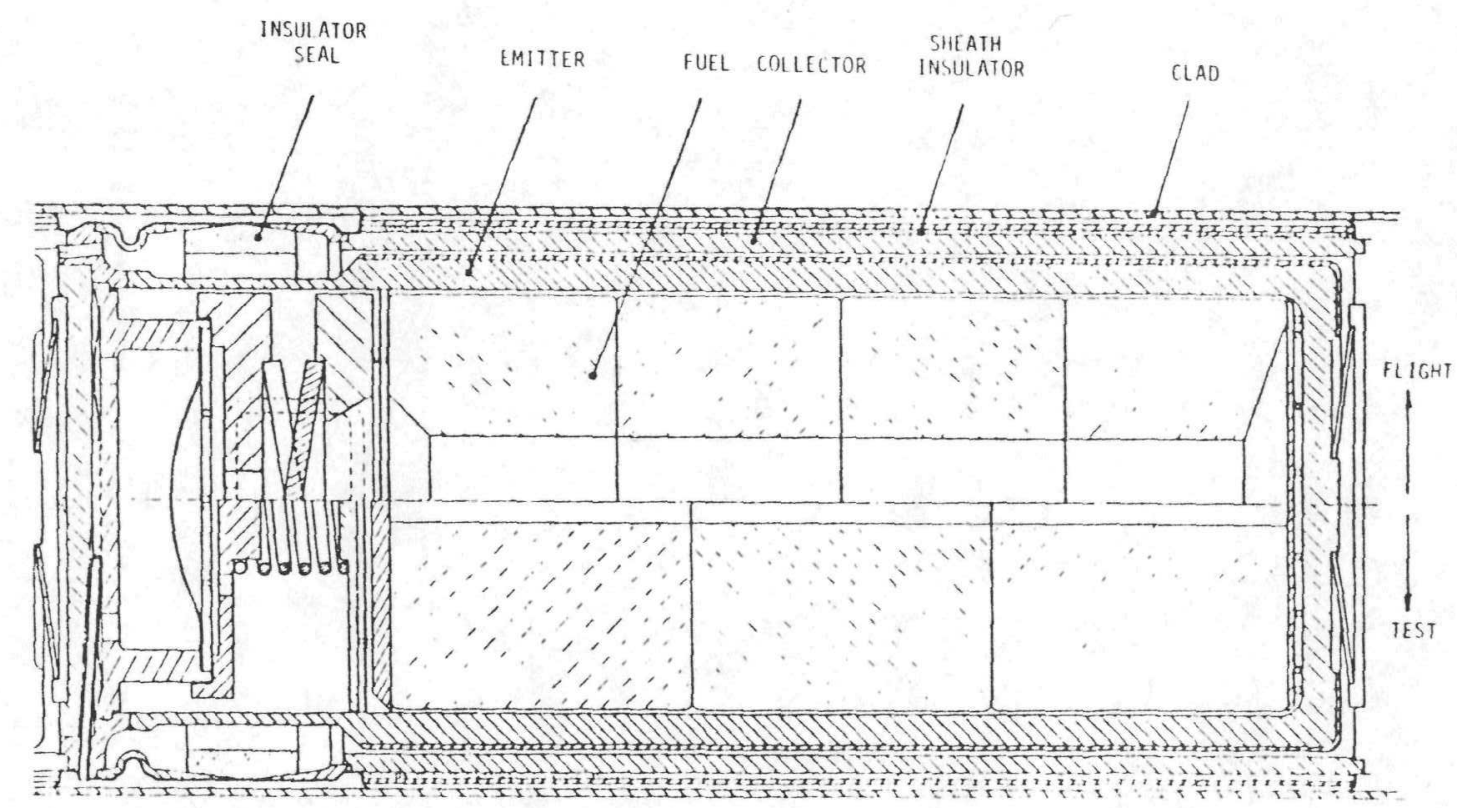

Fig. 5-6 GGA F-SERIES "UNIT ALL" CONVERTER DESIGN 


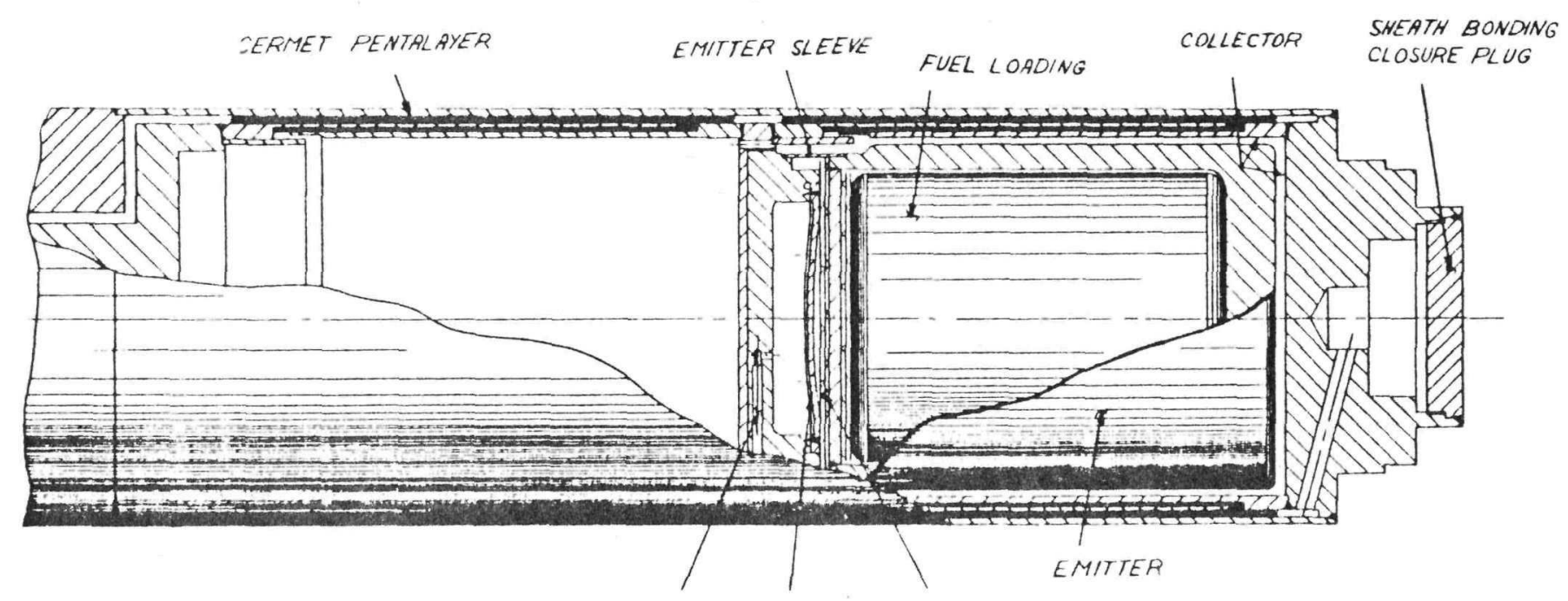

FISSION GAS PORTS

RADIATION SHIELDS

FISSION GAS DIAPHRAGM BACK-UP PLATE

Fig. 5-7 THERMO ELECTRON G-SERIES CONVERTER DESIGN 
but not in-core tested. These converter and TFE development activities were supported by a broad research and technology effort at several US sites addressing thermionic performance, material compatibility, radiation effects, fuel behavior, reactor and thermionic converter dynamic behavior, etc.

\subsection{Test Program}

\subsubsection{Overview}

Table 5-1 summarizes the types and numbers of in-pile tests of the dry-cell-type completed between 1962 and 1973. Typically, three or four devices were initially tested per year, a limit imposed by the TRIGA test capability. A new core installed in mid-1971 permitted 10-15 simultaneous tests. A total of 68 cells were tested, accumulating 319,614 cell-hours of test time, as of June, 1972. In addition, three fuel capsules, each including three cells, were tested [19].

A large number of thermionic converters tested across the country served to support the program. The most relevant cylindrical converter data was obtained with the out-pile LC-series of twelve converter tests. This test series examined the affects on performance of depleted uranium carbide and oxide fuels in the emitter structures. Two out-of-pile cylindrical converters, $\mathrm{OC}-5$ and $\mathrm{OC}-\mathrm{A} 4$ were performance mapped extensively and used as thermal standards against which in-pile tests could be calibrated.

As can be seen in Fig. 5-8, lifetimes for in-pile tests were steadily improved. The third TFE fabricated, (TFE-2E2) achieved over 11,000 hours of operation with stable performance. The potential for much longer life was demonstrated by the stable 46,647 hour life test of an out-of-pile converter (LC-9) with an emitter temperature of $1970 \mathrm{~K}$. The LC-9 test was terminated for programmatic reasons, and no degradation in performance or integrity was observed.

The relatively short lifetimes of early in-pile experimental cells was usually the result of envelope failures. Eleven out of fifteen experimental cell tests eventually failed due to envelope leaks, which let the helium 


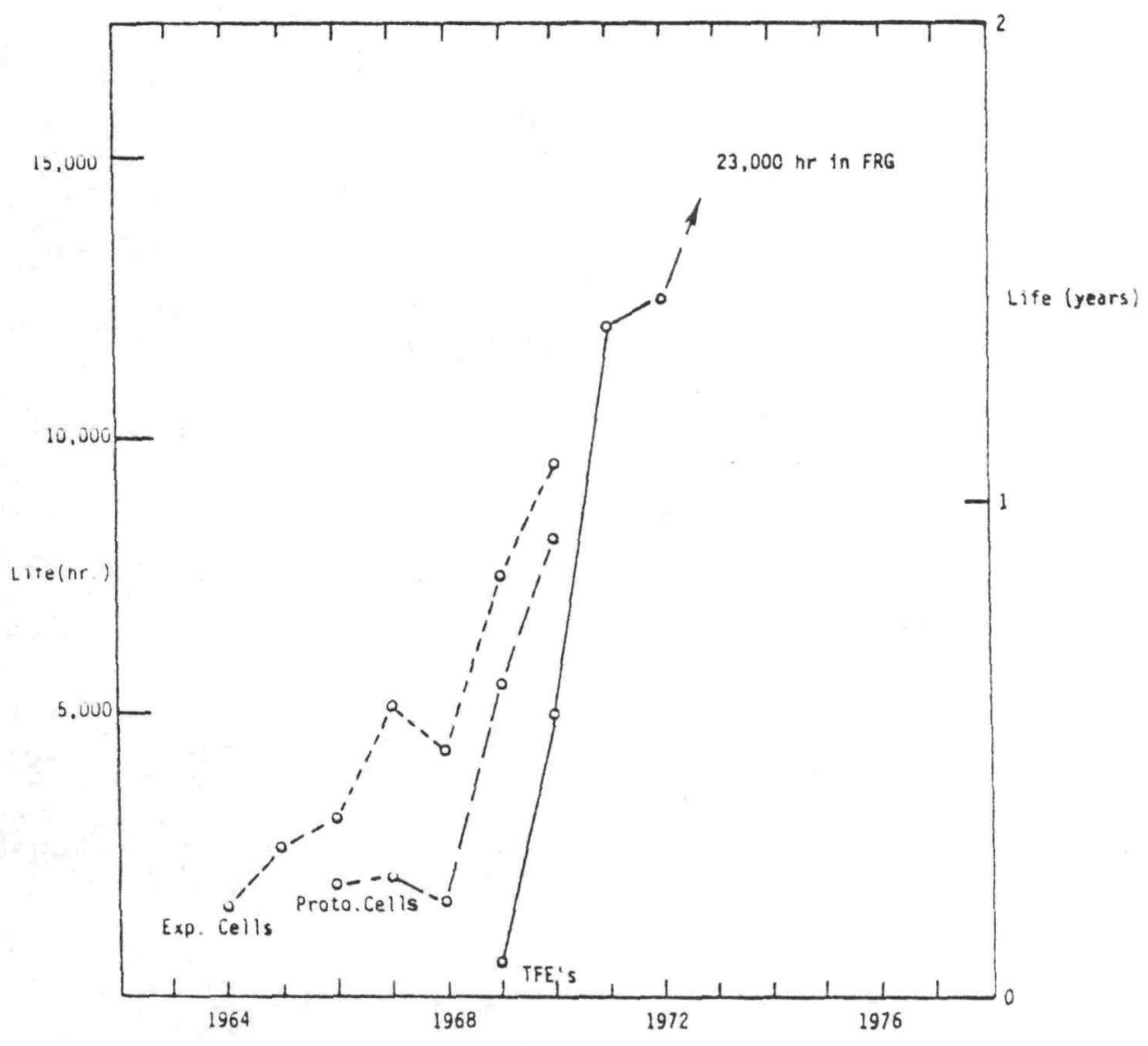

Fig. 5-8 THE RECORD OF TFE LIFETIME IMPROVEMENT 
Sumbrv of GEA Thermionte in-2fle Life Tests"

Out-of-p1le

Experimental

\begin{tabular}{|c|c|c|c|c|c|c|c|}
\hline Cells & Protat & De Cells & & mionic Fue & Elemenes & & Prototyole \\
\hline Mark VI & Mark VI:A & Mark VII:B & $\begin{array}{l}\text { ESeries } \\
\text { (Two Cell) }\end{array}$ & $\begin{array}{l}\text { F Sertes } \\
\text { (One Cell) }\end{array}$ & $\begin{array}{l}\text { F Series } \\
(T \text { wo Cell) }\end{array}$ & $\begin{array}{l}\bar{f} \text { Sertes } \\
(\text { Six Cell) }\end{array}$ & (One Cell) \\
\hline 15 & 3 & 4 & 3 & 4 & 2 & 3 & 5 \\
\hline 41487 & 4604 & 15915 & 24424 & 19196 & 9062 & 16881 & 100.069 \\
\hline $2760^{\circ}$ & $: 535$ & 3979 & 8143 & 4870 & 4531 & 5590 & 20,014 \\
\hline 6.5 & 5.2 & 3.7 & 4.1 & 3.7 & 4.4 & 2.4 & 6.2 \\
\hline 9754 & 2006 & 7881 & 12535 & 8228 & 6444 & 1685 & 46.647 \\
\hline 6.0 & 6.2 & 3.4 & 4.0 & 4.0 & 4.1 & 2.3 & 7.2 \\
\hline
\end{tabular}

"as of iune 1972

Table 5-1 SUMMARY OF GGA TFE IN-PILE LIFE TESTS 
primary containment gas into the interelectrode space. Only one of the five out-of-pile tests failed prior to the end of the program and it, too, was an envelope leak. Most of the leaks were associated with braze fajlures, typically in copper-to-refractory metal joints. These were caused by the large differential thermal expansion between copper and the refractory metals. The number of such joints were reduced in the prototype cells and were completly replaced by welds in TFE's. Only one of twelve TFE's failed due to an envelope leak (a cracked emitter) as of June, 1972. Thus, the reliability of joints in the outer envelope of the TFE had largely been demonstrated by the beginning of 1973 .

Fifteen TFE's were tested in-core, incorporating a total of 46 converters. Table 5-2 summarizes some of the most pertinent data concerning these tests. As noted above, the $E$ and F-series of TFE's differed mainiy in diameter fuel $U_{2}$ or UC-1ZC, and emitter wall thickness. The smaller, higher power density E-series devices had emitter diameters of $1.6 \mathrm{~cm}$. The F-series used emitters with diameters of $2.8 \mathrm{~cm}$. The number of converters in a TFE was noted by a prefix to the series designation; e.g., a 6F TFE had six converters in series, a IF had only one converter. The tests were numbered consecutively within types, i.e., the TFE $2 F 3$ was fabricated after TFE $2 F 2$.

Several interesting points can be made:

1. 5 of 15 TFE's were oxide-fueled, 10 of 15 were carbide.

2. 2 of 5 oxide tests failed. Their average irradiation time was 10547 hours. Both failures were due to interelectrode shorting.

3. 7 of 10 carbide tests failed. Average irradiation time: 6845 hours. Failures were due to fission product leaks, performance loss and interelectrode shorting.

4. The remainder were still operational at the time of program termination, so that their ultimate life was not established.

Fig. 5-9 serves to contrast the relative characteristics of $\mathrm{UO}_{2}$ and $U C-Z r C-W$-fueled TFE's. As can be seen, the longest carbide-fueled tests did not operate as long as the shortest oxide-fueled devices. During testing the carbide-fueled TFE's tended to have unstable and deteriorating performance due to fuel component diffusion or leakage through the clad. In contrast, 


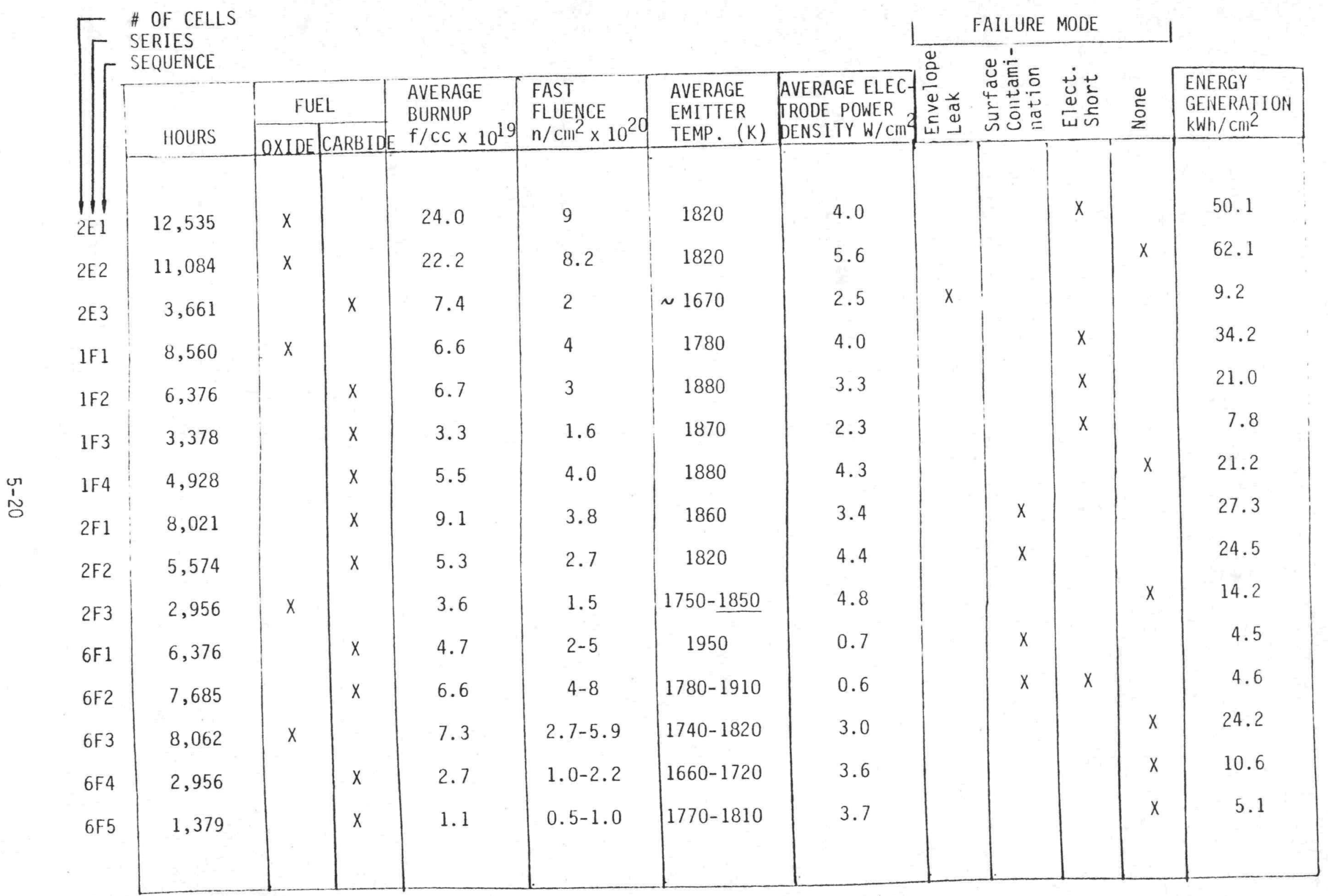

TABLE 5-2 SELECTED TFE TEST DATA 

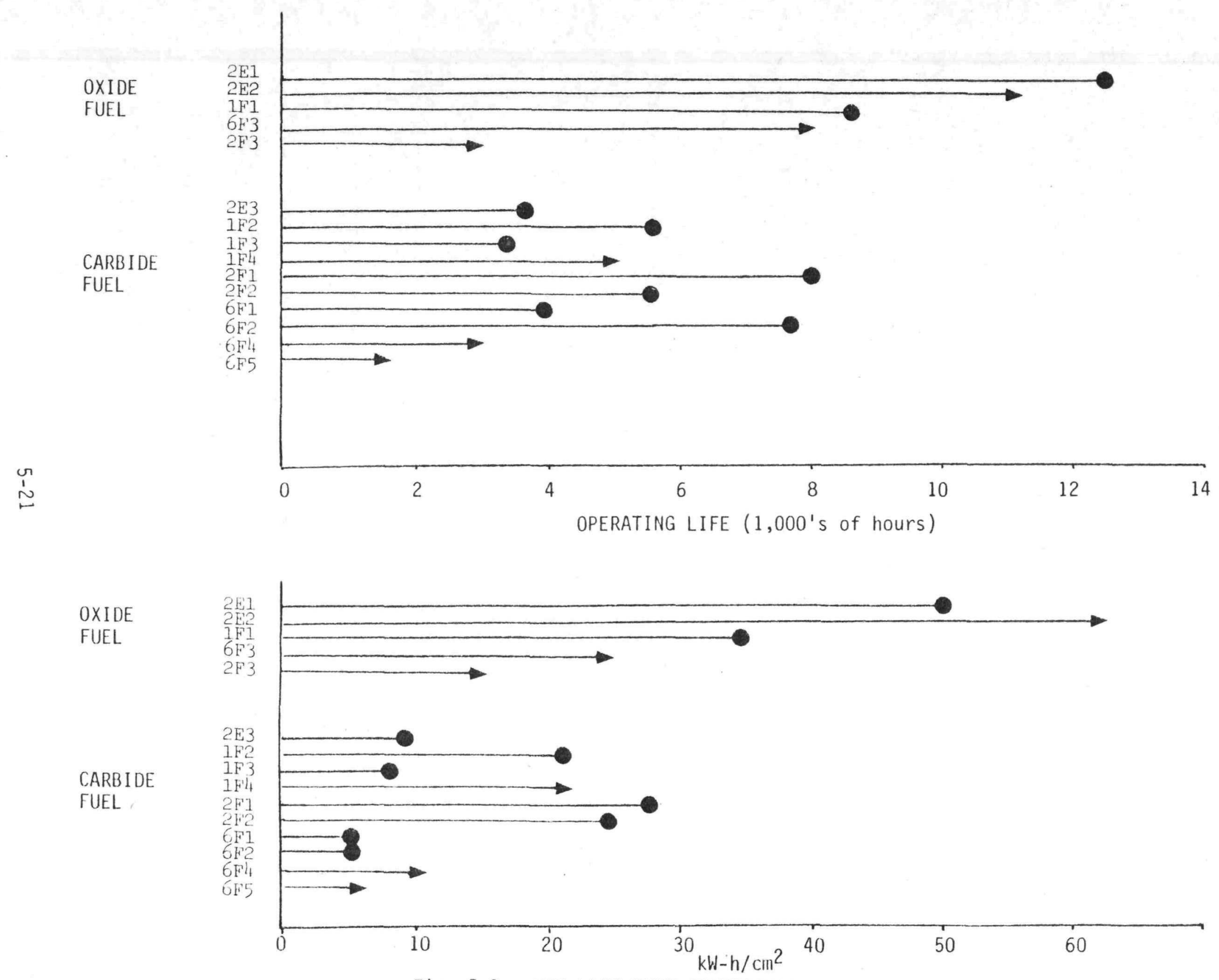

Fig. 5-9 TFE LIFE TEST EXPERIENCE 
the thermionic performance of oxide-fueled devices remained relatively stab?e and high until emitter distortions resulted in an interelectrode short. The high, stable output of oxide-fueled converters also resulted in more power production oyer the life of those devices as illustrated in Fig. 5-9.

Interelectrode shorting was common in carbide-fueled devices and was the life-limiting phenomena in the oxide-fueled tests. In both cases the shorts resulted from distortion of the emitter. The progressive distortion of the emitter was observed and measured periodically ( 1500 hour intervals) during the test by shutting the reactor down, removing the TFE's from the core, and taking neutron radiographs. Diametral swelling was measured relative to the diameter of the bottom of the emitter. Individual swelling estimates had a standard deviation of $17 \mu(0.7 \mathrm{mi} / \mathrm{s})$.

Fig. 5-10 shows the emitter distortion records for each of the six emitters in the carbide-fueled TFE's 6F1 and 6F2. The carbide fuel pellets typically sintered and shrank during the first few thousand hours, closing the open porosity built into the fuel. Fission gas trapping then led to rapid fuel swelling by 4000-5000 hours with subsequent emitter distortion and performance degradation. Control of carbide fuel swelling due to this mechanism comprised a substantial part of the TFE development effort. As can be seen in Fig. 5-10 lifetime projections based on TFE emitter distortion data are in the vicinity of $8,000-10,000$ hours.

Fig. 5-11 shows the diametral distortion observed in each of the 8 emitters in the oxide-fueled TFE's, 6F3 and 2E2, in this case as a function of burnup. Seven-year "hot spot" burnup in a 100 kWe reactor design will typically be near $5 \times 10^{20} \mathrm{f} / \mathrm{cc}$. The highest observed distortion rates in these tests correspond to lifetimes of $1 \frac{1}{2}-2 \frac{1}{2}$ years with a $10 \mathrm{mil}$ interelectrode space and 3-5 years with a $20 \mathrm{mil}$ interelectrode space. A variety of possible emitter distortion mechanisms have been described and determination of their relative importance and control techniques is an important development objective. $\mathrm{UO}_{2}$-emitter interactions are discussed in detail in section 7.0 . 


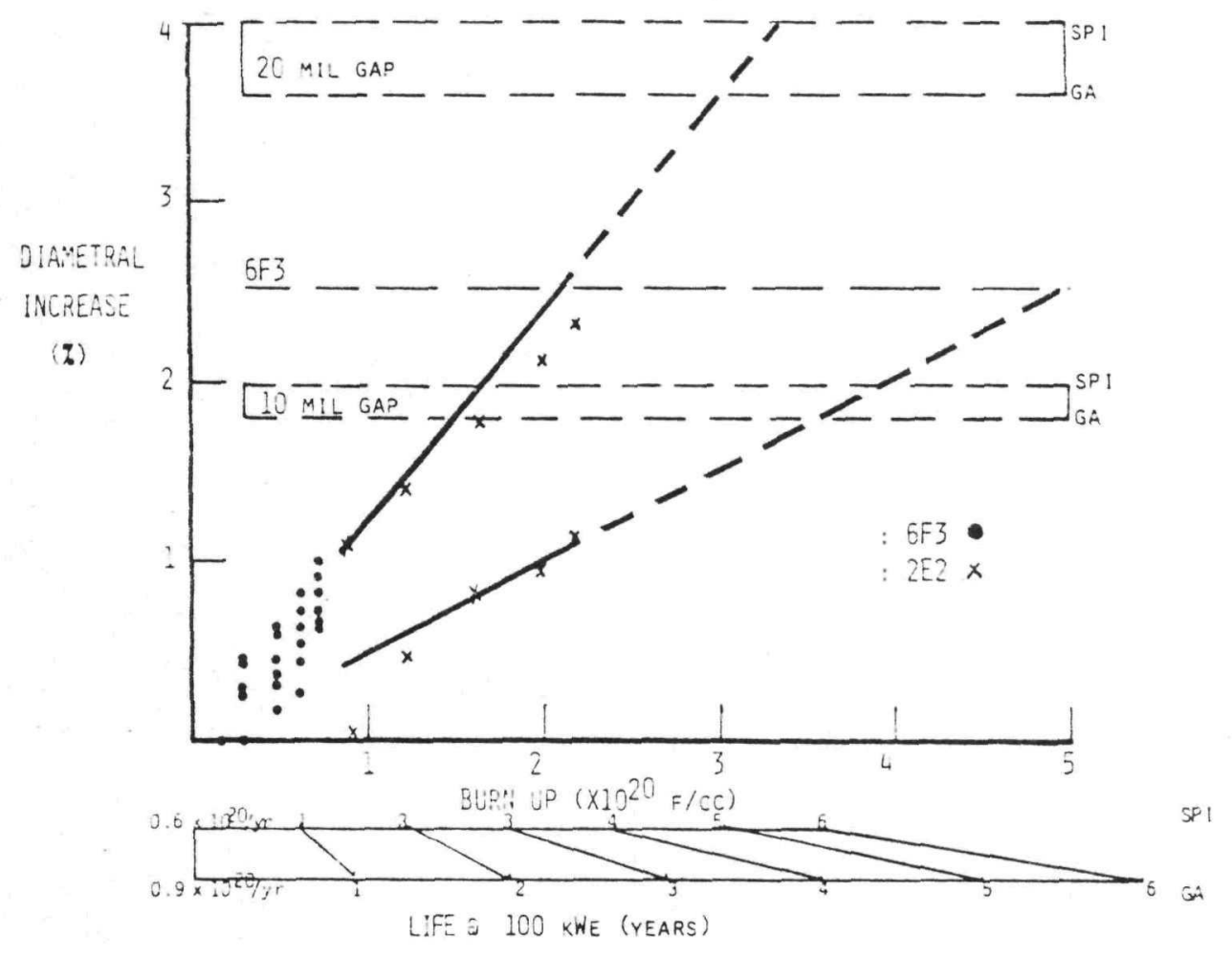

Fig. 5-11 EMITTER DISTORTION EXTRAPOLATION BASED ON OXIDE-FUELED TFE DATA

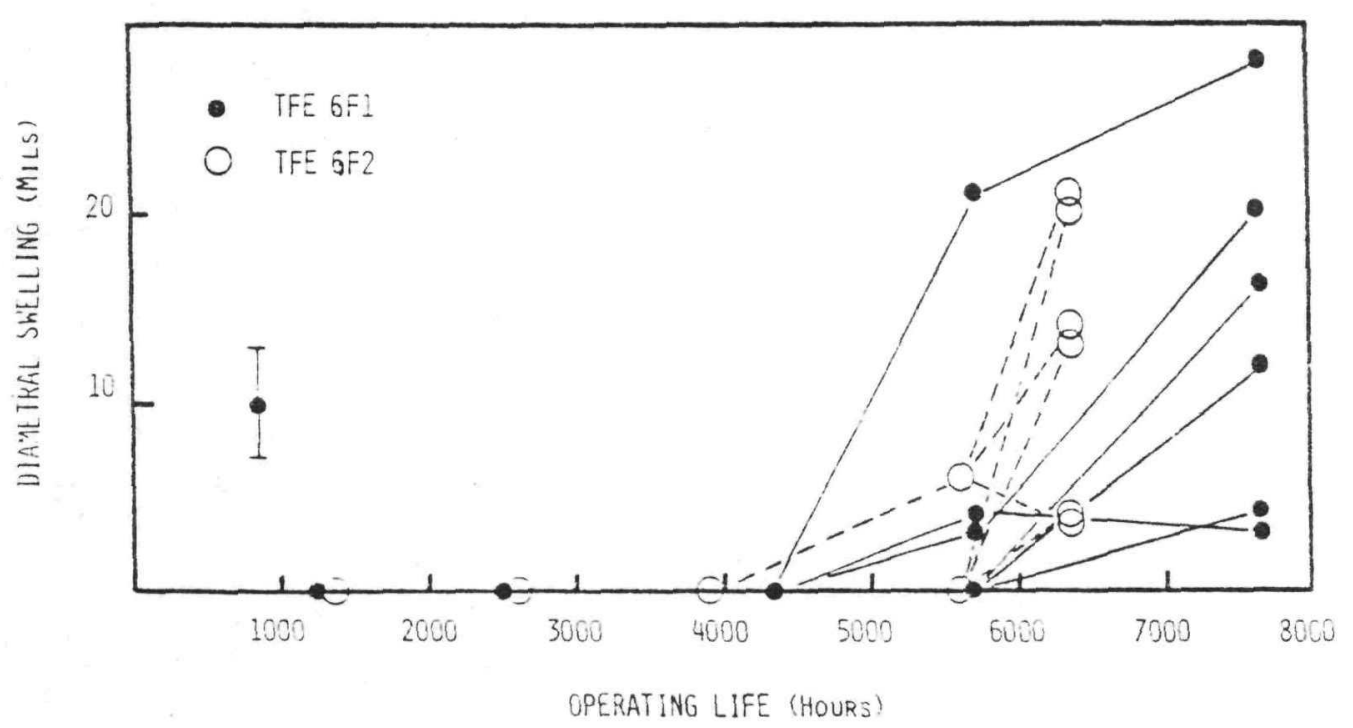

Fig. 5-10 EMITTEF DISTORTION EXPERIENCE IN CAREICE-FUELED TFE DATA 
A large amount of converter performance data was acquired and is summarized in section 5.3. The data available on other potential life limiting phenomena, such as insulator degradation, cesium loss, etc. are discussed in section 5.4 and 6.0.

\subsection{Performance: Power Density and Efficiency}

\subsubsection{Data Interpretation: Electrode Data, Lead Data, and Relative Performance}

The two critical performance parameters for a TFE are power density and efficiency. The bottom line for both is their value at the leads of the TFE, where interconnections to other TFE's and the rest of the system can be made. However, significant electric losses must be incurred in delivering power from the surfaces of the emitter and collector to the TFE leads. Thermal losses not associated with the emitter and collector electrodes also exist in every TFE design. Both types of loss are very design-dependent, and as a result the performance of any particular TFE is a combination of two things: how well the thermionic conversion function is accomplished between the emitter and collector and how well the TFE was designed to deliver this power to its leads. In order to separate these two issues test data is always presented in a manner that shows both lead performance and electrode performance. The electrode performance numbers are a measure of thermionic performance, the lead numbers combine thermionic performance with TFE losses, and the spread between them is a measure of the adequacy of the TFE design.

Typically, lead power densities will be, at most, $90 \%$ of corresponding electrodes power densities due to voltage drops imposed by that portion of the leads which connect directly to the emitter. Similar thermal losses (about 10\%) down the emitter lead set a ceiling on lead efficiency near $80 \%$. Any further losses are the result of design trade-offs and are not imposed by physical limitations inherent to the converter.

An example of the electrical losses in a two-cell E-series TFE are shown in Table 5-3. As can be seen, the two required losses, the emitter lead losses, result in only a $0.1 \mathrm{~V}$ voltage loss at $9.5 \mathrm{~A} / \mathrm{cm}^{2}(2 \times 0.053)$. Other 


\section{Each Cell}

Emitter $(2073 \mathrm{~K})$

Emitter Lead (1723 K)

Cell Top

Collector (973 K)

TOTAL

TFE

Two Cells

TFE Lead and Cesium Reservoir

TOTAL FOR TFE
Resistance

$(m \Omega)$

0.223

0.216

0.026

0.176

0.641

$=$

1.282

0.950

1.833
Voltage Drop

at $9.5 \mathrm{~A} / \mathrm{cm}^{2}$

(volts)

0.027

0.053

0.006

0.022

0.110

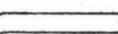

0.220

0.234

0.450

TABLE 5-3 GGA TWO-CELL E-SERIES TFE ELECTRICAL LOSSES 
losses, totaling $0.35 \mathrm{~V}$, are imposed by the design of the rest of the converter and TFE, with most of that loss in the TFE lead. A typical converter with $T_{E}=1900 \mathrm{~K}$ will produce $0.8 \mathrm{~V}$ at $9.5 \mathrm{~A} / \mathrm{cm}^{2}$, at the electrodes. Two cells in series produce $1.6 \mathrm{~V}$. Thus the $0.23 \mathrm{~V}$ loss in the TFE lead and Cs reservoir reduces the TFE voltage and efficiency by $14 \%$. As a consequence, data taken with a two-cell E-series TFE saddled with the lead design for a 6-cell TFE, shows a low lead output voltage and lead efficiency.

With 6 cells in the TFE, this loss will be reduced inversely in proportion to the number of cells, to only $5 \%$. Finally, the 2-cell design described used a niobium TFE lead. Development of a molybdenum-niobium lead, which was in progress, would cut this loss nearly in half again.

This example is given to sensitize the reader to the fact that the measured lead efficiencies of the TFE devices, as reported, can be misleadingly low, since they represent interim design steps. Consequently, electrode performance figures are always reported so that the designdependent losses can be separated from actual thermionic performance. The life test record of TFE-2E2, Fig. 5-12 shows these differences clearly.

Design-dependent thermal losses analagous to the electrical lead losses also exist in every TFE design. Examples in the $E$ and $F$ unit cell designs include conduction and thermal radiation from the bottom of the emitter to the top of the next cell, radiation out the top of the emitter through the emitter lead, and radiation form the outside of the large emitter lead itself. The advanced Thermo Electron G-series design reduced these losses by using the bottom of the emitter as an active electrode, putting this heat to work instead of incurring the loss. Similarly, the G-series uses a shorter emitter lead, reducing radiation losses from that surface. The West German ITR design carried this approach even further by using an emitter lead that is both narrow and short.

The difference in performance that can be achieved in planar and cylindrical converters must also be considered when assessing the status of demonstrated TFE performance and the potential for improvements. Much of the research work in thermionic conversion is performed with converters that have 


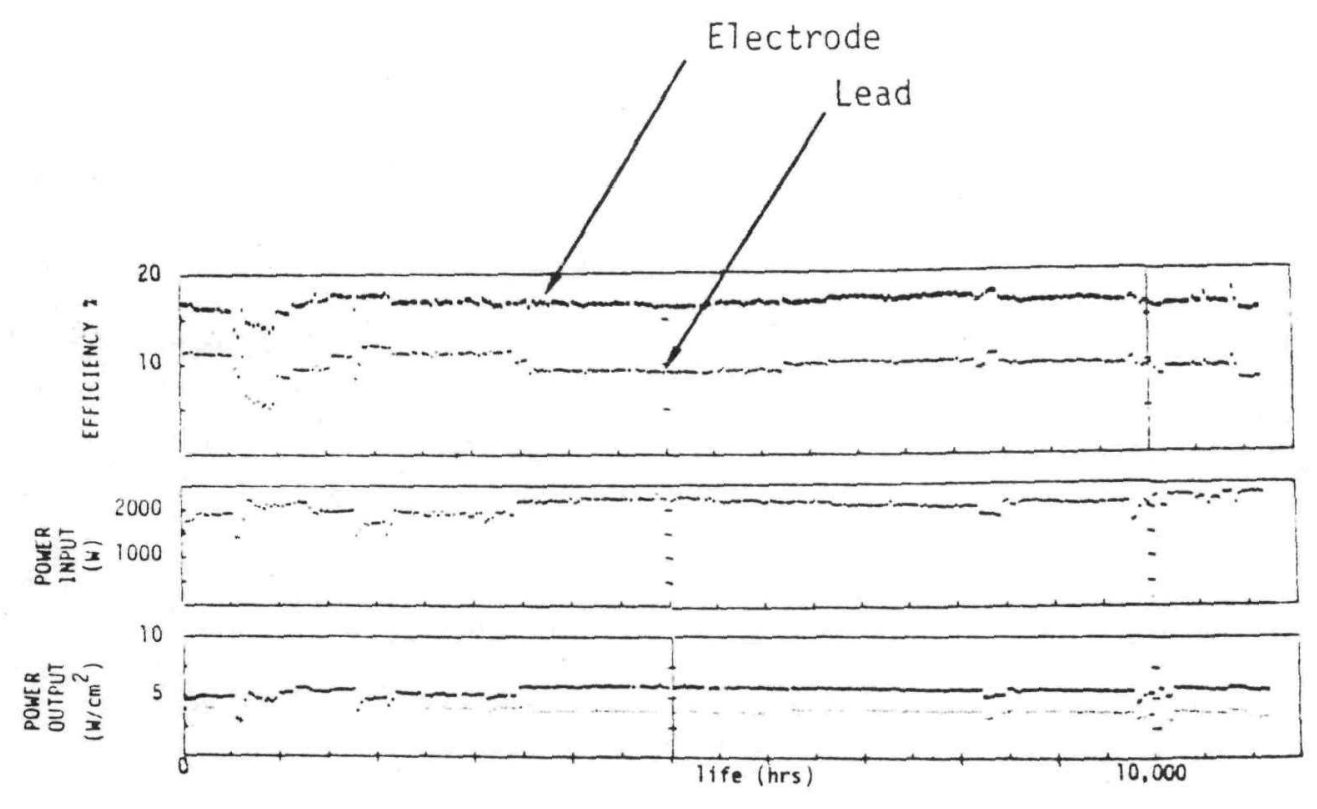

Fig. 5-12 TFE 2E2, $\mathrm{UO}_{2}$ Fueled, Operated With Stable Performance For Over 11,000 Hours. 
small $\left(\sim 2 \mathrm{~cm}^{2}\right)$ flat opposed electrodes. These planar devices have uniform temperatures, uniform and easily adjusted interelectrode gaps, and very well-defined electrode areas. They can be closely adjusted to give nearly fully optimized performance. Examples of practical converters designed to use these features were the SET converters built by Thermo Electron and EOS for JPL in the mid-1960's. These converters, designed for use with a solar concentrator, had interelectrode spacings below four mils. These produced in the vicinity of $20 \mathrm{w} / \mathrm{cm}^{2}$ with an emitter temperature of $2000 \mathrm{~K}$ [21]. Their lead efficiencies were $5-10 \%$ despite the loss of nearly half their themal input power by radiation from the back and sides of the emitter (a major disadvantage of the planar design).

Cylindrical converters can be designed to have minimal radiation losses but they have not been designed to have 1-5 mil interelectrode gaps, but, rather, 10-15 mils. They typically have $25-50 \mathrm{~cm}^{2}$ of emitter area, not 2 $\mathrm{cm}^{2}$. Their input power is not applied uniformly and, as a consequence, there is a variation in emitter temperature and current density over their surfaces. Finally, uniform spacing between emitter and collector is difficult to achieve. As a result the performance of a cylindrical converter cannot be fully optimized and it will always have somewhat reduced (by 5-8\%) average electrode performance figures.

Finally, test data, particularly that of in-pile devices, frequently shows abrupt variations in performance with time because of reactor operating constraints. Typically 10 devices may be in operation simultaneously in the reactor. Typically, in past tests, the reactor was shut down every few weeks to remove old devices and install new devices. At that time the location of each test in the core was re-evaluated and frequently changes were made. Following startup the new reactor operating power level was selected to give the best average for all 10 devices. Thus the thermal input power of a particular test changed every few weeks (highly conducive to thermal ratcheting). Current densities, output voltage, collector temperatures, etc. were readjusted to maintain design emitter temperatures. To back-out the effect of these changes a relative performance number was calculated along with actual test data. Relative performance is the ratio of the output power density the device would give if it were at its initial operating conditions 
(emitter temperature, collector temperature, and current density) to the performance calculated with the standard analytical model at that point. The best available out-of-pile converter performance maps and analytical models were used to extrapolate from the operating conditions at a given time to the intial operating conditions. Note that any new thermal losses (such as from fission gas in the interelectrode space) do not affect this relative performance figure. In summary, changes in in-core locations and reactor power resulted in frequent changes in a device's operating condition. These variations do not reflect variations in the thermionic performance of the device, and relative performance plots should be used to observe real performance variations.

\subsubsection{Performance Level and Reproducibility}

Figs. 5-13 and 5-14 show the initial electrode performance for a wide variety of in-core and out-of-core TFE's and cells built prior to 1973. Al1 data has been normalized to optimized collector and cesium temperatures. Typically the output power density increases with current density, although at the lower temperatures $(<1600 \mathrm{~K}$ ) there is an efficiency penalty above $\sim 6$ $\mathrm{A} / \mathrm{cm}^{2}$. At higher temperatures $(>1800 \mathrm{~K})$ one must operate at or above 10 $\mathrm{A} / \mathrm{cm}^{2}$ to realize the highest efficiency. Consequently data is shown for both $7 \mathrm{~A} / \mathrm{cm}^{2}$ and $10 \mathrm{~A} / \mathrm{cm}^{2}$.

Shown for comparison is performance data for cells and TFE's reported by GA for 1973 and data obtained in 1978 on two cylindrical converters built at Rasor Associates, Inc. for JPL, and Thermo Electron data showing the average performance obtained in 1979 with five heat pipe converters $[22,23,24]$. The GGA converters had tungsten emitters, some with (110) and some with (100) orientation. Both niobium and molybdenum collectors are represented. The converters with $W(110)$ emitters with molybdenum collectors tend to fall in the upper half of the band of GGA devices. Converters with W(100) emitters and niobium collectors occupy the bottom half. Occasionally converters with unusually low performance were built. This could normally be attributed to the adverse effects of electrode contamination. The GA converters had W(110) emitters and Niobium collectors and the RAI converter had rhenium emitters and molybdenum collectors. In these converters a performance improvement was 


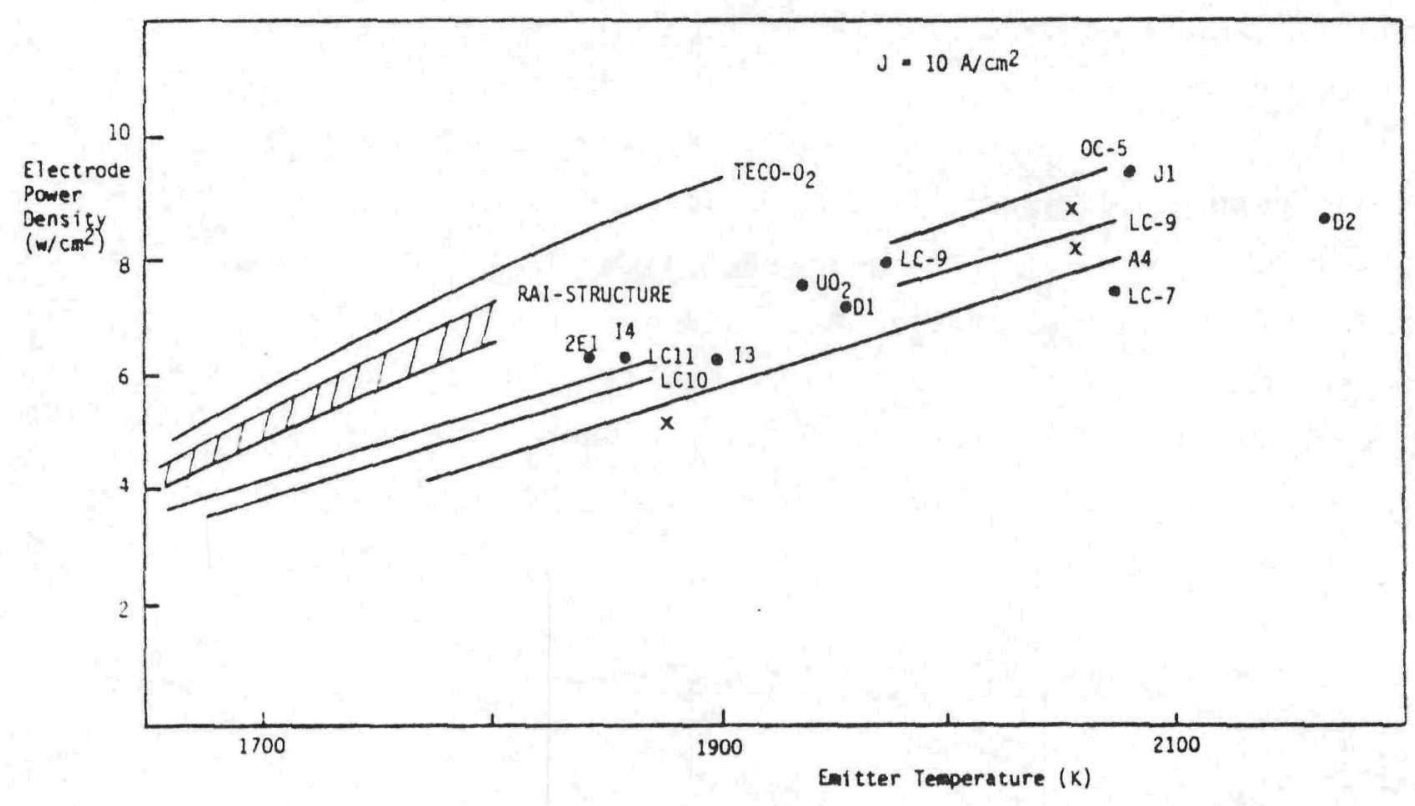

Fig. 5-13 Cylindrical Converter Performance

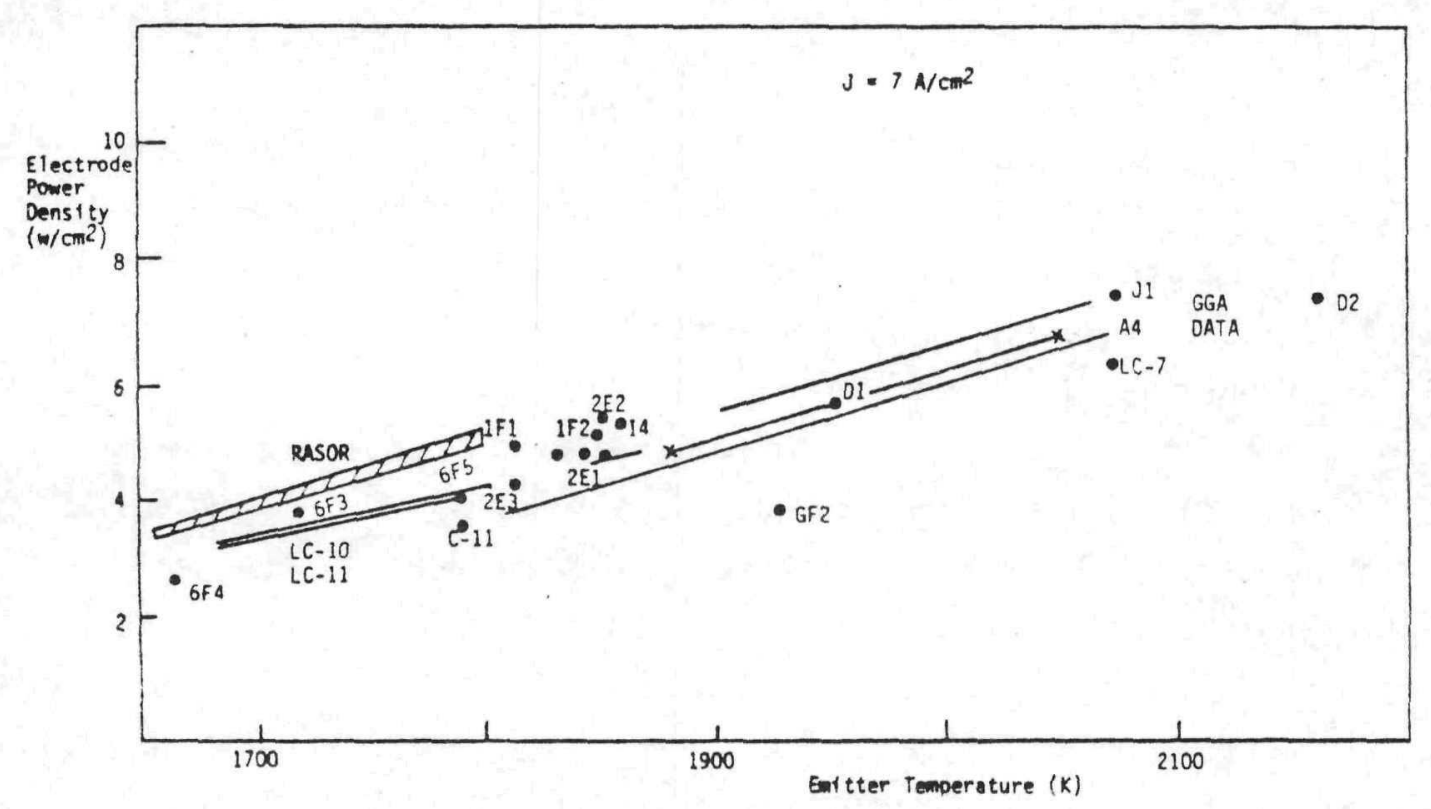

Fig. 5-14 Cylindrical Converter Performance 
obtained using a structured (CVD-Re) emitter in one case and a structured (grooved) collector in the other. The TECO converters had a W(110) emitter and a sublimed molybdenum collector applied in a partial pressure of oxygen.

Two things should be noted from this data. First, good and reproducible performance can be obtained using cylindrical converters. For converters with similar electrodes output power differences of less that $\pm 10 \%$ are to be expected. Second, the use of rhenium emitters and structured electrodes provides a performance advantage, particularly at high power densities. This advantage is equivalent to a $50 \mathrm{~K}$ increase in temperature at $7 \mathrm{~A} / \mathrm{cm}^{2}$ and $75-100 \mathrm{~K}$ at $10 \mathrm{~A} / \mathrm{cm}^{2}$.

The electrode efficiencies which are presently available are illustrated in Fig. 5-15. The band shown encompasses the results from two structured electrode converters built by Rasor Associates for JPL in 1978. Also shown is an envelope of the best data from GGA. The longest stable TFE test, TFE-2E2, was also one of the best performers.

Power output and efficiency, in addition to their dependence on emitter temperature and current density, also depend strongly on collector temperature. The highest performance converters typically have low collector work functions and begin to loose efficiency at collector temperatures above $900 \mathrm{~K}\left(1160^{\circ} \mathrm{F}\right)$. Converters with higher collector work functions and relatively low peak efficiencies actually have superior performance at high heat rejection temperatures, $1050 \mathrm{~K}\left(1431^{\circ} \mathrm{F}\right)$ and above. There is an abundance of data available characterizing conventional converters with collector temperatures to up to $1100 \mathrm{~K}$. There is relatively little data on the performance of oxygenated converters with collector temperatures above $1000 \mathrm{~K}$ or conventional converters with collector temperatures above $21100 \mathrm{~K}$ $[25,26]$. These higher collector temperature regions may be quite important for very high power applications.

The output power density (and efficiency) of a converter also depends on the interelectrode gap. Almost all of the early inpile converters were targeted at the relatively high power densities needed in high power (250-400 kWe) systems. This required electrode power densities of $6-8 \mathrm{~W} / \mathrm{cm}^{2}$. As 


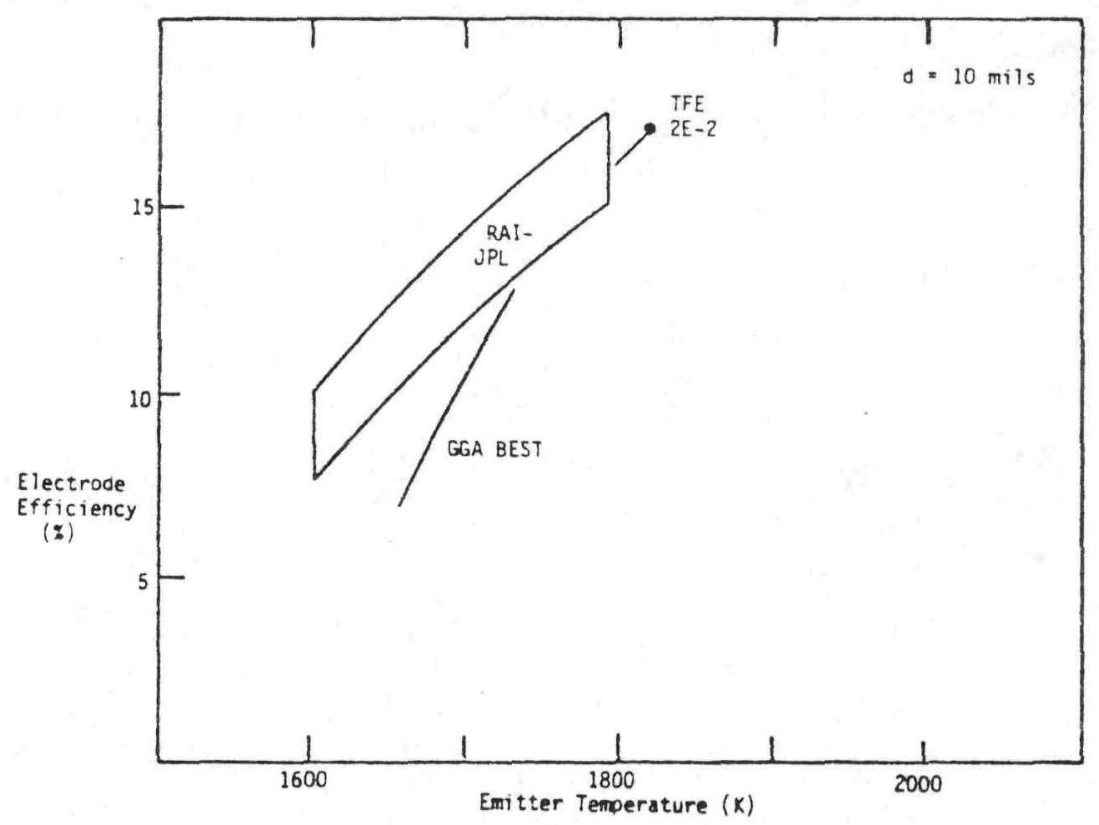

Fig. 5-15 Cylindrical Converter Electrode Efficiency

$$
\text { 5-32 }
$$


shown by planar converter data in Fig. 5-16, high power density led to the selection of relatively high operating temperatures ( $1850-1950 \mathrm{~K}$ ), and high current densities $\left(210 \mathrm{~A} / \mathrm{cm}^{2}\right)[27,28,29]$. This constrained the early TFE designs to the use of relatively small $10 \mathrm{mil}$ gaps, even with the best non-oxygenated surfaces. However, present long endurance $100 \mathrm{kWe}$ reactor designs require electrode power densities below $4 \mathrm{~W} / \mathrm{cm}^{2}$. As shown in Fig. 5-17, this objective can be met with gaps as large as $20 \mathrm{mils}$ or more at an emitter temperature of $1800 \mathrm{~K}$. The larger gap potentially doubles TFE lifetimes which may be life limited by interlectrode shorting. TFE-6F3 was designed with a 14 mil gap in order to take partial advantage of this effect.

The very beneficial effect of oxygenated performance is also obvious in the figures. The addition of oxygen permits the use of large gaps even at high power densities. It also results in a performance improvement at all gaps, but this may simply be the result of a lower collector work function, an effect which is not useful in high power space power systems with very high heat rejection temperatures.

Ongoing research efforts hold the promise of doubling the performance of thermionic converters under some conditions. While not a subject for review in this study, such an improvement would have a profound effect on future thermionic reactor designs.

\subsubsection{TFE Thermionic Performance Stability}

The performance stability of the basic thermionic converter with a tungsten emitter, metal collector, and liquid cesium reservoir is excellent, as shown by the life test data in Fig. 5-18. Such stability remains to be demonstrated with advanced converters embodying sophisticated surface tratments. The use of oxygenated collector materials is a case in point. Recognized as an important additive by Thermo Electron in the late 1960's, a converter was run with an oxygenated sublimed molybdenum collector and high stable performance $\left(4.6 \mathrm{w} / \mathrm{cm}^{2}, 6 \mathrm{~A} / \mathrm{cm}^{2}, 1800 \mathrm{~K}\right.$ emitter, $875 \mathrm{~K}$ collector) for over 5000 hours. However, reproducible stable performance under the conditions appropriate for space reactors $\left(T_{C}{ }^{21000} \mathrm{~K}\right)$ remains to be demonstrated $[19,30,31,32]$. 


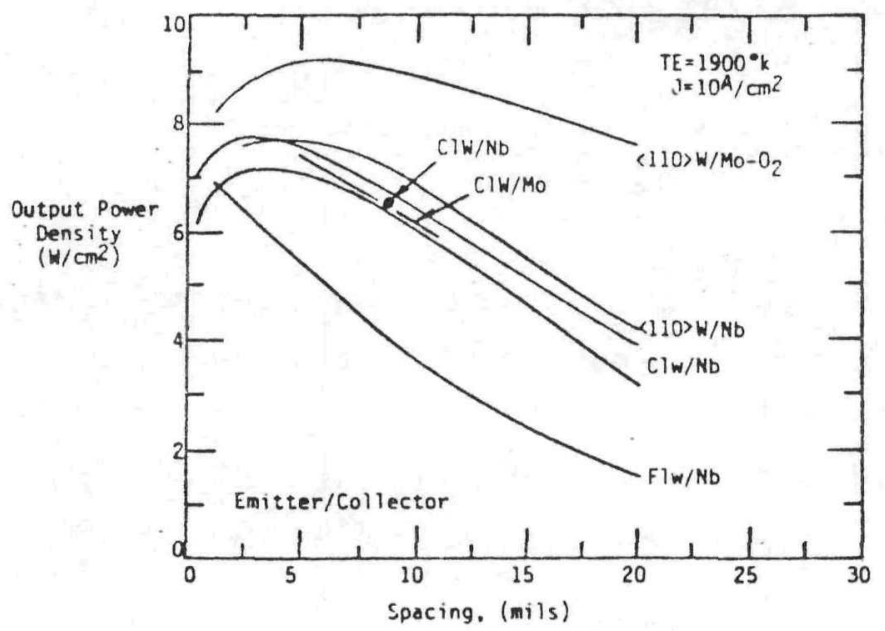

Fig. 5-16 Converter Performance Spacing Dependence 

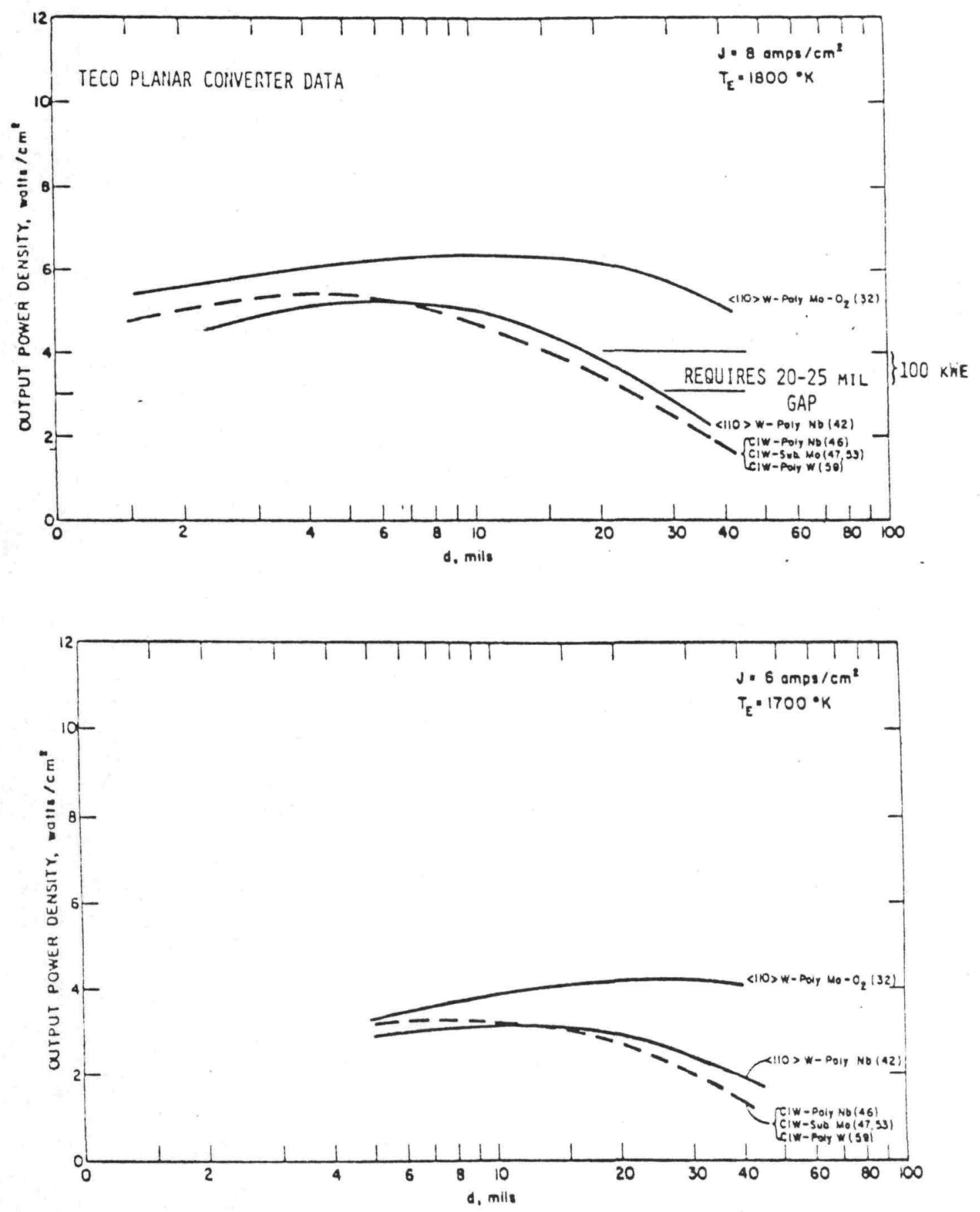

Fig. 5-17 Planar Converter Performance Vs. Gap 

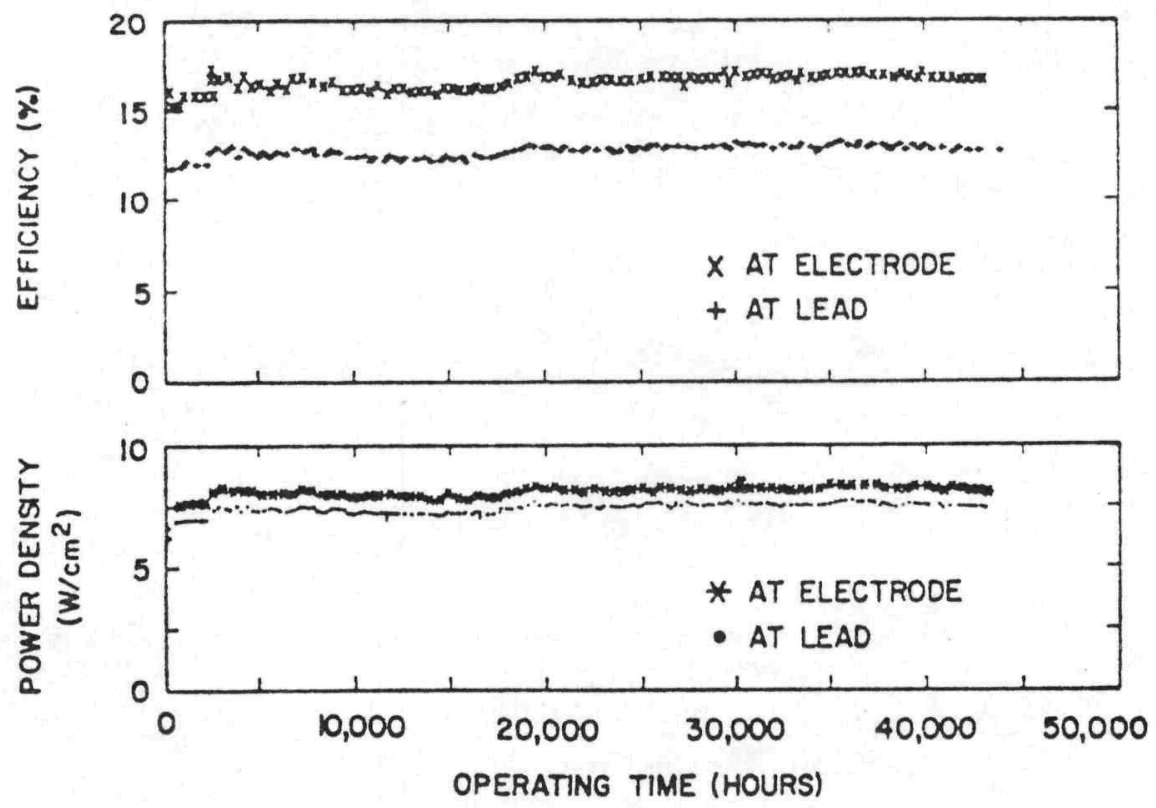

Fig. 5-18 Electrically Heated LC-9 Lifetest: $T_{E}=1970 \mathrm{~K}$ 
Performance stability in actual TFE in-pile tests depended strongly on the fuel $[19,33]$. U0 2 fueled devices typically had high and stable performance. They frequently showed evidence of a positive oxygen effect. Leaks between fission gas and cesium space did not always result in a loss in relative thermionic performance. However, such leaks did result in a loss of efficiency due to the additional gaseous conduction thermal losses in the interelectrode space. When a performance loss did occur it was typically the result of an envelope leak (early devices) or a short circuit between emitter and collector. The life test history of the in-pile test of TFE-2E2, Fig. 5-19 is an example. Similar results were obtained out-of-pile with electrically heated converters containing depleted $\mathrm{UO}_{2}$ in the emitter structure as shown in Fig. 5-20 [34], although at very high temperatures $(2000 \mathrm{~K})$ some performance degradation has been reported [35].

By contrast UC-ZrC fueled devices typically showed steady performance losses during operation which was attributed to the diffusion of uranium or carbon through the emitter. When envelope leaks occurred, permitting fission products to reach the electrodes, the performance always fell sharply. The performance loss due to fuel component diffusion was being solved by proper selection of fuel stoichiometry and control of the grain structure in the tungsten emitter. By the end of 1972 the carbide fueled converters were showing stable performance to 3000-4000 hours as shown in Fig. 5-21. At that time, swelling of the carbide fuel following sintering had proceeded to the point where emitter deformation began to occur. This apparently results in grain boundary separations in the tungsten emitter, embrittled by the presence of carbon, with a resultant increase in fuel component contamination of the elctrodes. Hot cell examination of carbide fueled emitters that had suffered substantial distortion generally showed cracking of the tungsten.

Fig. 5-22 shows the performance history of two out-of-pile tests in which depleted UC-ZrC fuel bodies were encapsulated in the emitter structure to ascertain adverse fuel diffusion effects without the problem of fuel swelling. The longer test, LC-11 had a duplex tungsten emitter, the substrate of which was made from equiaxed grains of tungsten, selected to minimize diffusion of carbon, LC-10 had a duplex emitter with a substrate of tungsten having columnar grains. The advantage of the equiaxial structure is 

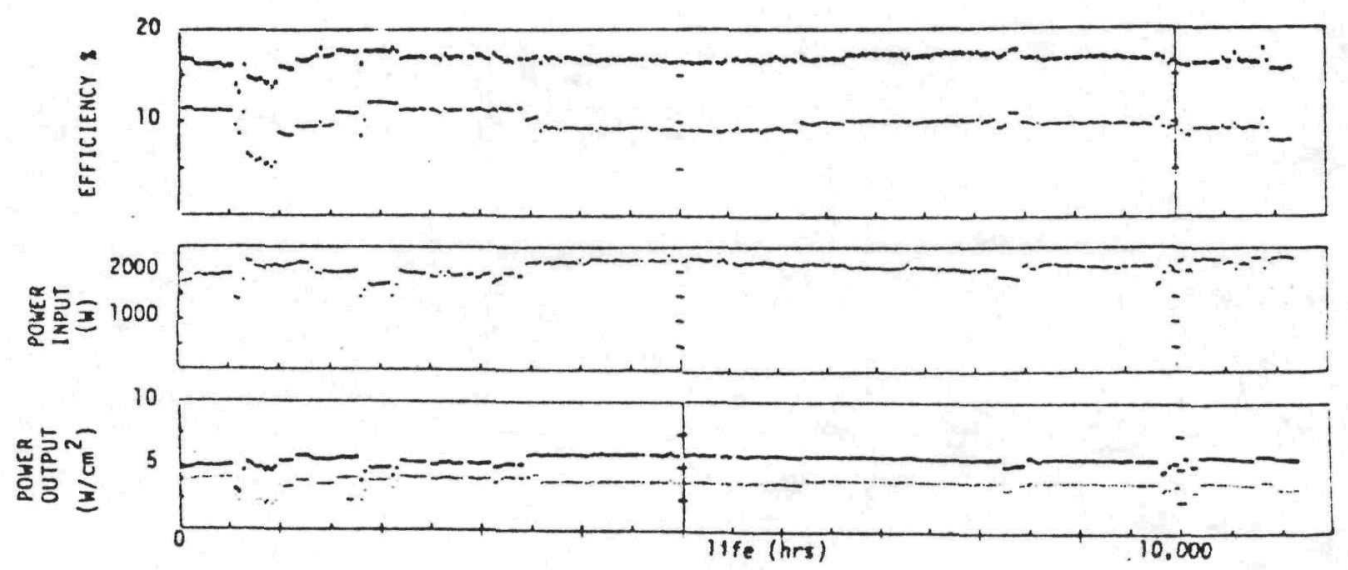

Fig. 5-19 In-pile U02 Fueled TFE-2E2 Life Test: $T_{E}=1850 \mathrm{~K}$
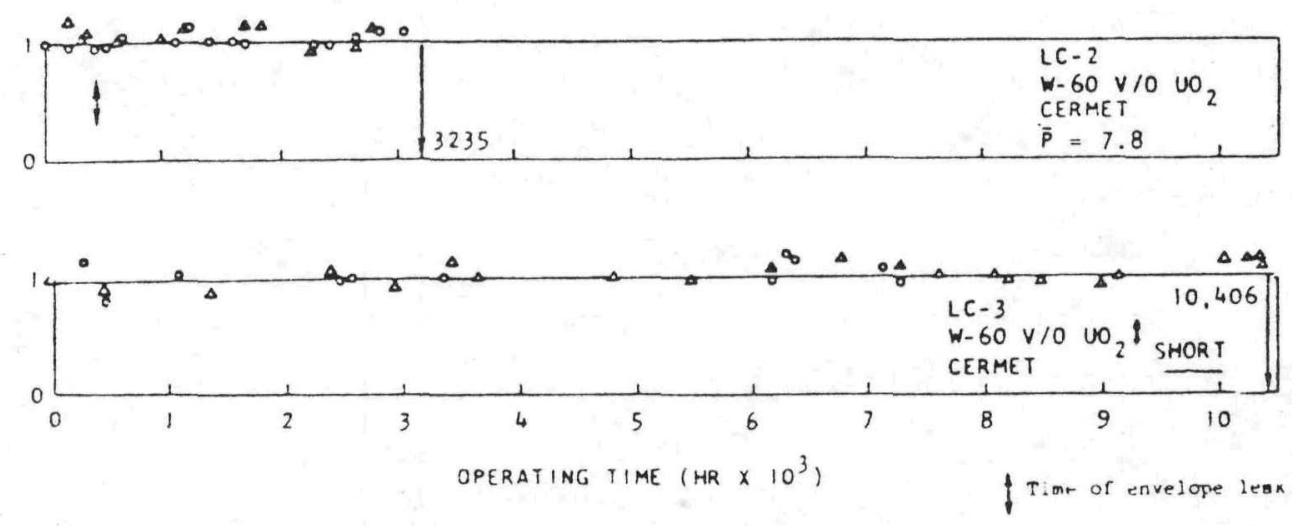

Fig. 5-20 Relative Power and Efficiencies of Out-of-Pile Tests Incorporating $\mathrm{UO}_{2}$ 

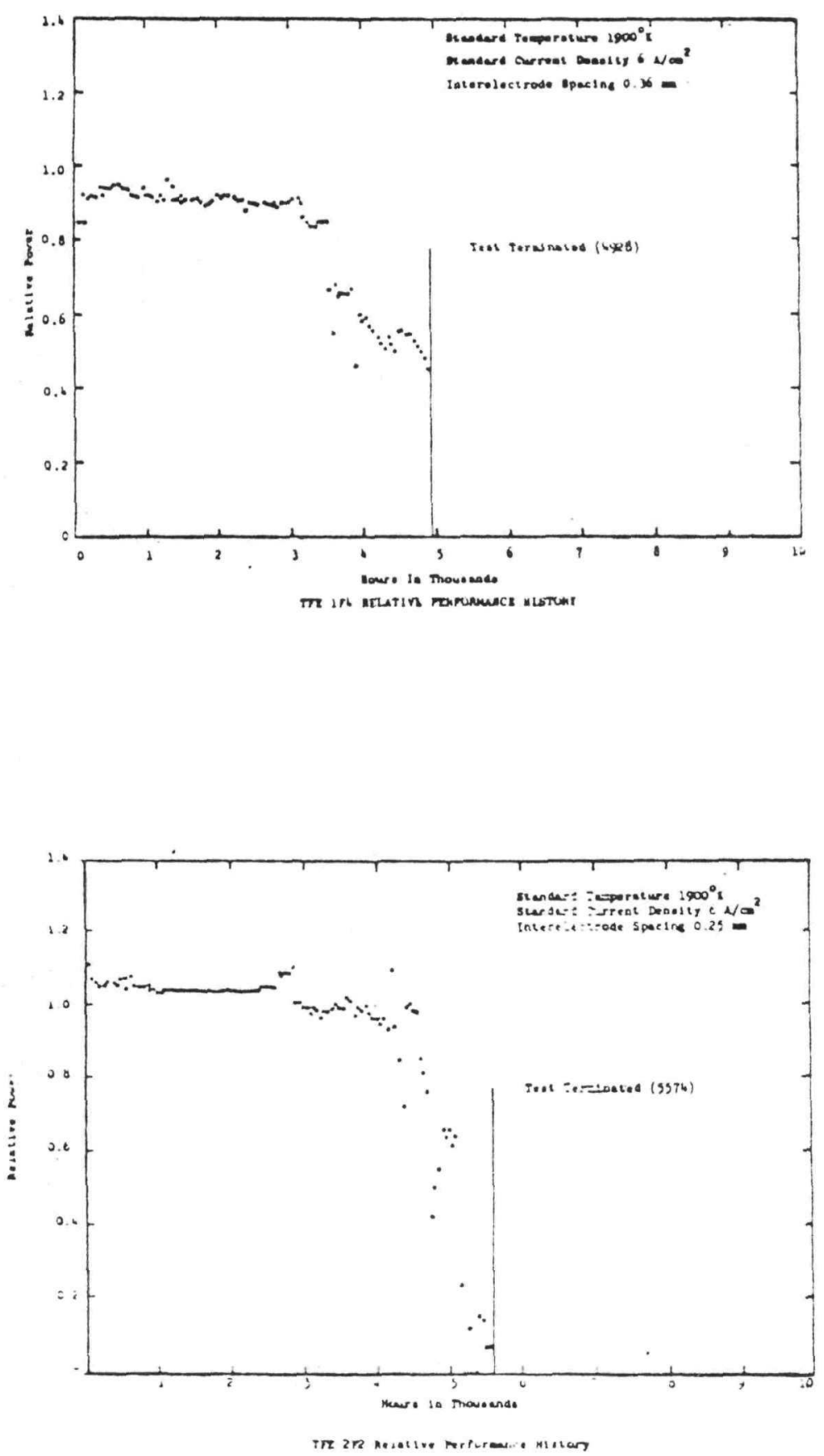

Fig. 5-21 Relative Performance of Carbide Fueled TFE's Showing On-set of Performance Loss at 3,000-4,000 Hours 

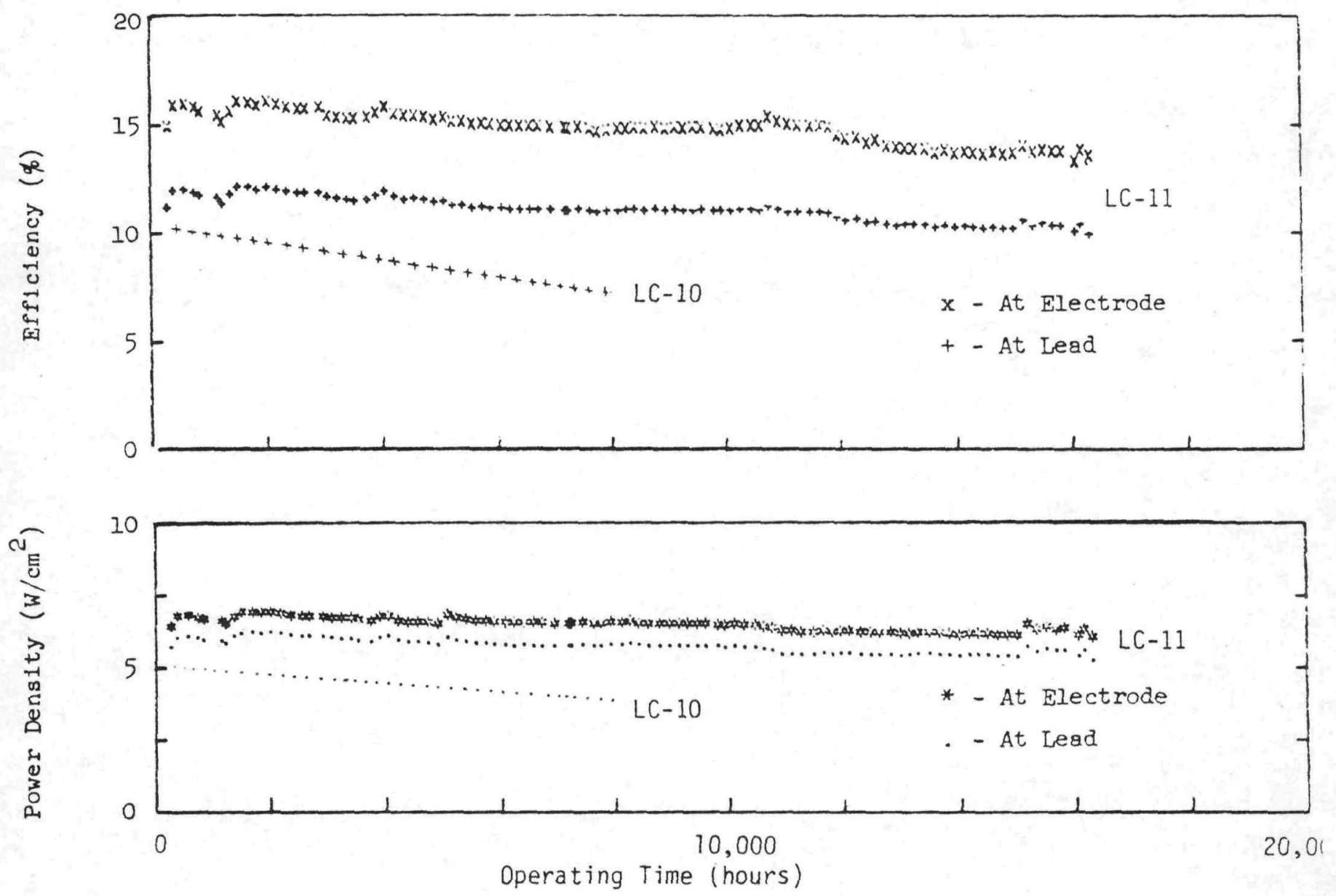

Fig. 5-22 A Comparison of LC-10 And LC-11 Performance (Depleted Carbide Fuel Slabs In Clads) 
clear. Unfortunately this structure was not tested in-pile prior to program termination.

A variety of approaches for controlling carbide fuel sintering and consequent swelling were incorporated in TFE'S 6F4 and 6F5. As shown in Fig. 5-23, their performance seemed to stabilize after 1000 hours of operation near design levels. Unfortunately, the test program was terminated before the tests could accumulate much life.

In summary, the initial thermionic performance of TFE's was predictable and reproducible in 1973. Performance with oxide fuels was stable to past 11,000 hours. Carbide fuels typically resulted in significant performance losses in 5000 hours or less, but out-of-pile and in-pile data indicate that control of this problem to 16,000 hours or more was possible with a good control of fuel stoichiometry and tungsten grain structure control.

\subsection{Component Development Status}

\subsubsection{Overview}

The TFE consists of a large number of individual components that work in concert. The most critical of these are the emitter and fuel the components which presently limit TFE life and performance. They are described in detail in Section VII. However, other components may require further development if the full life and performance potential of the TFE is to be realized. For example, leaks between the fission gas and cesium spaces, through the insulator seal or joints in the TFE, were common and adversely affected TFE performance due to thermal losses when they occurred. Low electrical resistance and unbonding in sheath insulators can result in parasitic electrical losses and high collector temperatures. Carbon transport from integral cesium-graphite reservoirs can contaminate the electrodes.

The basic feasibility of operating each of these components acceptably for 10,000 hours was demonstrated in the previous program. It is helpful, however, to review each in order to identify development priorities in a program which is targeting a 60,000 hour lifetime. 

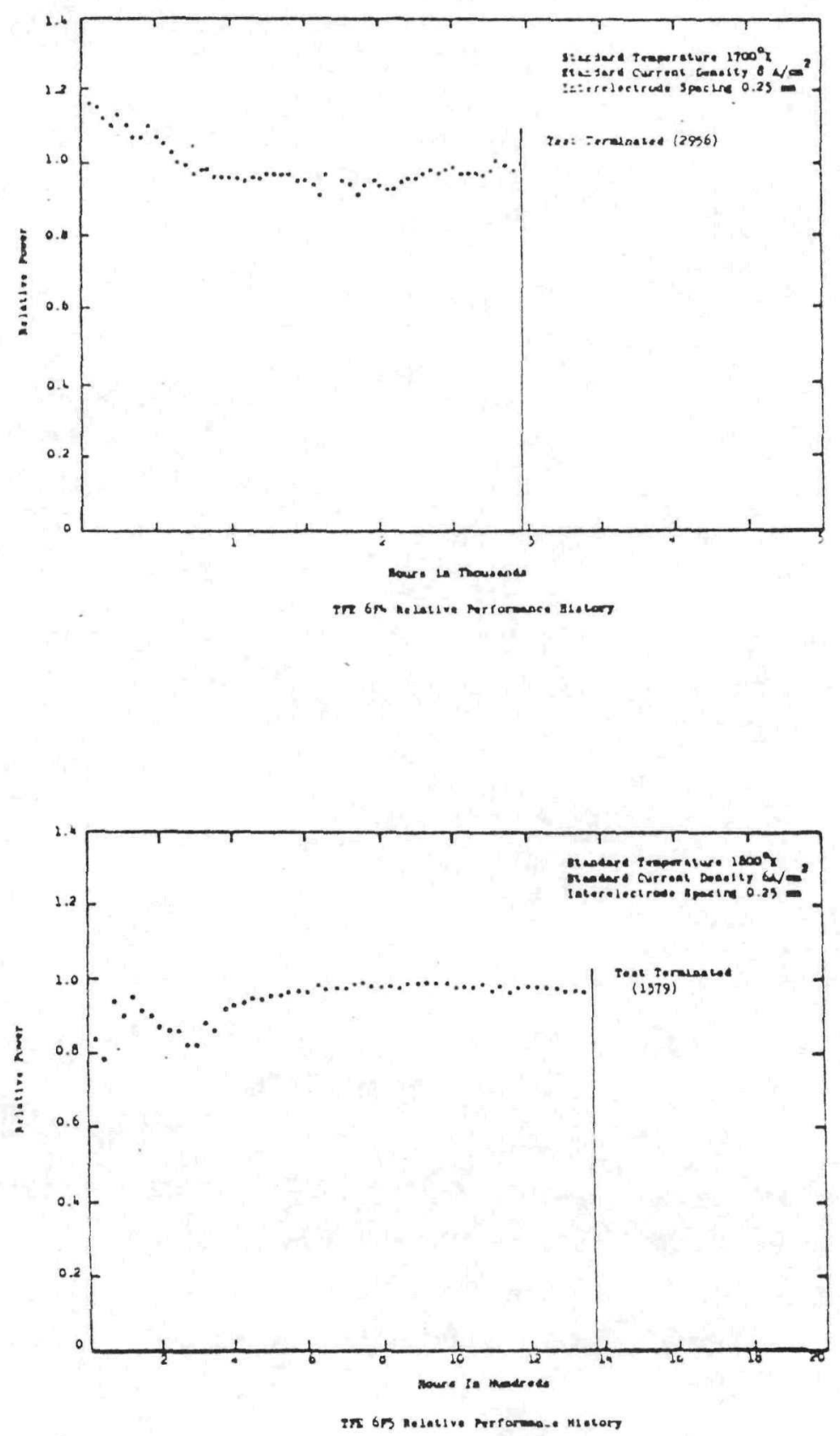

Fig. 5-23 Carbide Fueled TFE Relative Power Performance 


\subsubsection{Insulator Structure}

As shown in Fig. 5-24, three types of electrical insulator are required in a dry-cell TFE. First, each emitter must be insulated from its collector. The electrical insulator that accomplishes this must also serve as a seal to separate cesium and fission gas spaces. Second, each collector (except the last) must be electrically isolated from the common sheath tube which contains them all. Finally, wherever surfaces of opposite polarity are exposed to each other across a gap a protective insulating layer (i.e. plasma sprayed alumina) must be applied to avoid electrical discharges in the presence of cesium. Each type of insulator was developed sufficiently to project $2 \frac{1}{2}$ years life at ten volts by the end of the program, with a good possiblity of 7 years life at even higher voltage.

Two sheath insulators were developed, the F-series graded insulator and the G-series cermet insulator. The structure of the F-series design went through several development iterations, evolving to a seven-layer $\mathrm{Nb}-\mathrm{Al}_{2} \mathrm{O}_{3}-\mathrm{Nb}$ structure. This basic design has been demonstrated in a TFE in-pile for 12,000 hours at a temperature of $1000 \mathrm{~K}$ with a heat flux of $40 \mathrm{~W} / \mathrm{cm}^{2}$ to a fast fluence of $9 \times 10^{20}$, through over 20 shutdowns and scrams.

The graded tri-layer structure is fabricated by sequentially plasma spraying seven layers of mixed niobium-alumina powder on a cylindrical niobium substrate. The sequence begins with a high niobium content, proceeds through a pure alumina layer, and ends with a high niobium content. The outside of the resulting structure is trued, a niobium outer cylinder slipped on, and the sprayed region sealed. The structure is then bonded and densified with three hours of treatment at $1823 \mathrm{~K}\left(2822^{\circ} \mathrm{F}\right)$ and $10 \mathrm{Ksi}$ in an inert gas autoclave.

The TECO G-series insulator is a composite structure of niobium and a cermet of niobium spheres ( 1 to $2 \mathrm{mils}$ in diameter) surrounded by a continuous matrix of alumina. Individual spheres are coated with alumina using powder metallurgy techniques of mixing and screening. The coated spheres are cold pressed on mandrels to form thick-walled cylinders of the approximate diameter required. These cold-pressed cylinders are removed from 


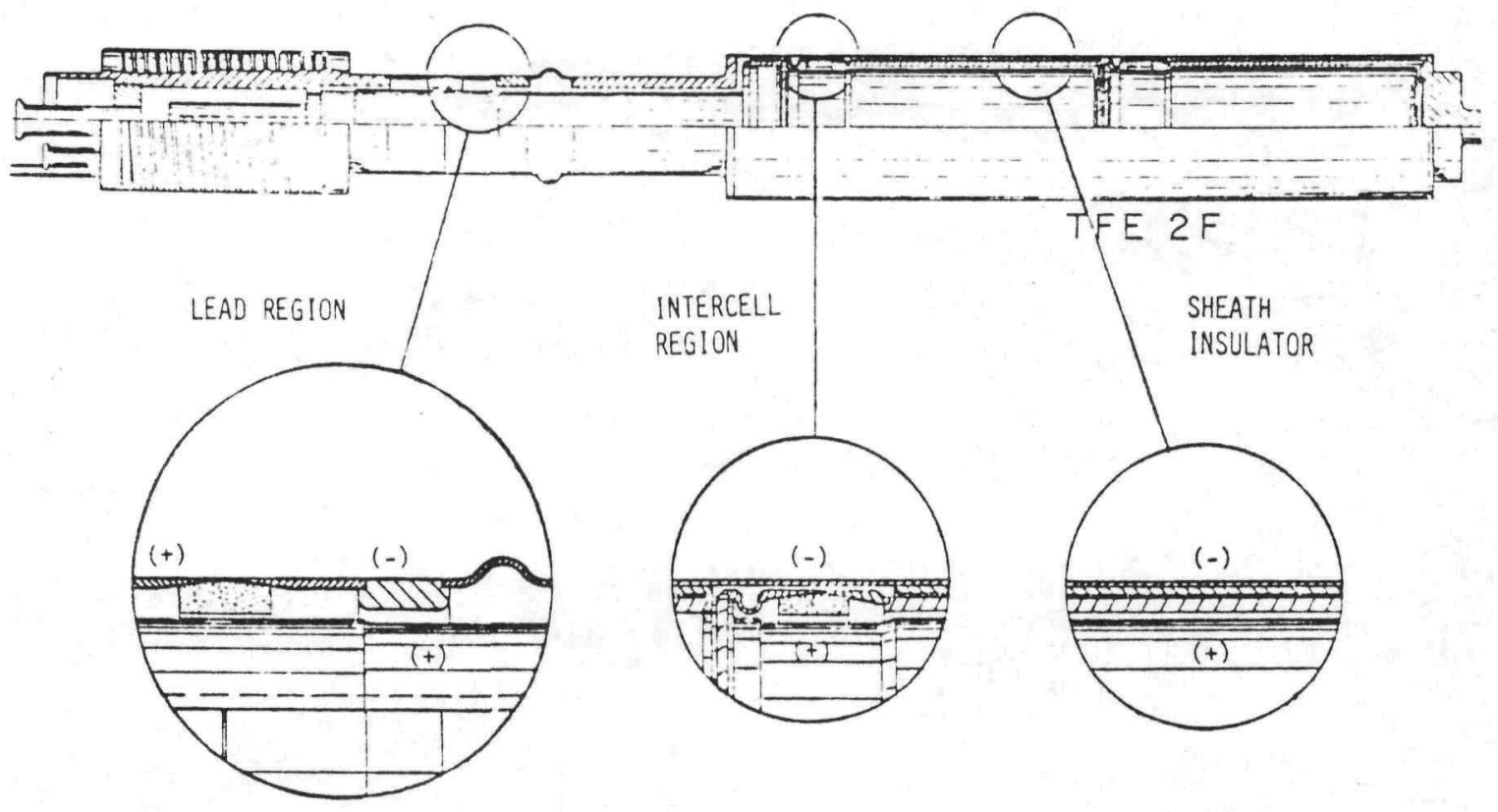

Fig. 5-24 Insulation Regions in a TFE 
the mandrel and fixed in vacuum at $1573 \mathrm{~K}\left(2372^{\circ} \mathrm{F}\right)$ to remove the binder and to achieve partial sintering. The partially sintered cylinders are machined to the thin wall configuration required for pressure bonding into subassemblies. The sheath structure subassembly is formed by pressure bonding at 10,000 psi and approximately $1823 \mathrm{~K}\left(2822^{\circ} \mathrm{F}\right)$. During this operation, sintering of the cermet is completed and bonds are formed between the cermet and the niobium components.

As shown in Fig. 5-25, the electrical resistance of simple $\mathrm{Nb}-\mathrm{Al}_{2} \mathrm{O}_{3}-\mathrm{Nb}$ insulators remains high and shows no sign of deterioration to beyond 15000 hours in out-of-pile tests at 10 volts [36]. A similar tri-layer structure developed at Siemans was reportedly tested at 100 volts to 5000 hours at 973 $K$ with a stable leakage current [37]. However, accelerated testing for 5313 hours at 100 volts and $1473 \mathrm{~K}$ showed evidence of electrolytic transport of ions in the tri-layer [38]. In-pile converters using this insulator design concept (TFE 6F1) exhibited poor thermal bonding with high resulting collector temperatures and poor performance. Fig. 5-26 shows preliminary test results on the seven-layer graded insulator structures described above. The resistance of the speciman remains high with no sign of degradation. Also shown are similar results of tests with a graded yttria sheath insulator and a TECO cermet sheath insulator. The data on yttria insulators is mixed with the much poorer performance shown in Fig. 5-27 having been obtained in a test of a plasma sprayed yttria insulator at Los Alamos with twenty volts applied [39].

Electrical leakage measurement in the presence of cesium is compiicated by the need to simultaneously test the sheath insulator and an insulating coating of some type. Such tests with the F-series graded alumina insulator showed no evidence of serious resistance loss or leakage current due to the cesium. The G-series cermet insulators did degrade in the one test run, however, with a resistance near $0.5 \mathrm{ohm}$ in some regions. No tests of yttria insulators were performed. Test data with simulated cracks in the sheath insulator showed in the presence of cesium, that discharge powers approaching $1 \mathrm{~kW}$ could exist with sustaining voltages near 15 volts. The NaK-cooled ceramic sheath tube used in the test was affected locally by this discharge, but not penetrated $[40]$. 


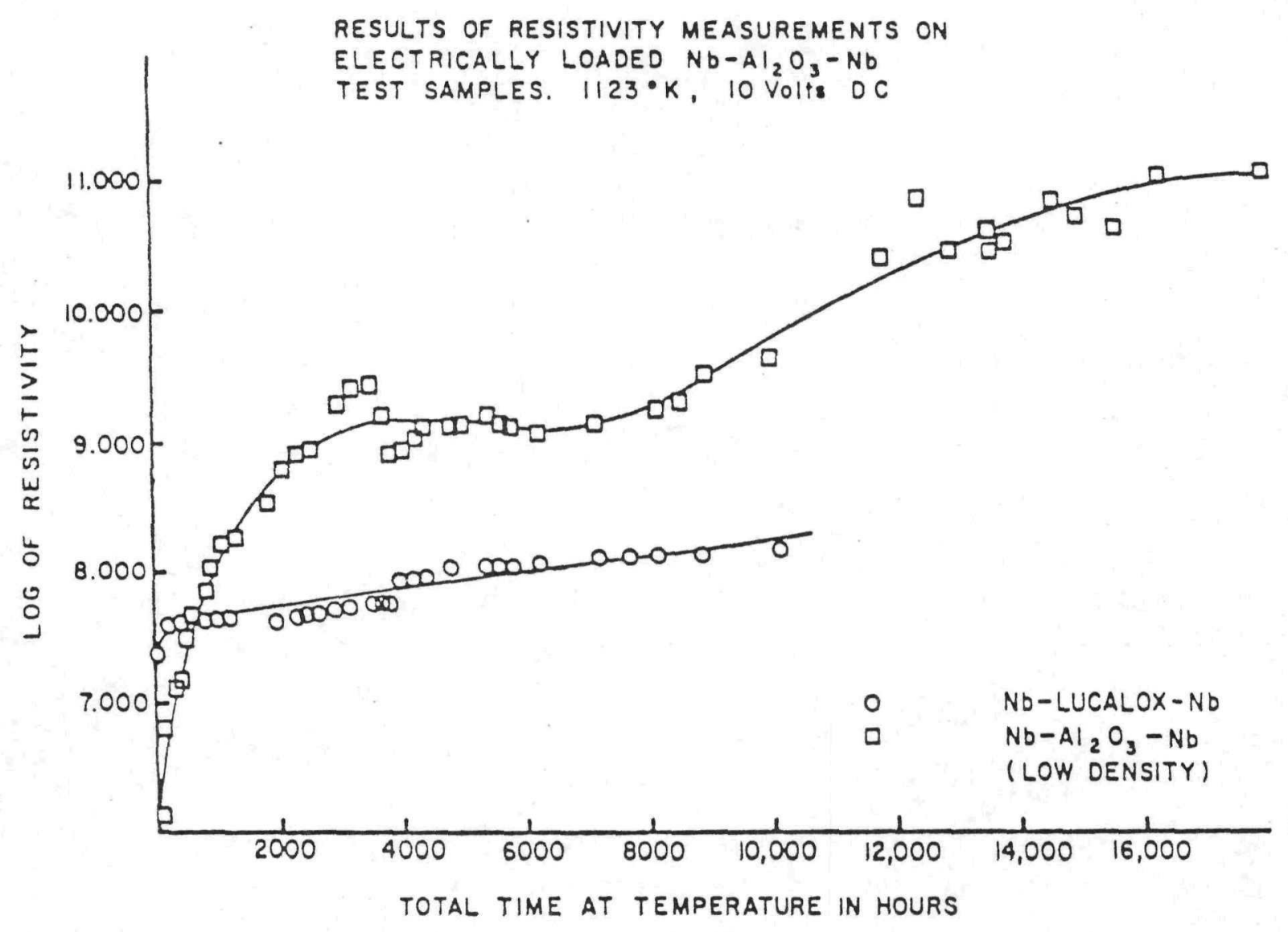

REF: G-GA A 12397, 6/15/73

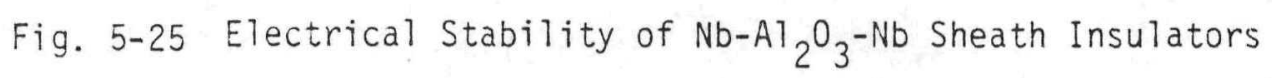




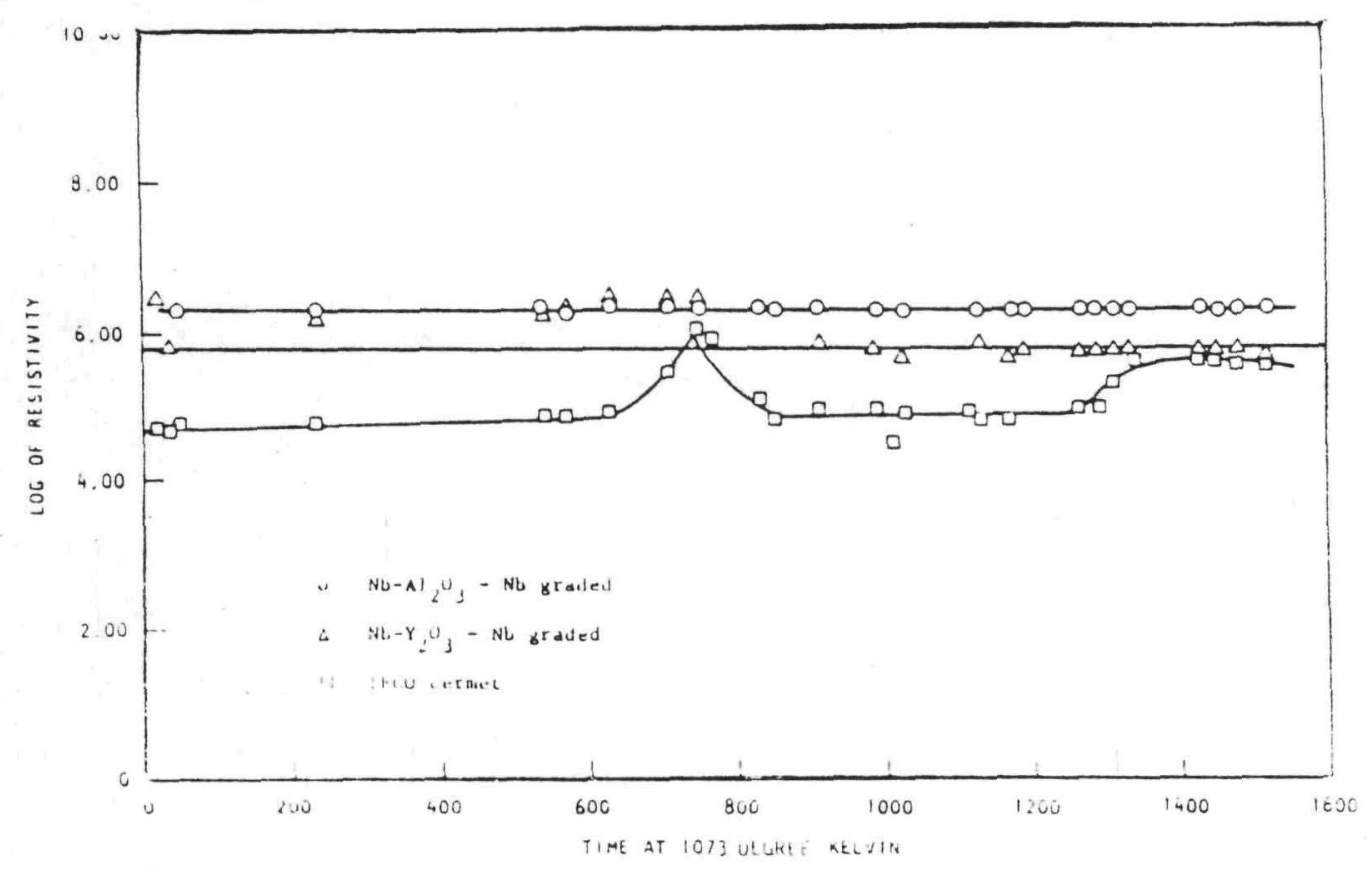

Fig. 5-26 Log of Resistivity vs. Time for Selected Trilayer Samples

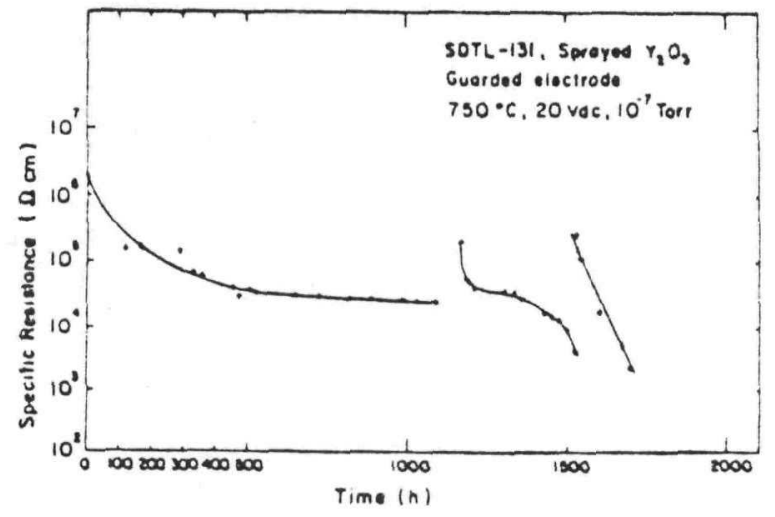

LANL LA-5113-PR, 10/72

Fig. 5-27 Resistance Stability of a Yttria Sheath Insulator at 20 volts 
The use of plasma sprayed alumina to limit discharge currents over exposed surfaces in the case of a cesium leak was largely successful. Discharge currents could be maintained below one ampere at 10 volts in mockup tests of the exposed regions between cells [41]. Fig. 5-28 illustrates the evolutionary development of this capability as a sequence of cell regions (CR) mockups were tested. As can be seen, current flow drops quickly at lower cesium pressures. A port tube similar to that used in the wet-cell GE TFE was being developed as a backup approach to keeping cesium pressures low in the event a leak does permit entry of cesium into the sheath insulator and fission gas spaces.

Electrical tests of the insulators in a TFE were made in four single-cell TFE's in-pile. The TFE-1F1 test operated for 8560 hours at 9-10 volts with a stable integrated current flow of one ampere. However, the sheath insulator in IFI was a solid alumina type, not the graded design. A graded sheath insulator was used in TFE-1F2, which operated at 5.0 volts between 2120 and 5618 hours of TFE testing. Current flow was 0.3 amperes. Following a reactor shutdown the emitter was found to be shorted to the collector and the sheath insulator was also shorted. The high collector temperature near the emitter short is suspected to have resulted in the sheath insulator failure. A short was also observed in a TFE-1F3 after 551 hours of testing at 5.0 volts. Cesium was intentionally introduced into the fission gas and sheath insulator region in that device TFE-1F4, which had a TECO cermet sheath insulator, operated at 5-10 volts for 1787 hours at which time a bistable discharge mode developed and testing was terminated. This mode was similar to that observed out-of-pile in contaminated insulators.

During in-pile testing of other TFE's there was evidence of low resistance in two of thirty sheath insulators. Hot cell examinations showed evidence of some alumina coating cracking, particularly in the bellows-region of the insulator seal.

These tests established the basic feasibility of operating at ten volts in-pile. It is clear that better coating techniques will be reeded if significantly higher voltages are contemplated, and such techniques (sputter coated alumina, high velocity spray, etc.) were under development but 


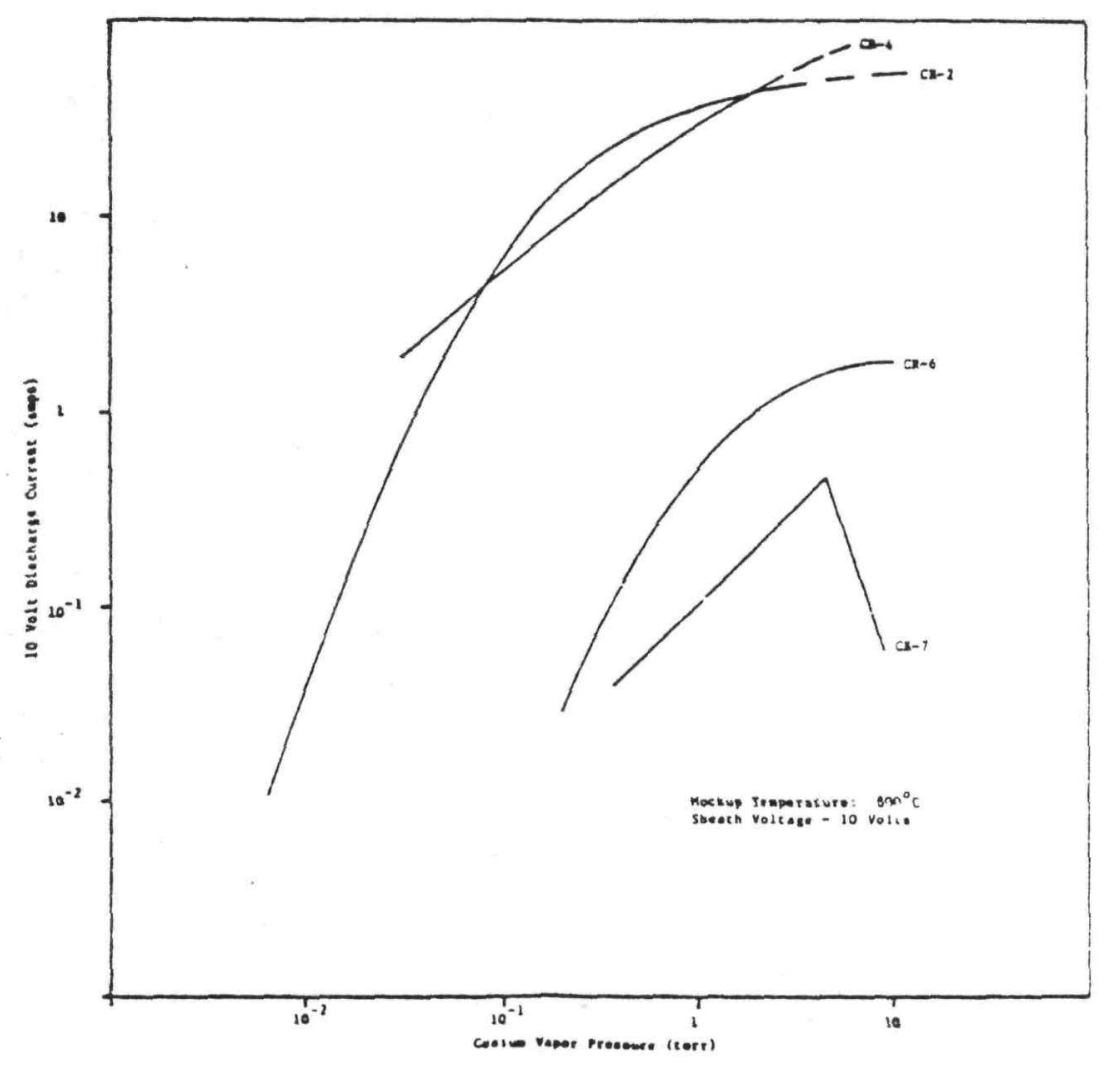

Fig. 5-28 Parasitic Discharge Currents in Inter-Cell Region Mockups in the Presence of Cesium 
relatively untested at the end of the program. Problems with the sheath insulators seem largely to have been ones of quality control.

A more serious concern with respect to insulator lifetime is radiation damage, although no significant problems were encountered due to such damage in any in-core tests of TFE's. Both alumina sheath insulators and insulator seals have been used in TFE's tested to fast ( $>0.1 \mathrm{MeV}$ ) fluences greater than $8 \times 10^{20} \mathrm{n} / \mathrm{cm}^{2}$. LANL tests in EBR-II of free standing ceramic bodies, with temperatures in the 850-1200 $\mathrm{K}$ range, showed a swelling rate for Lucalox alumina of about $0.6 \%$ per $10^{21} \mathrm{n} / \mathrm{cm}^{2}$ [42]. There was little evidence of microcracking at $6 \times 1^{21} \mathrm{n} / \mathrm{cm}^{2}$, although some specimens showed vacuum leaks at swelling levels of $2.5 \%$, corresponding to $4 \times 10^{21} \mathrm{n} / \mathrm{cm}^{2}$. This corresponds to

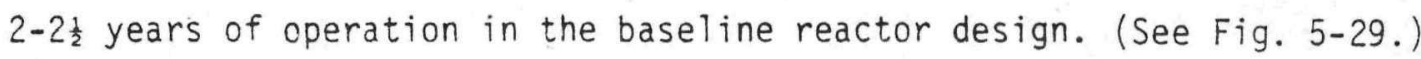

Tests of trilayer sheath insulators in EBR-II [39] showed that neither $\mathrm{Nb}-1 \mathrm{Zr}$ or $\mathrm{Nb}$ outer sheaths restrained the swelling of the $\mathrm{Al}_{2} \mathrm{O}_{3}$ under irradiation. When a niobium collector was used it crept, following the expanding alumina. Cracking at the $\mathrm{Al}_{2} \mathrm{O}_{3}$ - $\mathrm{Nb}$ interface was observed at the highly stressed ends of the structure at $3 \times 10^{21} \mathrm{n} / \mathrm{cm}^{2}$. Nb-12r collectors did not creep to follow the expanding alumina, resulting in separation at $22 \times 10^{21} \mathrm{n} / \mathrm{cm}^{2}$. The TECO cermet insulator performed best, with only minor cracking visible at $3 \times 10^{21} \mathrm{n} / \mathrm{cm}^{2}$.

Tests of yttria insulators have shown very encouraging results. Free standing bodies show no volumetric swelling to $10^{22} \mathrm{n} / \mathrm{cm}^{2}$, equivalent to $6-7$ years of 1 ife. Tests of trilayers to $4.8 \times 10^{21} \mathrm{n} / \mathrm{cm}^{2}$ showed no swelling when a $\mathrm{Nb}-1 \mathrm{Zr}$ collector was used and low swelling, attributable to the niobium, when a $\mathrm{Nb}$ collector was used. There was no ultrasonic evidence of bond separation in these tests.

\section{Insulator Summary}

The data to date thus suggests that a strength loss in alumina could result in leaks (in insulator seals) at $w_{2}$ years operation. This can be accomodated in the TFE design. More serious is unbonding in trilayer structures with a consequent raise in collector temperatures. This too may 

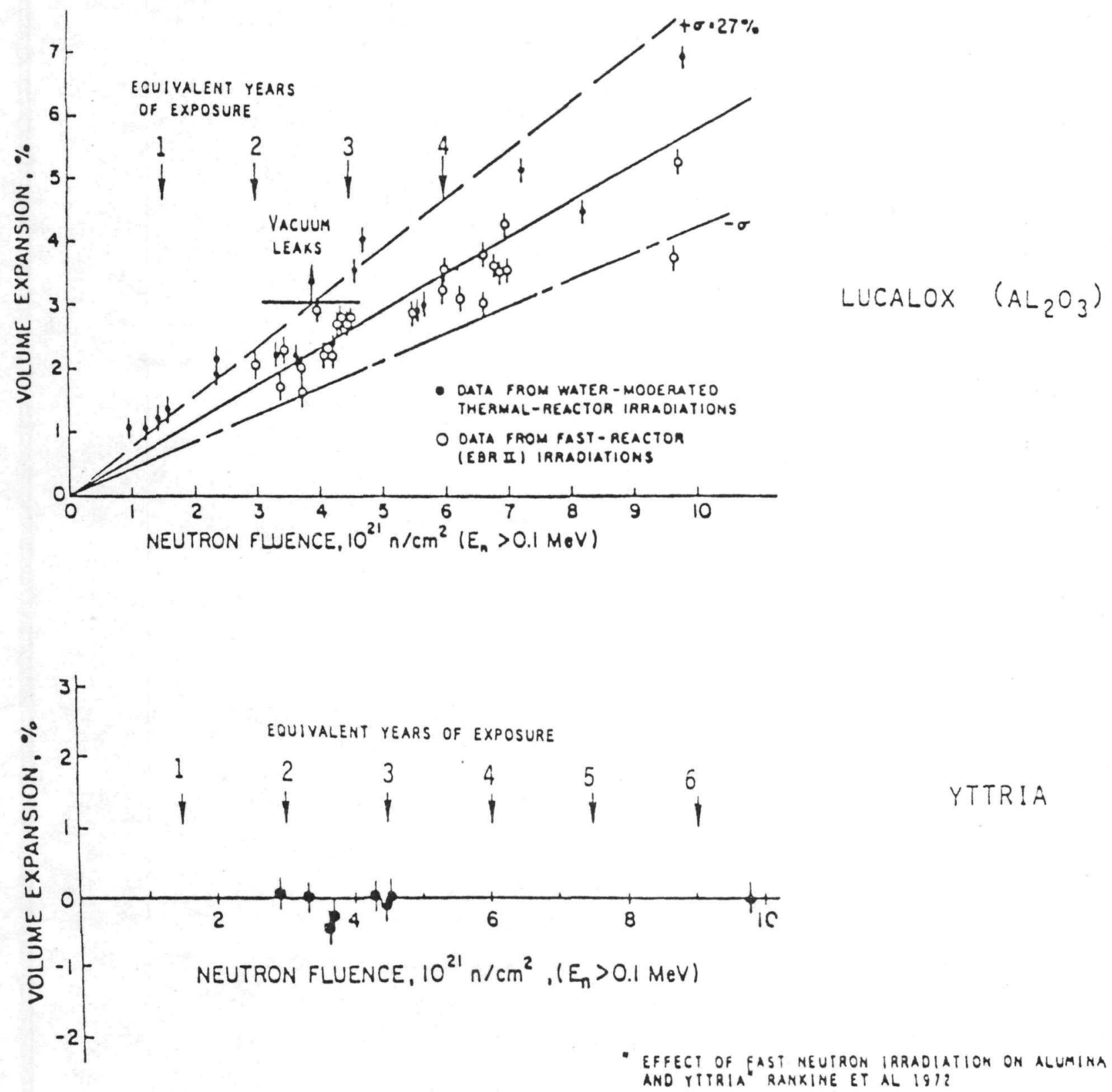

Fig. 5-29 Insulator Swelling Due to Fast Neutron Irradiation 
be a problem in the 2-3 year region. Yttria appears to provide an approach to reaching 6-7 years life or more. Insufficient development had occurred in the previous program, however, to establish yttria insulator feasibility in a11 respects.

\subsubsection{Cesium Reservoirs}

Two alternative cesium reservoirs are available. The conventional design uses a liquid cesium reservoir at about $600 \mathrm{~K}$ to establish the desired vapor pressure. This is below the reactor coolant temperature and consequently the reservoirs are located outside the reactor and the cesium is delivered to the converter through a hole in one electrical lead. An alternative is the use of an "integral" reservoir, a cesium compound or high surface area substrate containing adsorbed cesium, which can establish the desired cesium pressure at the heat rejection temperature. A cesium-graphite lamellar compound is normally selected for this purpose, as it permits use of a substantial cesium inventory (several hundred $\mathrm{mg}$ cesium per gram of graphite), thereby minimizing the effect of cesium loss on cesium pressure. Fig.5-29 shows the characterisitics of a typical material [43].

Integral reservoirs could be incorporated in each individual cell, designed thermally to autonomously establish the desired cesium pressure over a range of converter operating conditions. Alternatively they can be used external to the reactor, as in the case of liquid reservoirs, permitting independent ceium control during operation. The use of Cs-Gr reservoirs in converters has been well demonstrated in Europe [44], the Soviet Union [45], and the U.S [30]. One of the longest 1 ife test records, OC-A4, is shown in Fig.5-30. The slow drop in performance was attributed to carbon transport from the reservoir to the collector, resulting in a higher collector work function and emissivity. This was confirmed in post-test examinations. The sudden loss in power at 15,229 hours was not due to the reservoir, rather it was caused by an over-temperature of a Cu-Ti braze in the converter which contaminated the emitter. Such brazes were eliminated in favor of all-welded construction in TFE's. (See Fig. 5-31.) 


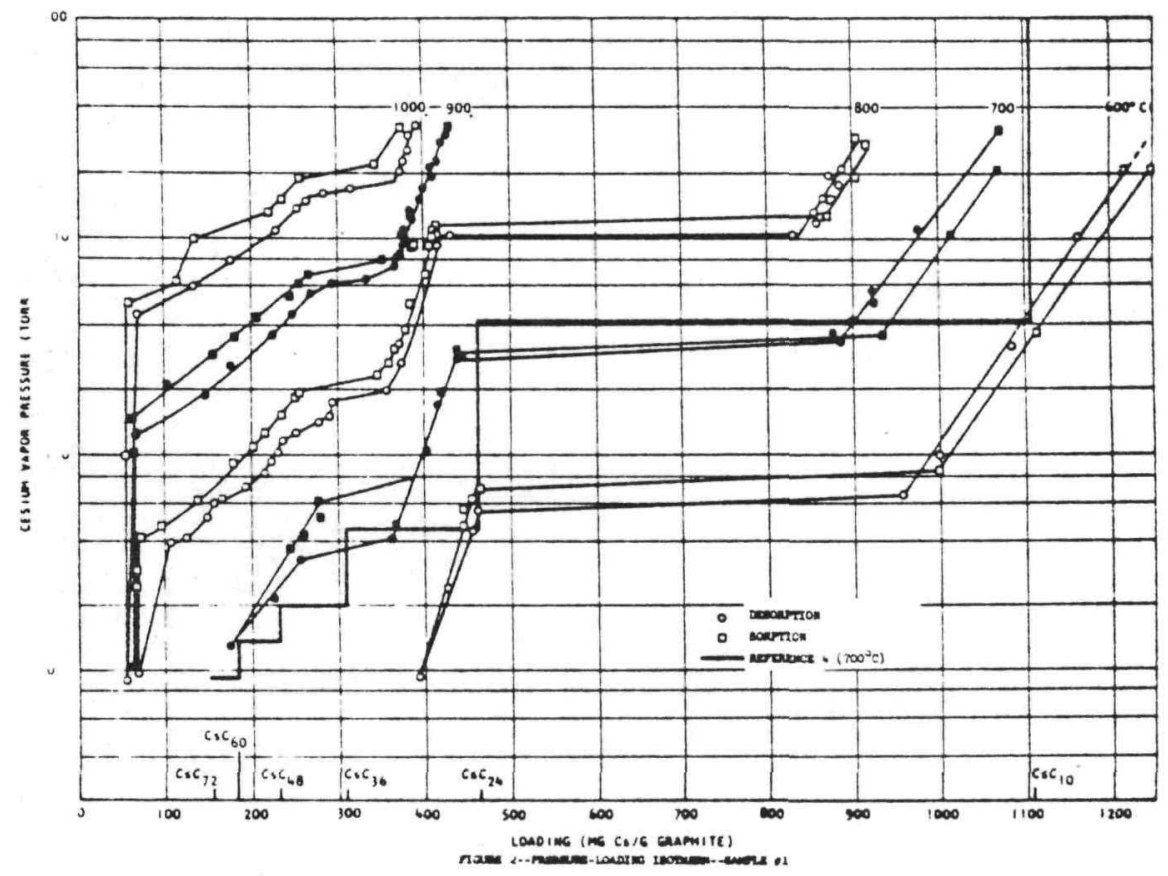

Fig. 5-30 Cesium Pressure-Loading Characteristics Of Pyrolytic Graphite. 


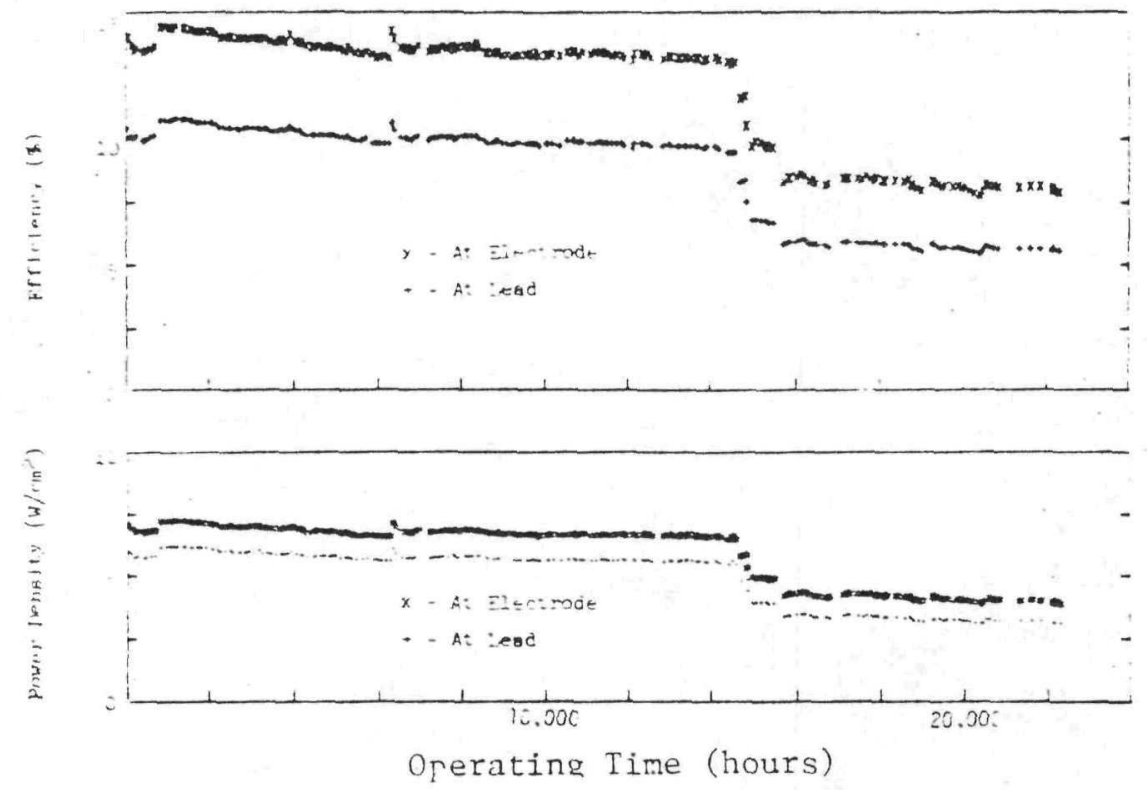

Fig. 5-31 Performance History of an Out-of-Pile Converter with Cs/Gr Reservoir 
The Cs-Gr reservoir is a feasible high temperature reservoir. More development of techniques to isolate the converters from carbon transport is required, as is in-pile testing and testing in the presence of oxygen before the usefulness of this component can be totally confirmed.

\subsubsection{Leaks in Joints and Seals}

Leaks between the fission gas and cesium spaces in the TFE were common, occuring in over half the TFE's tested. The thermionic performance of UC-ZrC fueled TFE's was adversely affected by leaks between the fission gas and interelectrode spaces, largely due to contamination of the collector surface by solid fuel and fission product components. The fission gas leaks generally did not affect the thermionic performance of $\mathrm{UO}_{2}$ fueled devices, but it did result in increased thermal conduction between emitter and collector, reducing the efficiency of the device. The presence of fission gas also served to slow the converters response to cesium reservoir pressure changes. Not infrequently cesium in the fission gas space would condense on relatively cold spots, resulting in cesium pressure variations during the test. Early experiences with this phenomena led to the additions of heaters in the lead region of the TFE to insure no such cold spots existed. Porting tubes between the fission gas space in the TFE and the fission gas traps were under development for use in later tests to prevent undue cesium loss in the event of such leaks. These ports were designed to keep fission gas pressure low and converter efficiencies high.

It is clear that additional joint development is required to obtain reliable long-life separation of cesium and fission gas. With oxide-fueled TFE's, however, such separation may well be unnecessary because the $\mathrm{O}_{2}$ released during fission oxidizes the volatile fission products to a non-volatile oxide that can be cold trapped in the fueled emitter cell. Thus the only gas or material leaking to the Cs space is $\mathrm{Kr}$ and $\mathrm{Xe}$. These gases can be swept out of the system without Cs loss. Further evaluation of the latter possibility is needed. 


\subsubsection{Special Tests}

The data base includes a number of special oxide-fueled tests discussed elsewhere in this report. They include the following:

1. IC-C13: This converter incorporated the only fuel hot snorkel vent tube tested. Unfortunately, the cell went open-circuit at 138 hours due to a bus bar break external to the converter. It was operated as a fuel capsule test until 3512 hours.

2. IC-D3: This converter was intentionally taken open-circuit to measure the effects of such a failure. Emitter temperatures were monitored with a thermocouple. This converter also incorporated a Cs-Gr integral reservoir.

3. IC-I6: I6 was operated stably until 3320 hours. Following a performance map, it was periodically cycled through $100 \mathrm{~K}$ emitter temperature changes until 6334 hours. Data from periodic neutron radiographs suggest a strong correlation between the temperature cycling and emitter distortion (thermal ratcheting).

4. IC-I4: This converter operated stably for 9754 hours with an emitter temperature of $1850 \mathrm{~K}$. It failed due to an envelope leak which permitted entry of the containment gas, helium. The fuel in I4 was vented to a charcoal trap which was instrumented to observe fission gas. The data suggested some continuous release of the fission gas during the first 2800 hours of testing. While gas bursts were observed during operation, they were not judged to be responsible for most of the venting. 
5. Fuel Capsules: Three fuel capsules were tested, FC-1, 2, and 3. Each had 3 failed "emitters" designed to operate at different temperatures. $\mathrm{FC}-1$ and $\mathrm{FC}-2$ showed very high anomolous fue? swelling and emitter distortion. They differed from TFE tests primarily due to the presence of a static He overpressure in the fuel cavity. The anomolous behavior has not been explained. FC-3 was operated only 1379 hours. 


\section{REFERENCES}

1. R. Pruschek, "Status Report on Reactor Development Activities in the FRG," 3rd Int. Conf. on Thermionic Electrical Power Generation, Juelich, Germany (June, 1972).

2. W. Haar, H. Holick, A. Jester, R. Krapf, and J. Herion, "Irradiation Experiment with a Triple Thermionic Diode," 3rd Int. Conf. on Thermionic Elec. Power Generation, Juelich (June, 1972).

3. W. Haar, H. Holick, A. Jester, and A. Minor, "State of Development of Diodes for In-core Thermionic Fuel Elements," 3rd Int. Conf. on Thermionic Elec. Power Generation, Juelich (June, 1972).

4. W. Haar, H. Holich, R. Krapf, and A. Minor," Long-Life In-Pile Testing of a Molybdenum Emitter Thermionic Converter," Thermionic Conversion Specialists Meeting, Eindhoven, Netherlands (September, 1975), and H. Grass, private communication (February, 1978).

5. B. Devin, "Status Report on Reactor Development Activities in France," 3rd Int. Conf. on Thermionic Elec. Power Generation, Juelich (June, 1972).

6. M. Clemot, B. Gayte, and J. Triplet, "Bilan de six annees d-essais de convertisseurs au laboratoire," 3rd Int. Conf. on Thermionic Elec. Power Generation, Juelich (June, 1972).

7. R. Lebourg, J. Bliaux, M. Clemot, and R. Marquer, "Synthese des essais et des examens post mortem de convertisseus irradies entre 200 et 5,000 heures," 3rd Int. Conf. on Thermionic Elec. Power Generation, Juelich (June, 1972).

8. Ned S. Rasor, "A Summary of USSR Thermionic Energy Conversion Activity," 13th Intersociety Energy Conversion Engineering Conf., San Diego (August, 1978).

9. G. M. Gryaznov, et a]., 4th Int. Conf. on the Peaceful Uses of Atomic Energy, Geneva, Switzerland, Paper No. 852 (1972).

10. V. A. Kuznetsov, et al., "Development and Construction of the Thermionic Nuclear Power Installation TOPAZ," Soviet Atomic Energy (USA) 36, 578 (1974).

11. V. A. Kuznetsov, "Operation of Thermionic Reactor-Converters TOPAZ-1 and TOPAZ-2," Proc. of the 3rd Int. Conf. on Thermionic Elec. Power Generation, Vol. 1, p. 365, Juelich (June, 1972).

12. V. A. Kuznetsov, et al., "Power Tests of the TOPAZ-3 Thermionic Reactor," Proc. of the 1975 Thermionic Conv. Spec. Meeting, Eindhoven, p. 137 (September, 1975). 
13. V. A. Kuznetsov, "The USSR Thermionic Energy Converters STatus and Prospects," presented at the meeting of the INEA International Liaison Group on Thermionic Electrical Power Generation, Eindhoven (September, 1975).

14. "Technical Information in Support of Thermionic Reactor Experiment Facility," GESR-2123 (February, 1970).

15. D. S. Beard, "Thermionic Fuel Element Development," 4th Intersociety Energy Conversion Engineering Conf., Washington, D.C. (September, 1969).

16. D. S. Beard, "The United States Thermionic Reactor Program," 3rd Int. Conf. on Thermionic Elec. Power Generation, Juelich (June, 1972).

17. "Development of a Thermionic Reactor Space Power Systems, Summary Report for Period July 1, 1971 - October 31, 1971," Gulf-GA-Al1061 (January, 1972).

18. "Development of a Thermionic Reactor Space Power Systems, Summary Report for Period November 1, 1971 - February 29, 1972," Gulf-GA-A11073 (July, 1972).

19. "Development of a Thermionic Reactor Space Power Systems, Final Summary Report," Gulf-GA A12608 (June 30, 1973).

20. "Thermionic Fuel Element Development, Volume I - E-Series," GACD-9553 (August 9, 1971).

21. G. Stapfer, "Thermionic Converter Life-Test Program," Thermionic Conv. Spec. Conf. (October, 1969).

22. G. I. Sanstad, J. C. Danko, and J. M. Case, "Performance of Cylindrical Converters with Preferred-Crystal-Orientation Emitters of Chemically Vapor Deposited Tungsten," NASA-CR-1898.

23. G. L. Hatch, L. Nakata, and E. J. Britt, "Low Cost Cylindrical Converter for Measuring Lead Efficiency," 14th Intersoc. Energy Conv. Eng. Conf. (August, 1979).

24. 1979 TECO Tests.

25. R. S. Dick, J. McVey, E. J. Britt and G. O. Fitzpatrick, "Collector Temperature Effects on the Performance of Advanced Thermionic Converters and Nuclear Electric Propulsion Systems," 15th Intersoc. Energy Conv. Eng. Conf., Seattle (August, 1980).

26. G. Stark, M. Saunders, and D. Lieb, "Thermionic Converter Output as a Function of Collector Temperature," 15th Intersoc. Energy Conv. Eng. Conf., Seattle (August, 1980).

27. D. Lieb and F. Rufeh, "Thermionic Performance of CVD Tungsten Emitters with Several Collector Materials," Thermionic Conv. Spec. Conf. (October, 1970). 
28. M. C. Wright, Compiler, "Performance Comparison for Several Variable Spacing Thermionic Converters," TE4150-62-72 (1972).

29. J. F. Morris, "Cesium-Diode Performances from the 1963-to-1971 Thermionic Conversion Specialist Conferences," NASA-TM-X-2589 (September, 1972).

30. M. K. Yates, G. 0. Fitzpatrick, and J. Kay, Jr., "Long-Term Operation of Out-of-Pile Thermionic Converters," Thermionic Conv. Spec. Conf. (October, 1970).

31. F. Rufeh, "Performance Improvement of Cesium Thermionic Converters by Addition of Oxygen," 7th Intersoc. Energy Conv. Eng. Conf., San Diego (September, 1972) and private communications.

32. J. W. Holland, "Thermionic Fuel Element Development Status Summary," 3rd Int. Conf. on Thermionic Elec. Power Generation," Juelich (June, 1972).

33. M. K. Yates, G. 0. Fitzpatrick, and D. E. Schwarzer, "Thermionic Fuel Element Testing at Gulf General Atomic," 3rd Int. Conf. on Thermionic Elec. Power Generation," Juelich (June, 1972).

34. J. W. Holland, M. K. Yates, D. E. Schwarzer, and J. Kay, "Long-Term Operations of In-Pile and Out-of-Pile Thermionic Converters," 2nd Int. Conf. on Thermicric Energy Conv., Stresa, Italy (1968).

35. K. Shimada, "Out-of-Core Evaluations of a Nonfueled and a UO,-Fueled Cylindrical Thermionic Converter," 1971 Thermionic Conv. Spec. Conf., San Diego (October, 1971).

36. "Development of a Thermionic Reactor Space Power System - Summary Report for Period July 1, 1972 - October 31, 1972," $\star \star \star \star \star \star$ Company?

37. H. Bahm, G. Kaspar, M. Peeks, H. Schorner, "Quality Inspection of Multi-layer Collector Systems," 3rd Int. Conf. on Thermionic Elec. Power Generation," Juelich (June, 1972).

38. J. Chin and C. W. Messick, "Thermal Stability Testing of an Electrically Loaded Sheath Insulator," Thermionic Conv. Spec. Conf., Carmel (October, 1969).

39. Quarterly Progress Report, LA-5113-PR (October, 1972).

40. G. M. Kikin and J. C. Danko, "High Power Electrical Breakdown Tests of Cracked-Insulator Sheaths with Liquid Metal Coolant," Thermionic Conv. Spec. Conf., Miami Beach (October, 1970).

41. G. O. Fitzpatrick, M. K. Yates, and J. Chin, "Electric Discharges in Cesium in the Sheath Region of Thermionic Fuel Elements," GACD-10316 (Apri1, 1971).

42. W. A. Ranken, T. G. Frank, and G. W. Keilholtz, "Effect of Fast Neutron Irradiation on Alumina and Yttria," 3rd Int. Conf. on Thermionic Elec. Power Generation, Juelich (June, 1972). 
43. G. 0. Fitzpatrick and M. K. Yates, "Cesium Sorption in Materials for Thermionic Converters," GA-8574, Vol. 1 \& 2 (April, 1970).

44. F. Imbert and A. M. Shroff, "Thermionic Integrated Cesium Reservoir Module," Thermionic Conv. Spec. Conf., Carmel (October, 1969).

45. I. G. Gverdtsiteli, A. G. Kalandarishvili, and V. K. Tskhakaya, "High Temperature Cesium Vapor Sources Based on a Cesium-Graphite System for Thermionic Converters," 3rd Int. Conf. on Thermionic Elec. Power Generation, Juelich (June, 1972). 


\subsection{FAILURE MODES AND EFFECTS SUMMARY}

Three primary problems can affect the performance of a TFE: slow performance degradation, short-circuits, and open circuits. In addition, there are two phenomena that can affect other reactor components; TFE bowing or distortion and TFE-to-coolant leaks. The previous section has described the experimental experience with most of these problems. Each is reviewed in summary below.

\subsection{Performance Degradation}

Slow performance losses by three processes typically occurred in TFE tests: contamination, partial short-circuits in cells or through insulators, and thermal losses due to fission gases in the interelectrode space. Emitter deformation or other phenomena affecting the size of the interelectrode space did not appear to adversely affect performance.

Electrode contamination during manufacture was largely eliminated in the previous program. The only significant source of such material was diffusion or leakage of UC-ZrC-W fuel components through the emitter clad or through leaks between fission gas and cesium spaces. A substantial effort was made to solve the carbide fuel contamination problem by very careful control of its stoichiometry and control of the crystal structure of the tungsten emitter. Steady progress was made but substantial performance losses due to this mechanism continued to occur after $\sim 4000$ hours of operation. The carbide fuel also reacted with and embrittled the tungsten, leading to emitter cracking in many cases. [Note: $\mathrm{UO}_{2}$-fueled devices showed no adverse contamination effects and exhibited evidence of beneficial oxygen additive effect.] The use of a Cs-Gr reservoir may also introduce a source of electrode contaminants. A more extensive review of the European data and further testing is needed to address this issue.

Thermal losses due to the presence of fission gas in the interelectrode space was a frequent problem. Constant emitter temperatures could be maintained in TFE tests when this occurred by suitabie adiustments of input power and current density. In a thermionic reactor operating at a constant 
thermal power level and output current such a leak would result in a drop in emitter temperature and output power, as shown in Fig. 6-1, assuming series TFE connection. However, at SP-100 lower current and power densities, 2.5 to $3 \mathrm{~W} / \mathrm{cm}^{2}$ and 5 to $6 \mathrm{~A} / \mathrm{cm}^{2}$, with larger .020" gap spacing, the losses due to inert gas thermal conduction will be less than those shown in Fig. 6.1. In the 1700 to $1800 \mathrm{~K}$ emitter temperature range of interest it may be possible to design for $\mathrm{Xe}$ and $\mathrm{Kr}$ venting through the cesium gap spaces with litter performance loss.

At point 1 in the figure the TFE is operating at the design point, $T_{E}=1700 \mathrm{~K}, J=8 \mathrm{~A} / \mathrm{cm}^{2}$, output power 700 watts. The input power to the TFE is assumed constant. As the thermal conductivity of the gas in the gap grows to $2 \times 10^{-4} \mathrm{~W} / \mathrm{cm}-\mathrm{K},(\mathrm{Kr})$ the output power falls to 200 watts (point 2) with $T_{E} \sim 1560 \mathrm{~K}$, a substantial loss. Point 3 represents another alternative. In that case the current density is reduced to $5 \mathrm{~A} / \mathrm{cm}^{2}, T_{E}$ increases slightly and the output power remains near 700 watts. This second procedure would not be followed in the case of an isolated fission gas leak in a single TFE. However, it would be very effective if all TFE's experienced the same problem, as in the Soviet TOPAZ design with a common cesium reservoir.

The electronic losses due to the presence of inert fission gas in the interelectrode space has been shown to be modest, amounting to only one millivolt per torr of gas.

As can be seen, the adverse effects of fission gas are very design dependent. The approach used in the U.S. TFE program was to pump the fission products with a charcoal trap sufficiently fast to minimize adverse effects in the case of a leak, yet limit the pumping speed with an in-line port tube to prevent excessive cesium loss in that same event. The Soviets directly dumped fission gas into the interelectrode space (a wet-cell design) and flushed them out with flowing cesium.

A third performance degradation mechanism arises from poor bonding in the collector sheath insulator. The effect is to raise the collector temperature with a consequent loss in output power. TFE 6FI suffered from this problem. Its sheath insulators used a solid alumina insulator. Later 


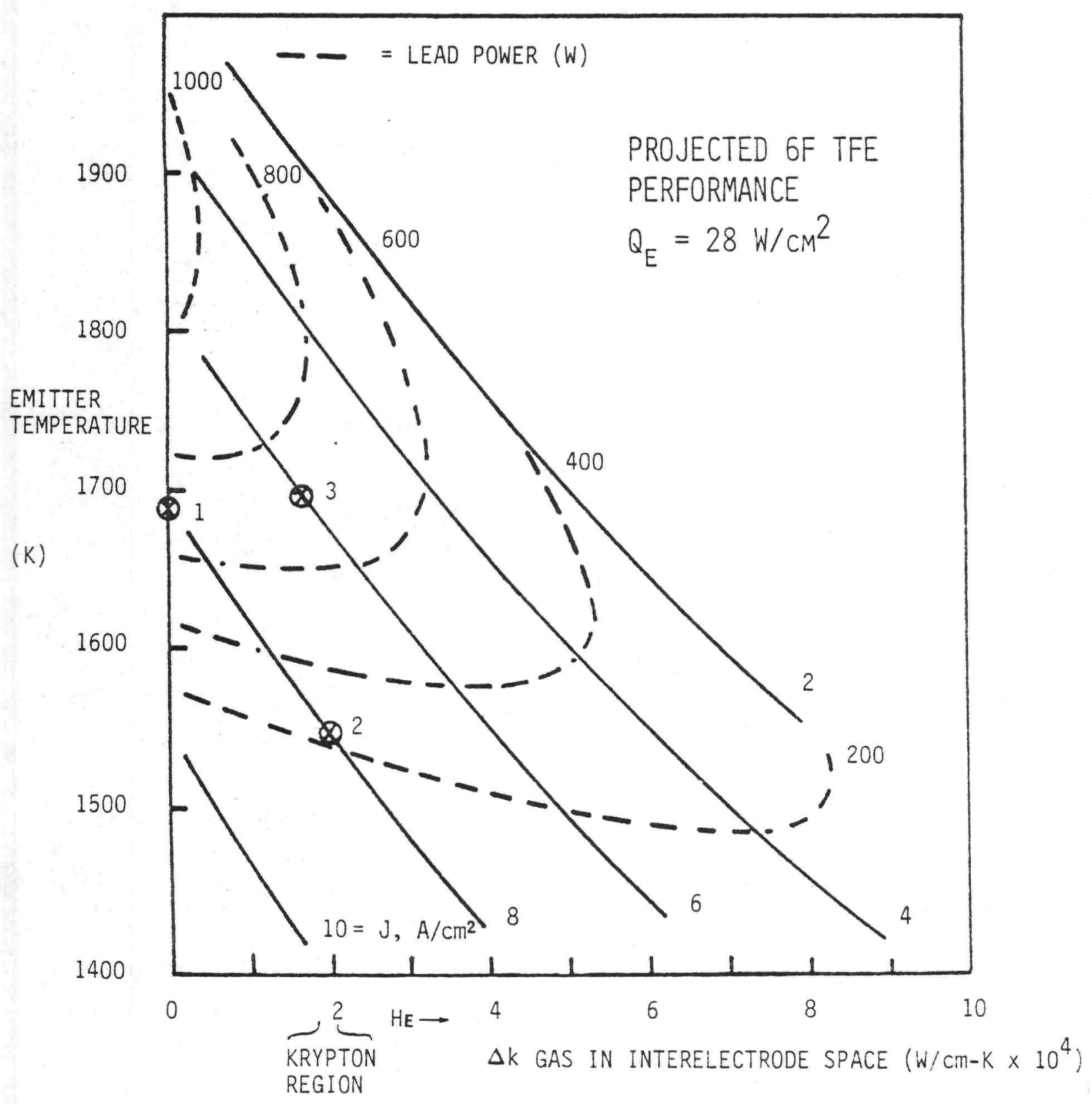

Fig. 6- 1 PROJECTED TFE PERFORMANCE WITH INTERELECTRODE GAS 
TFE tests with graded insulators did not appear to suffer this difficulty. A significant concern is a return of the problem as testing progresses due to fast neutron damage to the alumina. As described in section 5.0 , the use of yttria may provide a solution to this potential difficulty.

A fourth potential performance loss mechanism is low resistance or shorting of the sheath insulators or electrical discharges between surfaces of opposite polarity exposed to cesium. As described in section 5.0 , only 2 in 46 TFE sheath insulators tested showed evidence of such shorting, one following an emitter-collector short-circuit. However the operating voltages were low, below 5 volts.

It should be appreciated that an insulator resistance as low as $0.2 \Omega$ does not significantly reduce the output of a single TFE (a 15 ampere loss in current at 3 volts compared to 300 amperes total output). Rather the concern is for sheath tube damage, since high local power dissipation near the sheath raises the possibility of penetration. Tests performed in the presence of cesium at 10-15 volts showed no evidence of visible damage despite loss currents of $10+$ amperes. A test of a purposely cracked insulator in a sheath insulator geometry was performed [2]. The sheath tube was NaK-cooled, the crack was $20.2-1 \mathrm{mil}$ across. Breakdown voltages of $\sim 20-100$ volts were observed, with arc sustaining voltages of 12-16 volts. A 10-hour test with 900 watts in the discharge showed local melting on a ceramvar sheath tube, but no sheath failure. A 1100 watt discharge (14 volts) for approximately 20 minutes resulted in grain growth in a niobium sheath tube, but no sheath failure. In all cases the current-carrying capability of the discharge increased rapidly with voltage, encouraging the use of voltages below $\sim 15$ volts. In contrast, however, the Soviets have claimed successful operation to 35 volts despite the use of a wet-cell TFE design. More work is clearly needed to understand these losses and to develop further confidence in high performance coatings.

\subsubsection{Open Circuit}

Open circuit in a TFE can arise in two ways: loss of cesium, or loss of cesium electrode coverage, and a break in the current carrying portions of 
the structure. The latter was experienced in only one case, IC-C13, an in-pile cell which was suspended from its own copper bus bar. Early in the test of this device the bus bar crept and separated with the resultant open circuit. Avoiding this type of problem is largely a matter of good design.

The most common open circuit problem is a loss of cesium. The "envelope leak" failures referred to frequently as failures in early out-of-pile tests really ceased operation because of cesium loss. In the TFE such a loss requires either an envelope leak, never experienced in in-pile TFE testing, or a leak between cesium and fission gas spaces which results in cesium transport to the fission gas trap. Two measures are taken to avoid this loss; the use of a port tube to limit the traps pumping speed and the provision of a large supply of cesium ( $<0.1$ gram is required by the TFE).

A second form of "cesium-1oss" can occur if the cesium pressure is not maintained sufficiently high. As shown in Fig. 6-2, under fixed output voltage conditions and with an increasing input power it is possible to suddenly realize a loss in output current and a rapid raise in emitter temperature. No TFE's tested in-pile suffered this phenomenon and it can be avoided by proper design and quality control.

The final cause of a cesium loss is a liquid cesium reservoir heater malfunction which results in a lower temperature and pressure. Proper design of the reservoir, whether liquid or integral, so that its design operating temperature is not controlled electrically but is established by the temperature of the emitter in the TFE and the reactor coolant can serve to reduce the probability of such an open circuit.

The final question of course, is the adverse impact of an open circuit. The in-pile $\mathrm{UO}_{2}$ fueled cell IC-D3 was purposely taken open circuit under high load conditions to answer this question. The principal data are shown in Fig. 6-3. As can be seen the converter had emitter thermocouple which could be correlated with other techniques for estimating emitter temperature. The converter was operated for 280 hours at $9 \mathrm{~A} / \mathrm{cm}^{2}$ (a high input power) with an emitter temperature of $1650 \mathrm{~K}$ (thermocouple $1900 \mathrm{~K}$ ) and a collector temperature of $1000 \mathrm{~K}$. The converter was then taken open circuit and the 


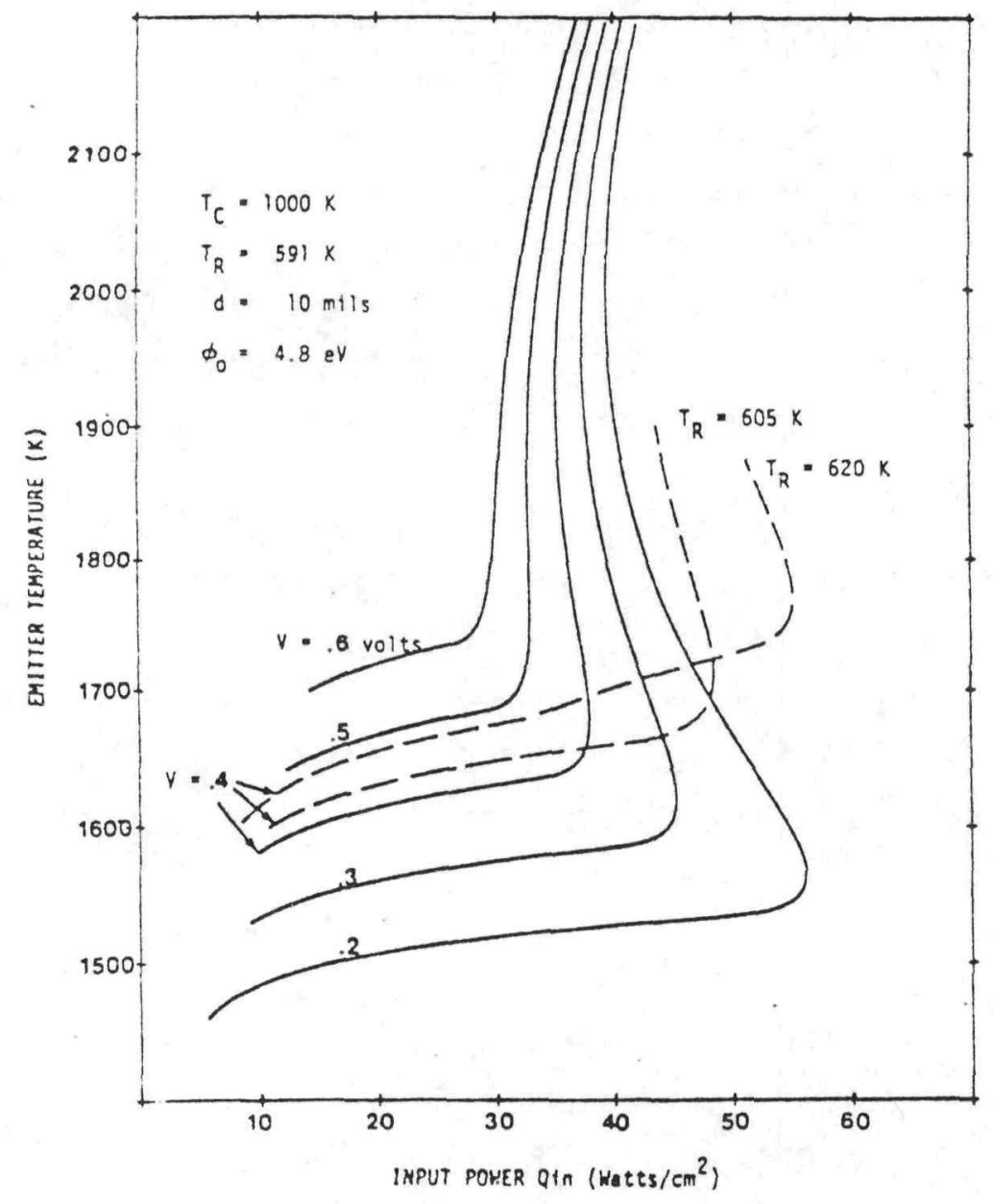

Fig. 6-2 OPEN CIRCUIT BEHAVIOR DUE TO CESIUM DESORPTION 

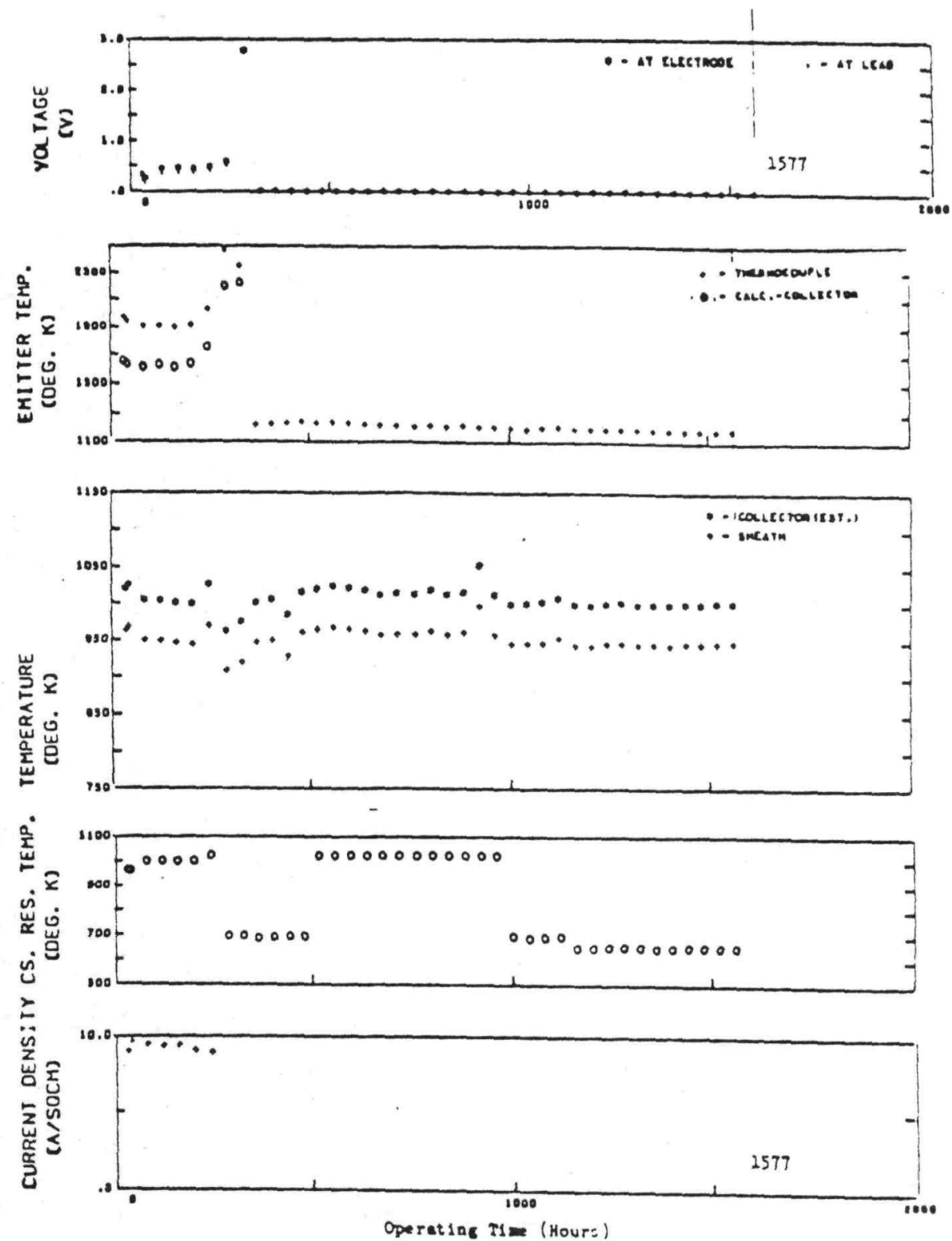

Fig. 6-3 OPEN CIRCUIT BEHAVIOR OF IC-D3 
cesium reservoir temperature reduced to maximize the emitter temperature rise. The emitter temperature went up to $22300 \mathrm{~K}$ (thermocouple $2450 \mathrm{~K}$ ). The collector temperature dropped slightly because of increased radiation losses out the top of the emitter. Fifty-seven hours after open circuit the emitter shorted to the collector and its temperature dropped to $\sim 1200 \mathrm{~K}$. The collector temperature returned to normal. Post-neutron radiographs confirmed swelling of the emitter as the source of the short and cooling. It should be noted that there was about one atmosphere of helium over the fuel.

This test confirmed the relatively benign effect of an open circuit. Other than a temporary inability to pass current, no evidence of other problems (collector distortion, fuel escape, etc.) which could propogate failures were observed. The relatively high output voltage of the open circuit converter must be recognized but it can drive very little current under such conditions.

\subsubsection{Short Circuit}

Short circuits, particularly between the emitter and collector, were the most common form of failure in oxide fueled TFE's. These normally result in emitter cooling (as described above), a small raise in collector temperature, and no other observable phenomenon. If interconnected in a large array of converters such a short could carry a substantial total current, and proper design of parallel interlinks may be wise to limit such currents.

Normally, however, a short circuit is in reality only a low resistance, and a converter will continue to generate some power. Fig. 6-4 illustrates the effect of a short circuit in the oxide fueled TFE-1F1 after 8000 hours of stable operation.

\subsubsection{TFE-to-Coolant Leaks}

The liquid metal coolant in the reactor core can potentially penetrate the TFE sheath tube, enters the fission gas space and then the cesium space. Evidence of sheath tube cracking in hydride moderated reactor tests encourage the examination of this possibility. However, the primary source of the 


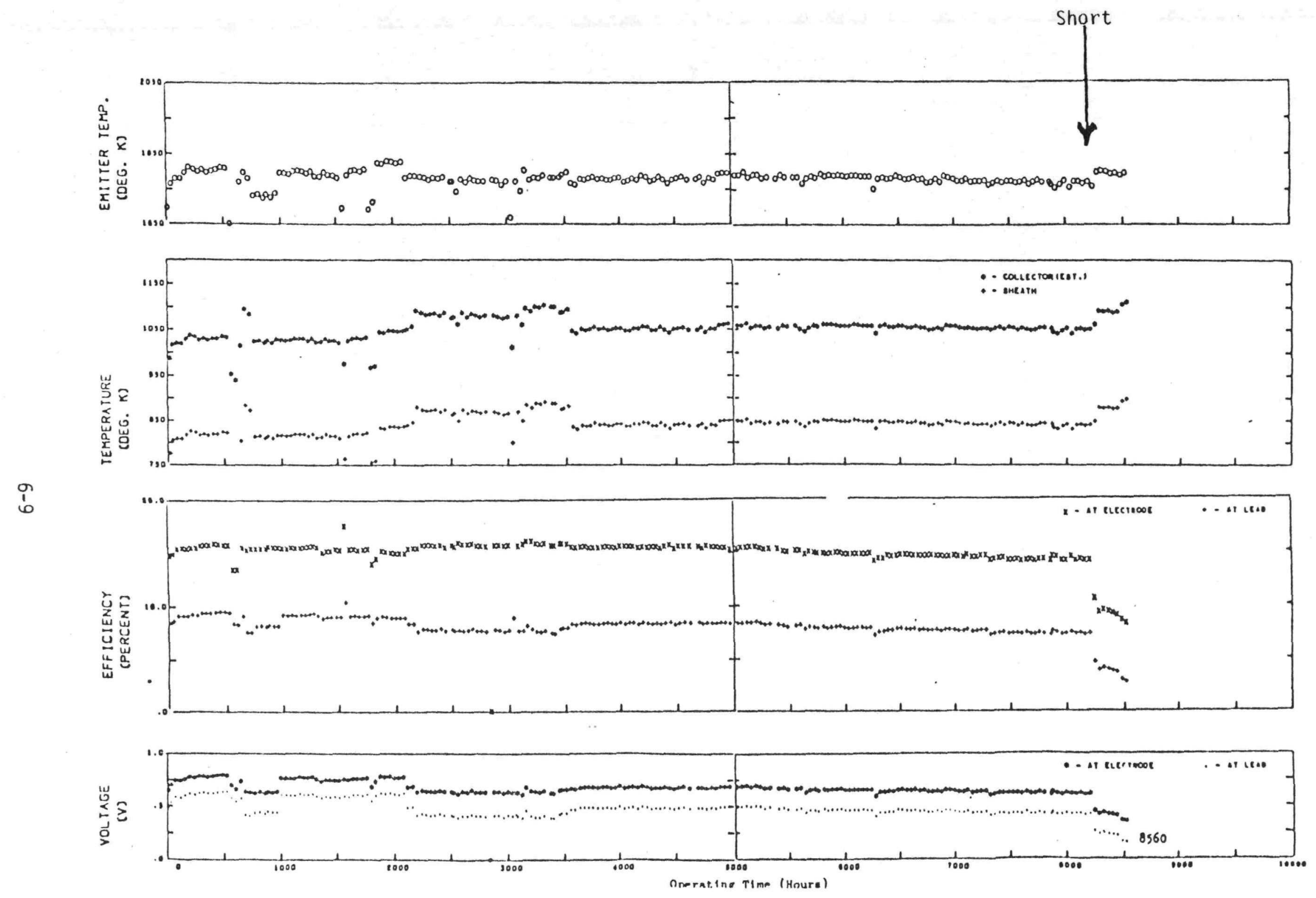

Fig. 6-4 THE EFFECTS OF A SHORT CIRCUIT TFE 1F1 
problem in conventional fuel rod designs, fuel clad interactions, is greatly ameliorated in the TFE by the mechanical isolation of the fuel in a thick, high temperature tungsten cladding. This fuel-emitter structure is then separated by 10-20 mils from the TFE sheath tube. The sheath in the vicinity of the fueled emitter in fact is comprised of the combined sheath tube and trilayer structure a refractory metal structure totaling almost $100 \mathrm{mils}$ in thickness. Following any emitter deformation sufficient to contact the collector the emitter temperature will fall, and the total "sheath" thickness will be 140-180 mils, a very strong sheath indeed compared to conventional fuel pin design of only 15 to $20 \mathrm{mils}$ of stainless steel cladding protection.

The intercell regions of the TFE are sheathed with a tube of more conventional thickness. In those regions, however, there is little possibility of fuel-sheath problems. In these regions care must be taken to avoid mechanical and thermal stress related tube failure due to temperature cycling. This problem is unlikely to be significant. In-pile test to date have shown no evidence of such failures, and they have experienced far more large temperature cycles than those anticipated in space power systems. Care must be taken in the design, however, to insure that such phenomena as fission gas vent plugging do not cause high pressures to build up in the TFE with a resulting sheath tube failure.

Finally, care must be taken to insure that the TFE is qualified to withstand the voltages which may occur in off-design operating conditions. Data to date show that TFE's can be qualified at designs operating voltages near 10 volts. Further work will be required to confirm this capability at higher voltages. 


\subsection{FUEL-EMITTER DEFORMATION}

\subsection{Identification of Potential Causes of Deformation}

During the in-core testing program previously performed at General Atomic, some thermionic emitter deformation was observed. In some cases the deformation was significant enough to cause the emitter to short-circuit the diode.

Three potential mechanisms leading to the observed emitter deformation have been advanced: thermal ratcheting; fission gas pressure buildup (bladder); and $\mathrm{UO}_{2}$ fuel swelling.

Thermal ratcheting occurs because $\mathrm{UO}_{2}$ has a higher expansion coefficient than that of tungsten $(W)$, i.e., approximately $1 \%$ differential at operating temperature (see Fig. 7-1). An undersized $\mathrm{UO}_{2}$ fuel pellet is introduced into the $W$ emitter structure such that it does not excessively contact the cladding upon initial startup. At fuel temperatures encountered within the emitter, $\mathrm{UO}_{2}$ vaporization readily occurs. This vaporization process will fill any radial gap remaining during initial startup between the fuel and cladding (see Fig. 7-2).

If at a later time, the power level and temperature of the thermionic fuel element is decreased, the fuel will tend to pull away from the emitter surface because of it.s higher expansion coefficient creating an annular gap. With an annular gap exisitng between the fuel and cladding, (approximately $0.5 \mathrm{mil}$ on radius/100 $\mathrm{K}$ in SP-100 fuel) evaporation of the relatively hot fuel occurs and the gap is eventually closed (see Fig. 7-3). When the fuel element is subsequently brought back up to temperature, the emitter is pushed outward resulting in plastic deformation in the cladding shell (see Fig. 7-3). Twenty to forty such temperature cycles could result in accumulated plastic deformation such as to short-circuit the $20 \mathrm{mil}$ gap, SP-100 emitter to the collector body. Question: will several hundred $10 \mathrm{~K}$ thermal oscillations create the same effect? This answer can be provided with analysis if the elastic properties of the emitter at temperature are known. 


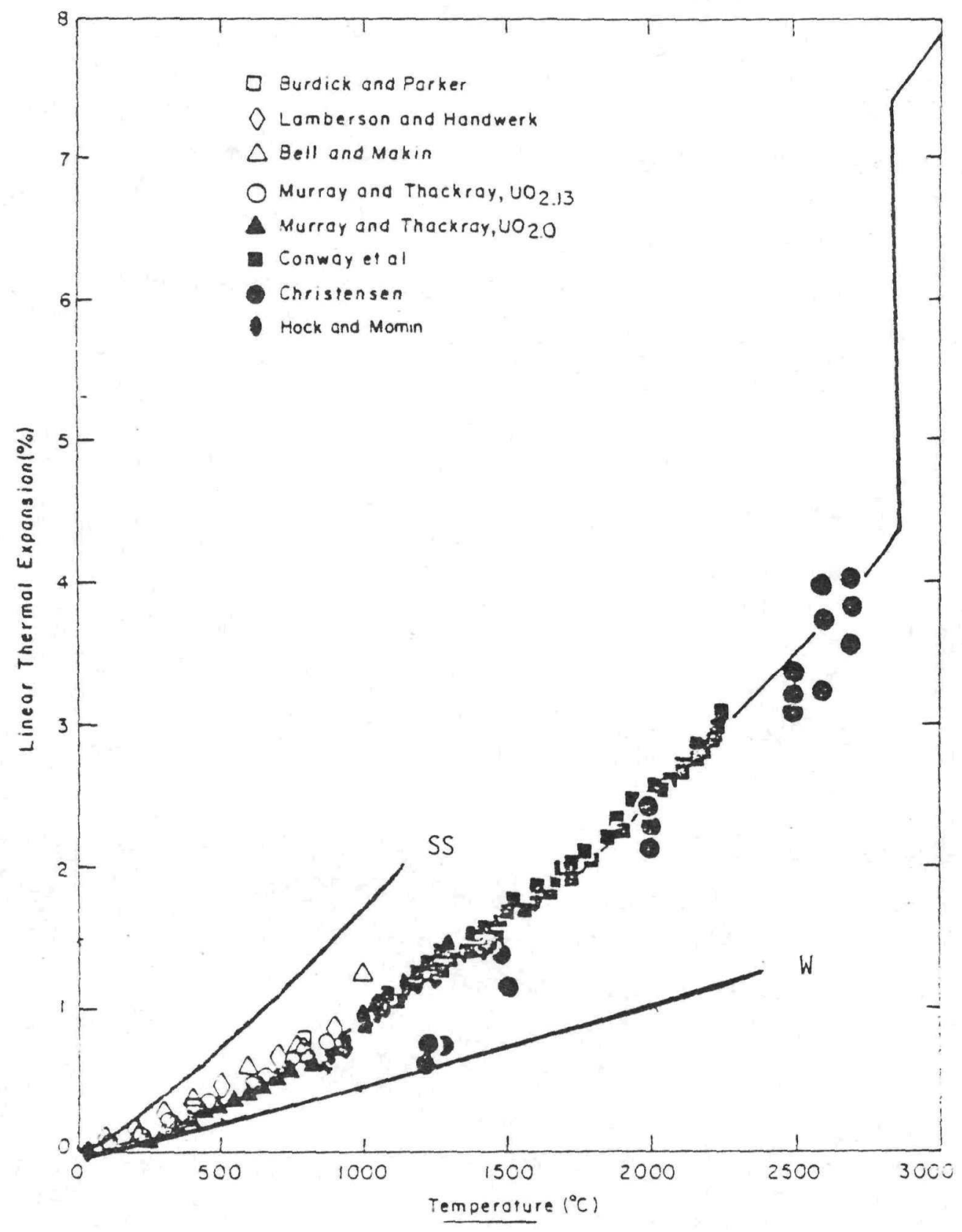

Fig. 7-1 Thermal Expansion Data 


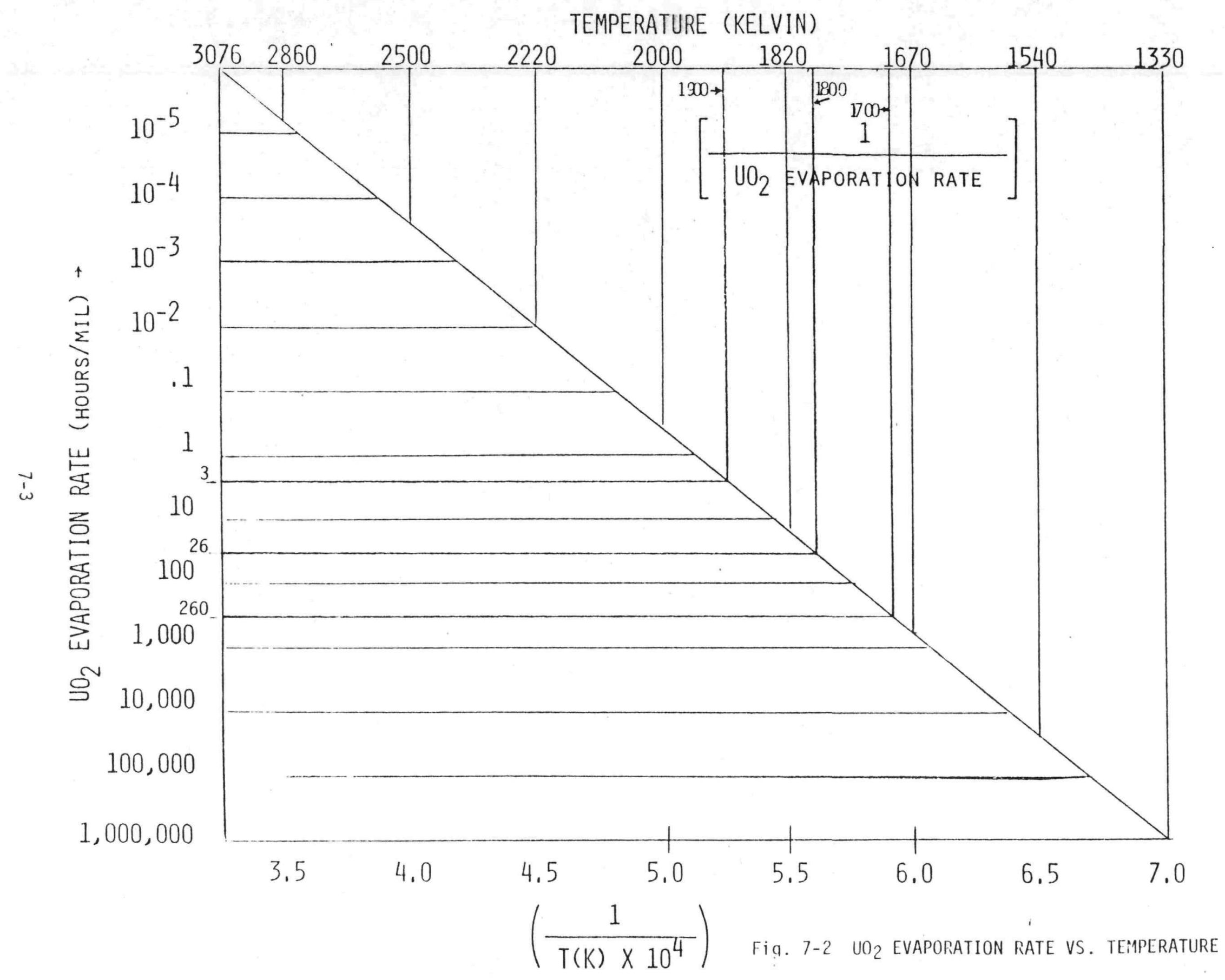




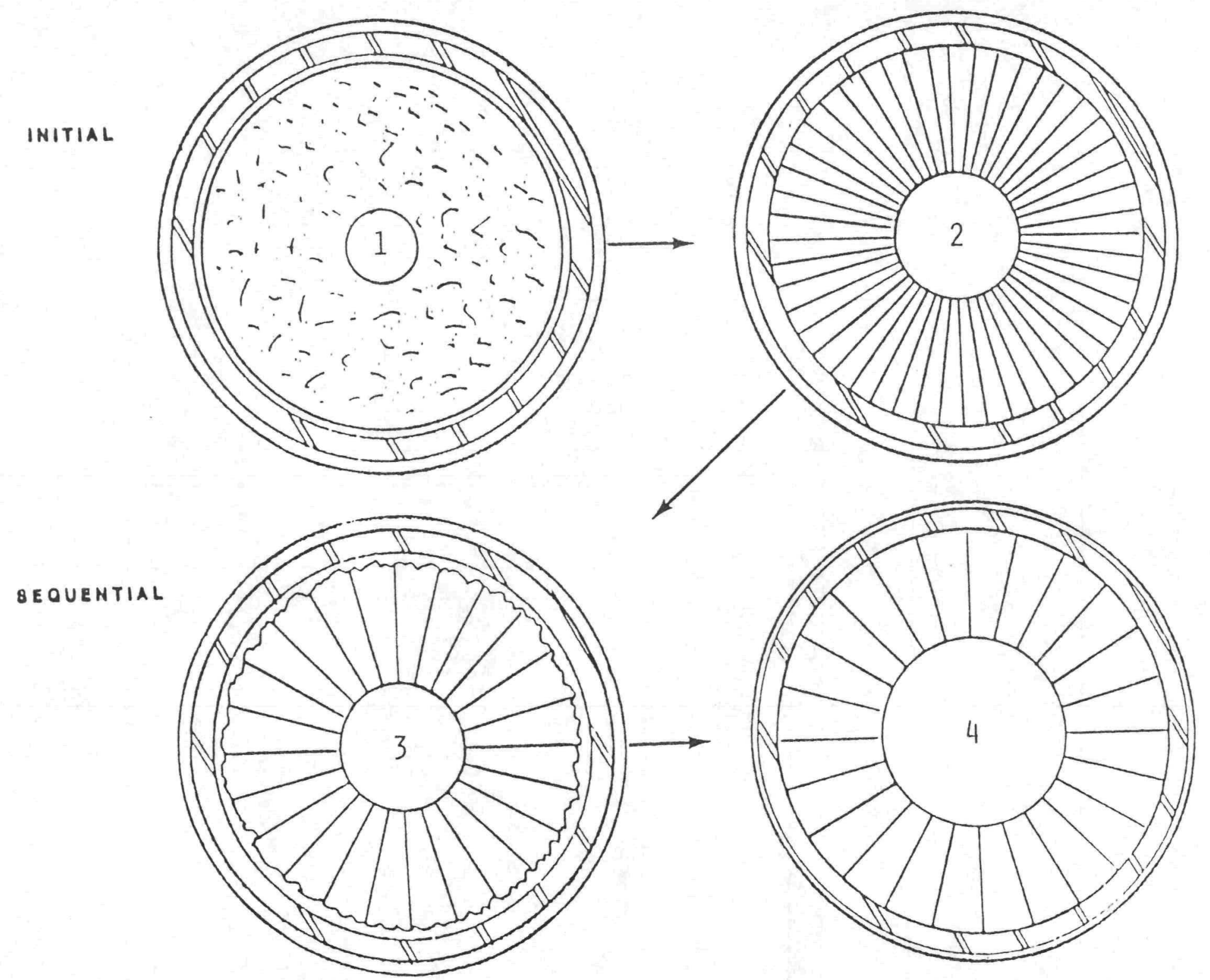

Fig. 7-3 THERMAL RATCHET 
The second deformation mechanism, the bladder effect, is concerned with the release of fission gas within the $\mathrm{UO}_{2}$ fuel. When typically $94 \%$ dense pressed powder $\mathrm{UO}_{2}$ fuel is heated to operating temperatures under a thermal gradient the fuel redistributes due to vaporization and condensation to form a dense (typically 98\%) outer shell and a large internal void (see Fig. 7-4, 7-5, and 7-6). Due to neutron bombardment, certain gaseous by-products are created and released from the $\mathrm{UO}_{2}$ fuel over the system lifetime. Because of the radial temperature gradient in the fuel, these fission gases migrate inward and collect in the central void formed within the fuel. Over time, these gases lead to a pressure buildup in the central void. This pressure is structuraliy resisted by the strength of the $\mathrm{UO}_{2}$ fuel and the $\mathrm{W}$ cladding. Because of the low creep strength of both $\mathrm{UO}_{2}$ and $\mathrm{W}$ at operating temperatures, low central void pressure of less than 100 psi could force the fuel and cladding outward over time. This bladder effect deformation, due to internal pressure buildup from imperfect venting, might lead to emitter/collector shorting during system life.

The third effect of concern, fuel swelling $(\Delta V / V$ decrease in fuel density), is due to fission-induced swelling of the $\mathrm{UO}_{2}$ fuel within the cladding. Both solid and gaseous fission products are accumulated in the fuel due to uranium fissioning. These fission products decrease the fuel density and the subsequent volume increase may press the cladding outward, 20 mils to short-circuit the emitter/collector.

\subsection{Summary of Gas Release and Fuel Microswelling Research and Analys is}

A fundamental part in the understanding of (and prevention against) potential failure mechanisms of thermionic fuel elements due to distortion induced emitter-collector shorting is the assessment of the potential severity of fuel swelling. This area has received a vast amount of both experimental and theoretical attention, and this section will only highlight some of the key investigations and access their impact on the SP-100 project. It would be beyond the scope of this report to discuss all of the work done in this area and certainiy some important investigations will not be dicussed here. However, it is felt that the experiments and models discussed in this section provide a good representative sample of the work which has been done 


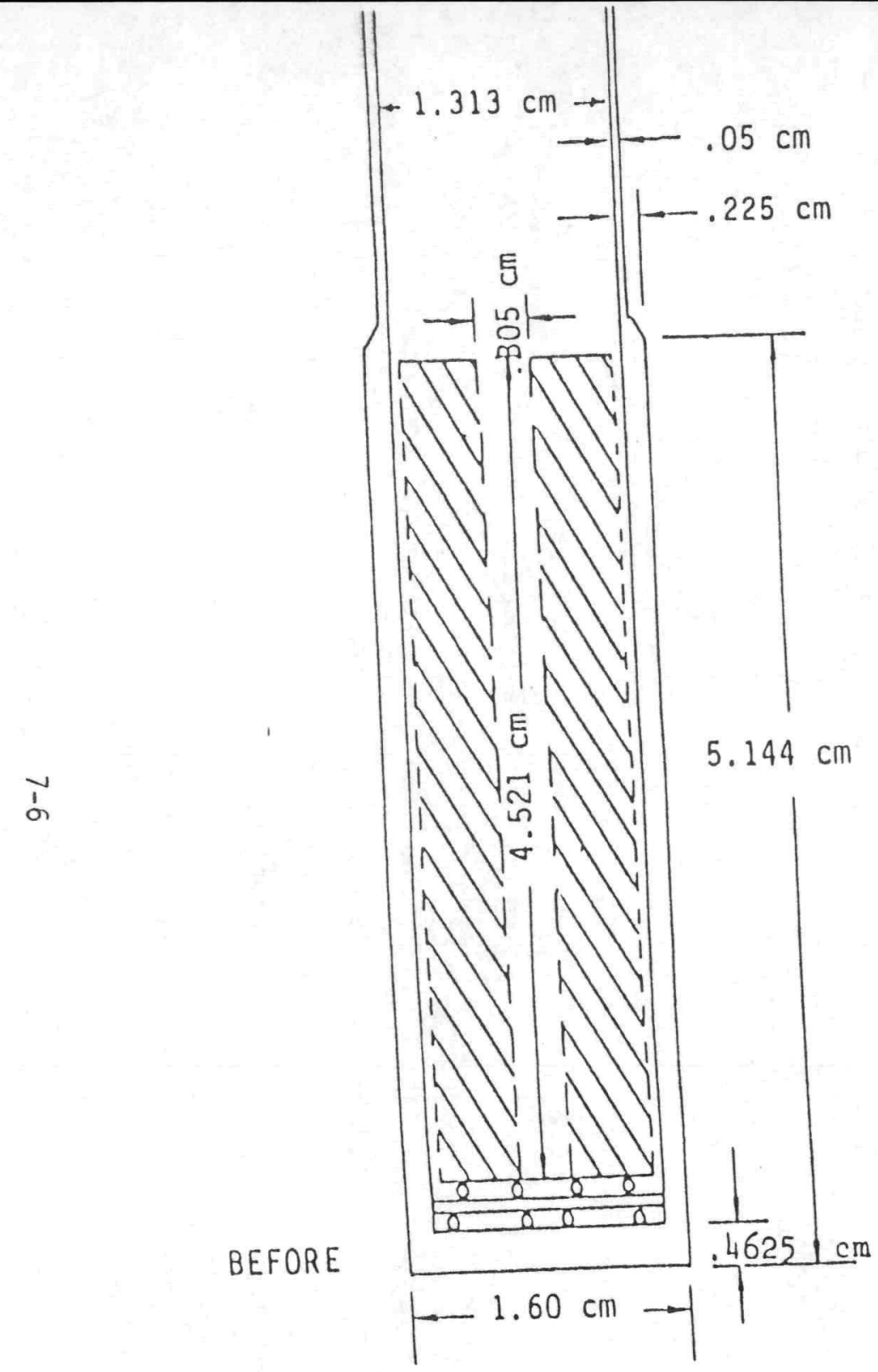

FUEL VOLUME: $\quad 5.788 \mathrm{~cm}^{3}$

TOTAL FUEL ELEMENT INCREASE AFTER EXPOSURE $=18 \%$

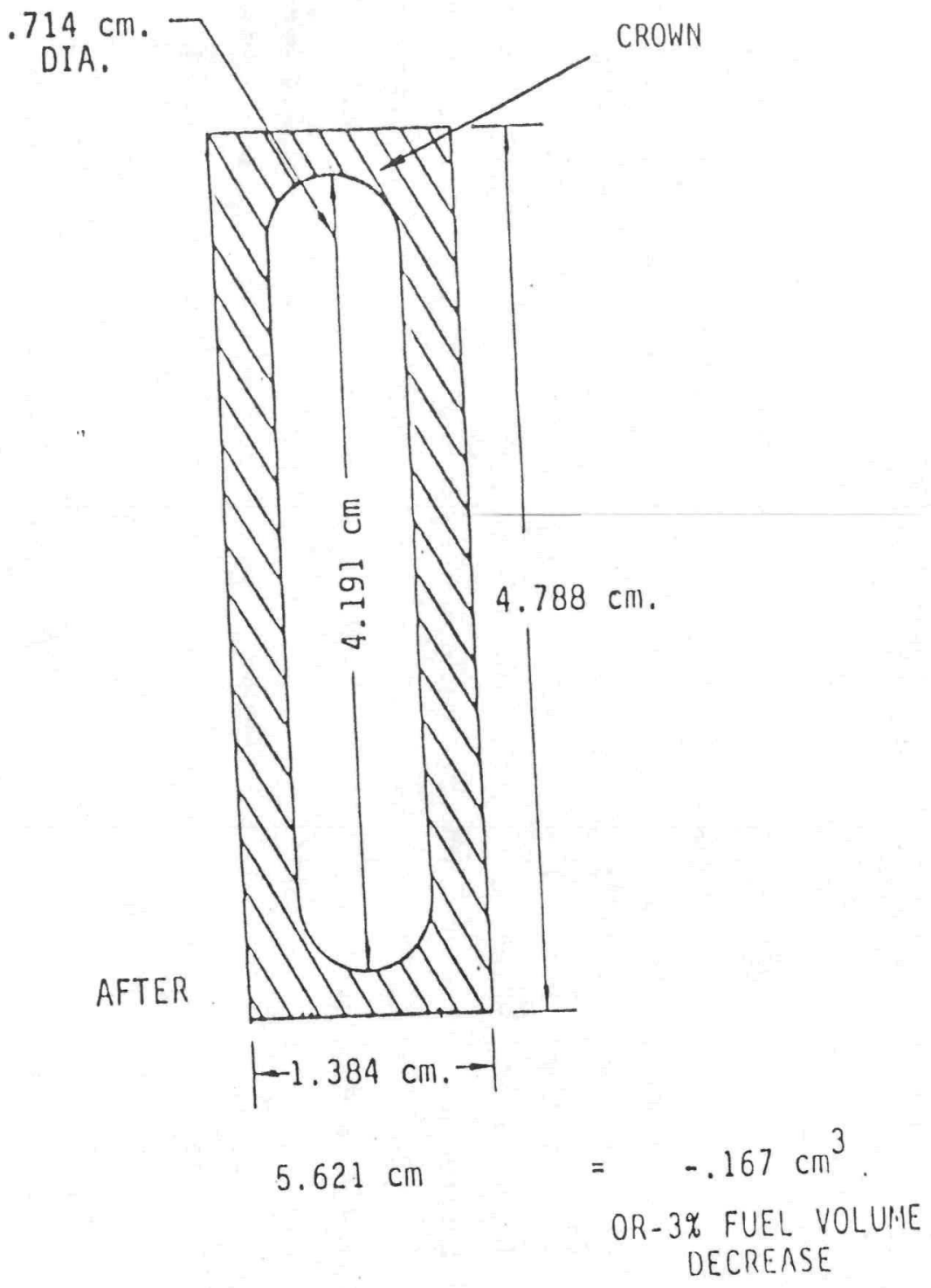

Fig. 7-4 FUEL RESTRUCTURING 


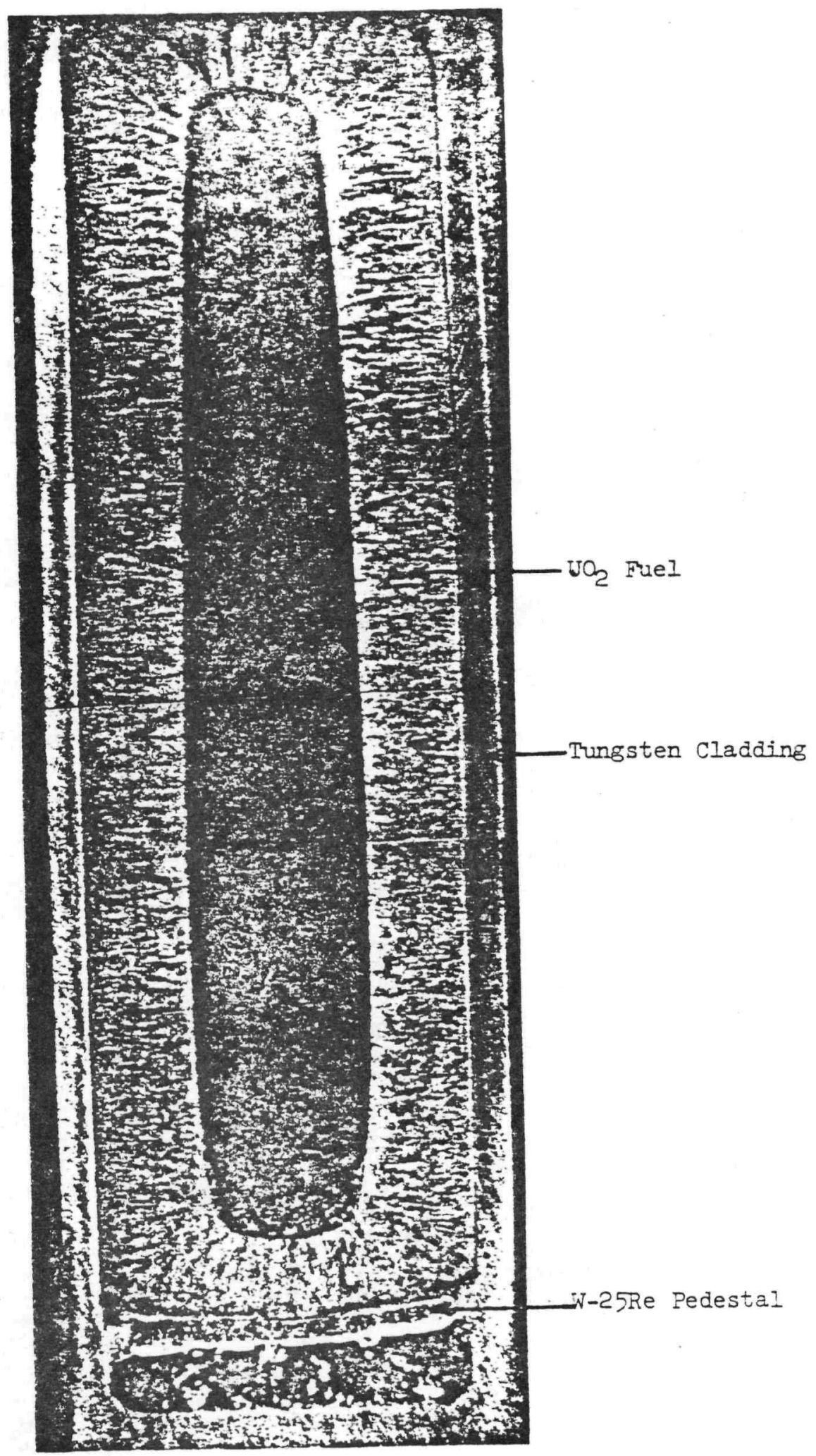

Fig. 7-5 Longitudinal cross section of upper emitter of $2 E 1(4.5 X)$ 


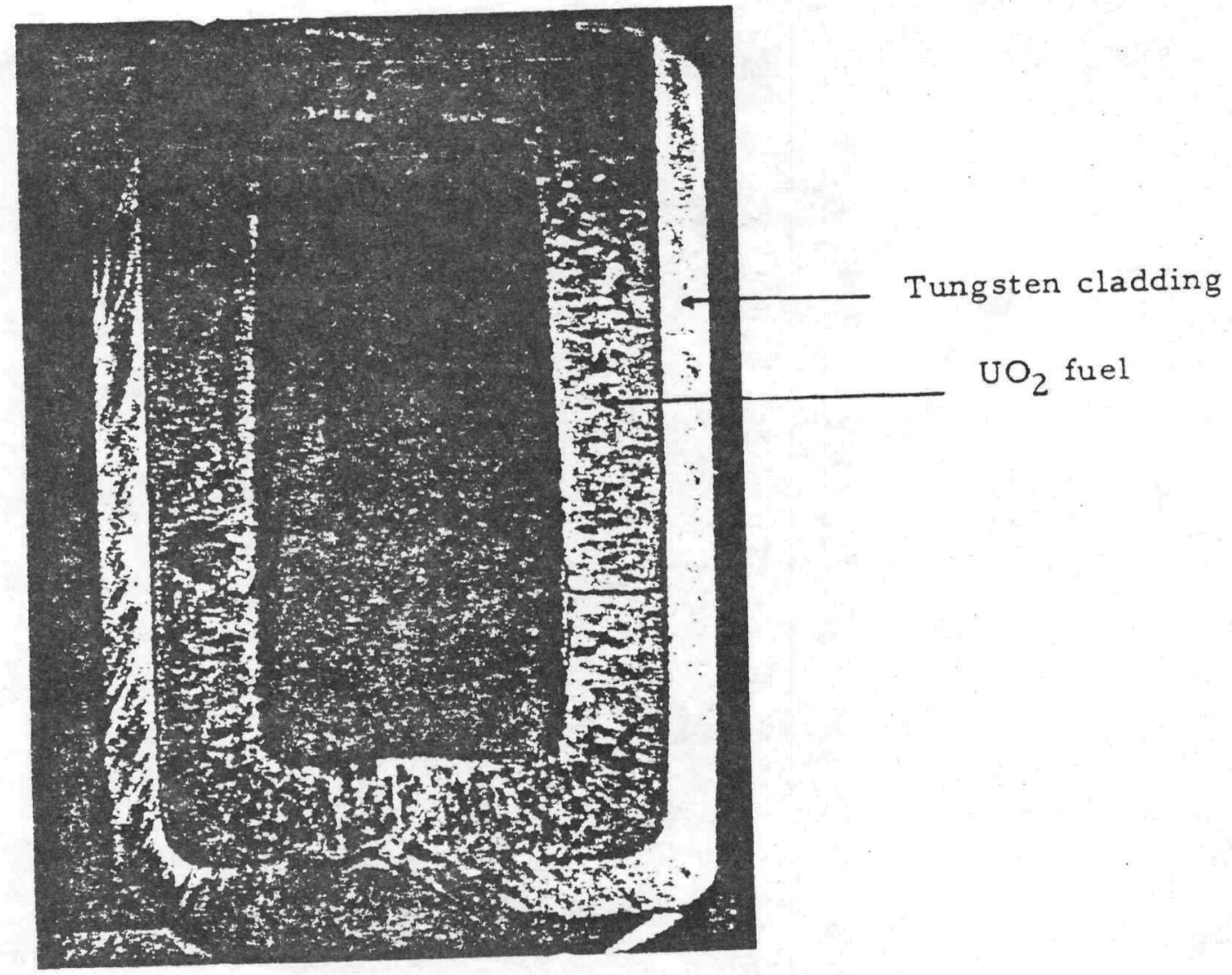

Fig. 7-6 Longitudinal section of $\mathrm{UO}_{2}$ fueled $\mathrm{I}_{4}$ fluoride tungsten emitter ( $5 / 8$ inch diameter, 50 mil thickness) irradiated at $18400 \mathrm{~K}$ for 9754 hours to $3 \times 10^{20}$ fission $/ \mathrm{cm}^{3}$ 
and conclusions which have been drawn. This section will discuss primarily the effects, magnitude and mechanisms of fission gas swelling; gas release, as it effects swelling and solid fission product induced swelling. Thermalmechanical failure mechanisms such as fission gas pressure buildup due to a bladder effect, thermal ratcheting and the effect of swelling on the overall fuel distortion will be discussed in section 7.5 .

Fuel swelling can be considered as arising from two distinct parts: 1) swelling due to gaseous fission products, e.g., xenon and krypton and 2) swelling due to solid fission products, e.g., everthing else (selenium to gadolinium). The swelling due to solid fission products differs for $\mathrm{UO}_{2}$ and $\mathrm{PuO}_{2}$. For $\mathrm{UO}_{2}$ fuel, Dollins and Nichols [1] estimate the solid swelling at $.4 \% / \%$ atom burnup, Zimmermann [2] estimates it to be $0.65 \% / \%$ atom burnup, and MATPRO-Version-11 [3] estimates it to be $0.5 \% / \%$ atom burnup, which is the same value which Zimmermann [4] estimates for mixed oxide fuels. Frost [5], however estimates the mixed oxide value to be $0.7 \% / \%$ atom burnup. For $S P-100$ ( $2 \%$ burnup) in a 1" diameter emitter, these would imply a solid swelling rate which would range between $0.8 \%-1.4 \%$ which by itself could not create more than a $.002 "$ radial deformation.

The potentially more serious problem may be due to gaseous fission products. It is in this area however that there is a large amount of what appears to be conflicting data and models. One of the major contributions to the confusion in this area is the lack of a universal meaning of swelling. Many investigators report external volume changes which may not be due uniquely to fuel swelling; they may in fact result from a variety of mechanisms, e.g., they could be in part the result of thermal ratcheting or gas pressure induced creep, etc. Thus, the conditions under which the experiments were performed must be carefully considered when interpreting external volume change measurements.

Barnes and Masey [6] developed one of the early models of inert gas bubbles in metals (He in $\mathrm{Cu}$ ). They found that the inert gas did not dissolve even at high temperature, all bubbles migrate in the same general direction, possibly along a temperature gradient, that the bubbles could become anchored, and coalescence of bubbles increased the overall volume of the 
metal. Many of these early mechanisms were also found to apply to fission gas bubbles in nuclear fuels $\left(\mathrm{UO}_{2}\right)$. Barnes and Masey also suggested that for He bubbles in $\mathrm{UO}_{2}$, the diffusion mechanism along a temperature gradient might be via vapor transport from the leading to the trailing edge of the bubble. Barnes [7] then proposed that as for He in Cu surface diffusion might be the dominant mechanism for the motion of inert gas bubbles in $\mathrm{UO}_{2}$. Speight then compared the importance of these two mechanisms, surface diffusion and vapor phase deposition and pointed out that for small bubbles surface diffusion will dominate and for larger bubbles vapor-phase transport will dominate. A review of much of this early work is given in Frost [9]. A vast amount of work on identifying the mechanisms of fuel swelling and gas release was carried out during the 1970's and is still ongoing today. Of this work, there have been two detailed investigations on fuel swelling and gas release of $\mathrm{UO}_{2}$ and mixed oxide fuels. These two sets of investigations will be discussed in detail below.

One of the earlier detailed experimental studies of $\mathrm{UO}_{2}$ fuel behavior was done by the group at Battelle [10-15] in the early 1970's. The tests were performed at low burnup $(<1 \%)$ but very high fission rates $\left(1.2-1.7 \times 10^{13}\right.$ $\mathrm{f} / \mathrm{cm}^{3} \mathrm{sec}$ vs. $2 \times 10^{12} \mathrm{f} / \mathrm{cm}^{3} \mathrm{sec}$ for $\left.\mathrm{SP}-100\right)$. The temperature gradient across the samples were about $100^{\circ} \mathrm{C} / \mathrm{mm}$ and the power levels ranged between $80-120$ $W / \mathrm{cm}$. They observed that the fuel restructured into columnar grains at temperatures above $1650^{\circ} \mathrm{C}$. The mechanism proposed which caused this restructuring was lenticular void sweeping, which removed most, if not all of the circumferentially oriented grain boundaries. Once columnar grains were formed they felt that bubble formation (resulting in density decrease and swelling) followed by bubble migration via vapor transport (lenticular void sweeping and redensification) still occurred. This mechanism would then lead to the outer part of the fuel moving out and the central void growing which they observed for temperatures $>1475^{\circ} \mathrm{C}$ (this however is the same net effect as thermal ratcheting, discussed in section 7.5$)$. They reported very large swelling rates. However, the high swelling rates which were reported were only external volume changes and may not have been due entirely to fission gas swelling, but also to thermomechanicaliy induced mechanisms. It should also be noted that the reported temperatures were external clad temperatures not fuel temperatures. The exterior fuel temperatures may have been as much 
as $125 \mathrm{~K}$ hotter than the reported temperature. (A sample of the reported swelling rate is shown in Fig. 7-7.) Also for high fission rates it is possible that gas could be generated faster than it could escape. In the more recent work once again only diametral changes are reported, and a large temperature dependence is found for the observed diametral swelling. Once again, this could be the sum of many effects beside fuel swelling, as is the case where samples were subjected to varying temperatures during the course of the testing.

A more recent extensive series of investigations on the swelling and gas release behavior of both $\mathrm{UO}_{2}$ and mixed oxide fuels has been reported by Zimmermann $[2,4]$. These tests looked at the behavior of both constrained and unconstrained fuel samples. Although many of the reported tests were in the SP-100 operating temperature range, the fission rates considered were again one to two orders of magnitude higher than those of SP-100. Also as a tool for predicting SP-100 fuel behavior the restrained results probably provide the best estimates of the swelling to be expected in a thermioni fuel element.

In the $\mathrm{UO}_{2}$ fuel studies [2] Zimmermann considered high density samples (98.2\% for unrestrained and $96.7 \%$ for restrained samples) which were irradiated in the reactor FR2 at Karlsruhe. The operating conditions of the tests are listed in Table 7-1. Zimmermann finds an investigated swelling rate ranging from $1.2 \%$ per U \% burnup at $1250 \mathrm{~K}$ to approximately $20 \%$ per U \% burnup at $2000 \mathrm{~K}$ at the beginning of the irradiation. For all temperatures, at low and medium burnup the swelling increased linearly with burnup. At higher burnups the swelling rate diminishes (this gas saturation effect occurs sooner for higher temperatures). The fission gas swelling was found to saturate at 5 vol \% for temperatures up to $1250 \mathrm{~K}$ and at $2000 \mathrm{~K}$ the swelling rate was found to decrease even at burnups below $1 \%$. These rates were based on an assumed solid fission product swelling rate of $0.65 \%$ per $\%$ burnup. These unrestrained swelling rules are shown as a function of temperature in Fig. $7-8$ for $1 \%, 2 \%$ and $4 \%$ burnup. 


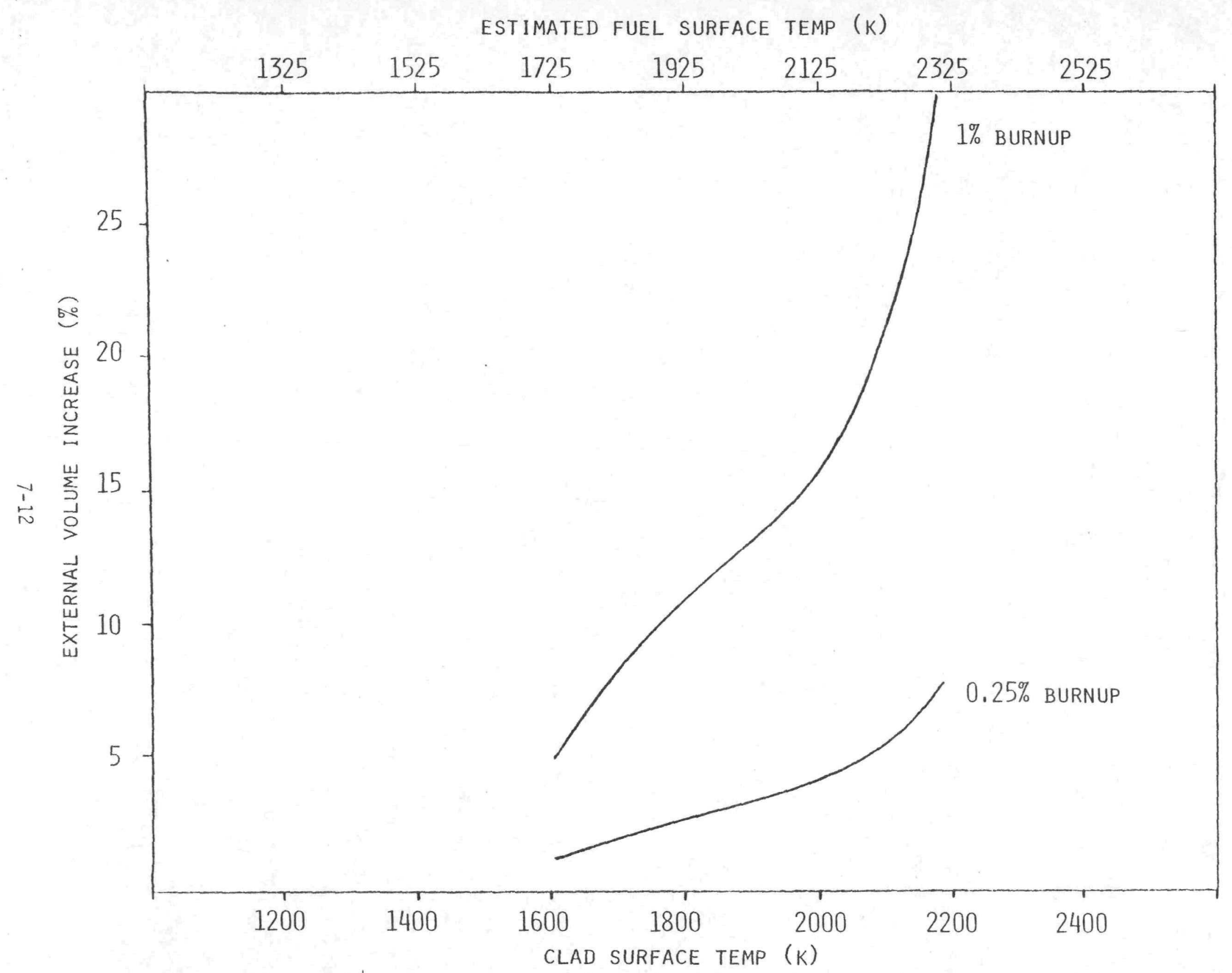

Fig. 7-7 The External Volume Increase as Observed by Chubb et. al. for $\mathrm{UO}_{2}$ Fuel is Shown as a Function of Clad Surface Temperature. Also Shown is the Estimated Fuel Surface Temperature $2125 \mathrm{~K}$ Higher. 


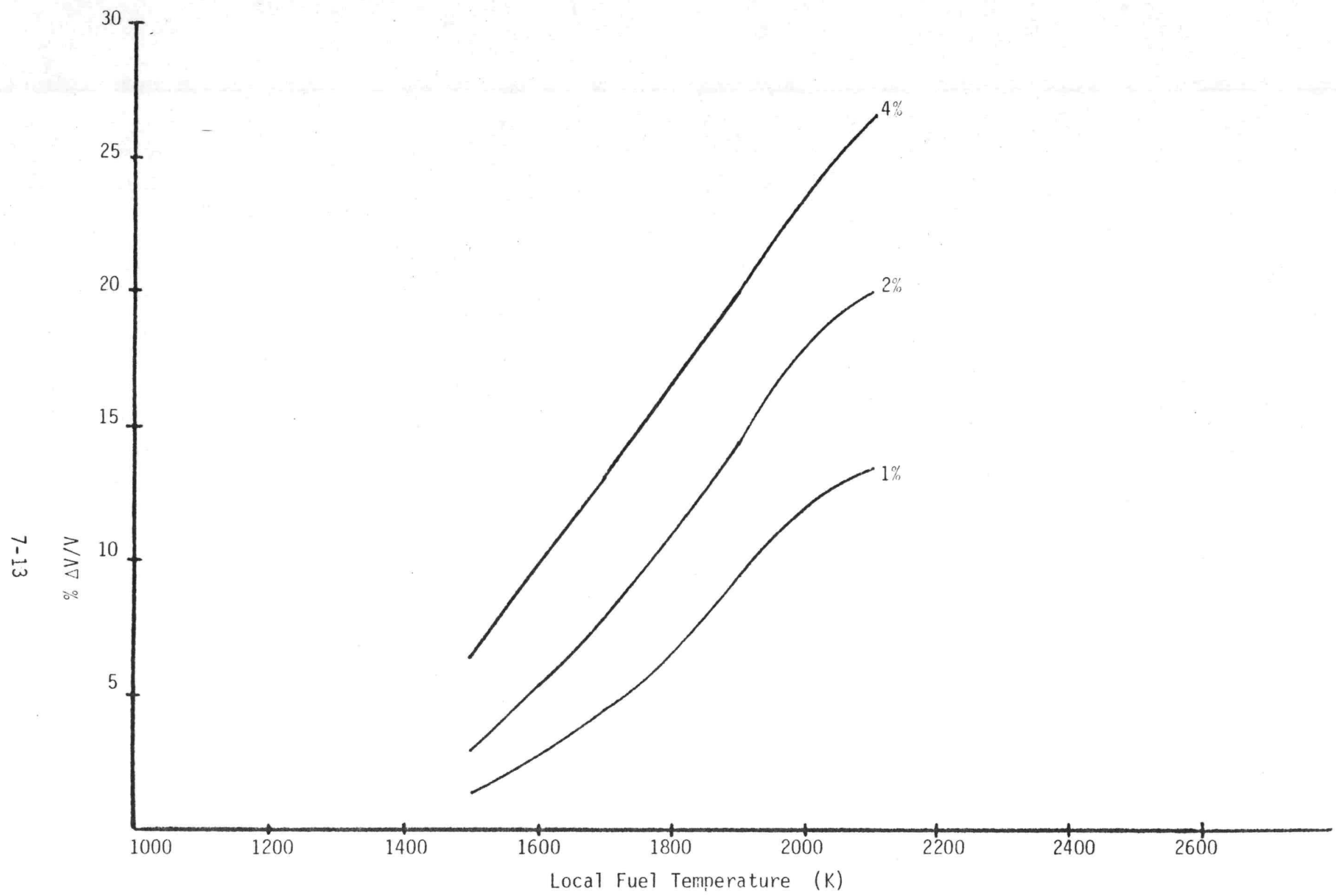

Fig. 7-8 ZIMMERMANS( 2 ) UNCONSTRAINED FUEL SWELLING DATA FOR U02 FUELS. THE FULE ELEMENTS WERE IRRADIATED IN THE REACTOR FR2 (KARLSRUHE) AT FISSION RATES OF $3.1 \times 1013 \mathrm{f} / \mathrm{cm}^{3} \mathrm{~s}$. THE PELLET DIAMETER WAS $5.1 / 2.2 \mathrm{rim}$ (ANNULAR PELLETS) WITH A HEIGHT OF $1 \mathrm{~mm}$. THE FUEL DENSITY WAS $98.2 \%$ TD WITH 15\% 235U ENRICHMENT. DATA WAS RECORDED FOR BURNUP OF 0.4-12.6\% U-ATOMS WITH MEAN TEMPERATURES 0F $1300-2020 \mathrm{~K}$ 
TABLE 7-1

Operation Characteristics and Irradiation Data of the

$\mathrm{UO}_{2}$ Samples Studied by Zimmermann

Unrestrained Sample Restrained Sample

Fue 1 Density, \% TD

98.2

96.7

$u^{235}$ Enrichment, \%

15

20

Pellet Diameter, mm

$5.1 / 2.2$

3.0

Height, mm

1

5.7

Burnup, \% U atoms

0.4-12.6

$2.0-9.8$

Fission Rate, $\mathrm{f} / \mathrm{cm}^{3} \mathrm{~s}$

$3.1 \times 10^{13}-1.4 \times 10^{14}$

$4.5 \times 10^{13}-6.3 \times 10^{13}$

Mean Temperature

$1300-2020$

1450-1920

For SP-100 the fuel will be confined in a tungsten cladding, and for restrained samples, Zimmermann observed a considerably reduced swelling even at low confinement pressure when at high temperature (see Fig. 7-9). The gas behavior was not greatly affected by the cladding resistance (see Fig. 7-10). The curves however point out the benefits of operating at higher temperature. Both the gas trapped in the pores (bubbles and grain boundaries) and the matrix for burnups above $3 \%$ is decreased with temperature and hence the net for burnups above $3 \%$ gas release is increased. For temperature above $1500 \mathrm{~K}$ and at burnups above $3 \%$ a saturation level of fission gas in the pores was reached and there was no longer a burnup dependence on swelling or gas release. It was also seen that at low temperature there was a large gas retention both in pores and in the matrix) which decreases rapidly with temperature.

Zimmermann also investigated mixed oxide swellings [4]. These investigations were at low surface temperature (700-1000 K), and as such are not directly relevant to SP-100. However, he found the volume averaged including high central temperature swelling due to fission gases to saturate at $\sim 6 \%$. His results for total swelling (gas plus solid is shown in Fig. 7-11). 


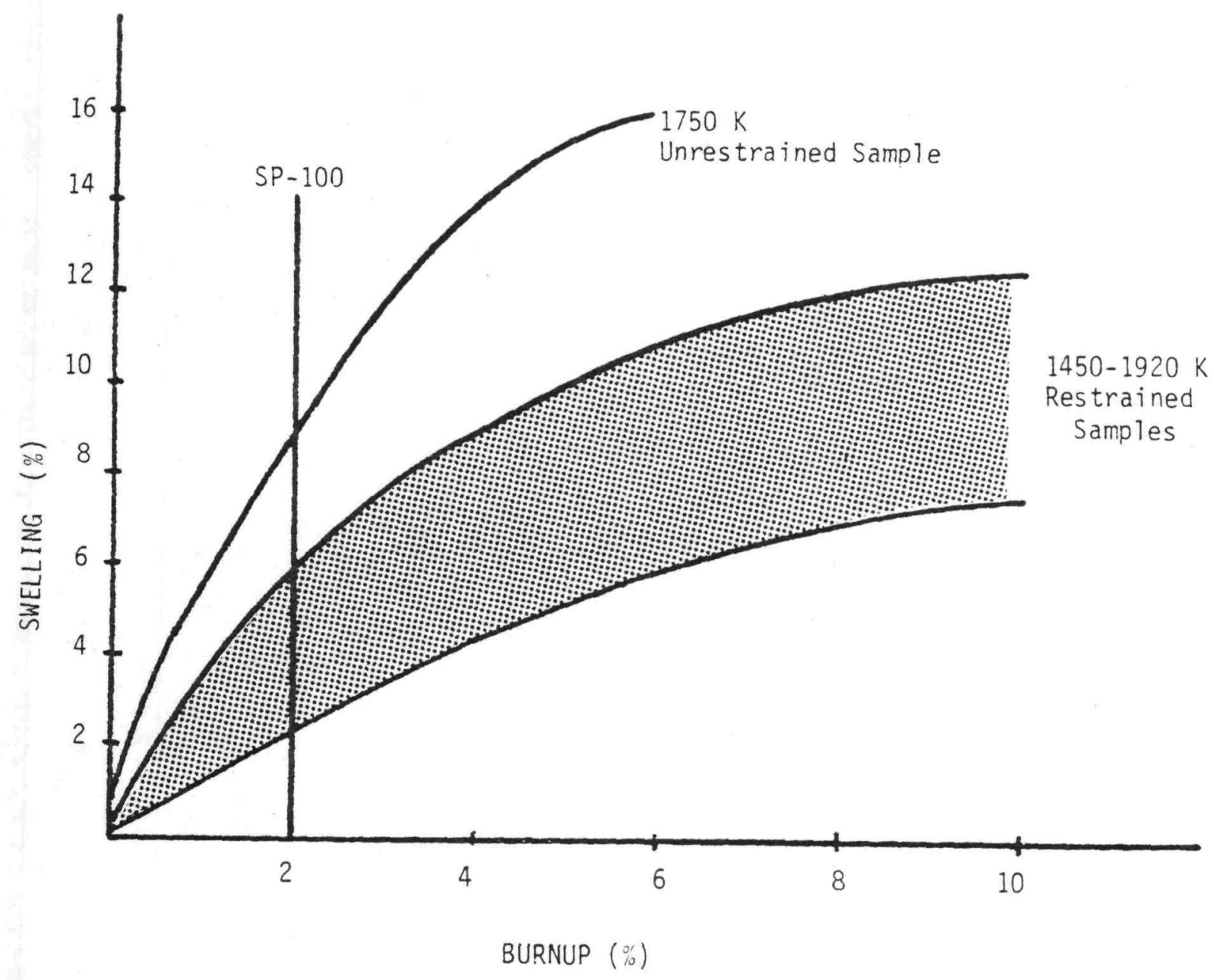

Fig. 7 -9 ZIMMERMAN'S SWELLING RESULTS FOR RESTRAINED UO 2 FUEL SAMPLES WITH FISSION RATES BETWEEN $4.5 \times 10^{13}-6.3 \times 10^{13} \mathrm{f} / \mathrm{cm}^{3} \mathrm{~S}$ WITH MEAN FUEL TEMPERATURES OF 1450-1920 K. THE SAMPLES HAD A $3 \mathrm{~mm}$ DIAMETER AND A $5.7 \mathrm{~mm}$ HEIGHT. FOR COMPARISON THE UNRESTRAINED FUEL SWELL AT $1750 \mathrm{~K}$ IS ALSO SHOWN. 

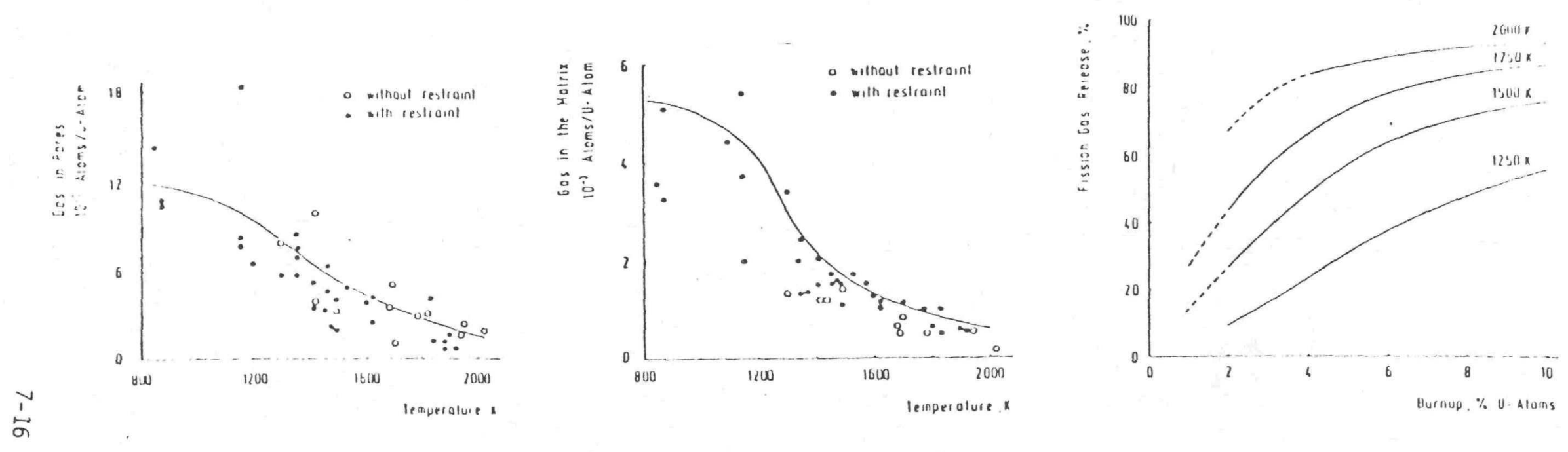

Fig. 7-10 THE GAS RELEASE (AND RETENSION) BEHAVIOR OBSERVED BY ZIMMERMAN IN BOTH RESTRAINED AND UNRESTRAINED U0 2 FUEL SAMPLES 


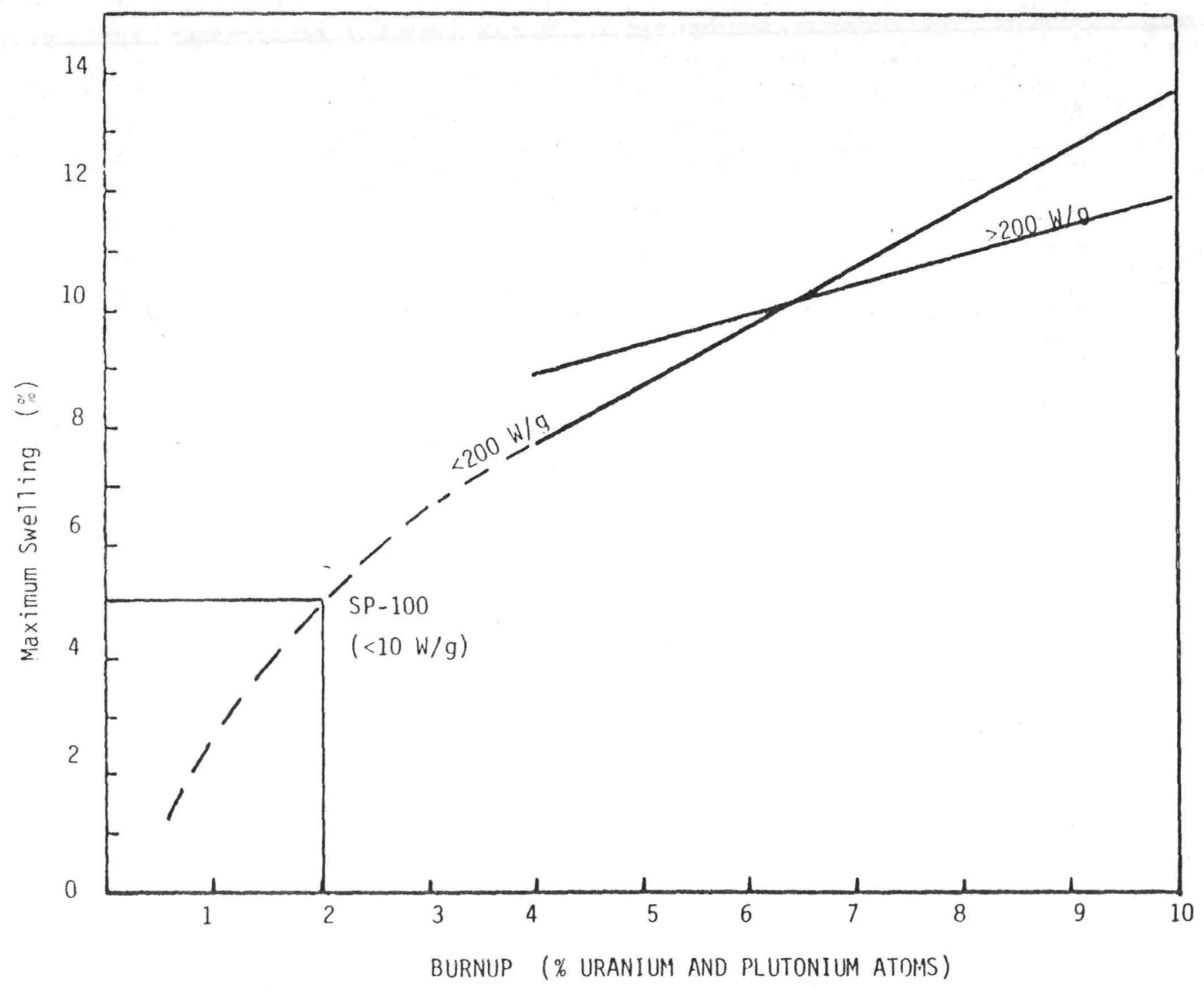

Fig. 7-11 MIXED OXIDE MAXIMUM SWELLING RESULTS OF ZIMMERMAN ( 4 ), WHERE SWELLING IS DEFINED AS THE INCREASE IN VOLUME PRODUCED BY SOLID AND GASEOUS FISSIONS PRODUCTS WITH RESPECT TO $100 \%$ DENSE FUEL. THE CLADDING TEMPERATURES RANGED BETWEEN 700-1000 K. TWO CLASSES OF POWER LEVELS WERE CONSIDERED: $>200 \mathrm{~W} / \mathrm{q}$ and $<200 \mathrm{~W} / \mathrm{q}$. THE SP-100 OPERATING POINT IS SHOWN ON THE FIGURE ALTHOUGH SP-100 OPERATING TEMPERATURES ARE MUCH HIGHER THAN THESE TESTS. 
There are also many other experimental investigations of swelling and gas release. For example, Cox [16] gives a reveiw of some of the early work done on mixed-oxide fuel pins under both thermal and fast flux irradiations; Turnbul1 [17] studied the effects of grain size on swelling and gas release of $\mathrm{UO}_{2}$ fuel at $1750^{\circ} \mathrm{C}$ and found swelling rates $\Delta \mathrm{V} / \mathrm{V}$ of $\sim 6 \%$ at $2 \%$ burnup for large grain materials and as high as $11 \%$ at $2 \%$ burnup for small grain materials; and Lewis [18] look at $\cup_{2}$ fueled rod gas release under low temperatures and low burnup conditions. Concurrent with and subsequent to the work at Battelle $[10-15]$, Karlsruhe $[2,4]$, etc. Many models have been proposed to describe the available experimental data with many of the mechanisms being incorporated into the codes discussed in the next section. Most of the models tend to agree that at high temperatures $\left(\sim 1650^{\circ} \mathrm{C}\right)$ the fuel restructures onto large grains (columnar grains) and at this point the gas release is $80 \%$ or higher. At these higher temperatures bubble size decreases and thus bubble motion along thermal gradients is dominated by surface diffusion, however, pore motion is via vapor deposition. Another important effect is fission-fragment-induced resolution. Fig. 7-12 shows the effect of the inclusion of resolution effect on reducing the predicted swelling (the details of these models, BUBL-1 and BUBL-2 is given in the next section). It is interesting to note that these models predict swelling to reduce for temperatures above $\sim 1600 \mathrm{~K}$. A similar effect is proposed by the model of Wood and Hayns $[19,20]$ (see Fig. 7-13). However, neither Chubb or Zimmermann's data show this decreased swelling at high temperatures (Zimmermann's curves (Fig. 7-8) suggest a "turnover," but at much higher temperatures, $22000 \mathrm{~K}$ ). Most of the data and models, however, suggest that for SP-100 operating conditions, the volumetric swelling will be of the order of $6 \%$ for a 7-year life. It is important that the swelling rate be firmly established in the proposed future experiment and theoretical studies.

Many other mechanisms have been proposed, such as the effects of random motion [20], as well as directed motion, and are currently incorporated in many of the available fuel modeling codes (discussed in detail in the next section). A review of many of these models and the range of applicability has been given by Hayns and Wood [20]. 


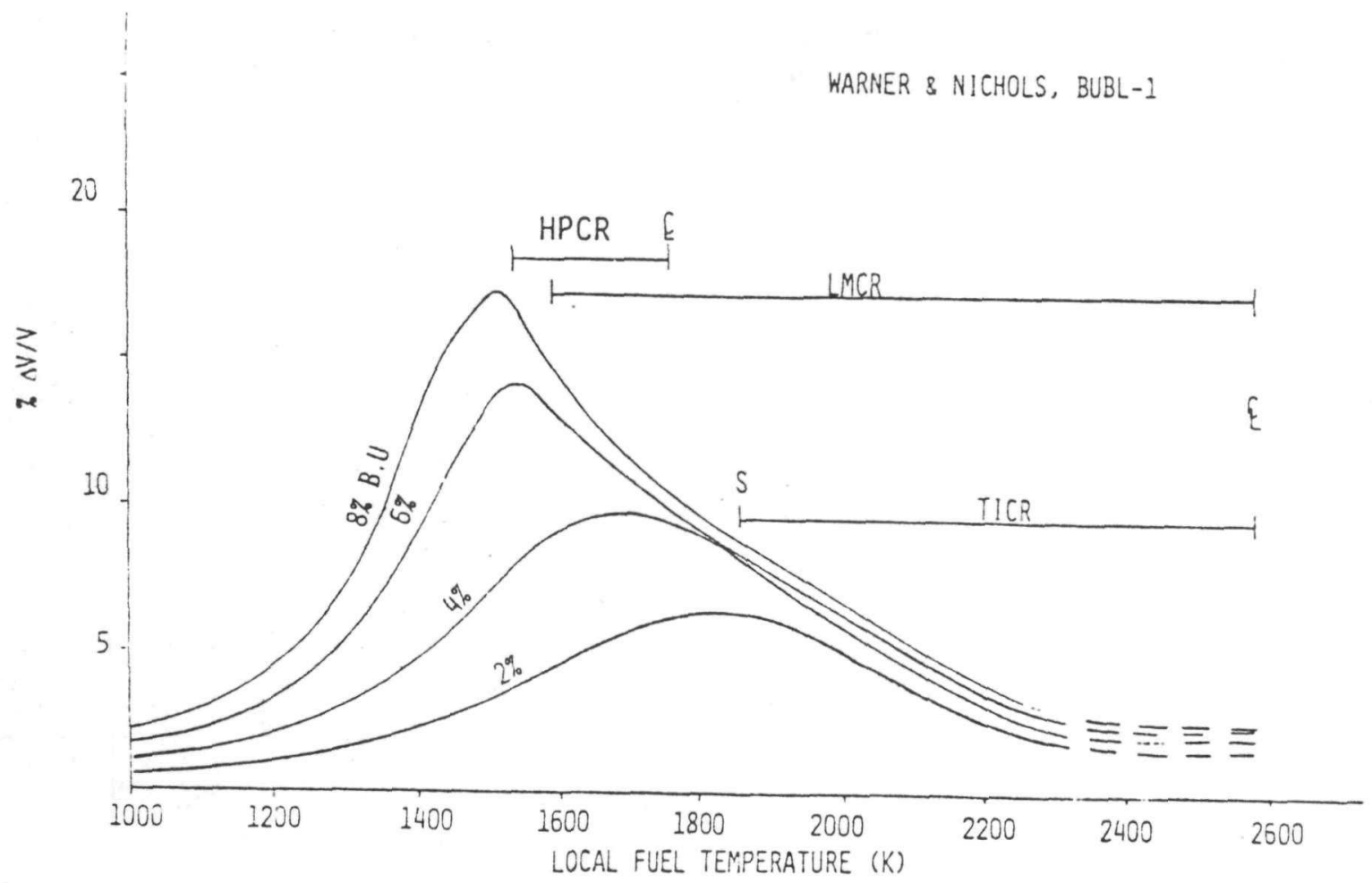

DOLLINS \& NICHOLS BUBL-[!

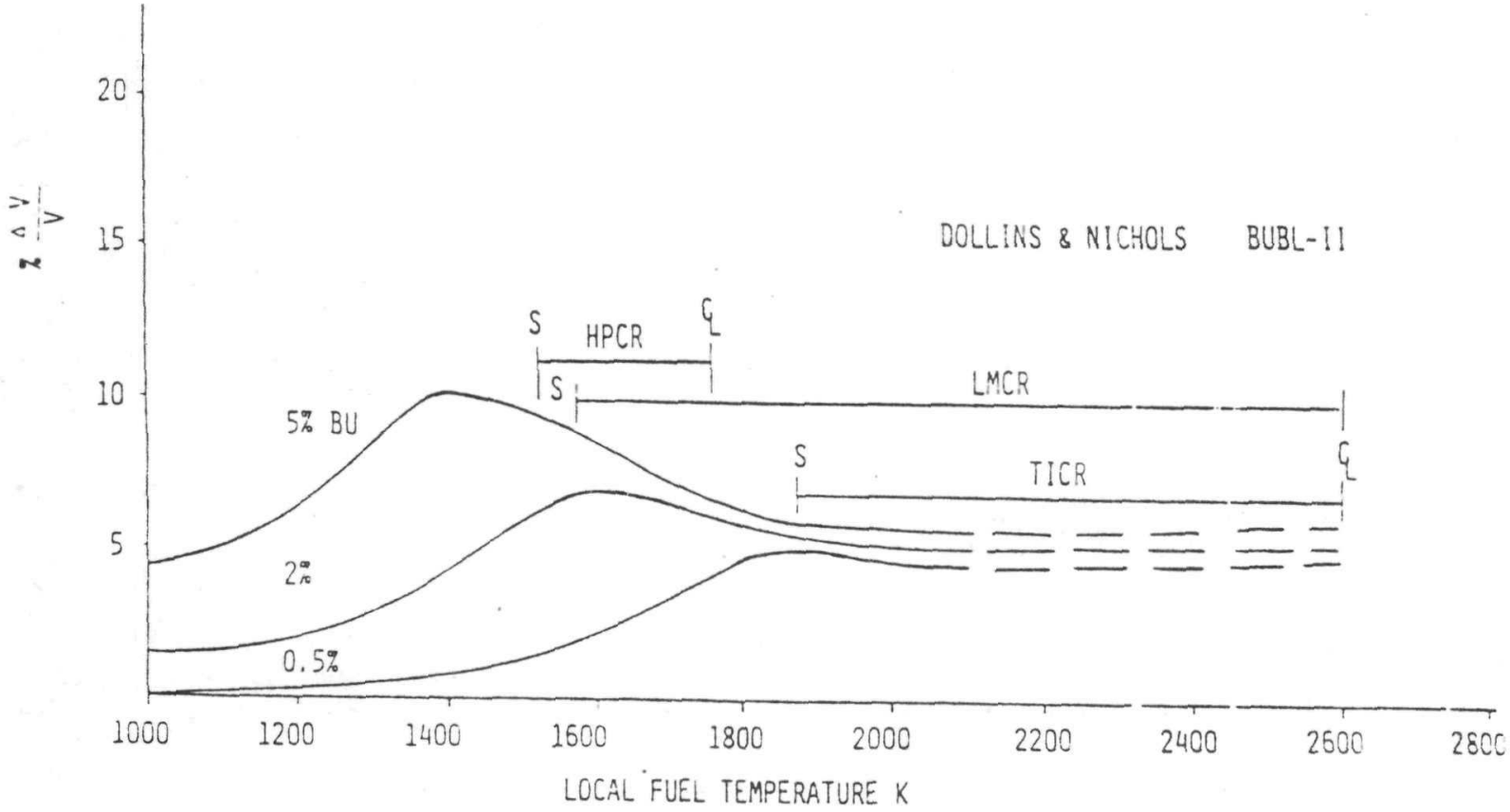

Fig. 7-12 Volumetric Swelling Rates as Predicted by the Warner and Nichols models. Dollins and Nichols Model Includes the Effects of Fission Fragment Induced resolution. Also shown are the proposed Operating Points for a Heat Pipe Cooled Reactor (HPCR), a Liquid Metal Cooled Reactor (LHCR) and a Thermionic In-Core Reactor (TICR). 


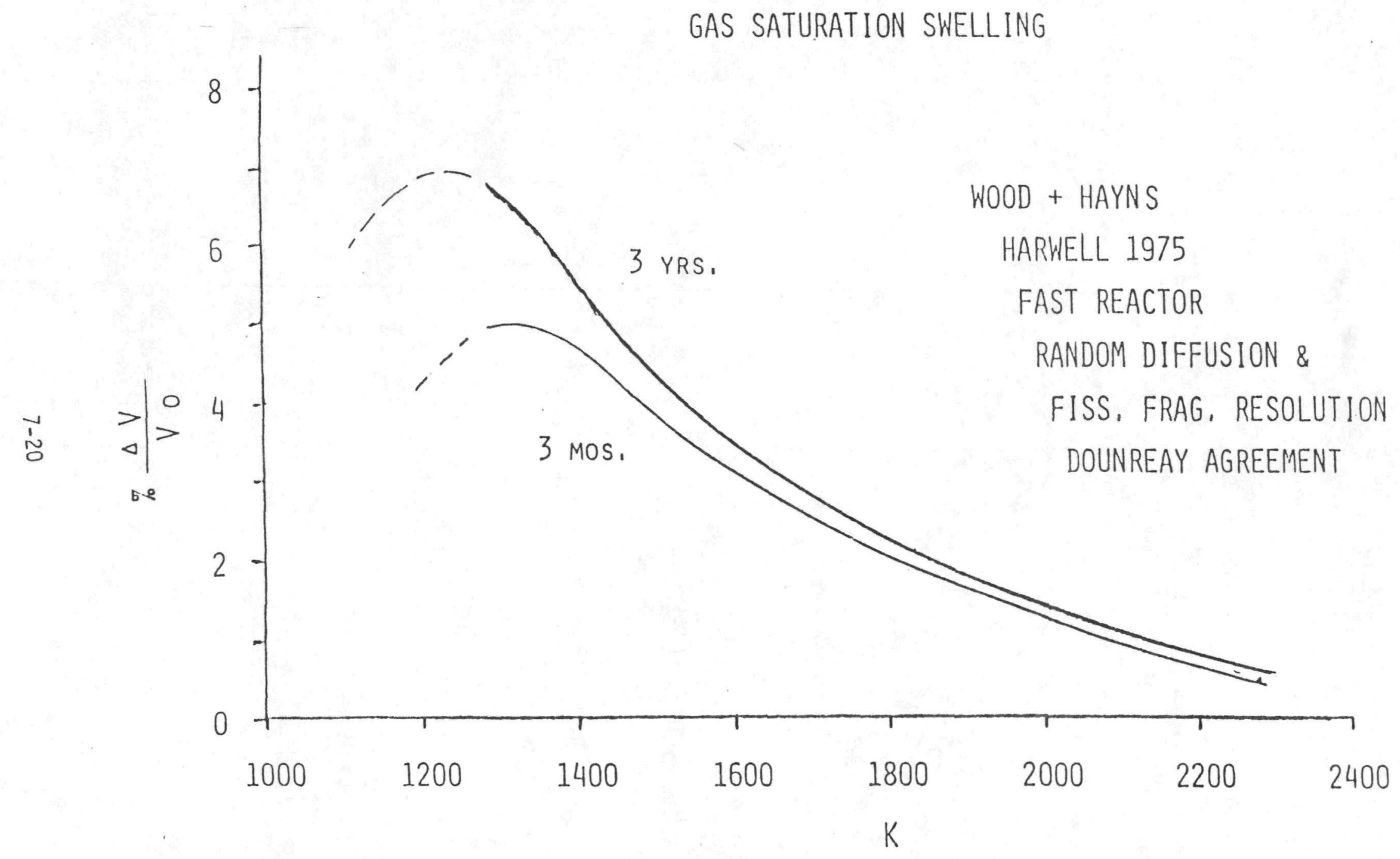

Fig. 7-13 Wood and Hayns Predicted Volumetric Swelling Rate as a Function of Local Fuel Temperature. 
None of the experimental data fits all of the SP-100 operating conditions. The indications of Zimmermann's data is that fuel swelling will not be a dominate failure mechanism ( $26 \% \Delta / V$ for 7 -year life), however the proposed series of experiments and modeling should help verify this conclusion. The available fuel models will be discussed in detait in the next sections. The proposed necessary testing is discussed in the later sections.

\subsection{Evaluation and Selection of Gas Release and Fuel Microswelling Analytical Program}

\subsubsection{Introduction}

Oxide fuel microscopic behavior codes can be divided into two main classes: 1) empirical models; those which are based on parameterized experimental data, such as FSWELL and FGASRL [3] (the swelling and gas release routines from MATPRO-Version 11) and the routines used in earlier versions of FRUMP [21] and; 2) mechanistic models; those which use the effects of various mechanisms of fuel behavior to compute the swelling and gas release, such as GRASS [22] (and its evolutions GRASS-SST [23,24], FASTGRASS [25] and PARAGRASS [26]), the fuel behavior sections in LIFE-I [27] (and its evolutions LIFE-II [28], LIFE-III [29] and LIFE-IV), ORGES [30,31] and BUBL [32] (and its co-development and evolution [33-39]). These models provide important input to the overall fuel structure codes. These microscopic swelling and gas release calculations usually require as input information on the fuel operating parameters and then give the resultant swelling and gas release. For example, a mechanistic code such as GRASS-SST [24] requires as input: the fuel temperature profile, grain-size, fission rates, porosity and hydrostatic pressure and gives as output: the amount of fission gas retained in each fuel zone, the amount of fission gas released to fuel cladding gap and to fuel-rod plenum, the amount of gas in the fuel-rod gap and plenum, swelling strain due to retained fission gas in each fuel zone, swelling strain due to retained fission gas in each axial section, and total fission-gas swelling strain in fuel rod, whereas, an empirical swelling routine such as FSWELL requires only temperature and burnup and gives as output $\Delta V / V$. In either case, empirical or mechanistic, the swelling and gas 
release data is then used as input to a structural run which calculates the overall fuel element response or distortion. (See sections 7.4 and 7.5 for the discussion of these structural calculations). For the SP-100 project, which considers reactors with low burnup $(\sim 2 \%)$, low fission rates $\left(22 \times 10^{12}\right.$ $\mathrm{f} / \mathrm{cc}$ ), low power densities $\left(\sim 50 \mathrm{~W} / \mathrm{cm}^{3}\right.$ ) and high temperatures ( $1850 \mathrm{~K}$ fuel surface temperature), the empirical models do not appear to be practical due to the lack of current experimental data which satisfies all or even most of the above operating conditions. As such the current selection of a gas release and swelling code has focused primarily on the mechanisitic models. It is hoped however, due to the long running time of many of the mechanistic models, that after some preliminary studies have been done using the mechanistic models and these are calibrated using the data to be provided by the proposed testing programs (both incore and out-of-core) that an empirical model suitable for the SP-100 operating conditions can be developed. With an empirical model the analysis of the structural fuel behavior deformation (discussed in sections 7.4 and 7.5 ) will be greatly facilitated, as they could be done without an accompanying mechanistic fuel behavior run. (Resulting in a considerable savings in computer time.) Even within the various mechanistic models there is a wide variety of running times, however, the shorter running models usually consider fewer mechanisims or make more approximations, and as such may or may not be applicable to the SP-100 operating conditions.

In the initial program evaluation, both existing empirical and mechanisitic codes were considered. The selection focused on two empirical codes: those in MATPRO [3] and those in FRUMP [21] and four mechanisitic models: GRASS [22-26], the fuel sections in LIFE [27-29], ORGES $[30,31]$, and BUBL [32-39]. Based on the large number of mechanisms included, its extensive testing, and its availability GRASS-SST, or possibly FASTGRASS, (the distinctions between these two codes will be discussed later in this section) appears to be the best choice to couple to a separate structural code such as ANSYS [40]. The LIFE codes [27-29] are also worth using for testing and calibration as they contain a complete 1-dimensional description of the fuel behavior, both microscopic and structural. LIFE thus cannot develop the "bladder effect" and because it was derived for lower surface temperatures is not equipped to handle thermal ratcheting. LIFE, since it 
was specifically designed for modeling fast reactor fuel elements may have a better description of some of the fuel properties than the fits used in ANSYS. However, there are several drawbacks to LIFE: 1) the description of the microscopic fuel behavior is not as rigorous as GRASS. It needs to be investigated for the SP-100 operating conditions how well the two models agree and to be able to understand any discrepancies in the models. (Currently Argonne National Laboratory is evaluating ; the possibility of incorporating GRASS-SST or FASTGRASS into LIFE-IV [41].) 2) LIFE-IV is designed to treat mixed oxide fuels. Since the SP-100 thermionic reactor project is currently considering only $\mathrm{UO}_{2}$ fuels, the LIFE modeling would never quite treat the same system. (Any LIFE runs could certainly be made with a low, but non-zero, amount of $\mathrm{PuO}_{2}$ ) and 3) the most serious drawback to LIFE is that it has only a one-dimensional structural analysis. This one-dimensional analysis while good for fuel pins, is not adequate for thermionic multi-cell fuel elements where many of the failure mechanisms are two-dimensional effects. (This need for a two-dimensional treatment will be discussed in more detail in section 7.5 It is proposed however, that some cross-calibration calculations between LIFE-IV and ANSYS + GRASS-SST/ FASTGRASS be undertaken for some fuel effects which are nearly 1-dimensional. The importance for and details of such calculations are discussed in section 7.5 .

In the remainder of this section a summary of the various fuel models considered is given, which points out the specific mechanisms that the model considers and its suitability to the SP-100 operating conditions.

\subsubsection{Empirical Models}

A. MATPRO-Version 11 (1979) - The swelling routine, FSWELL, written by R.E. Mason, calculates solid fission product swelling as a function of burnup and fission gas swelling as a function of temperature and burnup. The total volumetric change is then calculated as a sum of the solid swelling, the gaseous swelling and any fuel densification.

The major problem with the parameterization of the fission gas swelling is that it is largely based on the water reactor data of Chubb, et al. Which 
had a significantiy higher fission rate than those for SP-100 and as such this parameterization may not be suitable for modeling SP-100 reactor conditions (see discussion in Section 7.2). This model also has the disturbing feature of merely changing the maximum swelling as a function of temperature and height as a function of burnup but not shifting the temperature position of the maximum as burnup process (see fig. 7-14). (This is in contradiction with most data, see Section 7.2.)

The gas release treatment in MATPRO, FGASRL, written by R. E. Mason considers a two step procedure: 1) release from fuel grains to the grain boundaries and 2) release from the grain boundaries to the internal free volume of the fuel. Both the release from fuel grains to the grain boundaries and the fraction of grain boundary gas released to the free volume are functions of fuel density, grain size, temperature and burnup. The various mechanisms for gas release from grains to the grain boundary, (recoil or knock-out by fission fragments, random motion, biased motion, i.e. along a temperature gradient) are represented as a single mechanism. Once again as this was modeled for light water reactor conditions it is not likely to be suitable for SP-100 operating conditions.

RECOMMENDATIONS: Not suitable for SP-100.

B. FRUMP (Microscopic Fuel Behavior) (1973) - The earlier versions of FRUMP included only an empirical fit for fuel swelling as a function of fuel power density rating $(\mathrm{W} / \mathrm{gm})$ and temperature, and the gas release is not treated at all. The swelling appears to have been fit to data well out of the range of SP-100 operating conditions and as such this early version does not appear to be suitable.

RECOMMENDATIONS: Not suitable for SP-100.

\subsubsection{Mechanistic Codes}

A. GRASS (1971)/GRASS-SST (1978)/FASTGRASS (1982)/PARAGRASS (1983) The GRASS series of codes have been developed at Argonne National Laboratories. GRASS (Gas Release and Swelling Subroutine) has undergone a 


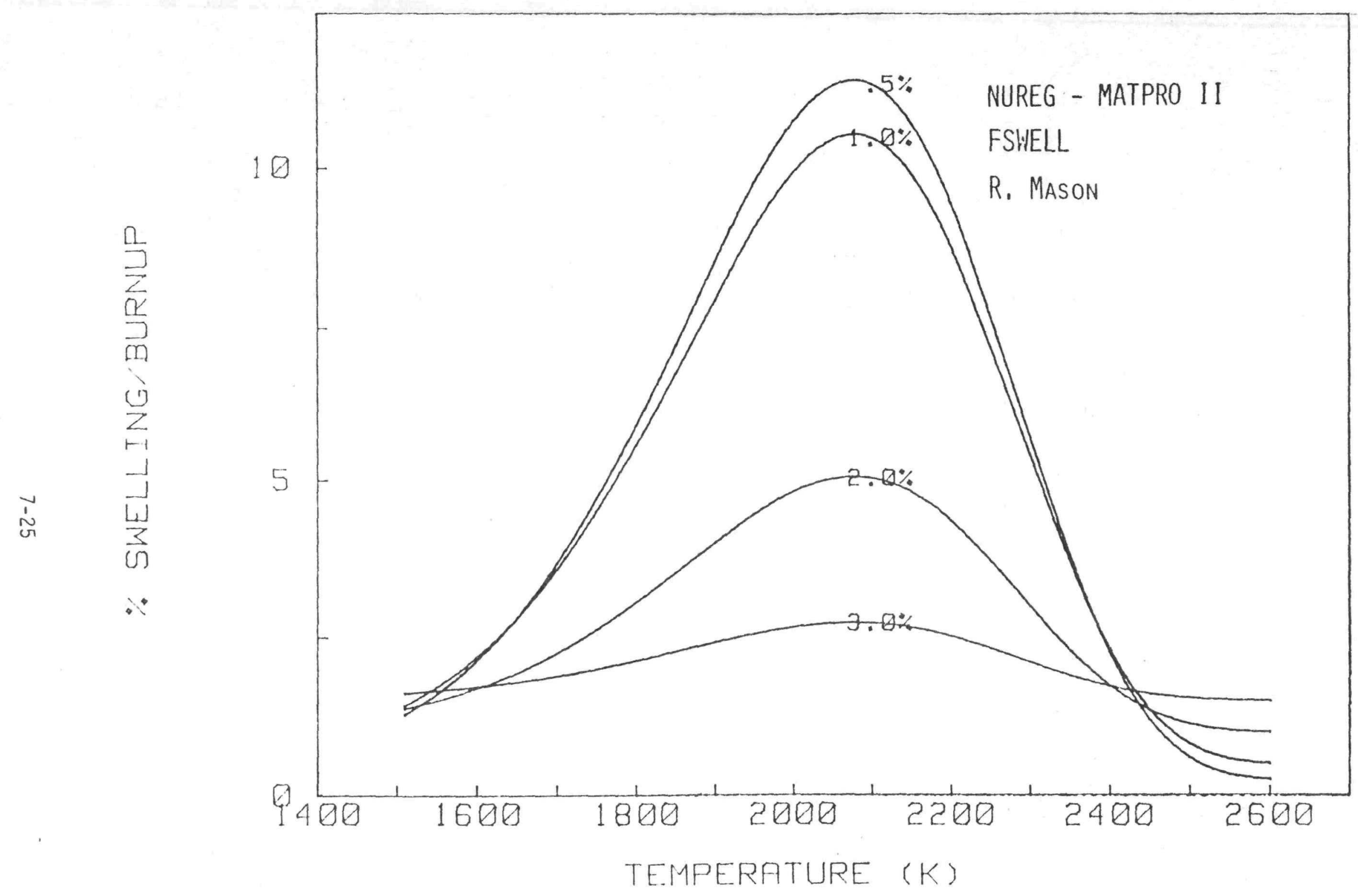

Fig. 7-14 
series of evolutions since the early 1970's with the recent development being done by J.Rest. It was originally written for inclusion in LIFE, however, it has evolved as an independently running code. (A study is underway at Argonne, however, to investigate incorporating GRASS-SST or more likely FASTGRASS into LIFE-IV. These two versions of GRASS also appear to be the best choice for a fuel code to mesh with ANSYS. The key features of each GRASS version are as follows:

1) GRASS (R. Poeppel) - In this version LIFE or ANSYS would supply: temperature, temperature gradient, fission rate and hydrostatic stress state (grain size and dislocation density could either be specified by LIFE or calculated by GRASS). The basic models in GRASS then assumed that:
a) Gas atoms nucleate to form bubbles which then move by both random motion and under the influence of a temperature gradient.
b) Bubbles can coalesce to form larger bubbles.
c) The gas pressure in the bubbles is balanced by capillarity and hydrostatic stress in the fuel material.
d) The gas in the larger bubbles is less dense than in smaller bubbles.
e) The bubbles are attracted to and pinned by structural defects, e.g. dislocation and grain boundaries.
f) The bubbles can move along defects and continue to grow by coalescence until they are pulled off by the temperature gradient and migrate to the central void.

g) A negative growth term is included which describes the rate of fission fragment - induced re-solution.

GRASS computes the evolution of the bubble-size distribution for three classes of bubbles: 1) free bubles, 2) bubbles pinned to dislocations, and 3) bubbles pinned to grain boundaries. These distributions are found as a function of the position in the fuel. Bubble velocity and mobility are based on three mechanisms: 1) surface diffusion, 2) volume diffusion, and 3) evaporation condensation, where for each bubble size in each fuel region the mechanisms which gives the largest velocity is used. 
RECOMMENDATIONS: Good but more recent updates are better.

2) GRASS-SST (J. Rest) - GRASS-SST is based on GRASS and extends the model from intragranular fission gas behavior (the primary concern of GRASS) to also include both intra- and intergranular fission gas bubble behavior and a mechanistic description of the role of grain-edge interlinked porosity on fission gas release and swelling. The code has evolved to treat transient as well as steady state. GRASS-SST calculations include:

a) The effects of the production of gas from fissioning uranium atoms.

b) Bubble nucleation.

c) A realistic equation of state for xenon, one of the major fission gases produced. The noble gases, $\mathrm{Kr}$ and $\mathrm{Xe}$ which are very insoluble in $\mathrm{UO}_{2}$, have been shown to play a major role in establishing the interconnection of escape routes from the interior to the exterior of the fuel.

d) Lattice bubble diffusivities based on experimental observations.

e) Bubble diffusion, including random and biased intragranular and intergranular diffusion of atoms and bubbles.

f) Bubble migration (e.g. along grain edges to the fuel exterior).

g) Bubble coalescence, possibly leading to channel formation.

h) Gas bubble channel formation on grain faces.

i) Fission-fragment induced re-solution.

j) Temperature and temperature gradients.

k) Interlinked porosity.

1) Non-equilibrium in $\mathrm{UO}_{2}$ lattice on fission gas bubble mobility and bubble coalescence.

m) Fission gas interactions with structural defects as it effects both fission gas distribution in the fuel and the amount of gas released from the fuel.

In GRASS-SST the bubbles are now classified by an average size into a set of discrete bubble sized classes. GRASS-SST follows the production of 
fission gas inside the fuel grains, the subsequent diffusion of gas atoms and bubbles through the $\mathrm{UO}_{2}$ matrix to the grain faces, the interaction of bubbles with dislocations, the diffusion of atoms and bubbles along the faces to the grain edges and finally the gas release into free volumes (e.g. plenum, cracks, pellet-pellet interfaces). Fission gas is released from the fuel by diffusing successively from the grains to grain faces and then to the grain edges where the gas is released through a network of interconnected tunnels of fission-gas and fabricated porosity. This is in contrast to other models where once the gas reaches a grain boundary it is considered to be released.

RECOMMENDATIONS: Very suitable for the SP-100, however, this is a very long running code.

3) FASTGRASS (J.Rest) - FASTGRASS is a faster running version of GRASS-SST. It no longer considers bubble dislocation interactions and approximates the bubble size distribution by a single averaged size bubble. The running time has been reduced by one to two orders of magnitude. FASTGRASS has now incorporated microcracking for modeling grain boundary separations due to overpressurized bubble, which would occur in a transient. The microcracks provide direct paths from grain faces to grain edges and from the fuel interior to the fuel exterior thus short circuiting diffusion. (This microcracking is currently being incorporated into GRASS-SST as well.)

RECOMMENDATIONS: Very promising. If the approximations are valid for SP-100 operating conditions this would be vastly prefereable to GRASS-SST due to its faster running time.

4) PARAGRASS (J. Rest, S.R. Rajan, and S.A. Zawadzki) - PARAGRASS is a simplified version of FASTGRASS designed to study water reactor fuels, however, there are no significant differences in the methodologies of the two codes.

RECOMMENDATIONS: Useful but GRASS-SST or FASTGRASS appear better suited for SP-100. 
B. LIFE I (1970)/LIFE II (1971)/LIFE III (1977)/LIFE IV (present) - The LIFE series of codes provide a complete one-dimensional description of mixed oxide fuel behavior. The structural aspects of these codes are discussed in section 7.4. A brief evolution of the fuel swelling and gas release treatment is given here.

1) LIFE I (V.Z. Jankus and R.W. Weeks) - LIFE I specifies fractional gas release in each zone. The release rate is increased if the swelling rises above a specific limit $(25 \%)$. The gas release is then given by the gas in the zone times the fractional release rate. The fuel swelling is due to both solid fission products, given by the net solid volume created per fission times the number of fissions in that region. Gaseous fission product are treated differentiy in the three regions. In the undisturbed region they are assumed incompressible and contribute to swelling in the same manner as the solid fission products. In the columnar and equiaxed regions the swelling is then treated in a reduced manner. The total swelling is the sum of these effects modified by the decreasing fuel porosity due to hot pressing of the fuel.

RECOMMENDATION: Newer LIFE versions are more rigorous and as such preferable.

2) LIFE II (V.Z. Jankus and R.W. Weeks) - In LIFE II rather than the constant gas release fraction used in LIFE I, which tended to overestimate the gas release a temperature dependent rate is used. Swelling is still treated in the same approximate manner as in LIFE I, however, at this point GRASS model, discussed earlier, was beginning to be incorporated into LIFE.

RECOMMENDATIONS: Not rigorous enough far treatment of space reactor fuel elements.

3) LIFE III (1977)/LIFE IV - By this point a for more rigorous fuel model had been incorporated into LIFE. Specific mechanisms were now being included such as: 
a) diffusion or migration of fission-gas atoms (or bubbles to short circuiting path to the free surfaces (e.g., grain boundaries, dislocations and microcracks.

b) migration along temperature gradients.

c) bubble migration via surface diffusion.

d) pore migration via vapor-phase transport and surface diffusion.

e) porosity reduction due to hot pressing.

Although the treatment is not as rigorous as in GRASS-SST or FASTGRASS, it would be worth comparing the results of the two models, in particular since LIFE does provide an overall fuel treatment (both microscopic and structural) it may be worth performing a LIFE-IV VS. ANSYS + GRASS-SST (or FASTGRASS) calibration for a fuel effect that is known to be 1-dimensional.

RECOMMENDATIONS: Useful, but 1-dimensional.

C. ORGES (M. H. Wood and J. R. Mathews) - ORGES (Operational Gas Release and Swelling) is a new mechanistic code designed to be incorporated into the FRUMP structural code. The model is broken into two parts: 1) intragranular gas and 2) grain boundary gas. The intragranular gas model is based on the assumptions that:

a) gas migrates through the fuel matrix as individual atoms.

b) release from the matrix is by diffusive flow to grain boundaries.

c) fission gas bubbles trap migrating gas atoms.

d) gas bubbles are immobile.

e) fission fragment resolution completely destroys a bubble.

f) gas bubble nucleation occurs heterogeneously by diffusion of gas atoms to small vacancies left by fission fragments. 
The grain boundary gas model assumes:

a) grain-edge and grain-corner porosity exists in two types: low swelling porosity, cigar-shaped edge bubbles and tetrahedral corner bubbles and higher swelling where the corners and edges are linked by tunnels.

b) a rate theory treatment of the flow of vacancies between grain faces and the various types of porosity.

c) a treatment of the distribution of fission gas between the grain faces and grain boundaries.

d) interlinking of pores leading to gas release from the fuel.

The model was designed to yield swelling and gas release for both thermal and fast reactor conditions.

RECOMMENDATIONS: May be useful, although it does not appear as rigorous as GRASS-SST. Also, it was developed in England, which may make it not as readily available in the U.S.

D. BUBL (Bettis) - The name BUBL is used here to describe many of the fuel models which have been developed at Bettis Atomic Power Laboratory. In the original BUBL written by Nichols and Warner, it was assumed:

1) Bubble migration was via surface diffusion along the thermal gradient.

2) That radiation-induced resolution was unimportant or unknown.

3) Bubbles are trapped along dislocations until a critical size is reached, then migration to a grain boundary can occur. At this point the bubble is once again pinned until a second critical size is reached at which point the gas is released.

4) Bubbles coalesce only at dislocations and grain boundaries.

Dollins and Ochen recognized the importance of fission-induced resolution effects. Dollins considered the effect of coalescence through random motion. The Dollins-Nichols version of BUBL then incorporated these two effects. This model assumed also that:

a) fission gas migrates to grain faces either as atoms or bubbles. 
b) from grain faces the motion was to three-grainintersections then to grain corners (four-grain intersections).

c) Gas remained at grain corners until swelling reached $5 \%$ of the total volume at point tunnels formed venting gas to the surface.

d) once a tunnel formed it remained.

Work by Dollins and Jursich have refined this model to treat the slow transients in temperature, temperature gradient, fission rates and pressures that occur in normal reactor operations.

RECOMMENDATION: Applicable, but not as convenient form as the GRASS codes.

\subsubsection{Summary}

For the SP-100 operating parameters GRASS-SST (or FASTGRASS) with extensive number of mechanisms considered appears to be the best choice to mesh with a two-dimensional structural code such as ANSYS. For the SP-100 certainly all of the mechanism considered in GRASS-SST will not be important (see the discussion in section 7.2). However, it does appear more reasonable, in view of the limited experimental data for SP-100 conditions, not to decide a priori which mechanisms to neglect.

It is felt that LIFE-IV with its complete fuel description, (both structural and microscopic), as well as its extensive development for fast reactor fuels, would be useful in modeling one-dimensional effects and also in providing calibration for some of the fuel properties used in an ANSYS run.

\subsection{Analytical Approach to Resolution of Causes of Emitter Deformation}

The worth of the analytical effort with respect to emitter deformation lies in its ability to identify the magnitude, if any, of each of the possible deformation mechanisms. Each mechanism can be evaluated independently of the others in order to establish the absolute and relative contribution of each effect toward cladding deformation. Most importantly, 
corrections or solutions to problems (i.e., power change rate limits to eliminate ratcheting or hot snorkel central cavity venting, or low creep rate emitter structures, etc.) can be tested analytically for adequacy before in-core testing.

The basic phenomena which cause deformation effects are varying combinations of the following: fuel/emitter differential thermal expansion, elasticity, swelling and creep; fuel restructuring and porosity migration; fission gas entropment and diffusion release and fuel cracking from thermal cycles. The analytical tools used in the deformation analysis will show the thermomechanical response of the $\mathrm{UO}_{2}$ fuel and tungsten emitter in the SP-100, in-core and out-of-core test environments to these basic phenomena.

One fuel/cladding analytical model presently exists in the form of the comptuer code LIFE-IV. LIFE-IV models the basic phenomena and most effects which occur in a long fuel-pin/cladding nuclear environment. It will calculate radial temperature distribution in the fuel and cladding. Then for a specified time-step, LIFE will calculate incremental fuel swelling due to accumulation of fission products, fission gas release from fuel to central void and thermoelastic and creep deformations of the fuel and cladding. Based on the expected changes in total strains, LIFE-IV follows through an iterative calculation until reasonable agreement is achieved between estimated and calculated total strains. The result is a one-dimensional time history of fuel-pin/cladding behavior including cladding deformation. LIFE-IV was developed for modeling long, essentially one-dimensional, fuel pins where end effects are either insignificant or non-existent. The LIFE-IV fuel swelling subroutine is mechanistic and correlates abundant low surface temperature, high power density, small diameter fuel pin data related to water reactors and the LMFBR.

While LIFE-IV does a thorough job of modeling the behavior of basic phenomena which occur in the fuel-pin/clad environment (swelling, thermal expansion, etc.), it is unable to apply the effects of these phenomena to a two-dimensional, axisymmetric structure such as a thermionic fuel cell in a TFE. Given, for example, pressure buildup in the central void due to fission gas creation and migration: how is the fuel/cladding distorted? LIFE-IV 
does not address the thermal ratcheting effect because it does not occur to any great extent at surface temperatures below $1300 \mathrm{~K}$ (see Fig. 7-2).

In order to examine TFE fuel-emitter cell distortion a 2-dimensional viscoelastic approach must be utilized that allows for axial temperature variation and axial fuel-emitter discontinuity. As part of this contract SPI has adopted the well-known ANSYS code to the probiem at hand. As has been discussed, the most thorough and general fuel fission gas swelling and release mechanistic code available in the U.S. appears to be GRASS (Gas Release and Swelling Subroutine) and GRASS-SST (steady state and transient) codes developed at Argonne National Laboratories. A shorter version of GRASS called FASTGRASS is also available. SPI is currently involved in setting these codes up to compare them at SP-100 design and operating conditions. If they correlate well at the temperatures, power density and burnup range of interest the less costs ly FASTGRASS will be used. FASTGRASS and GRASS can be incorporated into LIFE-IV for a 1-dimensional check-out of LIFE-IV results. From GRASS runs, SPI will develop an empirical algorithm that fairly represents the swelling ( $\Delta V / V$ and gas release) over the relatively narrow range of interest to thermionic-fueled converters. The algorithm will be incorporated into ANSYS to determine the real cause of emitter distortion in past tests, current near-term, out-of-core tests, future confirmation in-core tests and to predict best reactor design expected performance and operating limitations.

ANSYS capabilities are shown in Table 7-3. A typical fuel/clad mesh network employed in such an analysis is shown in Fig. 7-15. Taking those basic phenomena as described by GRASS and applying them to ANSYS produces an analytical tool capable of investigating two-dimensional effects. The LIFE code may be used as a calibration tool for ANSYS in those regions where the effects are chiefly one-dimensional. 


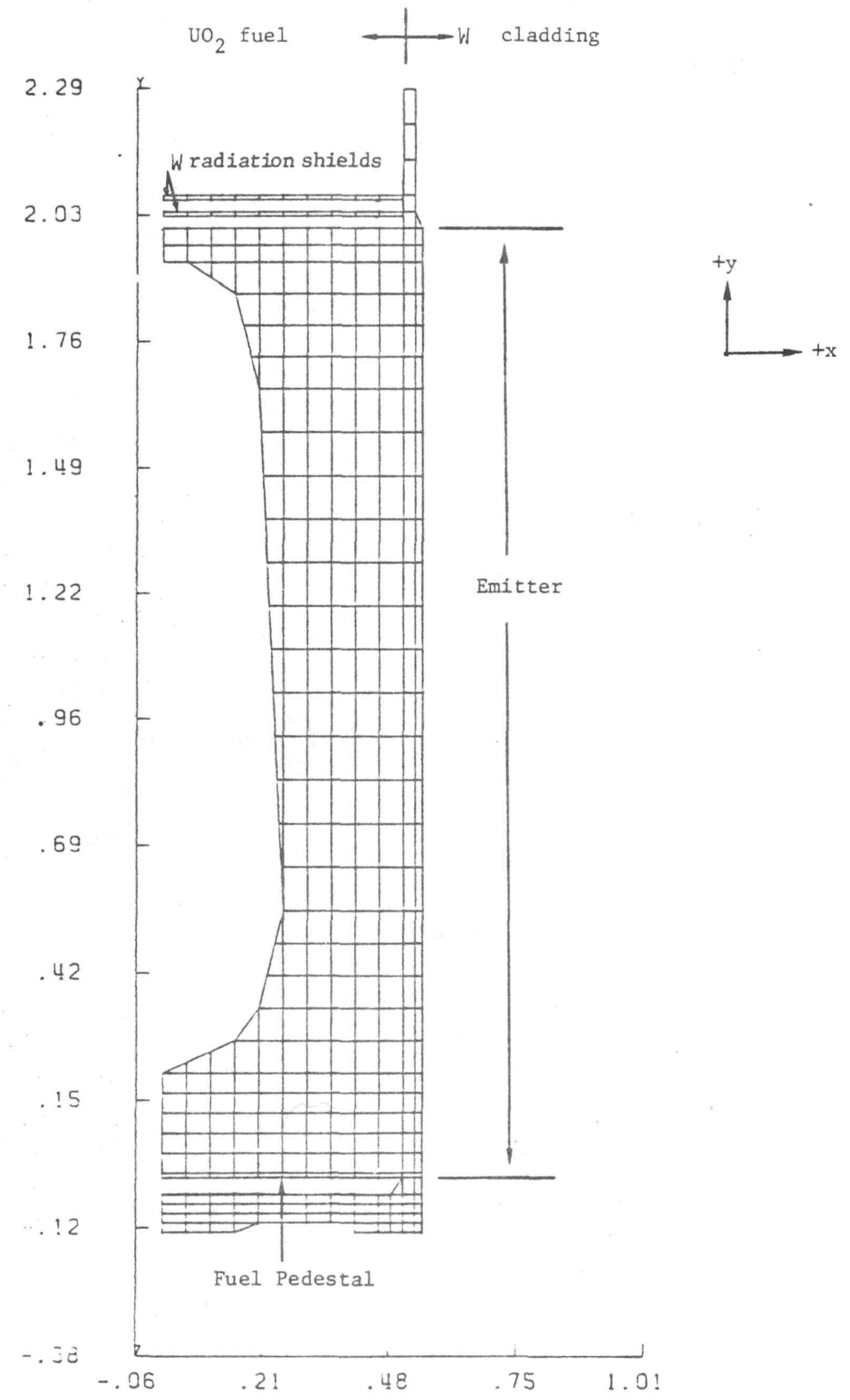

Fig. 7-15 T:NO-DIMENSIONAL FUEL/CLAD VISCOELASTIC MODEL 
TABLE 7-3

\section{ANSYS Capabilities}

- One, two, or three-dimensional finite element code

- Thermal Analysis:

- Steady state or transient

- Coupled to structural solution

- Temperature-dependent properties and boundary conditions

- Structural Analysis:

- Accepts pressure, thermal, force, inertia loads

- Structural elements for friction, adhesion, gaps

- Plasticity

- Work hardening during reversed loading cycles

- Creep: primary, secondary, irradiation induced

- Swelling

- Inelastic/nonlinear analysis

- Crack initiation

- Surface vaporization - thermal ratcheting must be manually inserted through case run selections. 


\subsection{Description Selected Deformation Analys is Approach}

\subsubsection{Thermal Analysis}

Determining the fuel/cladding thermal profile is the first step in the analysis task. The profile is affected by such variables as fuel void fraction, quantity of thermal radiation shields above and below fuel, neutron environment, thermal end losses and thermionic cooling performance. Once these and other variables have been selected and materials properties have been described, the ANSYS computer code will converge on a steady-state thermal solution.

A trial thermal and structural model test computed by SPI with ANSYS waS similar to the 6F3 in-core fuel elements tested by GA in 1972 and shown in Fig. 7-16. Basic dimensions and specifications were as follows:

\begin{tabular}{|c|c|}
\hline Cladding Outer Diameter & $1.100^{\prime \prime}$ \\
\hline Cladding Thickness & $\begin{array}{r}.070^{\prime \prime}(\text { CVD WCI } \text { Outer .021") } \\
\text { (CVD WF } 6 \text { Inner .049") }\end{array}$ \\
\hline
\end{tabular}

Fuel Length 2.000"

Fuel Void Fraction $\quad$ w12\%

The emitter was modeled as two layers of vapor-deposited tungsten. Thermal properties of both CVD tungsten and $\mathrm{UO}_{2}$ were temperature dependent. The emitter was modeled such that $210 \%$ of thermal input was lost up the lead, which operates at collector temperature. Two tungsten thermal radiation shields were modeled over the top of the fuel and a tungsten support pedestal under it. The shields and pedestal restrict the heat loss which would escape out the ends. The pedestal is particularly important in that it prevents large temperature differences in the emitter bottom which could lead to excessive structural deformation.

Material properties used in the following analyses were taken from sources listed in Refs. $[3,42-52]$. Many of the properties were dependent on 


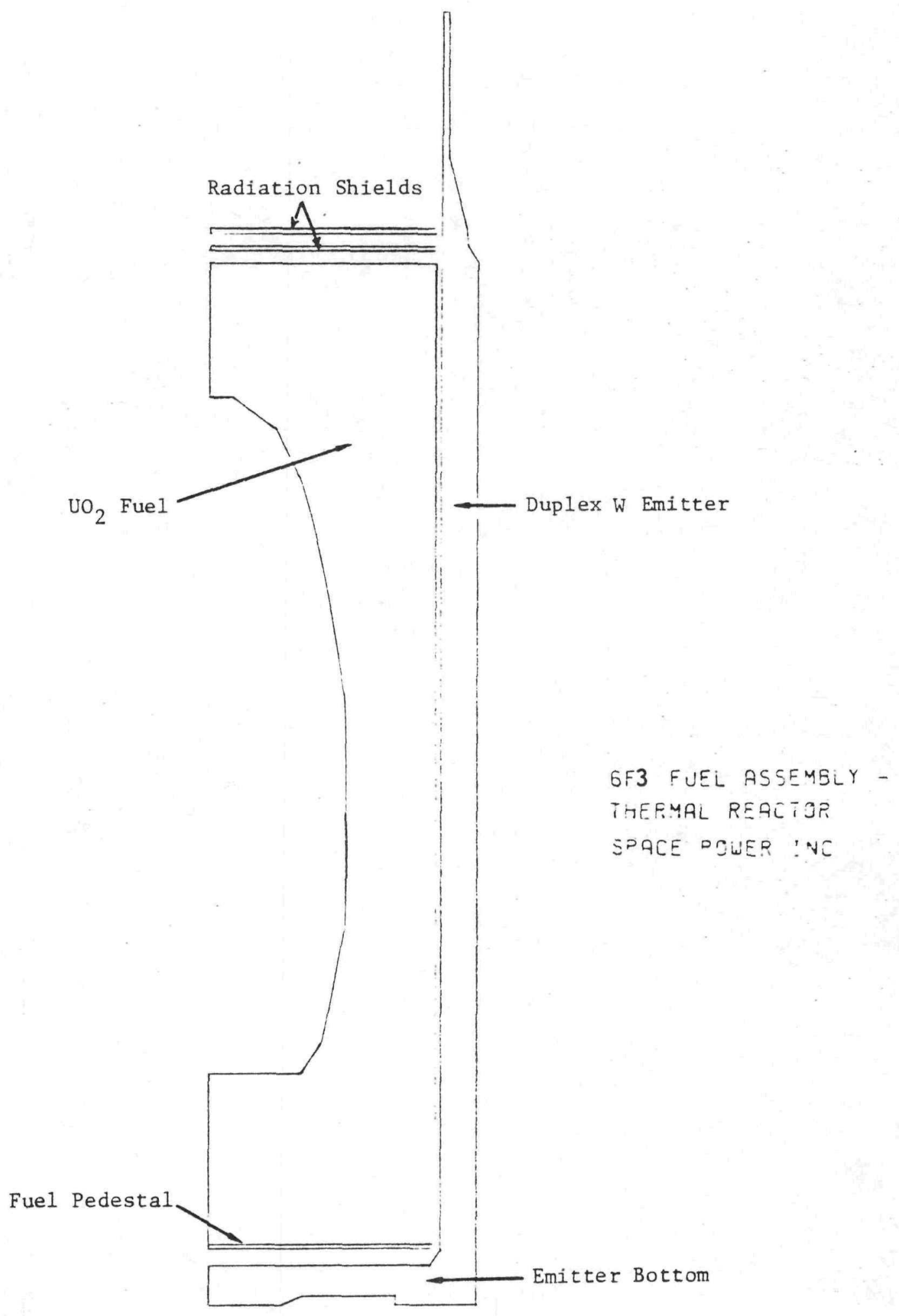

Fig. 7-16 FUEL/EMITTER MODEL 
temperature, fission rate, density, grain size, stress, etc., and were modeled to include these dependencies.

Thermionic emission was allowed to vary with temperature. Electron cooling, thermal radiation and gas conduction cooling were all included in the emitter surface heat flux. At the design calculation point of $1750 \mathrm{~K}$, the current density was $6 \mathrm{~A} / \mathrm{cm}^{2}$ surface. Both thermal and fast neutron flux cases were analyzed. In the fast neutron case, a uniform heat generation rate of $57.7 \mathrm{~W} / \mathrm{cm}^{3}$, corresponding to $2 \times 10^{12} \mathrm{f} / \mathrm{cc} / \mathrm{sec}$, was used throughout the fuel. In the thermal neutron case, most of the fissioning occurs near the surface. An estimated TRIGA test reactor, thermal fission power profile such as shown in Fig. 7-17 was used across the $\mathrm{UO}_{2}$ fuel cross-section such that the total heat generated was equal to the fast neutron case. Local heat generation rates vary within the fuel from $10 \mathrm{~W} / \mathrm{cm}^{3}$ to $130 \mathrm{~W} / \mathrm{cm}^{3}$.

The temperature profile of the thermal and fast neutron cases are shown in Fig. 7-18 and 7-19, respectively. It is important to note the difference in shape of the cental void cavity between the two situations. The thermal neutron environment yields a much thicker skull over the central void. In the thermal case, the heat generation rate of fuel in the center is less than that of the fast neutron case. Hence it takes more fuel to make up the heat loss out of the top. The thickness of the fuel skull can be engineered, to a degree, by the amount of thermal radiation shielding placed over the fuel. This becomes an important point later when considering the bladder effect.

In the fast neutron case, the fuel has a significantly higher radial temperature gradient and subsequently higher average temperature. Conversely, the thermal neutron case has a small temperature gradient because most of the heat generated by the fuel occurs near the surface, relatively close to the emitter to which it is transferred (see Fig. 7-20 for a typical radial temperature distribution for the TRIGA thermal test and the SP-100 fast flux profile).

Local fuel geometry and temperature distribution data obtained from the ANSYS thermal analysis will be used as input to the GRASS-SST swelling code. Capabilities and characteristics of GRASS are described in section 7.3. 


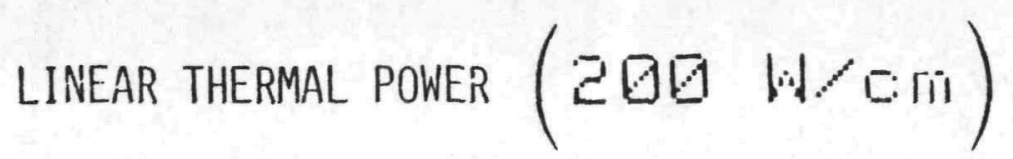

$\ddot{t}$

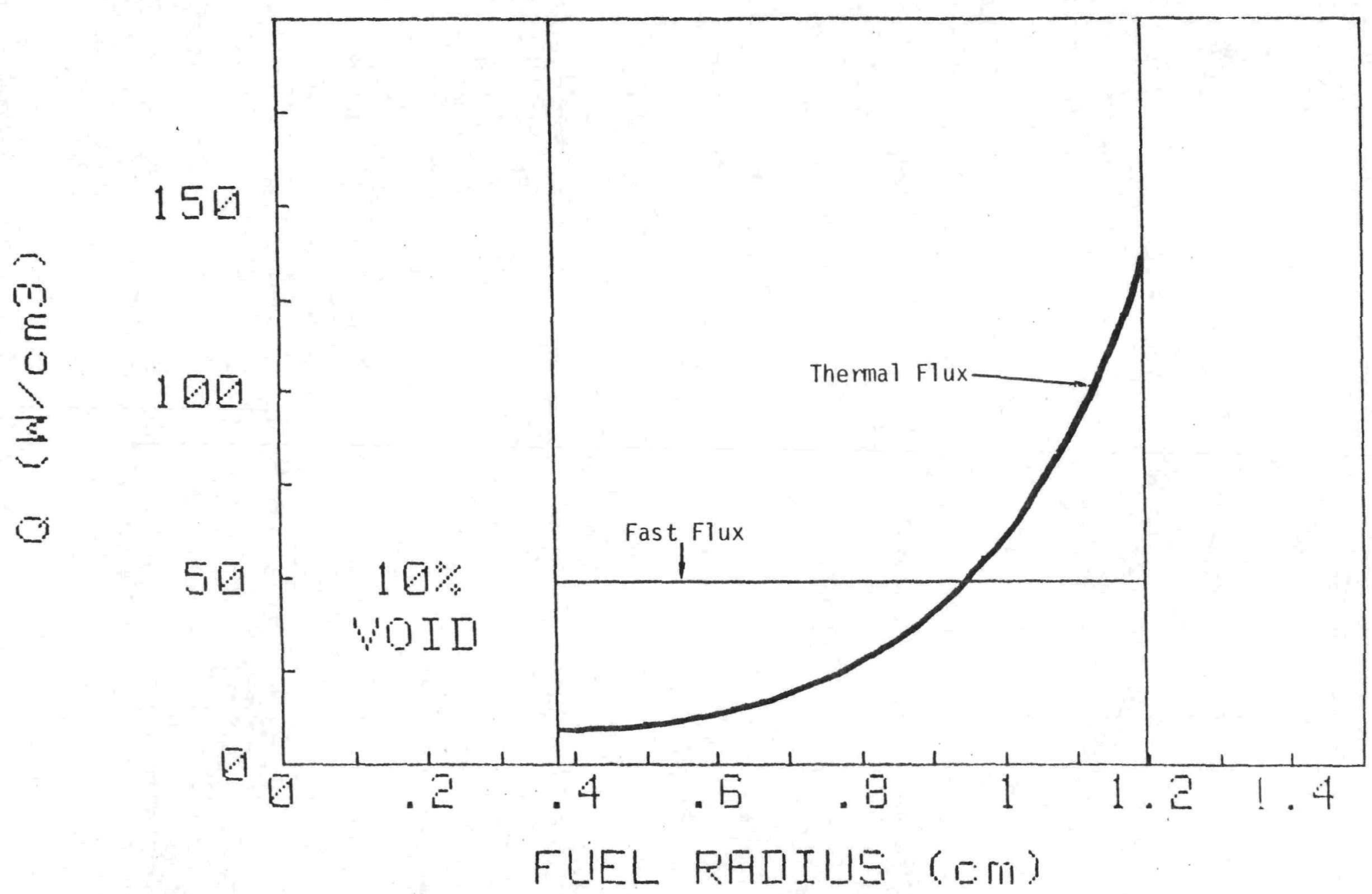

Fig. 7-17 Local Heat Generation Rate -6 F3 Fuel Element

Fast vs Thermal Neutron Flux 


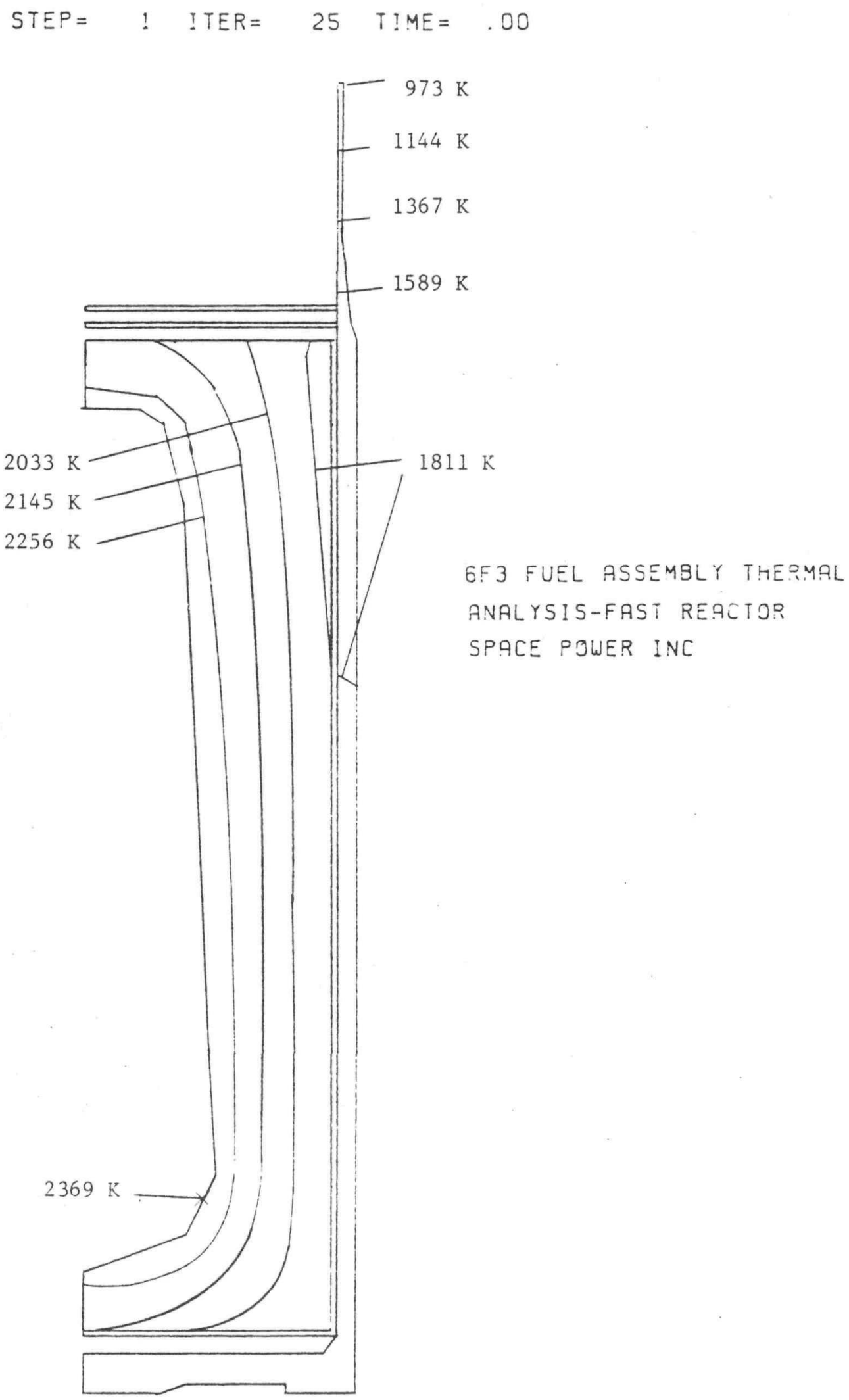

Fig. 7-18 Temperature Profile Fast Neutron Environment 


$$
\text { STEP }=\quad 1 \quad \text { ITEP }=10 \text { TIME }=.30
$$

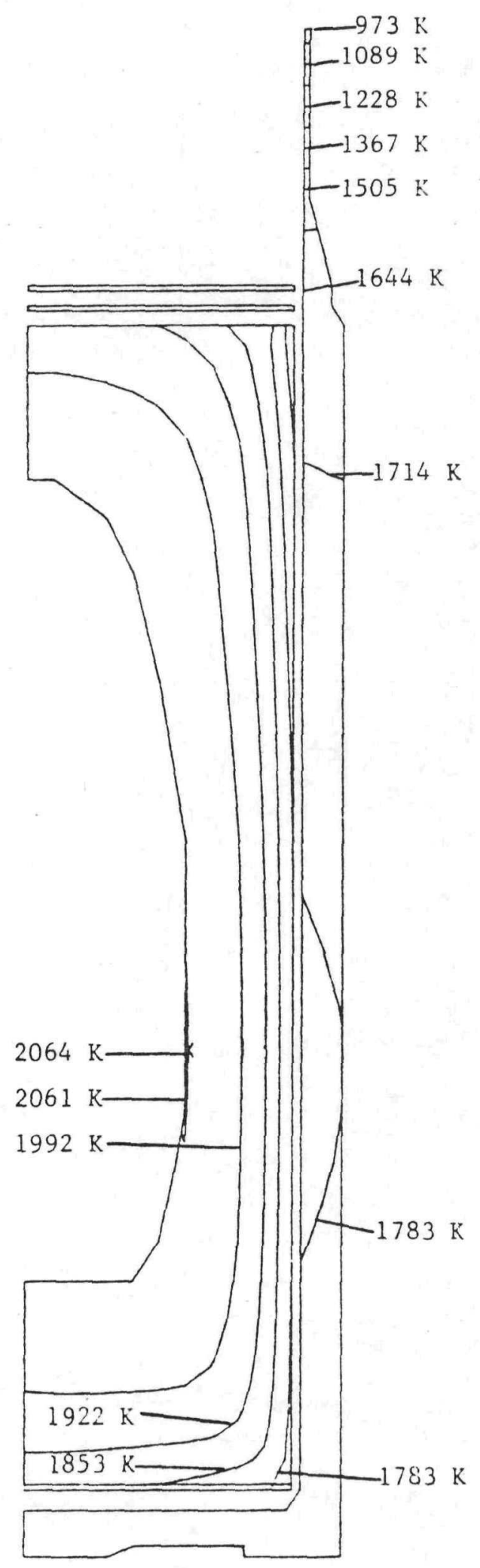

6 F3 FUEL ASSEMBLY -

THERMAL REACTOR

SPACE POWER, INC.

Fig. 7-19 TEMPERATURE PROFILE THERMAL NEUTRON ENVIRONMENT 


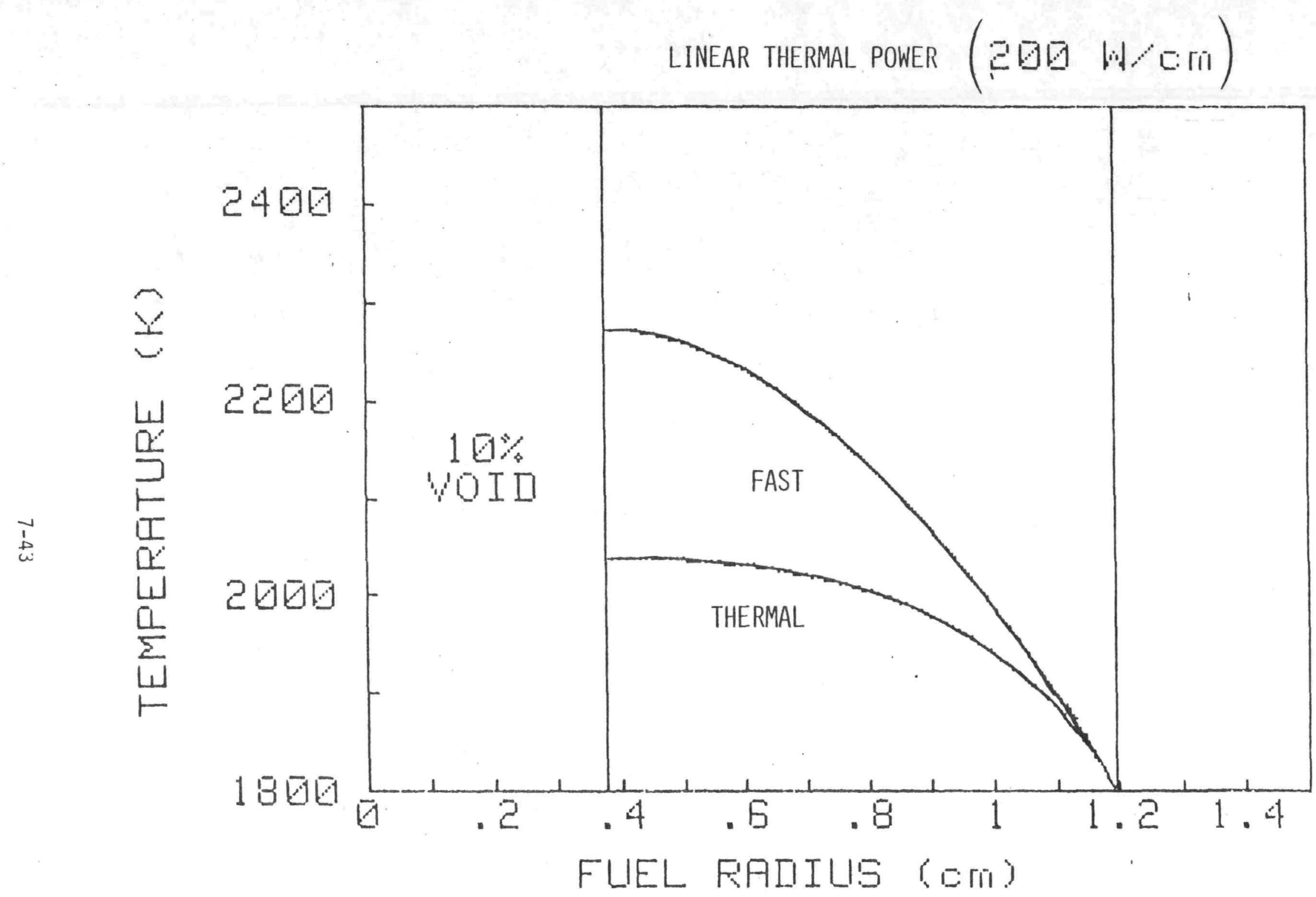

Fig. 7-20 Radial Temperature Gradient Fast vs Thermal Neutron Environment 
GRASS-SST provides volumetric change rates in the fuel to be used in the ANSYS fuel swelling analysis and gas arrival rates into the central void to be used in the ANSYS bladder and venting requirement analysis.

\subsubsection{Thermal Ratcheting}

If the fuel and cladding temperatures dropped $100 \mathrm{~K}$ from the operating temperatures displayed in Fig. 7-18, approximately a $\frac{1}{2}$ mil gap would form between the fuel and cladding. It is important to note that the rate of $\mathrm{UO}_{2}$ deposition is strongly dependent on temperature (see Fig. 7-2). Primarily because of thermal losses out the emitter lead, the ANSYS thermal solution shows the fuel in contact with the cladding near the emitter lead to be approximately $100 \mathrm{~K}$ cooler than the fuel located lower down the fuel/clad interface. Given this axial temperature distribution in the fuel, the gap in the region where the fuel is hotter will fill in at a substantially higher rate than the cooler regions. For this reason, thermal ratcheting induced emitter deformation will not be uniform along its length.

Fig. 7-21 shows emitter displacement before and after one $100 \mathrm{~K}$ ratcheting cycle. The bottom (hotter) region of the emitter showed greater distortion than that in the lead area because the gap in the lead region did not entirely fill. Note that the distortion is nearly constant approximately halfway up the emitter and decreases as it approaches the lead region. The time necessary to fill an annular gap is highly dependent on fuel temperature. Calculations based on Refs. $[3,53]$, and presented in Fig. 7-2 predict time necessary to redeposit $\mathrm{UO}_{2}$. According to Fig. 7-2, fuel vaporizing at $1900 \mathrm{~K}$ will $\mathrm{fill}$ a $1 \mathrm{mil}$ gap in 3 hours; at $1800 \mathrm{~K}$ it would take 26 hours; and at $1700 \mathrm{~K}$ it would take 260 hours. If, for example, a $\frac{1}{2}$ mil gap existed and the average fuel temperature was $1800 \mathrm{~K}$, except near the emitter lead region where it was $1700 \mathrm{~K}$, a $\frac{1}{2}$ mil gap would be filled in the $1800 \mathrm{~K}$ region in 213 hours. During this time, however, only 5/100 of $1 \mathrm{mil}$ would be filled near the top. Upon the power resumption back to operating temperature, the majority of the emitter would be pushed out beyond its original ratcheting displacement at this temperature. This incremental displacement increase is $v_{\frac{1}{2}} \mathrm{mil}$ over the bottom half of the emitter and decreases toward the lead region. 


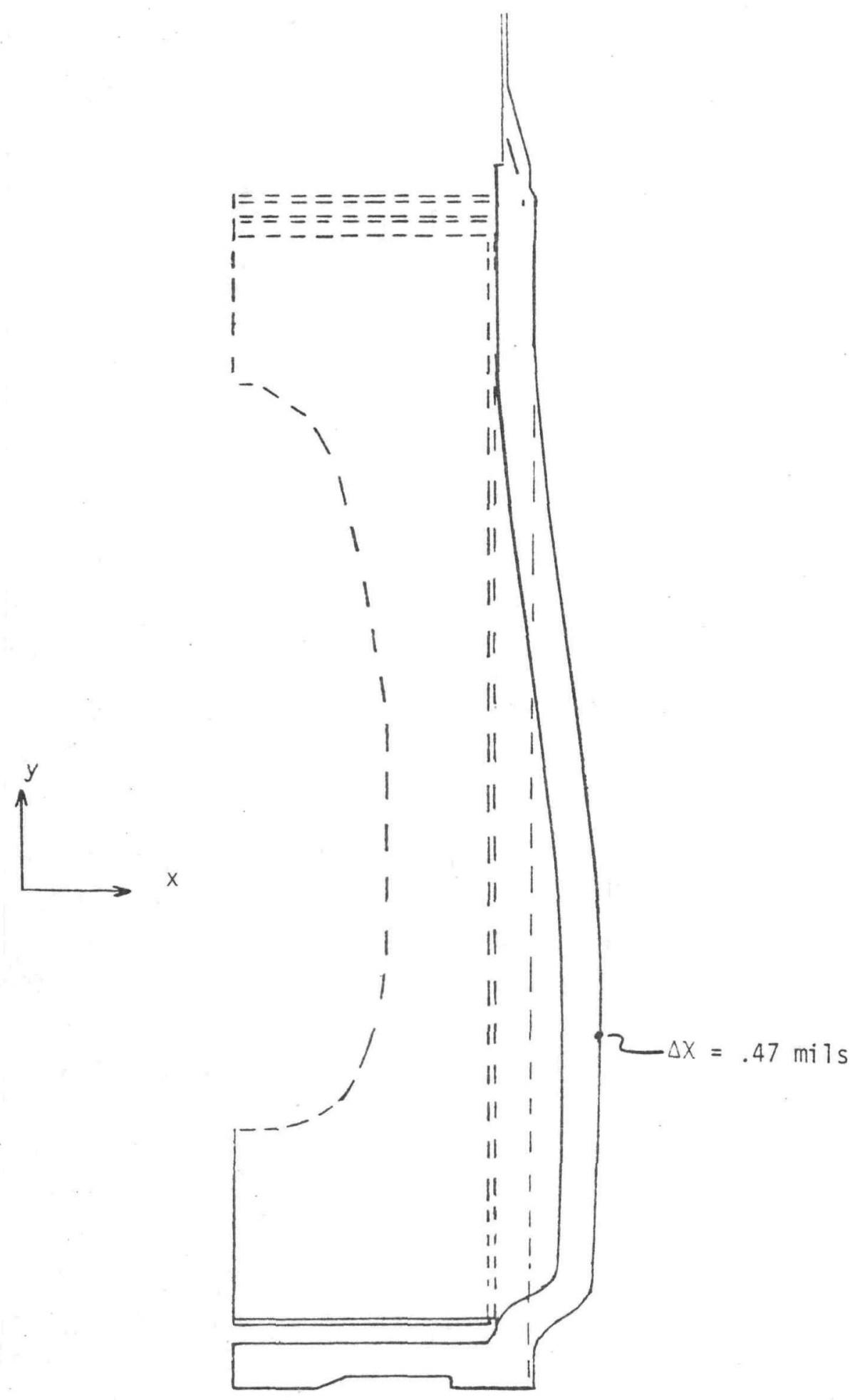

Fig. 7-21 DISTORTED EMITTER GEOMETRY $100 \mathrm{~K}$ RATCHETING CYCLE 
This .5 mil incremental strain consists of elastic and plastic components. If the power were reduced again, immediately after stretching the emitter outward, approximately .2 mil of the .5 mil strain would permanently remain in the emitter; this is the plastic strain portion of the incremental strain. If, however, the full power level (and temperature) is held for an indefinite period of time, the induced elastic stresses would relax-out due to creep and the .3 mils of elastic strain would be absorbed through creep by the fuel and emitter in proportion to their creep strengths. Consequently, to handle smaller temperature and power fluctuations, the elastic stress relaxation time as well as vapor deposition time become important considerations in developing a computational subroutine.

More work in this area is necessary to determine what range of power cycles, hold-times, and temperature regimes are acceptable and which conditions could lead to life-limiting deformation.

\subsubsection{Bladder Effect}

The bladder effect is the result of gas pressure buildup in the central void and becomes another potential deformation mode. Due to the arrival of fission gases into the cental void, pressure in the central void increases with time. The pressure differential across the fuel skull may force these captured gases to diffuse out of the void. At some pressure within the central void, gas migrating into the central void will reach equilibrium with gas diffusing out. Since gas arrival rates and diffusion rates are dependent on numerous parameters which change over time, gas pressure is not a constant over system lifetime.

To determine what effect, if any, a pressure loading would have on emitter deformation, a preliminary 2-dimensional viscoelastic analysis was performed using the SPI ANSYS model. Fuel void fraction was $12 \%$ and the

effect of central void pressure was evaluated at 50 psia, which could develop in about 5 weeks of SP-100 operation.

Upon initial application of the void pressure, deflection of both fuel and cladding is minimal. The pressure is resisted in part by both the fuel 


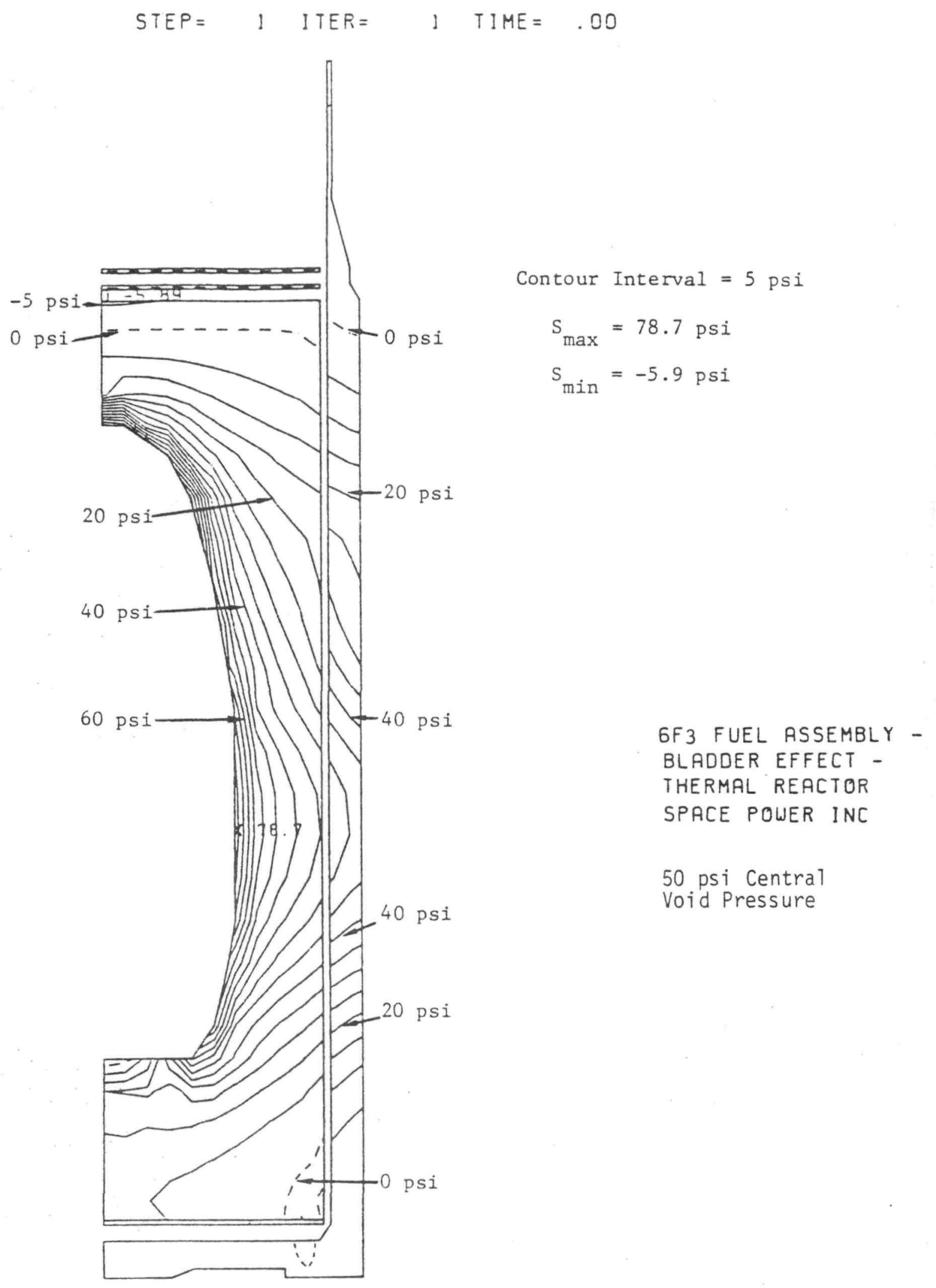

Fig. 7-22 BLADDER EFFECT @ O HRS. HOOP STRESS 
and the cladding. As shown in Fig. 7-22 the fuel central void pressure produces pressure-resisting hoop stress of 79 psi in the fuel while 53 psi appears in the emitter wall. Fig. 7-23 shows the distribution of "equivalent stress" which is a measure of triaxial stress.

$$
\text { SIGE }=\frac{1}{\sqrt{2}}\left[\left(\sigma_{1}-\sigma_{2}\right)^{2}+\left(\sigma_{2}-\sigma_{3}\right)^{2}+\left(\sigma_{3}-\sigma_{1}\right)^{2}\right]^{\frac{1}{2}}
$$

where $\sigma_{1}, \sigma_{2}, \sigma_{3}=$ principal stresses

At temperatures experienced in this example, structural creep occurs rapidly, especially in the $\mathrm{UO}_{2}$ fuel. Three creep mechanisms are present in $\mathrm{UO}_{2}$ : diffusion; dislocation; and irradiation.

$$
\begin{aligned}
& E_{S} \propto \frac{F \sigma e^{\left(-Q_{1} / T\right)}}{D G^{2}}+\frac{\sigma^{4.5} e^{\left(-Q_{2} / T\right)}}{D}+F e^{\left(-Q_{3} / T\right)} \\
& \text { Diffusion Dislocation Irradiation } \\
& \text { Where: } E_{S}=\text { steady state creep rate } \\
& F=\text { fission rate } \\
& \sigma=\text { stress } \\
& Q_{1}, Q_{2} \text {, } Q_{3}=\text { activation energy } \\
& D=\text { density } \\
& G=\text { grain size } \\
& T=\text { temperature }
\end{aligned}
$$

Diffusion creep occurs when vacancies diffuse from grain boundaries in tension to grain boundaries in compression. This creep mode is dominant in low stress situations. Fission rate has a significant influence on diffusion creep and, along with temperature and grain size, causes large variations in local creep rates within the fuel. 
STEP $=1$ ITER $=1$ TIME $=.00$

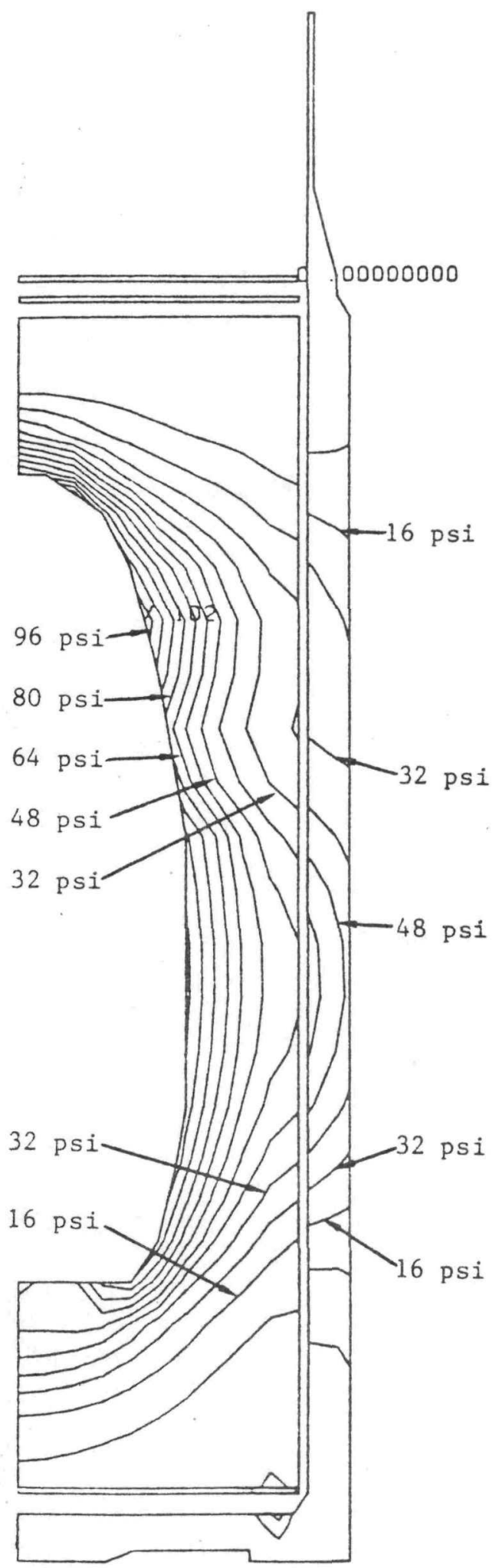

$$
\begin{gathered}
\text { Contour Interval }=8 \mathrm{psi} \\
\mathrm{S}_{\max }=102.1 \mathrm{psi} \\
\mathrm{S}_{\min }=0 \mathrm{psi}
\end{gathered}
$$

6F 3 FUEL ASSEMBLY BLADDER EFFECT THERMAL REACTOR SPACE POWER INC

50 psi Central Void Pressure

Fig. 7-23 BLADDER EFFECT @ O HRS. EQUIVALENT STRESS 
Dislocation creep becomes significant when shear stresses within the crystal structure allow movement of dislocations. This mode of creep becomes dominant at high stresses.

The activation energies of both diffusion and dislocation creep are highly sensitive to fuel stoichiometry as seen below in Fig. 7-24 from [51]. The degradation of activation energy significantly increases the creep rate of both modes.

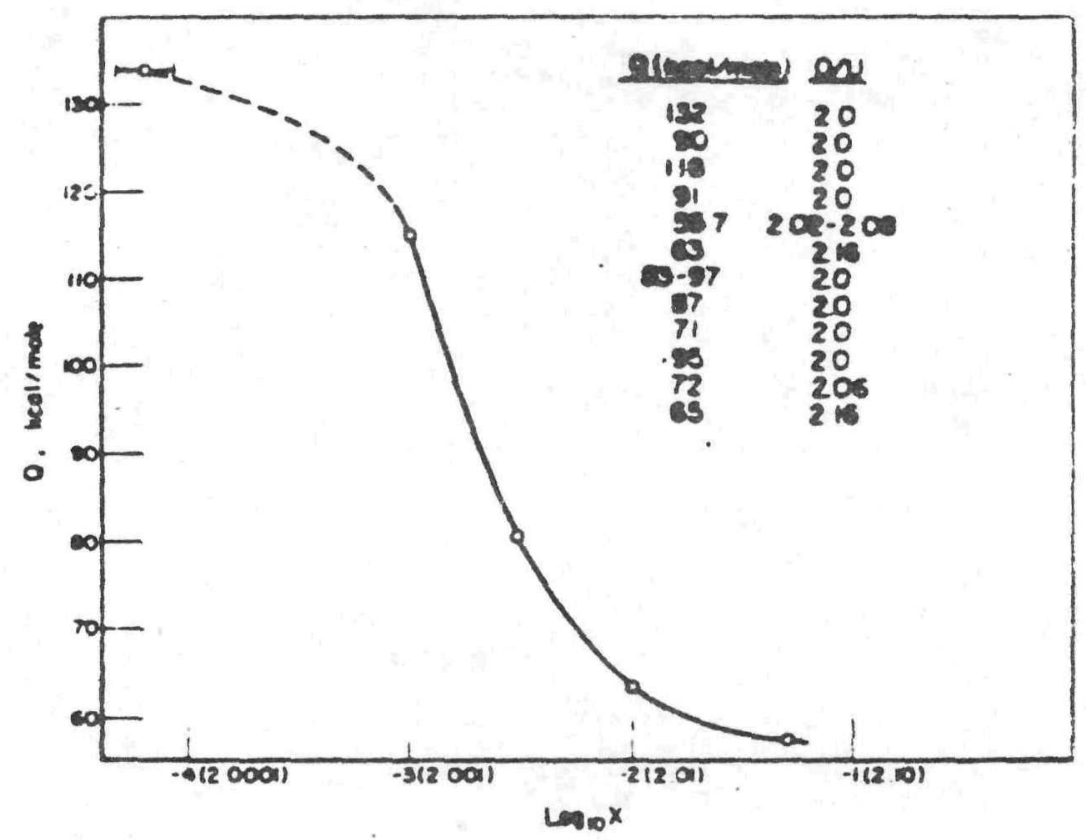

Fig. 7-24 CREEP ACTIVATION ENERGY VS. STOICHIOMETRY

The distribution of bladder effect hoop stress at 2.5 hours is shown in Fig. 7-25. With the exception of the inner surface of the fuel, the presence of hoop stress in the fuel has virtually disappeared. Because of the creep relaxation of hoop stress in the fuel, the cladding must now resist a greater proportion of the load caused by gas pressure. This is evidenced by the significant increase in cladding hoop stress, up to 174 psi from 53 psi at 0 time. At this point the fuel is offering virtually no resistance to the pressure load. Fig. 7-26 shows the equivalent stress distribution at 2.5 hours. The equivalent stress has increased in the cladding, as expected, and also in the outer fibers of the fuel. The increased equivalent stress is due 
STEP $=2$ ITER $=20$ TIME $=2.5$

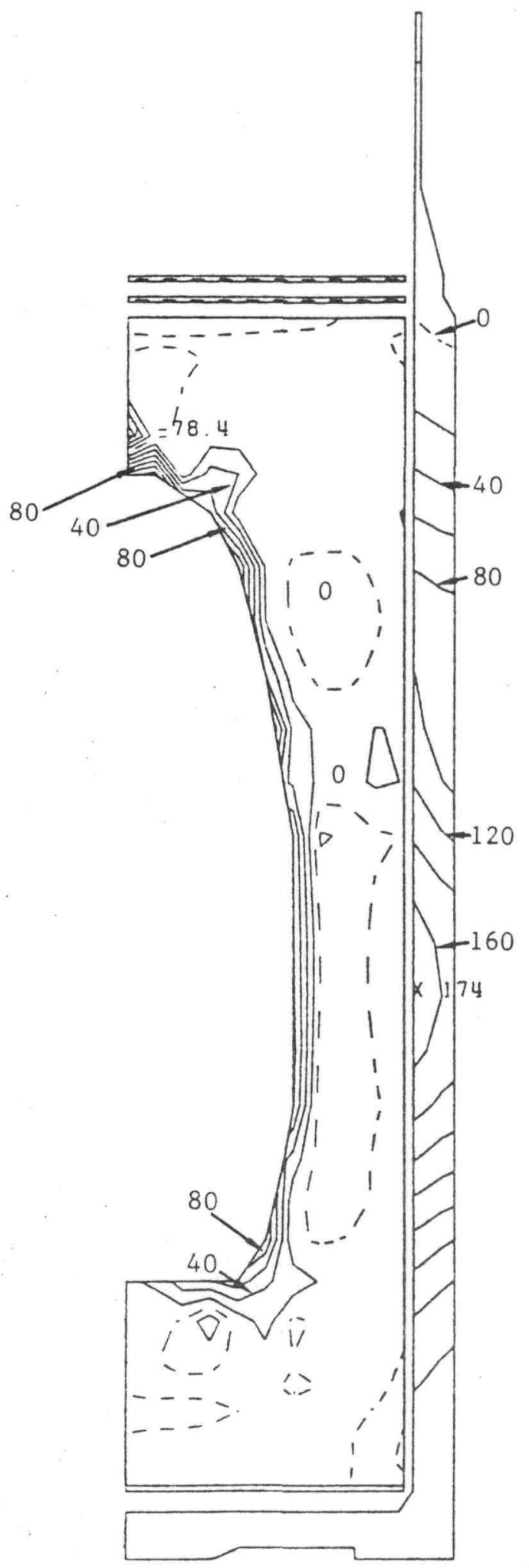

$$
\begin{aligned}
& \text { Contour Interval }=20 \mathrm{psi} \\
& \begin{aligned}
\mathrm{S}_{\max } & =173.6 \mathrm{psi} \\
\mathrm{S}_{\min } & =-78.4 \mathrm{psi}
\end{aligned}
\end{aligned}
$$

6F3 FUEL ASSEMBLY BLADDER EFFECT THERMAL REACTOR SPACE POUER INC

50 psi Central Void Pressure

Fig. $7-25$

BLADDER EFFECT @ 2.5 HRS. HOOP STRESS 
STEP $=2$ ITER $=20$ TIME $=2.5$

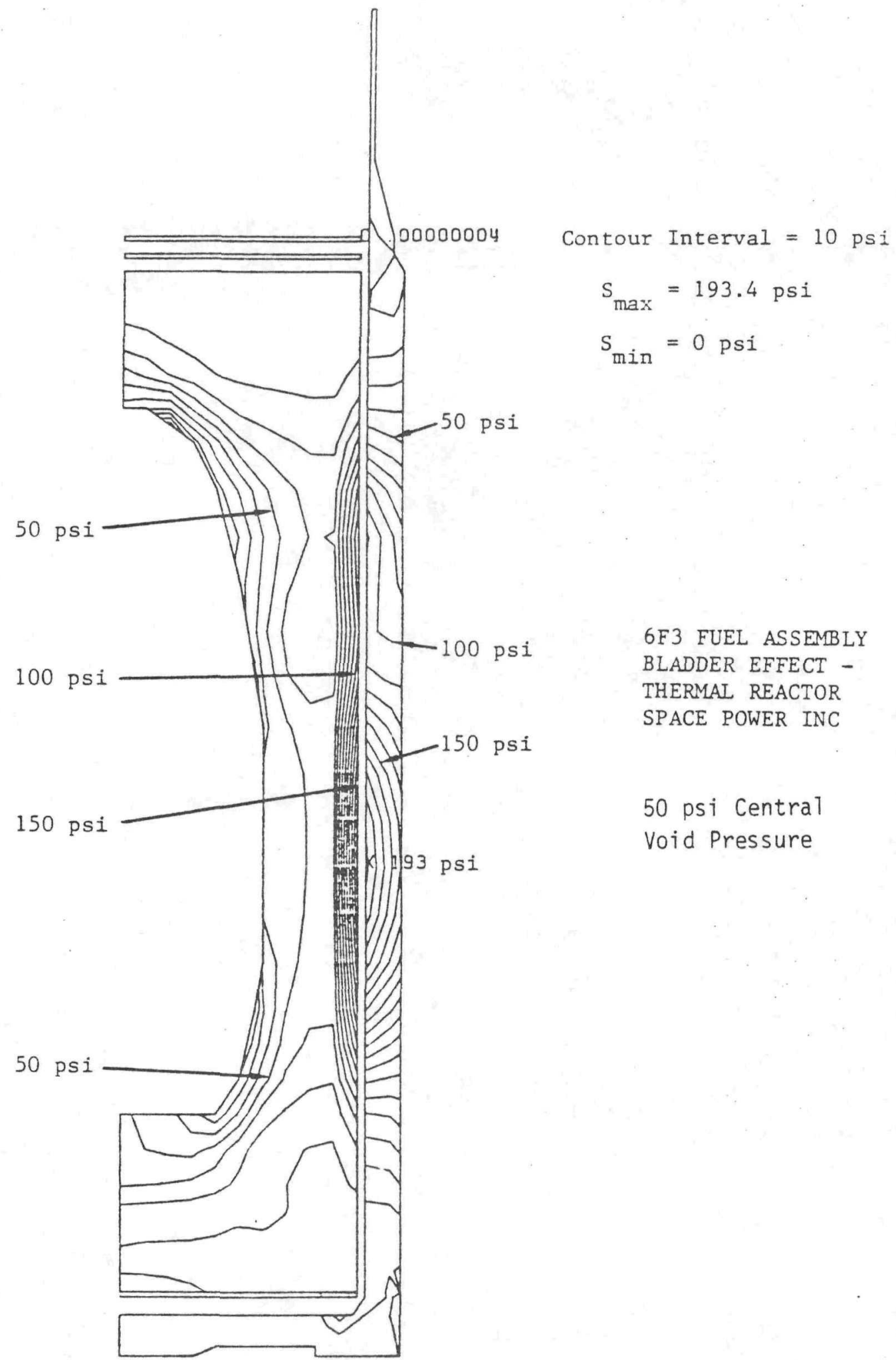

Fig. 7-26 BLADDER EFFECT @ 2.5 HRS. EQUIVALENT STRESS 
to its substantial increase in axial component of equivalent stress. This is evidenced by the axial stress plots at time $=0$ and 2.5 hours in Figs. 7-27 and $7-28$, respectively. Although the fuel transfers a large portion of the hoop load to the cladding, there is no other structural member to resist the pressure-induced axial load. As a result the increased axial stress causes an increase in equivalent stress.

Because of relaxation of hoop stress in the fuel, the emitter stress was highest where the fuel strength was lowest. The resultant cladding distortion was displayed by the exaggerated geometry plot of Fig. 7-29. As seen, the emitter bulges out the greatest amount at precisely the location of highest hoop stress in the emitter.

At the end of 2.5 hours, the emitter was creeping outward at the rate of 1.1 mils per 1 year. Because of the low creep strength of $\mathrm{UO}_{2}$ and no other structural restraint in the axial direction, the fuel crept upward in this example at the rate of $35 \mathrm{mils}$ per year. At this rate, the fuel could rupture in the top skull region before 7-year life was attained. No noticeable dome formation of the fuel skull was apparent at 2.5 hours. It was expected that it is too early for the effect to be observed.

Since both fuel and cladding were creeping radially outward under the pressure loading, both offer resistance to this load proportional to their relative creep strengths. In the fast neutron environment, the fuel has a higher average temperature and will have a correspondingly lower creep strength and will contribute less to the collective resistance of pressure. This forces the emitter to accept an even higher load and creep faster if the dome and dome diffusion rates could support an equivalent interval void pressure.

The choice of 50 psi was merely an estimate. However, it is certainly not an unreasonable pressure given the intent of this study is to determine that, if left unvented, the bladder effect could be a significant contributer to emitter deformation. Of particular interest is the distinctive shape of emitter distortion due to the bladder effect. The maximum radial distortion occurs at a location of approximately 1" from the emitter bottom. This 


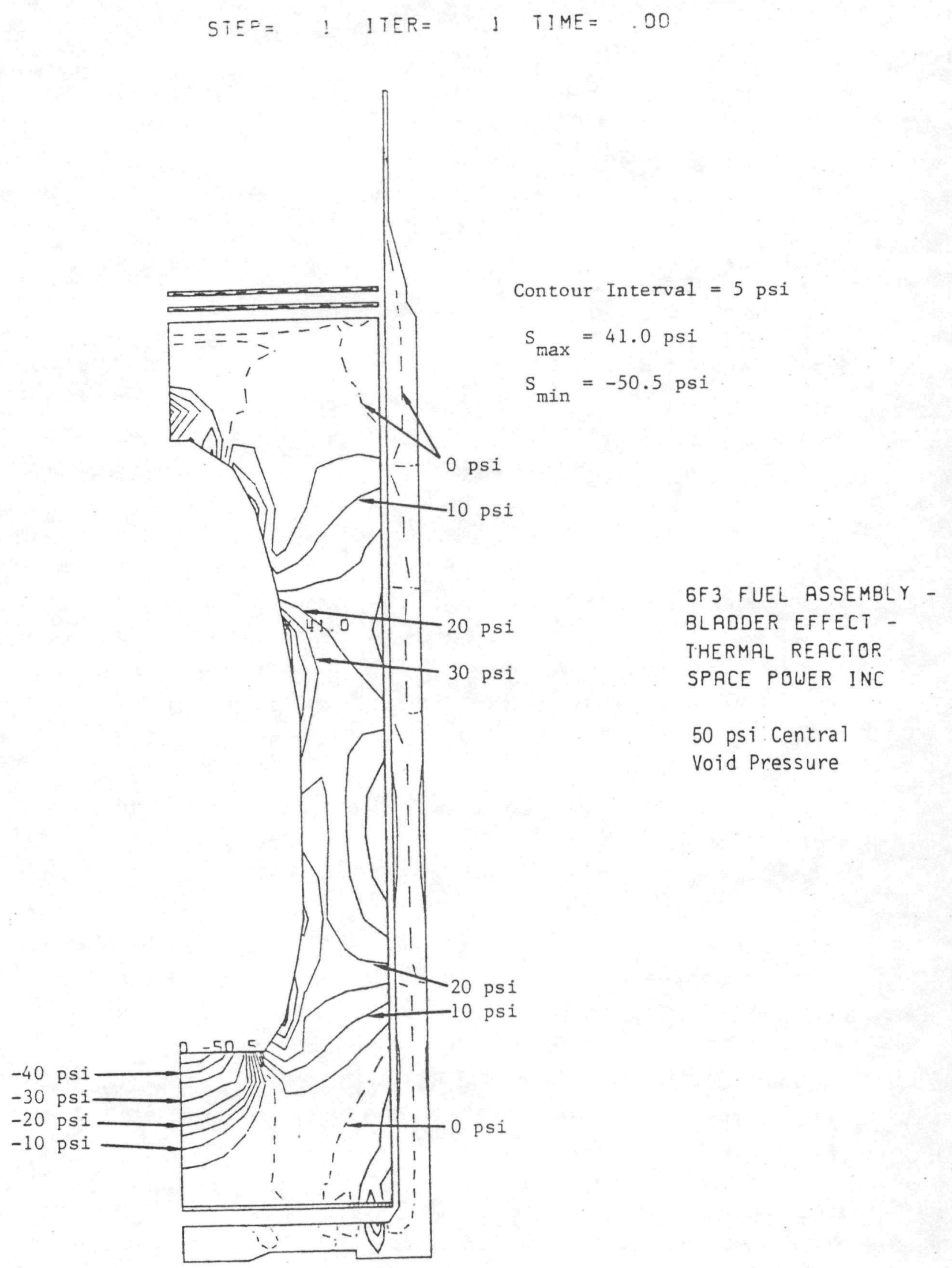

Fig. 7-27 BLADDER EFFECT \& 0 HRS. AXIAL STRESS 
STEP $=2$ ITER $=20$ TIME $=2.5$

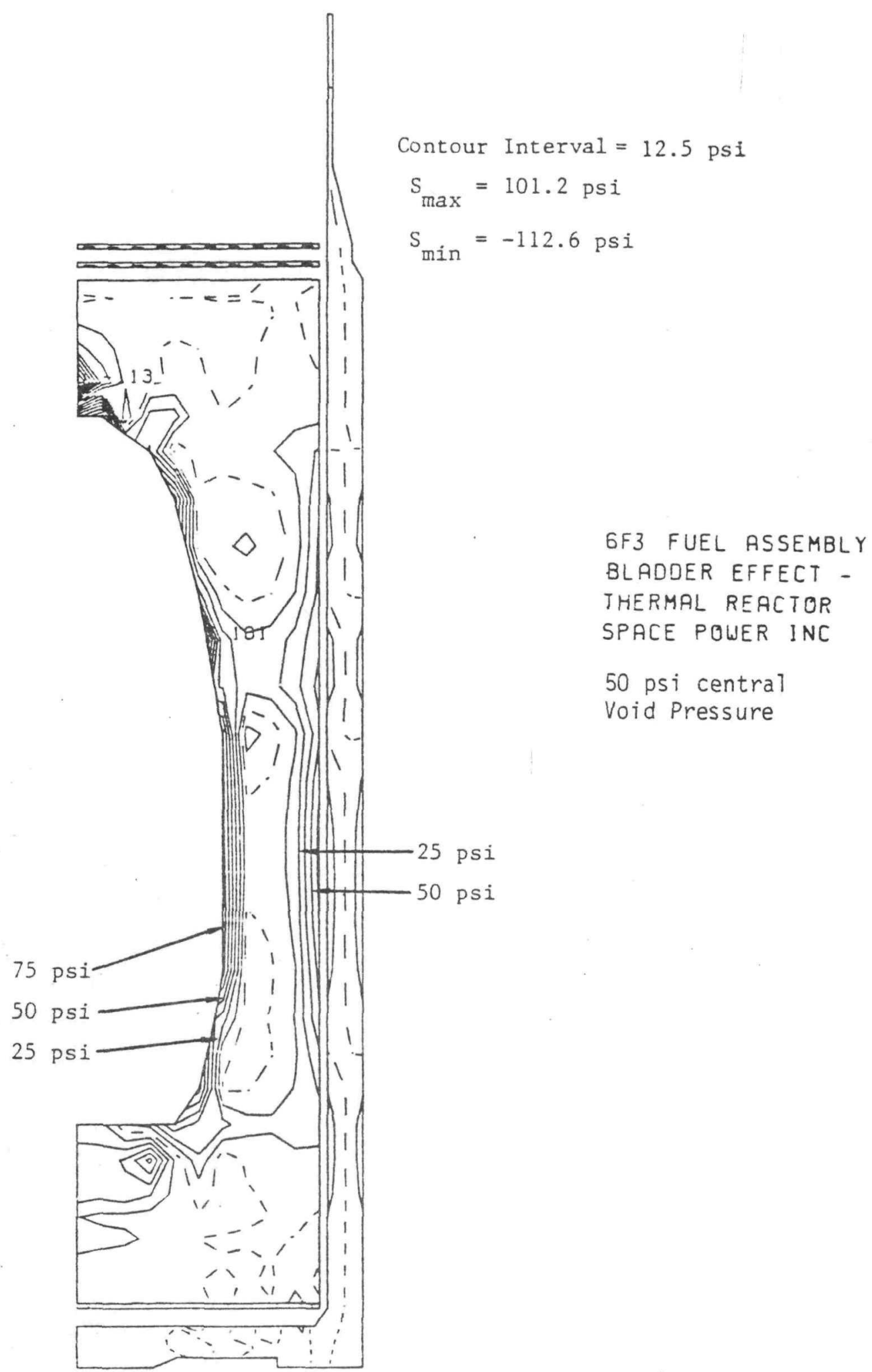

Fig. 7-28 BLADDER EFFECT @ 2.5 HRS. AXIAL STRESS 
STEP $=2$ ITER $=20$ TIME $=2.5$

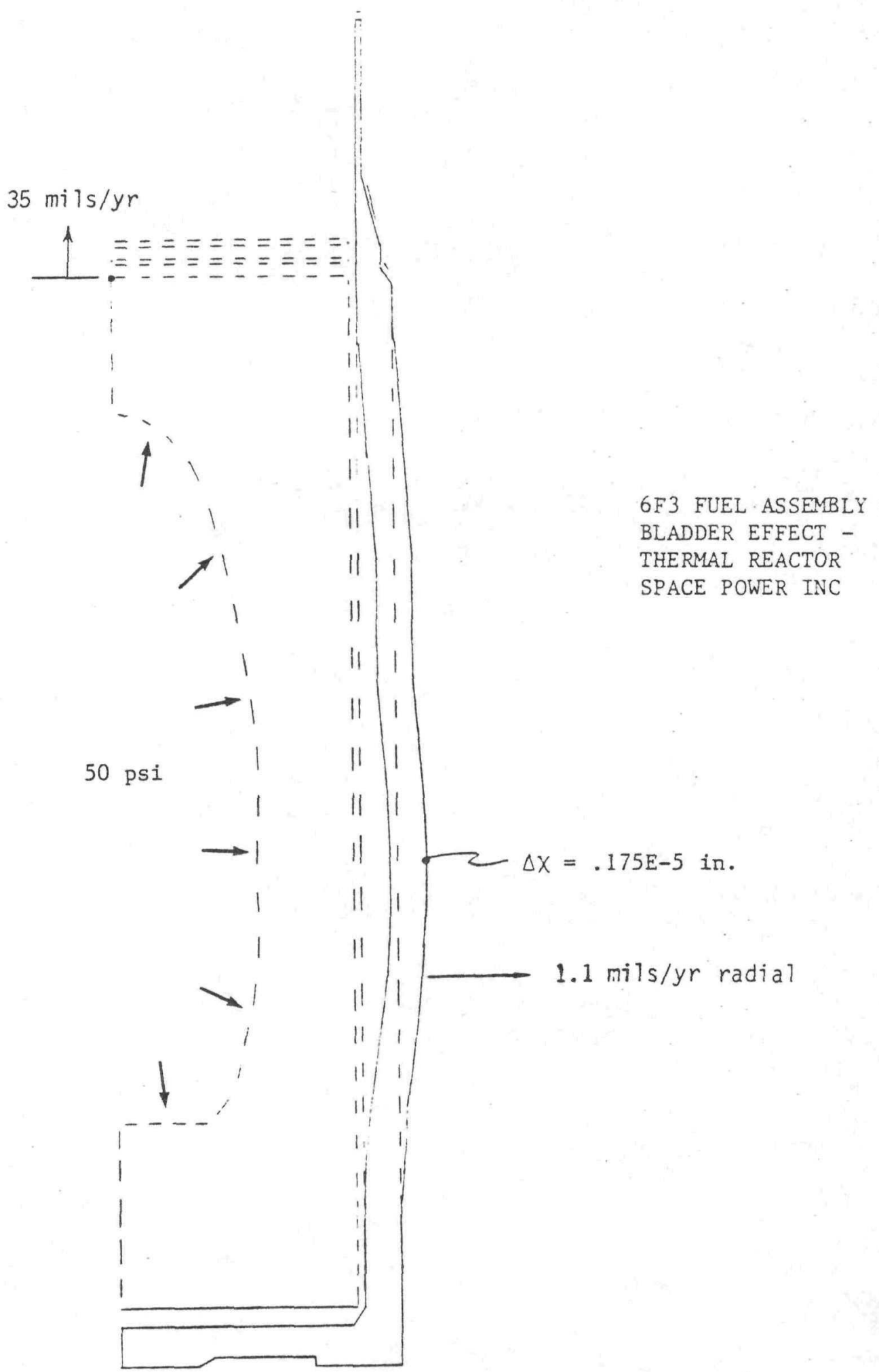

Fig. 7-29 DISTORTED EMITTER GEOMETRY DUE TO BLADDER. EFFECT @ $2.5 \mathrm{hrs}$. 
distortion, in the shape of a barrel, varies distinctively from that due to thermal ratcheting.

As fuel void fractions become smaller, the amount of fission gas being generated and accumulating in the void increases at the same time that the volume to receive this gas is decreasing. Because of the smaller void volume, gas arriving in the void causes a larger incremental pressure rise. Smaller void fractions also tend to develop a small diameter thicker skull. This decreases gas venting diffusion/dome extrusion and eventual gas release due to skull rupture.

The thicker skull does, however, make it more susceptible to cracking due to thermally-induced stresses. The thicker skull would develop a greater differential temperature gradient during transients, hence larger stress levels and a higher possibility of cracking to relieve this thermally-induced stress.

Comparing Figs. 7-18 and 7-19, and studying the shapes of the isothermal voids in the fast and thermal neutron flux situations, it is seen that a thinner skull develops over the void in the fast reactor environment. This thinner skull would enhance the fission gas diffusion rate allowing equilibrium to be established at a lower void pressure. The thinner skull also allows pressure to rupture the skull at a lower pressure level than might have a significant effect on reducing emitter distortion. The thinner sku11, however, is less likely to crack due to thermal shock. As a result, thermal cracking that may have allowed the void pressure to escape in the thermal neutron environment may not be possible in the fast neutron flux environment.

At the gas generation and release rates that will exist in SP-100 fuel, there is no question that central void gas must be removed in order to prevent void pressures which would cause unacceptable emitter deformation. It is possible that diffusion through the skull is sufficient to prevent a significant contribution to emitter distortion. Credible theoretical prediction of the pressure-driven diffusion rate through the skull against a thermal gradient is difficult. This is an important area for out-of-pile 
testing to supplement theoretical prediction. If pressure-driven diffusion through the central void skull is inadequate to prevent bladder effect emitter distortion, then intentional periodic thermal cycling to crack the skulls or a hot snorkel vent may be required.

No work has yet been performed to determine what power fluctuations would be necessary to thermally crack the fuel skull, thus releasing pressure. ANSYS is well-suited to predict this. In its thermal transient mode, ANSYS can accurately predict two-dimensional temperature distributions and resultant stresses based on user-supplied time-history of power levels. This future analysis will be able to determine the feasibility of periodically cracking the fuel through power fluctuation.

Venting snorkels could be required for very long life or high burnups in $\mathrm{UO}_{2}$ fueled emitters. A straight long cylindrical vent .032 inch $O D$ by .0055 wa11 W-25\%-Re tube was tested by GA (IC-C13) in 1971-72 (Fig. 7-30). The thin-walled constant cross-section large opening tube plugged and filled with condensed $\mathrm{UO}_{2}$ (Fig. 7-31). The $W-2 \%$-Re stood up well against solid $\mathrm{UO}_{2}$, but was attacked in the $\mathrm{UO}_{2}$ vapor region (probably by $\mathrm{O}_{2}$ ). The more recent Soviet work has emphasized detailed thermal analysis around the snorkel [54]. Due to the nearly 10 -fold higher power densities, $400 \mathrm{~W} / \mathrm{cm}^{3}$ and $1 \mathrm{~cm}$ diameter $\left(2100 \mathrm{~K}\right.$ emitters discussed by the Soviets, versus the $10 \mathrm{w}$ power $40-60 \mathrm{~W} / \mathrm{cm}^{3}$ and $2.8 \mathrm{~cm}$ diameter $(1700$ to $1800 \mathrm{~K}$ ) emitters being studied for SP-100, the Soviet central fuel cavity temperatures are in the range of 2600 to $2700 \mathrm{~K}$ vs $2200 \mathrm{~K}$ to $2300 \mathrm{~K}$ in the SP-100 central cavities. At these much higher temperatures and power densities the Soviet snorkels seem to emphasize very fine ( $1-2$ mil) single axial vent holes than a thick hot orifice plug backed by a larger diameter vent tube. The concept is to limit the amount of vapor that can transport through a very fine hole and to provide a sufficiently large condensation reservoir behind it that the vent tube cannot become plugged (see Figs. 7-32 and 7-33) [54,55].

\subsubsection{Fuel Swelling}

Fuel swelling due to fission products is also a concern. It is the intent of this analysis to show what effect, if any fuel swelling may have on 


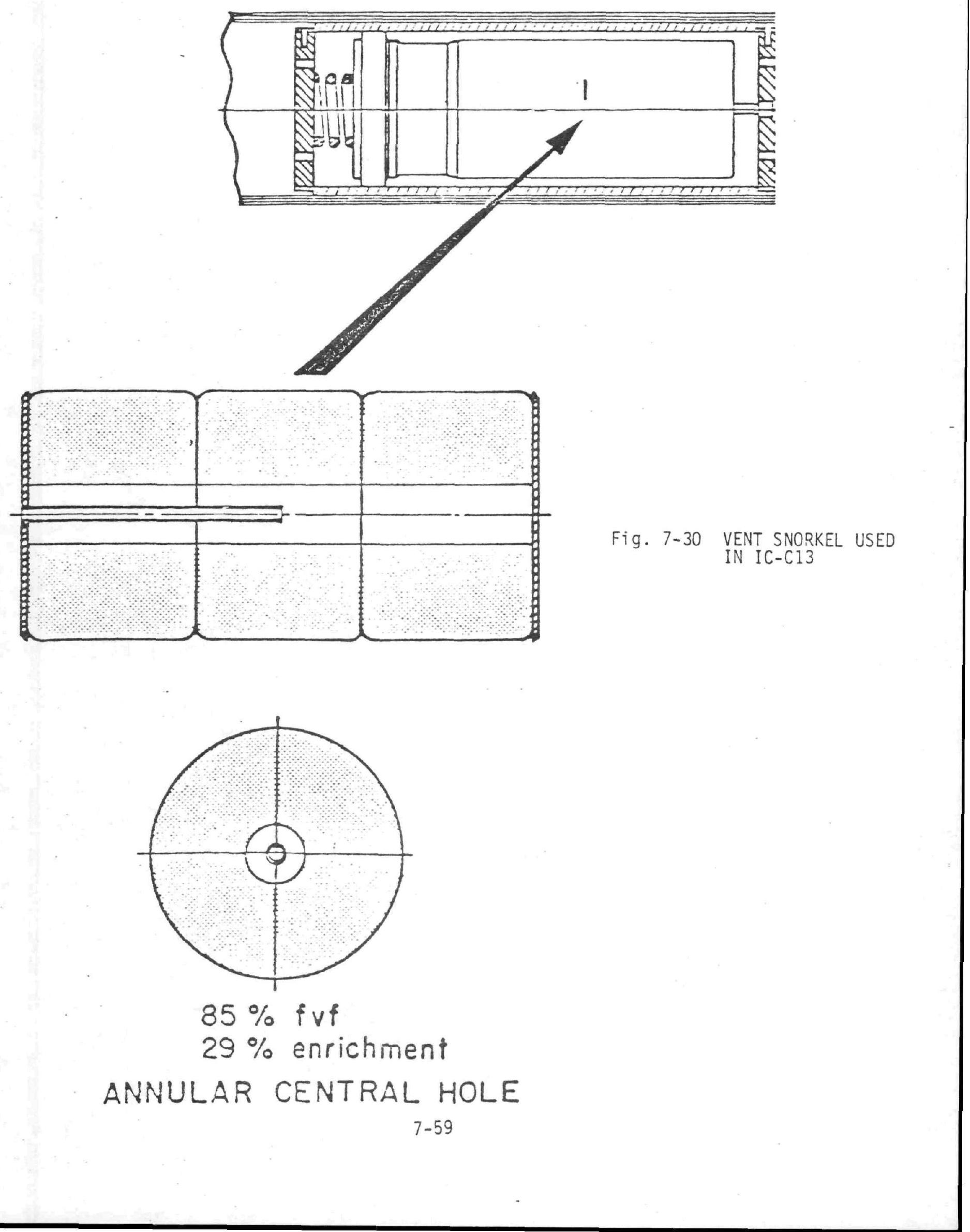




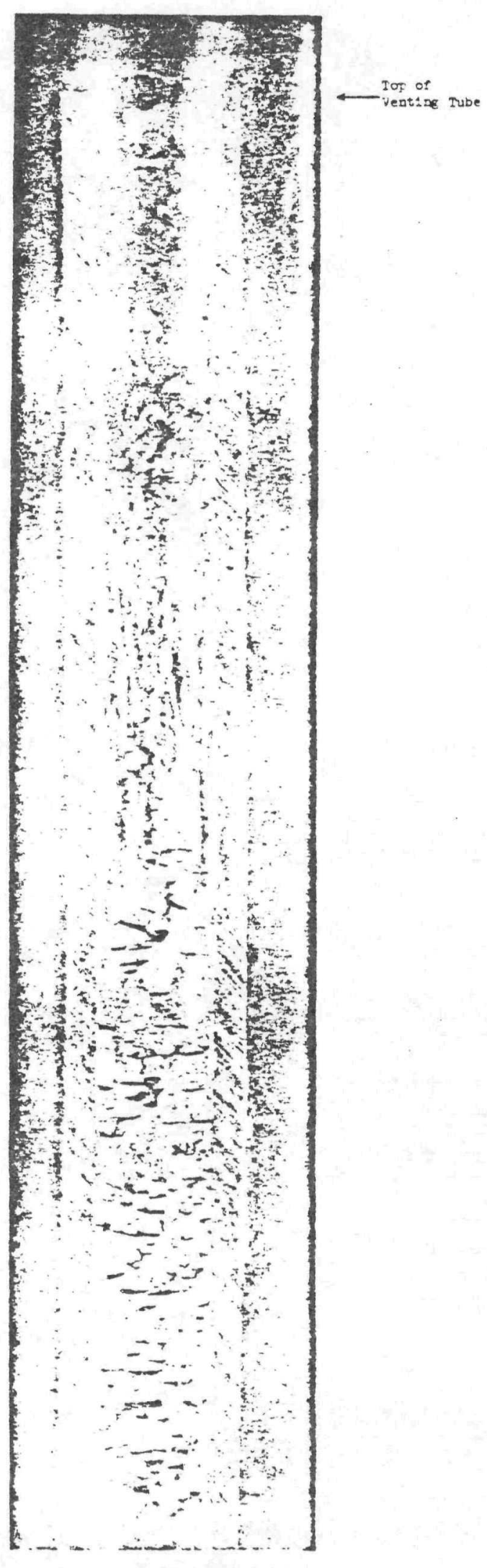

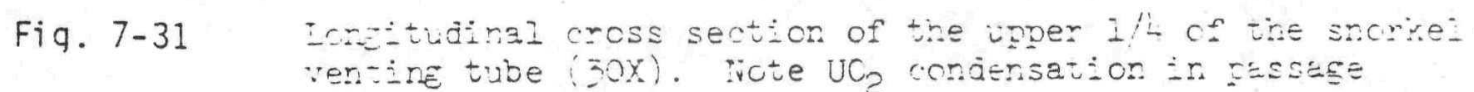



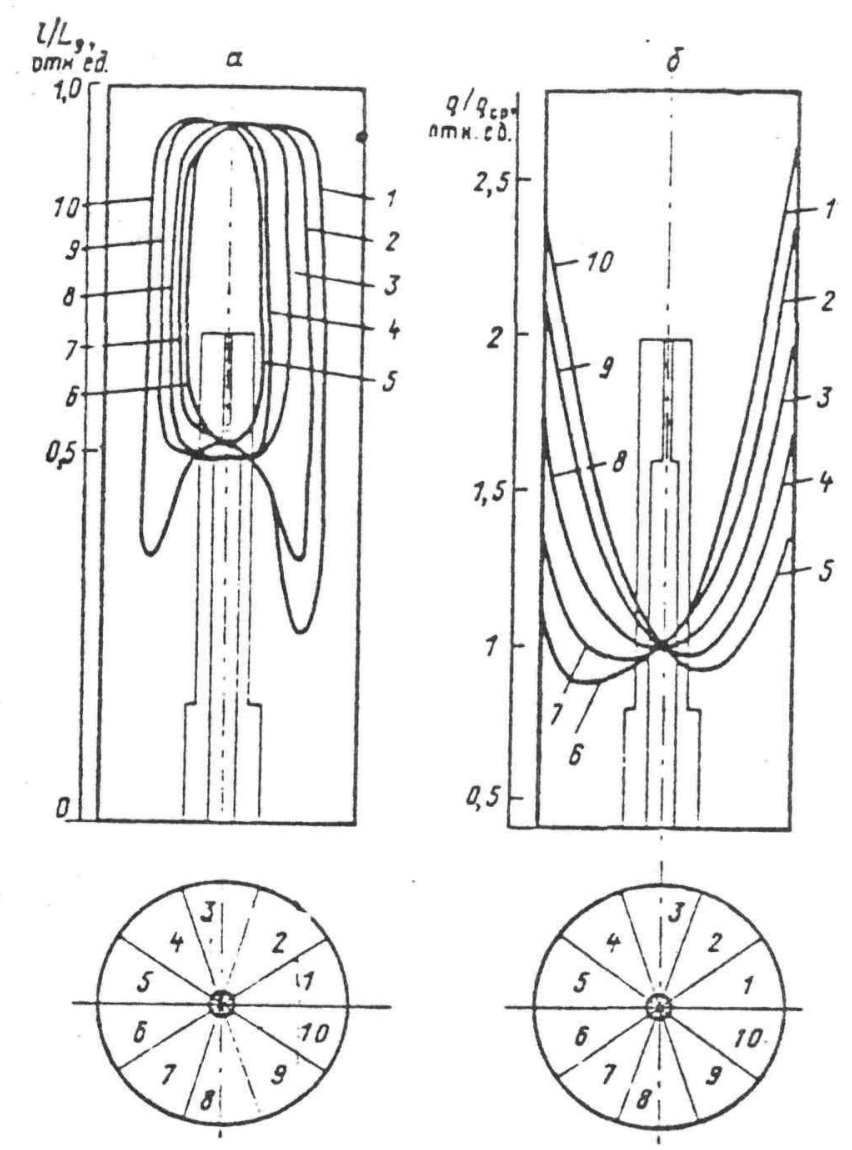

Fig. 7-32 SOVIET SNORKEL DESIGN

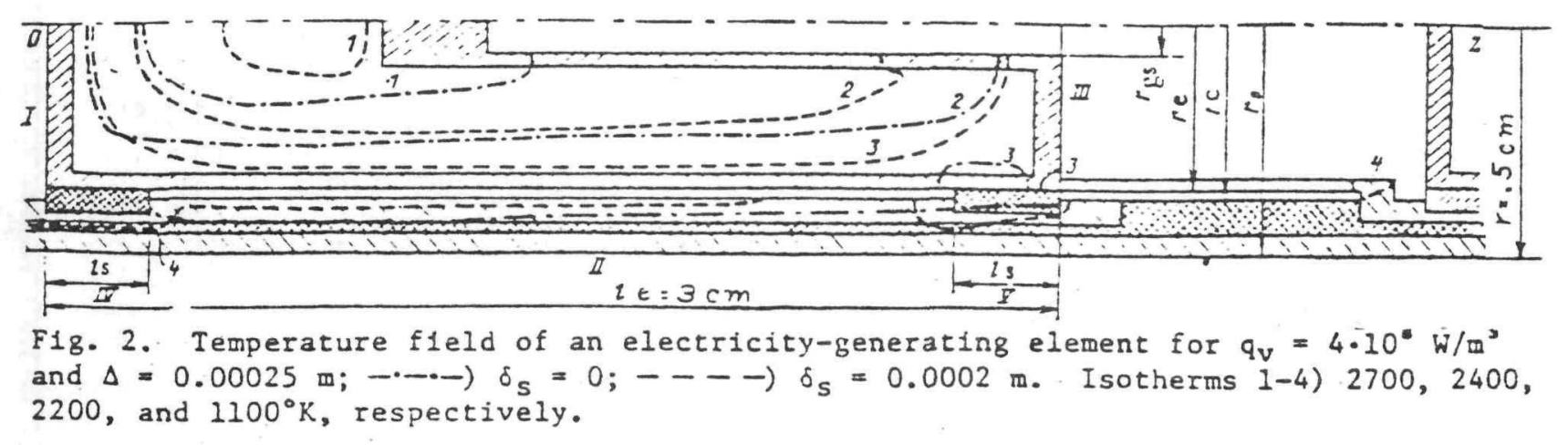

Fig. 7-33 SOVIET SNORKEL DESIGN 
the cladding. The subject of fuel swelling mechanics and swelling rates data are discussed in section 7.2 of this report. For the purpose of simplicity, very conservative swelling rates based on Zimmerman unconstrained data as presented in Fig. 7-34 have been incorporated into this ANSYS swelling demonstration analysis. This data [56] yields unconstrained swelling rates in the vicinity of $2.6 \% \Delta V / V$ per year on the surface where highest fission rate occurs. This assumed upper bound rate is only used in this demonstration to exhibit the effect of high fuel swelling rates if they exist and is not meant to be considered representataive of actual swelling rates to be encountered in SP-100.

The distorted geometry of the emitter and fuel after 4.8 hours of swelling are shown in Figs. 7-35 and 7-36 respectively from the ANSYS test analysis. A majority of the emitter distortion occurs at the top and bottom where the fuel is solid. At these locations, the fuel is stronger in comparison to the emitter. At a location midway along the length of the fuel where the central void exists, the fuel is weakest relative to the cladding emitter wall. Essentially an hourglass shape is taken by the emitter when distorted by redeposited fuel density loss.

As shown in Fig. 7-35, the radial emitter distortion at the top in 4.8 hours is slightly larger than the distortions at the bottom. At the hotter bottom region, the creep strength of the fuel relative to the emitter is less than in the top cooler region. For this reason, the cladding at the bottom is able to resist more of the fuel swelling and force the fuel to distort more so than at the top.

Figs. 7-37 and 7-38 show the distribution of hoop and equivalent stress respectively after 4.8 hours of fuel swelling. Emitter stress is highest at the two locations where distortion is greatest. Because of the relative high creep rate of $\mathrm{UO}_{2}$, peak equivalent stress in the fuel is $\sim^{\frac{1}{2}}$ that existing in the emitter.

Although the cladding has distorted some to accommodate the fuel swelling, the fuel has displaced to a greater degree. While the emitter has distorted in some locations up to $1.5 \times 10^{-6} \mathrm{in.}$, the central void has been 


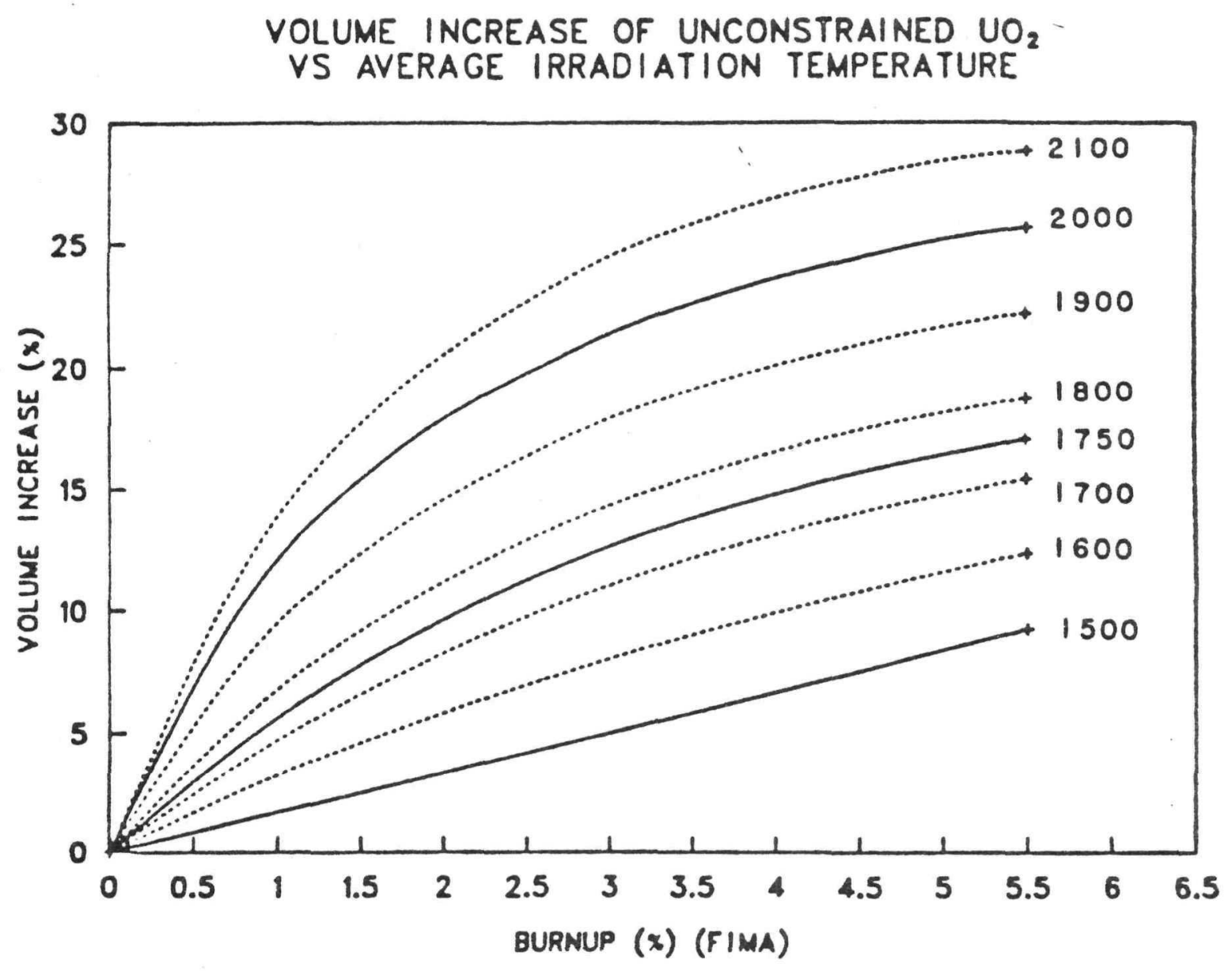

Fig. 7-34 FUEL SWELLING VS. BURNUP (REF. 16) 


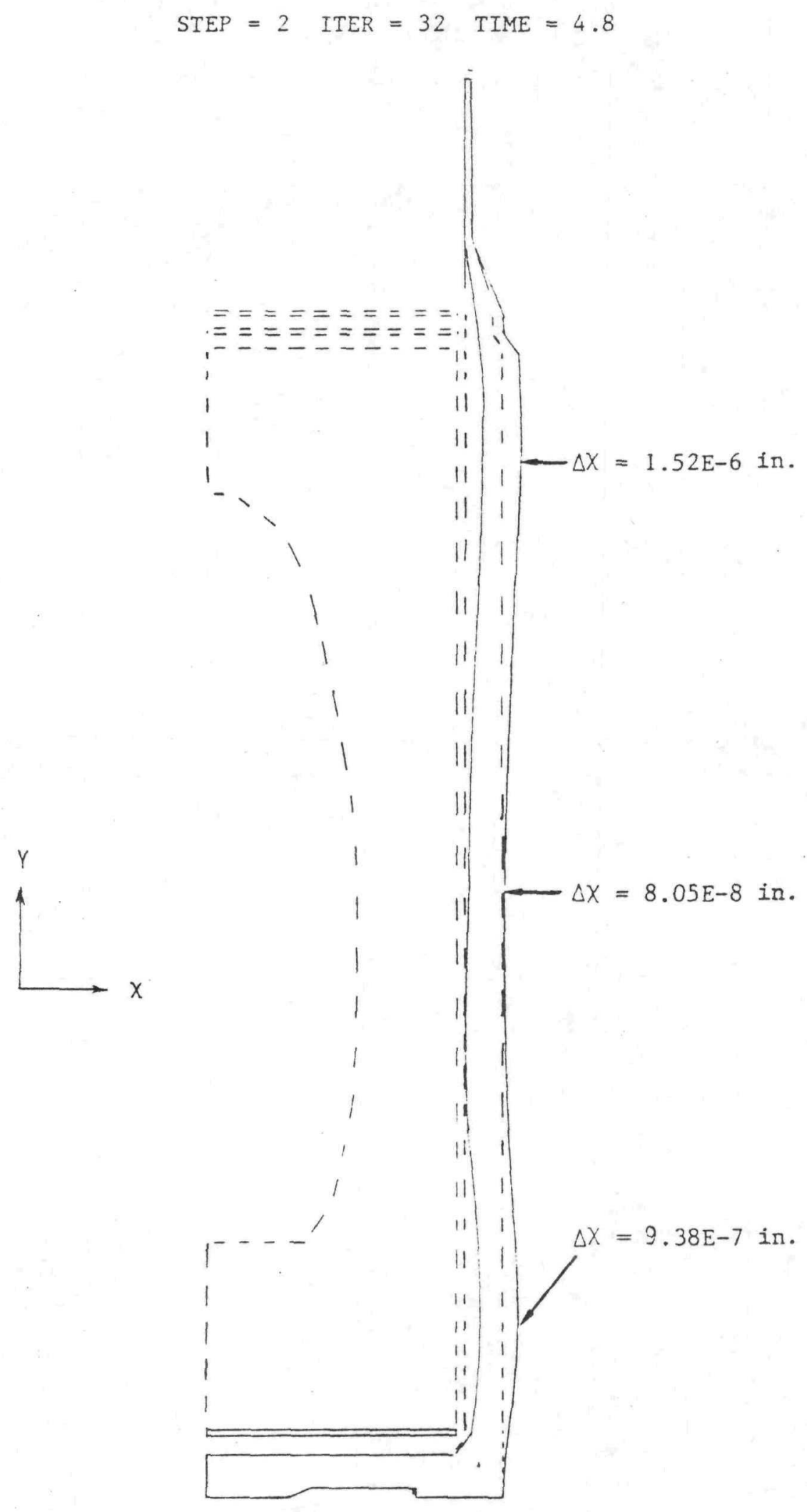

6F3 FUEL ASSEMBLY FUEL SWELLING THERMAL REACTOR SPACE POWER INC

Fig. 7-35 DISTORTED EMITTER GEOMETRY DUE TO FUEL SWELLING @ 4.8 HRS.

$$
7-64
$$




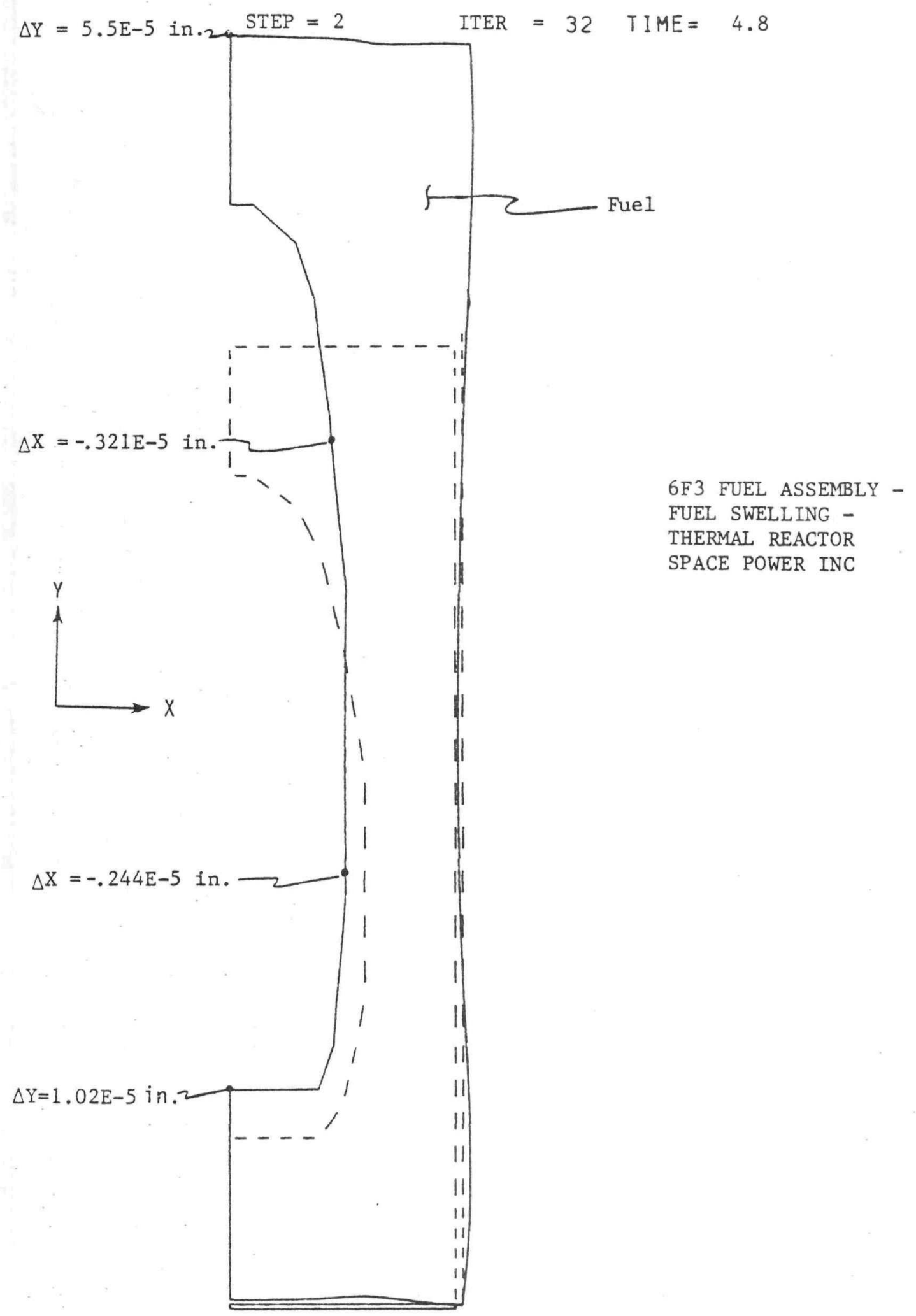

Fig. 7-36 DISTORTED FUEL GEOMETRY DUE TO FUEL SWELLING @ $4.8 \mathrm{hrs}$. 


$$
\text { STEP }=2 \text { ITER }=32 \text { TIME }=4.8
$$

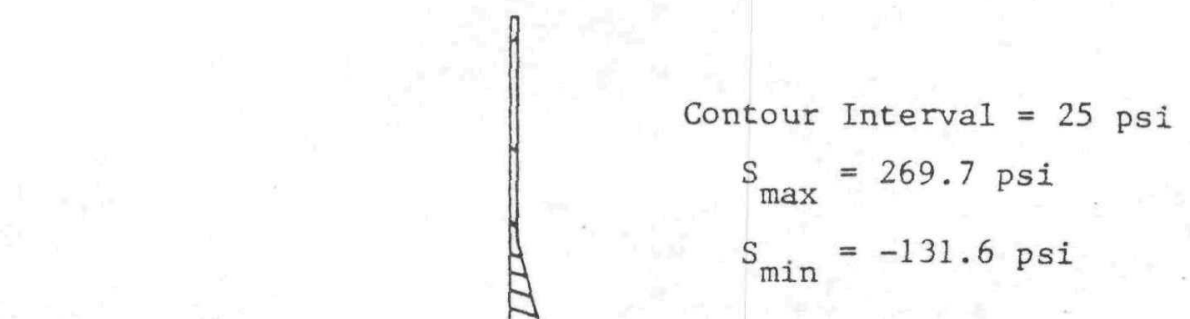

6F3 FUEL ASSEMBLY FUEL SWELLING THERMAI REACTOR $-50 \mathrm{psi}$ 0 psi
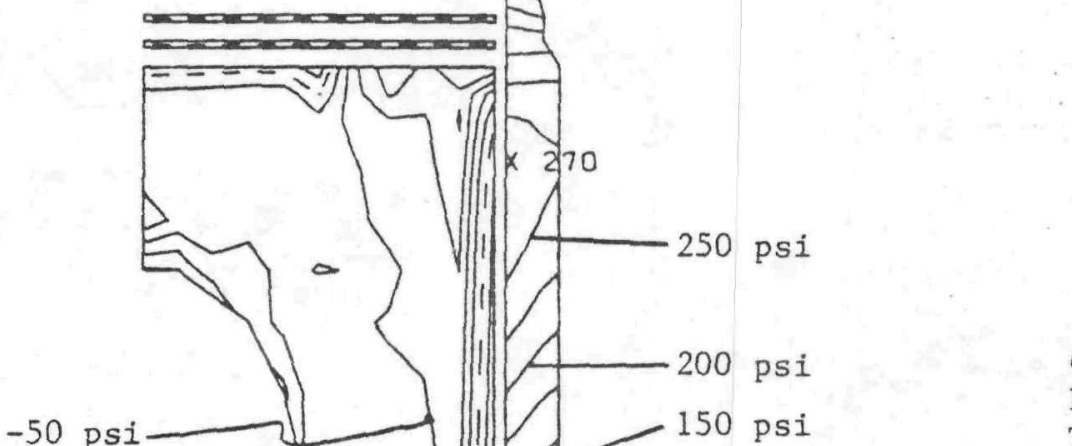
SPACE POWER

50 psi

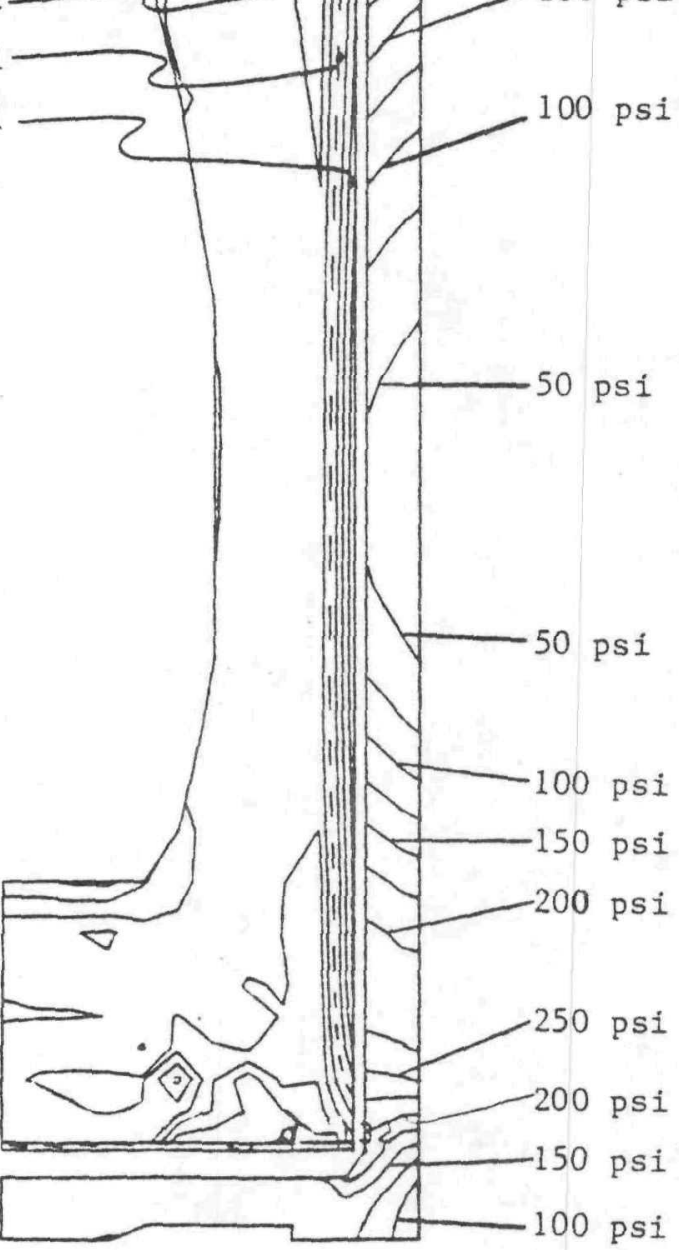

Fig. 7-37 FUEL SWELLING EFFECT \& $4.8 \mathrm{hrs}$ - HOOP STRESS 


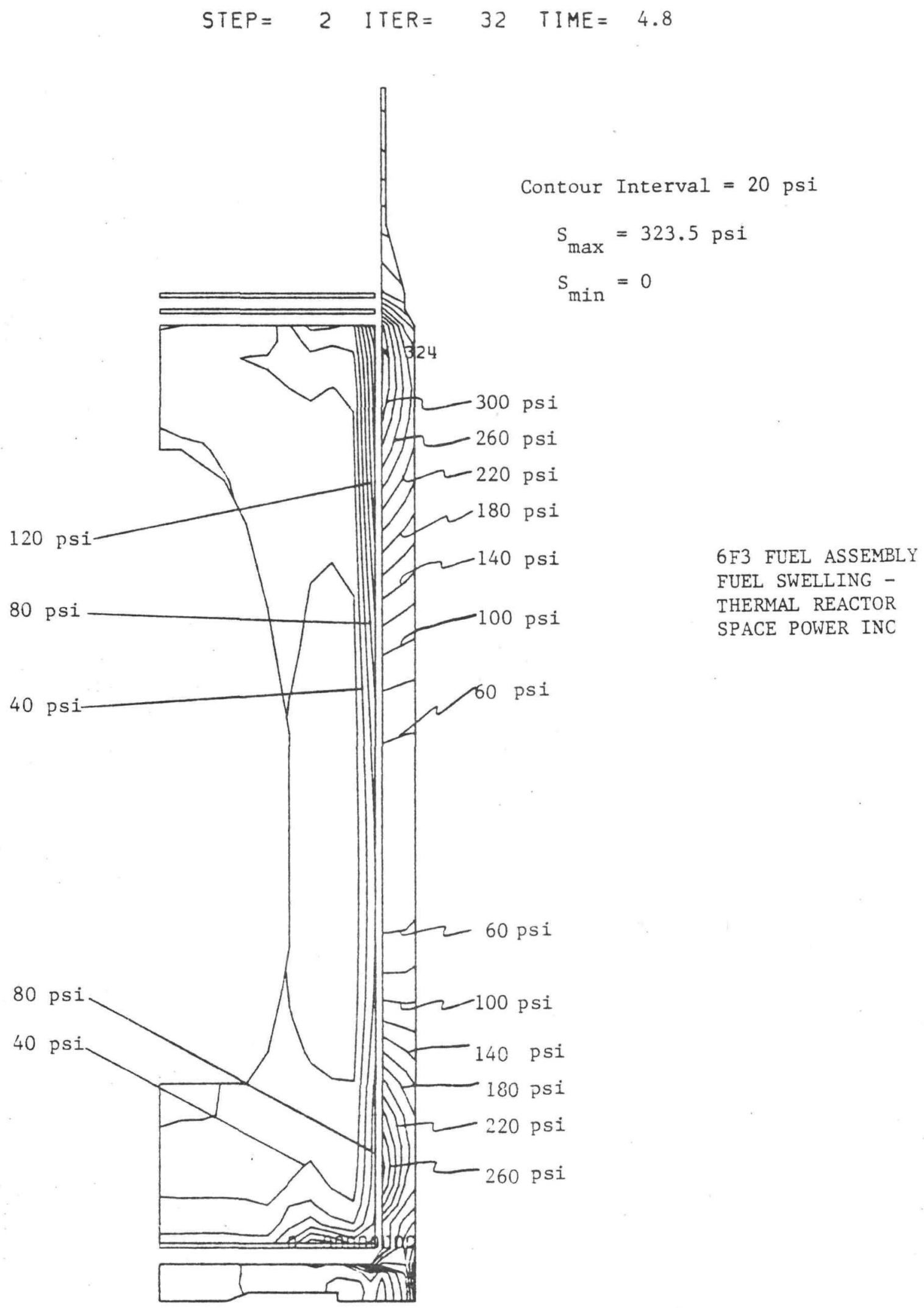

Fig. 7-38 FUEL SWELLING EFFECT AT $4.8 \mathrm{hrS}$ - EQUIVALENT STRESS 
squeezed inward and upward $255 \times 10^{-6}$ in., as shown exaggerated in Fig. 7-36. It may not be accurate to project lifetime radially distortion based upon such a short-time reference, and exaggerated unconstrained fuel swelling rates. Nonetheless the calculations would extrapolate to the emitter growth outward .019" on the radius in 7 years and the fuel moving upward .704" into the intercell plenum. While the fuel is swelling up to $18.2 \%$ in some areas, the cladding is being distorted only $23.5 \%$ during this time.

These measurements are made with several qualifications. The peak fuel swelling rate of $2.6 \%$ year at the fuel surface is totally non-typical in an actual situation, but was used to accelerate the relative expected fuel/clad distortion profile. At more realistic fuel swelling $\Delta V / V$ rates of 4 to 8 percent over reactor lifetime, emitter distortion of less than 0.010" should be expected.As seen in Fig. 7-35, the expected clad distortion is that of an hourglass shape, distinctly different from predicted clad distortion due to either the bladder or ratcheting effect. Examination of $6 F 3$ and 2E2 fueled emitter specimens after irradiation would indicate that the thermal ratchet "pear shape" or bladder "bladder shape" dominate over the "hourglass."

The swelling rate determined for a thermal neutron environment as modeled here, may be somewhat greater than the swelling rate for a fast neutron environment at the same power level. In the thermal environment, most of the neutron bombardment, and hence swelling, occurs near the fuel surface where the fuel is not fully restructured and gas release does not occur as quickly. In the fast neutron environment, gas fission rates and associated generation is generally uniform through the thickness and less gas may be generated in the portion of fuel which is not fully restructured. Because heat is generated generally uniformly through the fuel thickness in a fast neutron environment, a larger temperture gradient is established between fuel outer surface and centrai void surface, as displayed in Fig. 7-20. With temperature gradient being the driving force in gas transport toward the central void, the bubble migration velocity is significantly greater in the fast neutron case. The combination of these effects may lead to a high gas arrival rate into the central void. With this higher rate, equilibrium is reached sooner between gas formation rates (within the fuel) and gas arrival 
rates (into the central void) and less gas is accumulated in the fuel at any given time, resulting in a lower swelling rate.

Work is continuing on GRASS and on the interpretation of available experimental fuel swelling information in this field. Quantitative definitions of emitter distortion await resolution of fuel swelling rates. It is not anticipated that fission gas fuel swelling would be a life-limiting contributor toward emitter deformation in the fast space reactor environment. Given extended periods of time, thermal neutron exposures of highly enriched fuel may produce detrimental deformation. The deformation, if experienced, would produce an hourglass shape on the emitter as long as a central void and high temperatures are present.

While fuel swelling has been the subject of much study, irradiationinduced swelling in refractory metals has received relatively little attention.

Fig. 7-39 [57] indicates a peak swelling rate of $22 \%$ at $750^{\circ} \mathrm{C}$ with a possible second swelling peak at higher temperatures. No swelling data over $1200^{\circ} \mathrm{C}$ was presented in this study. Irradiation studies from [58] were performed at lower fluence but overlapped into irradiation temperatures of $1500^{\circ} \mathrm{C}$. This study, presented in Fig. 7-40, indicates that no second swelling peak exists. If a second swelling peak in fact does not exist, data indicates tungsten swelling <. $2 \%$ at emitter temperature $=1750 \mathrm{~K}$. As the emitter lead decreases in temperature down to $1000 \mathrm{~K}$, Ref. [57] indicates swelling in the range of $1.5 \%-2 \%$ could be experienced. It appears then that swelling at emitter temperatures may be insignificant but may become important as collector temperatures are approached. Because the lead region has much greater radial clearance to the collector, this increased swelling would probably not cause shorting.

It is vitally important to determine whether or not a second swelling peak exists. Existence of such a peak has a severe impact on the feasibility of using pure tungsten emitters. 


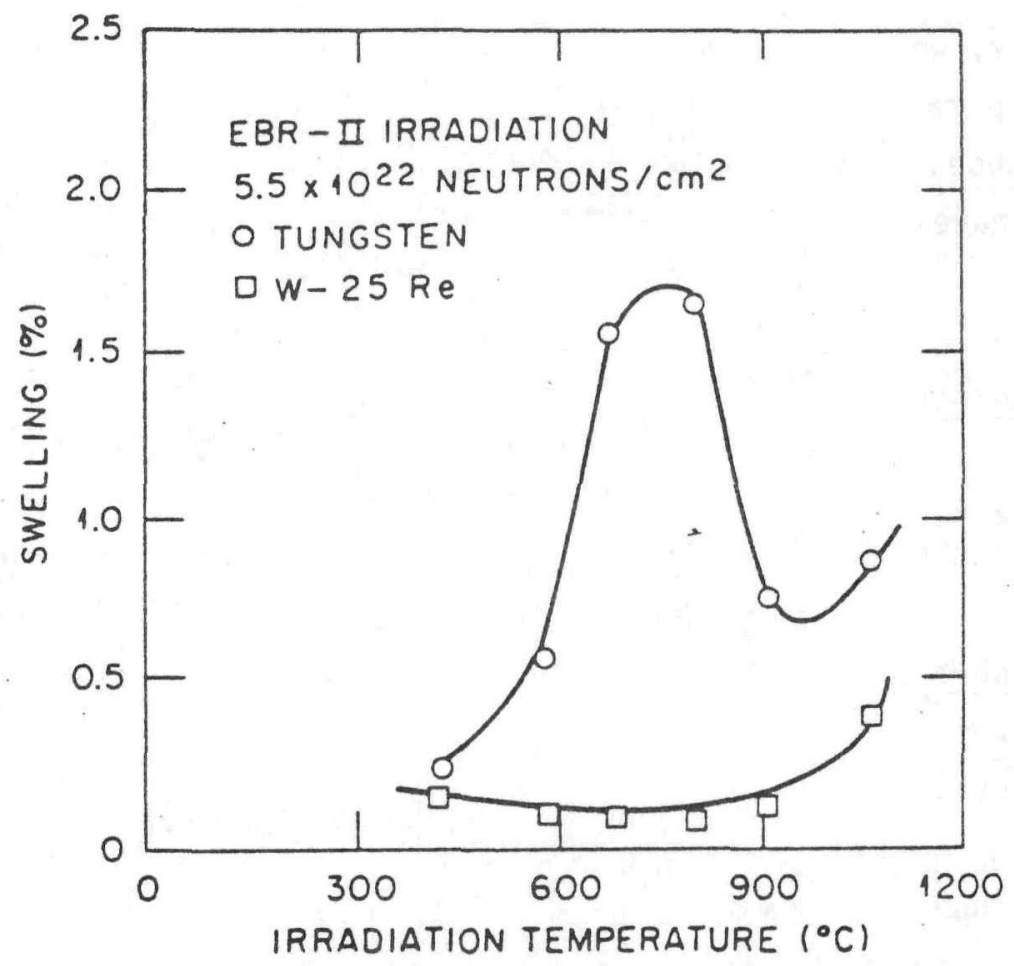

Fig. 7-39 OBSERVED SWELLING OF IRRADIATED TUNGSTEN ¿ FLUENCE $=5.5 \times 10^{22} \mathrm{n} / \mathrm{cm}^{2}$

SWELLING IN TUNGSTEN

EBR - II IRRADIATION; IMMERSION DENSITY

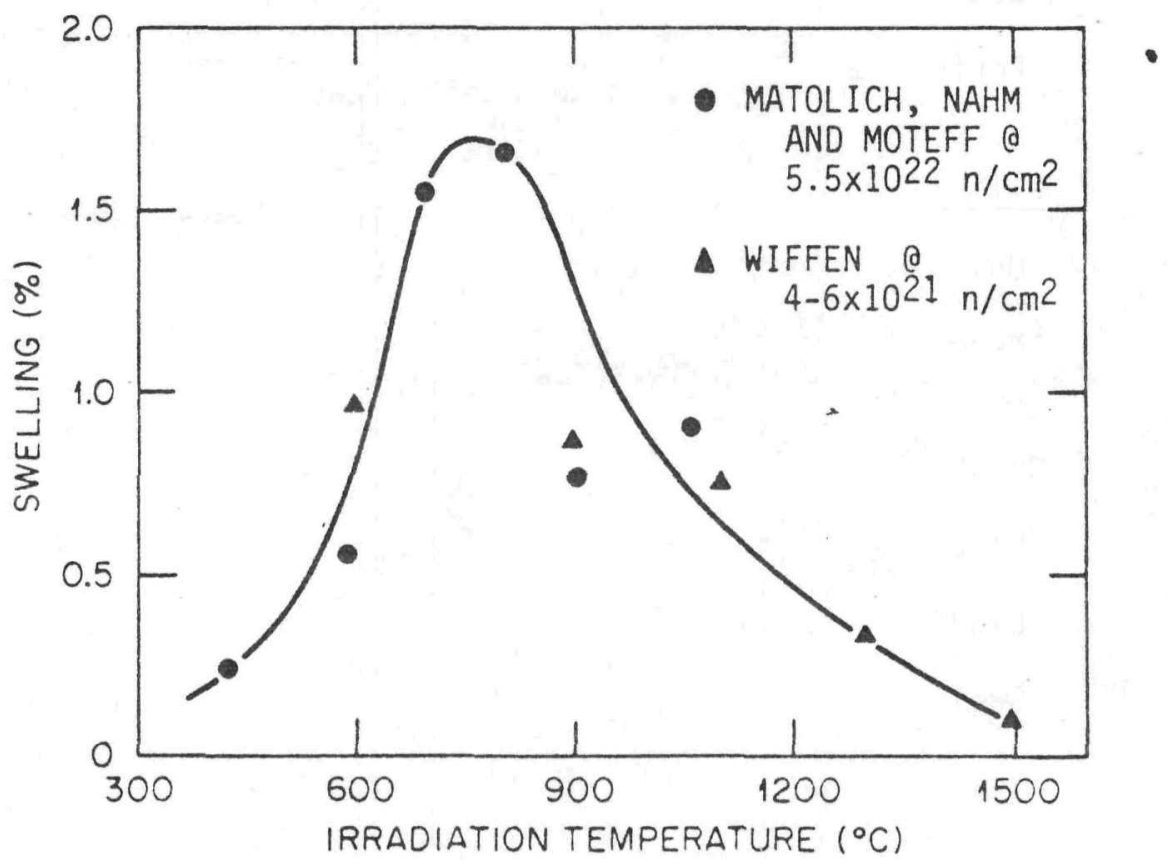

Fig. 7-40 OBSERVED SWELLING OF IRRADIATED TUNGSTEN 
Similarly, work needs to be performed on the effect of irradiation on tungsten creep rates. Should pure tungsten be found not be have adequate creep resistance, such alloys as $\mathrm{W}-26 \%-\operatorname{Re}, \mathrm{W}-23 \%-\operatorname{Re}-0.27 \mathrm{HF}-\mathrm{C}$ and $\mathrm{W}-4 \%-\mathrm{Re}-$ $0.40 \mathrm{Hf}-0.48 \mathrm{C}$ have been identified [59] to be particularly promising, see Fig. 7-41.

\subsubsection{Summary/Recommendations}

- Fast neutron environment produces central void with thinner skull than thermal environment.

- Ratchet Effect

- Can produce $\sim \frac{1}{2} \operatorname{mil}$ permanent deformation on radius per $100 \mathrm{~K}$ cycle.

- Need analysis/testing to define acceptable range of power cycles (number and magnitude) and hold-times.

- Run out-of-core tests to confirm analysis.

- Bladder Effect

- Has potential to cause large emitter deformations.

- Need to investigate gas arrival, gas diffusion rates.

- Establish method/mechanism to vent void pressure.

- Perform out-of-core tests to confirm analysis.

- Swelling Effect

- Unlikely to cause significant emitter deformation.

- Need to run GRASS code to establish swelling rate.

- Each effect produces a distinctive distortion shape (Fig. 7-42).

- Ratcheting -- Pear-Shape

- Bladder -- Barrel-Shape

- Swelling -- Hourglass shape 


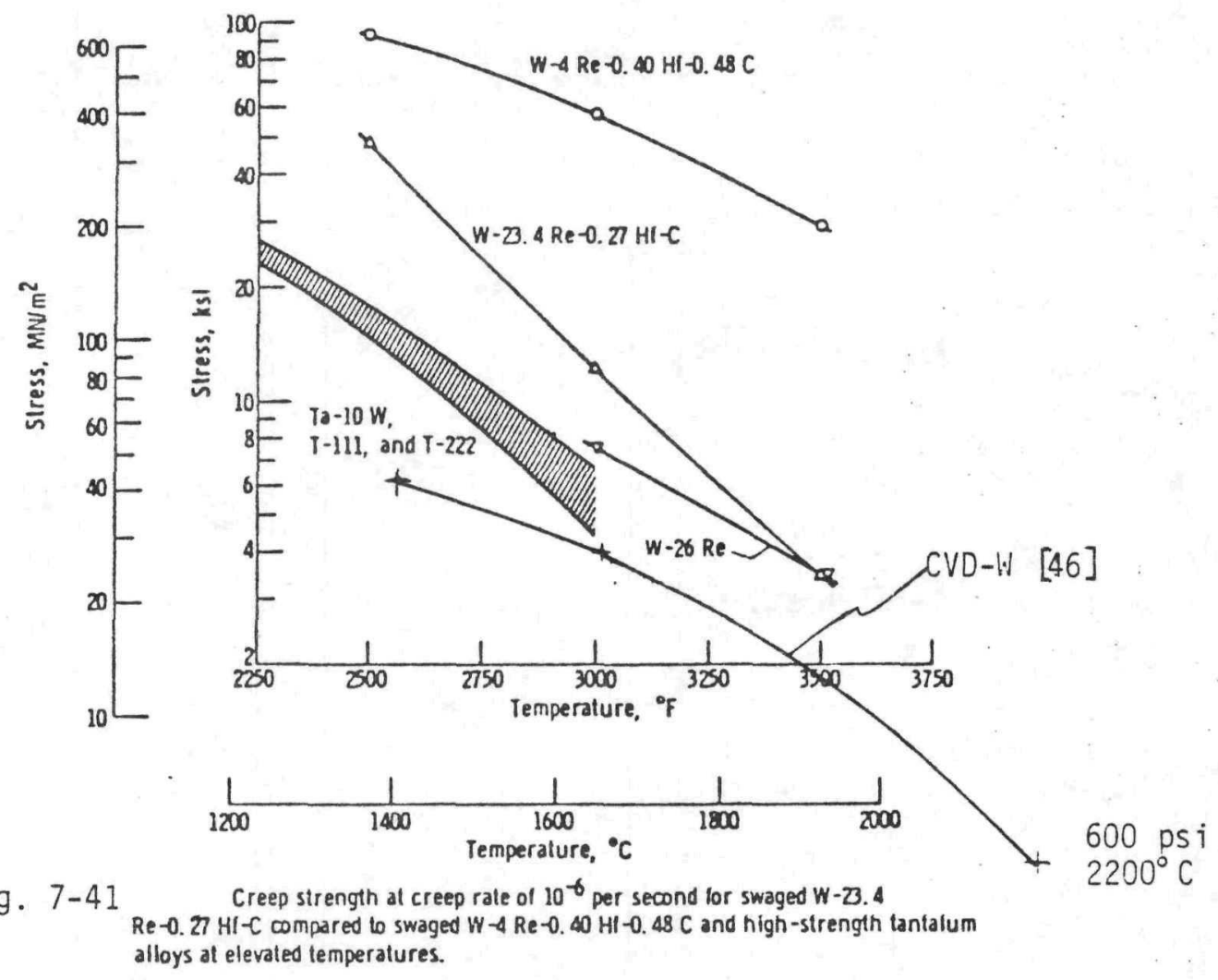




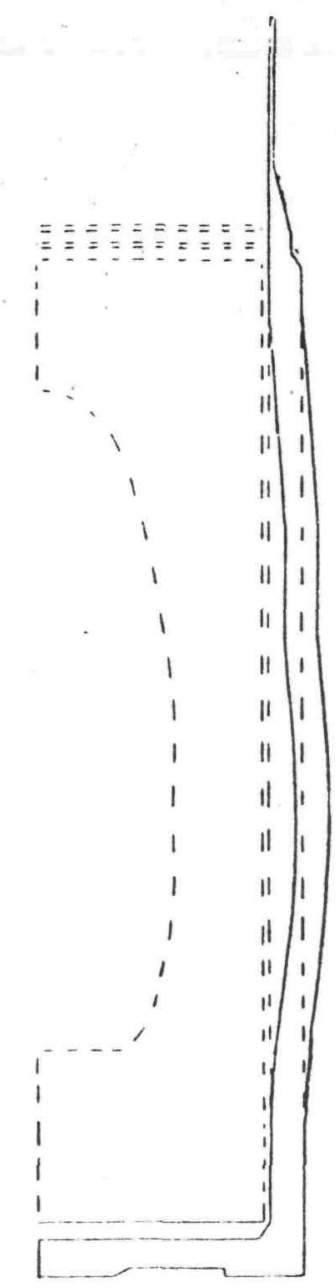

BLADDER EFFECT "BARREL SHAPE"

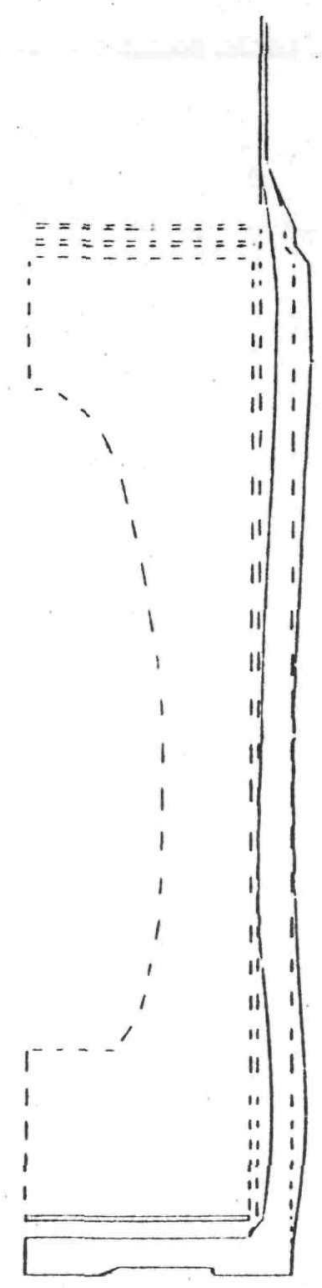

FUEL SWELLING EFFECT "HOURGLASS SHAPE"

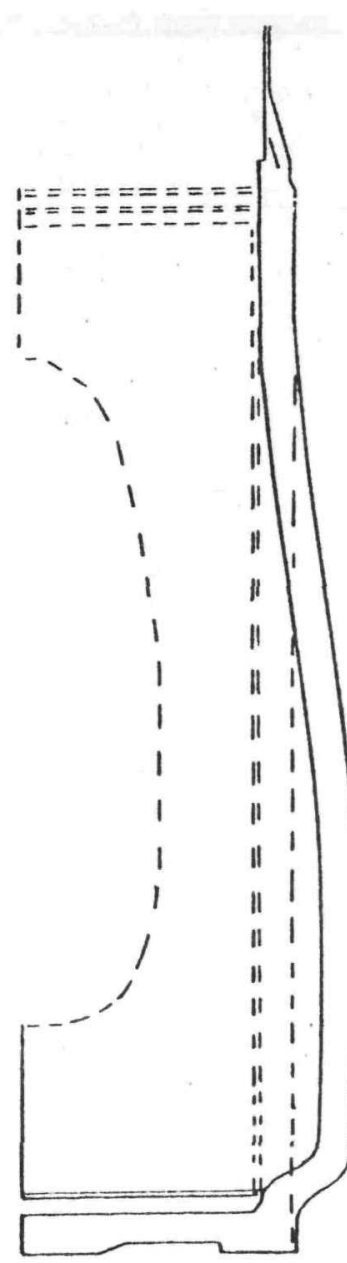

RATCHET EFFECT

"PEAR SHAPE" 
- Need to perform fast-flux irradiation tests on tungsten to determine effects on creep rate and swelling.

\subsection{SUMMARY OF OBSERVATIONS}

The ratchet and bladder effects are believed to be the dominant deformation modes in TFE operation. Results from the GA tests indicate that these mechanisms did cause measureable emitter deformation.

\subsubsection{Ratchet Effect}

Analysis has indicated that up to 0.4 mils of radial deformation can accumulate per $100 \mathrm{~K}$ temperature cycle. This analytical prediction is substantiated by the IC-I6 test performed at GA. This test was performed specifically to confirm the existence of the thermal ratcheting. After 8 cycles of $100 \mathrm{~K}$, radial deformation was measured be $\sim 2$ mils. After an additional 7 similar thermal cycles, incremental radial deformation was again 2 2 mils. For these 15 cycles, the average emitter deformation was $.27 \mathrm{mils}$ on the radius. Both analysis and the GA test indicate that thermal ratcheting does occur.

\subsubsection{Bladder Effect}

If fission gas pressure did buildup in the central void during testing, it would diffuse out not only the skull on the top but through the bottom a)so. The fission gas pressure would increase in that space between the bottom of the fuel and the emitter bottom as shown in Fig. 7-43. Equilibrium would be reached when the pressure in this space reached the pressure in the central void. At this pressure it would be expected that the bottom of the emitter would dish downward as the tungsten creeps over time.

The emitter bottom of IC-I4 did in fact dish downwara 9 mils at 9754 hours [60]. This is significantly larger distortion than would have been caused by temperature discontinuity in the emitter bottom.

6F3 operated at 8062 hours at emitter temperatures varying from $1740 \mathrm{~K}$ to $1820 \mathrm{~K}$. The $6 \mathrm{~F} 3$ design had a fuel pedestal/radiation shield between the 


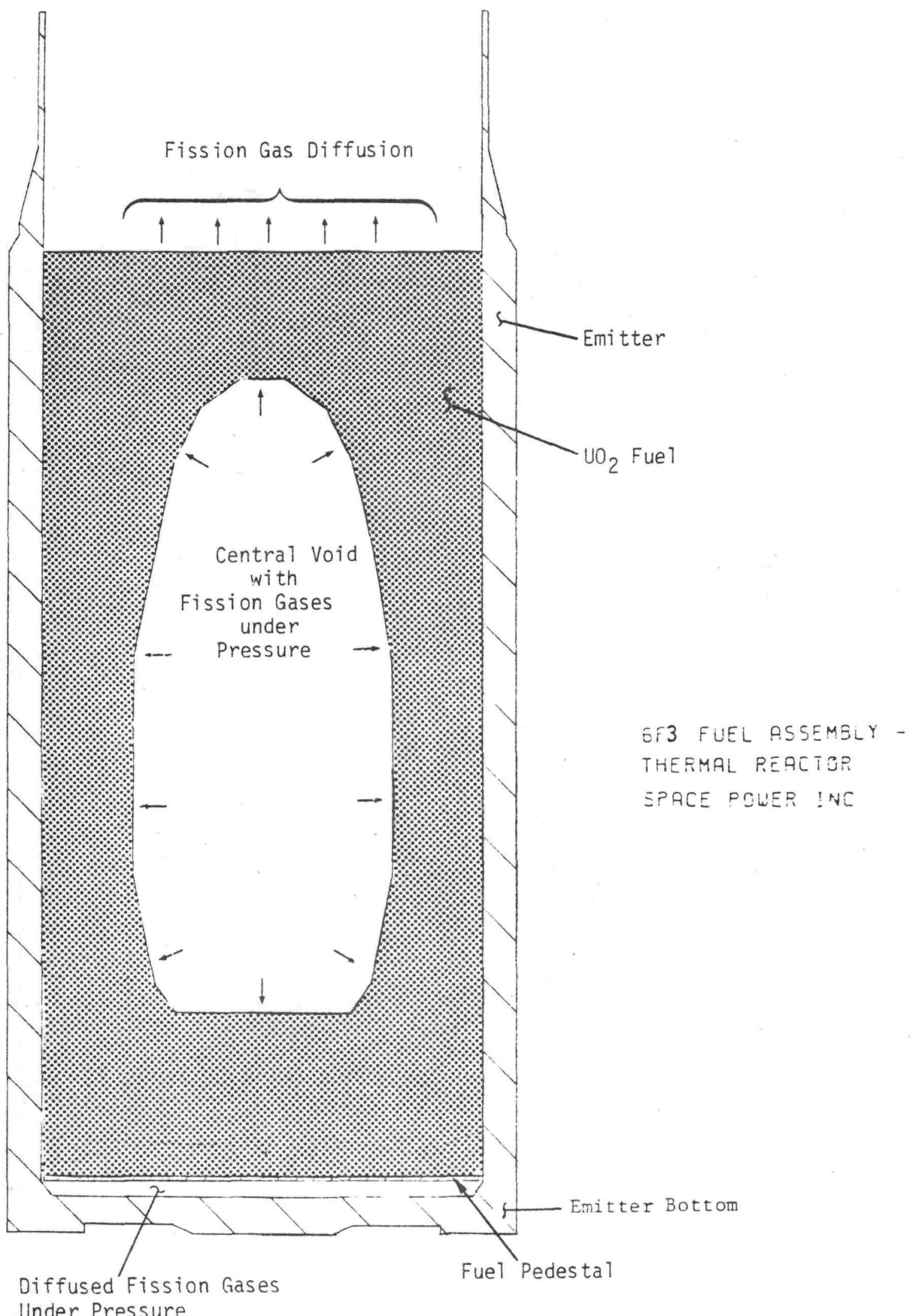

Fig. 7-43 6F3 FUEL ELEMENT - BLADDER EFFECT 
fuel and emitter bottom. As a result, temperature gradients in the emitter bottom were $\leqq 50 \mathrm{~K}$. Post-test measurements indicated the emitter bottom dished out up to 24 mils [61]. The magnitude of this distortion also is too large to attribute to temperature gradients. Both measurements seem to indicate the presence of pressure between the fuel and emitter bottom and hence the existence of pressure in the central void.

\section{REFERENCES}

1. C. C. Dollins and F. A. Nichols, "Swelling and Gas Release in VO, at Low and Intermediate Temperature," J. Nuc. Mat. 66, 143 (1977).

2. H. Zimmermann, "Swelling and Fission Gas Behavior in $\mathrm{UO}_{2}$," J. Nuc. Mat. 75, $154(1978)$.

3. D. L. Hagrman and G. A. Reymann, "MATPRO-Version-11," NUREG/CR-0497, TREE-1280, EG\&G, Inc., (February, 1979).

4. H. Zimmermann, "Swelling in Mixed-Oxide Fuel Pins," Nuc. Tech. 41, 408 (1978).

5. B. R. T. Frost, "Theories of Swelling and Gas Retention in Ceramic Fuels," Nuc. Applications and Technology 9, 128, (1970).

6. R. S. Barnes and D. J. Mazey, "The Migration and Coalescence of Inert Gas Bubbles in Metals," Proc. of the Royal Society 275A, 47 (1963).

7. R. S. Barnes, "A Theory of Swelling and Gas Release for Reactor Materials," J. Nuc. Mat. 11, 135 (1964).

8. M. V. Speight, "The Migration of Gas Bubbles in a Material Subject to a Temperature Gradient," J. Nuc. Mat. 13, 207 (1964).

9. B. R. Frost, "Theories of Swelling and Gas Retention on Ceramic Fuels," Nuc. Applications \& Technology 9, 128, (1970).

10. V. W. Storhok and W. Chubb, "Swelling of $\mathrm{UO}_{2}$ at $1700^{\circ} \mathrm{C}, "$ Trans. Am. Nucl. Soc. 12, 76 (1969).

11. R. F. Hilbert, V.W. Storhok and W. Chubb, "High Temperature Irradiation Behavior of $\mathrm{UO}_{2}$, UC and UN," Thermionic Conversion Specialists Conf., $p$. 331, (1969).

12. R. F. Hilbert, V. W. Storhok, W. Chubb and D. L. Keller, "Fission-Gas Swelling of UC, UN and UO, at High Irradiation Temperatures," Thermionic Conv. Spec. Conf., p. $18,{ }^{2}(1970)$.

13. R. F. Hilbert, V. W. Storhok, W. Chubb and D. L. Keller, "Mechanisms of Swelling and Gas Release in Uranium Dioxide," J. Nuc. Mat. 38, 26, (1971). 
14. W. Chubb, V. W. Storhok and K. L. Keller, "Observations Related to the Mechanisms of Swelling and Gas Release in Uranium Dioxide at High Temperatures," J. Nuc. Mat. 44, 136 (1972).

15. W. Chubb, V. W. Storhok and D. L. Keller, "Factors Affecting the Swelling of Nuclear Fuels at High Temperature," Nuclear Technology 18 231, (1979).

16. C. M. Cox, "The Irradiation Performance of Uranium-Plutonium Oxide Fuel Pins," Nuclear Safety 10, 380 (1969).

17. J. A. Turnbul1, "The Effect of Grain Size on the Swelling and Gas Release Properties of $\mathrm{UO}_{2}$ during Irradiation," Journal of Nuclear Materials 50, 62 (1974).

18. W. B. Lewis," Engineering for the Fission Gas in $\mathrm{UO}_{2}$ Fuel," Nuclear Applications and Technology 2, 171 (1966).

19. M. H. Wood and M. R. Haynes, "Modeling Fission Gas Release and Swelling in Fast Reactor Fuel Pins," Harwell Research Report AERE (1975).

20. M. R. Hayns and M. H. Wood, "Models of Fission Gas Behavior in Fast Reactor Fuels under Steady State and Transient Conditions," J. Nuc. Mat. $\underline{67}, 155$ (1977).

21. M. R. Hayns and D. Wilmore, "FRUMP - A Computer Programme for the Calculation of Stresses in Reactor Fuel Pins," Harwell Research Report AERE-R.7380, (1973).

22. R.B. Poeppel, "An Advanced Gas Release and Swelling Subroutine," Proc. Conf. on Fast Reactor Fuel Element Technology, Am. Nucl. Soc., Hinsdale, IL, 311 (1971).

23. J. Rest, "GRASS-SST: A Comprehensive, Mechanistic Model for the Prediction of Fission-gas Behavior in $\mathrm{UO}_{2}$-base Fuels during Steady-State and Transient Conditions," NUREG/CR-0202, ANL-78-53, Argonne National Labs, June (1978).

24. J. Rest, "GRASS-SST: A Comprehensive, Mechanistic Model for the Prediction of Fission-Gas Behavior in Nuclear Fuels during Steady-State and Transient Conditions: Users Manual and Model Development Update," (preprint).

25. J. Rest, "An Improved Model for Fission Product Behavior in Nuclear Fuels under Normal and Accident Conditions," J. of Nucl. Mat. (submitted for publication).

26. J. Rest, S. R. Rajan, and S. A. Bawadzki, "PARAGRASS: A Quick Running Comprehensive Steady-State and Transient Fission-Product Release and Swelling Model for Water-REactor Fuel," (pre-print).

27. V. Z. Jankus and R. W. Weeks, "LIFE-I, a Fortran-IV Computer Code for the Prediction of Fast-REactor Fuel-Element Behavior," ANL-7736, Argonne National Laboratory, (November, 1970). 
28. V. Z. Jankus and R. W. Weeks, "LIFE-II, a Computer Analysis of Fast-Reactor Fuel-Element Behavior as a Funciton of Reactor Operating History," Nuc]. Engineering and Design 18, 83 (1972).

29. "LIFE-III Fuel Element Performance Code," ERDA-77-56, Argonne National Laboratory, (July 1977).

30. M. H. Wood and J. R. Mathew, "A Simple Operational Gas RElease and Swelling Model II. Grain Boundary Gas," J. of Nucl. Mat. 91, 241 (1980).

31. J. R. Mathews and M. H. Wood, "A Simper Operational Gas Release and Swelling Model II. Grain Boundary Gas," J. of NuCl. Mat. 91, 241 (1980).

32. H. R. Warner and F. A. Nichols, "A Statistical Fuel Swelling and Fission Gas Release Model," Nuclear Application \& Technology, 9, 148 (1970).

33. F. A. Nichols and H. R. Warner, "Swelling and Gas-Release Model for Oxide Fuel Rates (LWBR Development Program)," Fast Reactor Fuel Element Technology, ANS, p.267 (1971).

34. C. C. Dollins and H. Ocken, "Re-Solution Effects and Fission Gas Swelling in $\mathrm{UO}_{2}, " \mathrm{~J}$. of Nucl. Mat. 45, 150 (1972/73).

35. C. C. Dollins, "Fission Gas Swelling and Long-Range Migration at Low Temperatures," J. of Nucl. Mat. 49, 10 (1973/74).

36. C. C.Dollins, "On Fission Gas Swelling Below $1200{ }^{\circ} \mathrm{C}, " \mathrm{~J}$. of Nucl. Mat. $60,107(1976)$.

37. C. C. Dollins and F. A. Nichols, "Swelling and Gas Release in $\mathrm{UO}_{2}$ at Low and Intermediate Temperatures," J. of Nuc1. Mat. 66,143 (1977). ${ }^{2}$

38. C. C. Dollins and M. Jursich, "Swelling and Gas Release on Oxide Fuels During Fast Temperature Transients," J. of Nucl. Mat. 107, 46 (1982).

39. C. C. Dollins and M. Jursich, "Fission Gas Release from Oxide Fuels at High Burnups," J. of Nucl. Mat. 105, 269 (1982).

40. ANSYS is a two-dimensional finite element code developed by Swanson Analysis Systems Inc.

41. Private communication with Dr. A. Biancheria.

42. Metals Handbook, Vol. 2, 9th Ed., Am. Soc. for Metals, (1979).

43. T. E. Tretz and J. W. Wilson, Behavior and Properties of Refractory Metals, (Stanford University Press, 1965).

44. Handbook of Chemistry and Physics, 55th Ed., (CRC Press, 1974).

45. R. L. Stephenson, "Material Selections for Thermionic Capsules," Proc. IEEE Thermionic Conversion Specialist Conf. (1979). 
46. R. L. S. Stephenson and J. I. Federer, "Creep Rupture Properties of CVD-Tungsten," Proc. IEEE Therm. Conv. Spec. Conf. (1970).

47. F. W. Wiffen, "Radiation Damage to Refractory Metals as Related to Thermionic Applications," Proc. IEEE Therm. Conv. Spec. Conf. (1971).

48. Proceedings of Chemical Vapor Deposition Conf. III, Am. Nuc. Soc. (1972).

49. S. A. Balankin, D. M. Skorov, V. A. Yartsev, "A Method of Determining the Thermophysical Properties of Reactor Materials at Elevated Temperatures," Atomnaya Energiya, 41, 4 (October, 1976).

50. 0. D. Slagle, "Deformation Behavior of $\cup \mathrm{O}_{2}$ above $2000^{\circ} \mathrm{C}$," Hanford Engineering Development Laboratory, HEDL-TME 79-37, UC-79,b,p, (September, 1979).

51. Clauer, Seltzer and Wilcox, "Effect of Non-Stoichiometry on Creep of Oxides," Materials Science Research, Vol. 5, (1971).

52. A. M. Ross, "The Dependence of the Thermal Conductivity of Uranium Oxide on Density, Microstructure, Stoichiometry and Thermal-Neutron Irradiation," Atomic Energy of Canada, Limited, AECL-1096, (September, 1960).

53. D. W. Green and L. Leibowitz, "Vapor Pressures and Vapor Compositions in Equilibrium with Hypostoichiometric Uranium Oxide in High Temperatures," Journal of Nuclear Materials, (North Holland Publishing Company, 1982).

54. V. A. Kornilov, Yu. I. Sukov, V. D. Yuditskig, "Method for Calculating the Temperature Fields of a Heterogeneous Fuel Core of a Thermionic Generating Element," (submitted for publication January 3, 1980).

55. A. G. Tsitsin, "Temperature Fields of Electricity Generating Thermal Emission Elements in Changes of the Width of the Gap between the Electrodes," translated from Atomnaya Energiya, 53, 4, pp. 273-274 (October, 1982).

56. J. A. Sultivan, "SP-100 Quarterly Technical Review, 10/1/82-12/31/82," Los Alamos National Laboratory, (February 1, 1983).

57. J. Matolich, N. Nahm, and J. Moteff, "Swelling in Neutron Irradiated Tungsten and Tungsten-25 Percent Rhenium," Scripta Met. 8, 837-842, (1974).

58. F. W. Wiffen, "Effects of Irradiation in Properties of Refractory Alloys, with Emphasis on Space Power Reactor Applications," Symposium on Refractory Alloy Technology for Space Nuclear Power Applications, (August, 1983).

59. James F. Morris, "Pre-1973 Refractory-Alloy Technology to Improve and Simpiify In-Core Thermionic Energy Conversion," Arizona State University, Air Force Wright Aeronatical Laboratory (December, 1983). 
60. "Development of a Thermionic Reactor Space Power System, Summary Report Period March 1, 1972 - June 30, 1972," Gulf-GA-A12251, UC-33 (January 5, 1973).

61. "Development of a Thermionic Reactor Space Power System - Final Summary Report," Gulf-GA-A12608, UC-33 (June 30, 1973). 